JOINT TRANSPORTATION RESEARCH PROGRAM

FHWA/IN/JTRP-2009/32

Final Report

USE OF STEEL SLAG IN SUBGRADE APPLICATIONS

Irem Zeynep Yildirim

Monica Prezzi

October 2009 


\section{TECHNICAL Summary}

INDOT Research

Technology Transfer and Project Implementation Information

TRB Subject Code: 35 Waste Materials

Publication No. FHWA/IN/JTRP-2009/32, SPR-3129

October 2009

Final Report

\section{Use of Steel Slag in Subgrade Applications}

\section{Introduction}

The steelmaking industries in the U.S. generate 1015 million tons of steel slag every year. In 2006, about 50 to $70 \%$ of the total steel slag produced in the U.S. was used as aggregate for road and pavement construction, and the remaining 10 to $15 \%$ of the total steel slag generated is utilized in miscellaneous applications. The excess 15 to $40 \%$ of the steel slag that was not reutilized in some manner was stockpiled in the steel plants and, eventually, sent to slag disposal sites. In comparison, all of the blast furnace slag (a byproduct of the ironmaking industry) generated each year is fully reutilized by the cement and concrete industry. As the current methods of stockpiling and landfilling are not sustainable, disposal of steel slag is a significant concern to both the slag-processer companies and the environmental agencies. Utilization of steel slag in geotechnical engineering projects, such as in the construction of highway embankments or in subgrade stabilization, is advantageous because large volumes of steel slag can be utilized. In addition, the use of steel slag in geotechnical applications can help alleviate the slag disposal problem and also provide a cost-effective alternative to conventional geo-materials. Therefore, the main goal of this research was to fully characterize steel slags from two different steel making plants in Indiana and to determine their engineering properties for use in geotechnical engineering applications.

There are two primary steelmaking operations that produce steel slag as a by-product: the basicoxygen-furnace (BOF) process and the electric-arcfurnace (EAF) process. Molten iron produced in the blast furnace is used as the primary supply (feed) for the basic-oxygen-furnace steelmaking process. In the BOF process, molten iron is charged into a basic-oxygen furnace together with steel scraps and fluxing agents (lime or dolomite) to produce steel. The steel slag that is a by-product of the BOF steelmaking process is known as basic-oxygenfurnace slag. In the EAF process, recycled steel scraps are charged into the furnace as the main feed together with the fluxing agents (lime or dolomite) to produce steel. The steel slag generated as a by-product of the EAF steelmaking process is known as electric-arc-furnace slag. After completion of the primary steelmaking operations, steel produced from BOF or EAF processes is typically refined in ladle furnaces in order to obtain high-grade steels. Ladle slag is generated during the steel refining process in ladle furnaces.

Two types of steel slag - a basic-oxygen-furnace (BOF) slag and an EAF ladle (EAF(L)) slag - and mixtures of steel slag and Class-C fly ash were considered in this research.

BOF and $\mathrm{EAF}(\mathrm{L})$ slag samples were characterized through a series of laboratory tests which include grain-size distribution, soil classification, specific gravity, XRD analysis and SEM examinations. The mechanical properties of BOF and $\operatorname{EAF}(\mathrm{L})$ slag samples were evaluated based on the results of compaction, maximum and minimum density, large-direct shear and triaxial tests. The expansive nature of BOF and $\mathrm{EAF}(\mathrm{L})$ slag was assessed by performing long-term swelling tests.

Mixtures of steel slag were prepared by adding 5 and $10 \%$ Class-C fly ash by weight to BOF slag and 5, 10 and 20\% Class-C fly ash by weight to $\mathrm{EAF}(\mathrm{L})$ slag. The mixtures were compacted in a mold at their optimum moisture content and subjected to unconfined compression tests after various curing times to evaluate their strength gain characteristics. Long-term swelling tests were also performed on both mixtures of BOF and 10\% Class-C fly ash and EAF(L) slag and 5, 10 and $20 \%$ Class-C fly ash (by weight). The effect of 
adding $10 \%$ ground rubber (by weight) to BOF slag on the long-term swelling behavior of the mixture was also investigated.

\section{Findings}

The present report includes the following findings:

1) BOF slag samples were classified as poorly graded sand with silt and gravel (SP-SM) and A1-b based on the Unified Soil Classification System (USCS) and American Association of State Highway Transportation Officials (AASHTO) soil classification systems, respectively. The specific gravity of the BOF slag was in the 3.29-3.34 range.

2) The optimum moisture content and maximum dry unit weight of BOF slag samples were in the ranges of $4-8 \%$, and 19.5-21.8 $\mathrm{kN} / \mathrm{m}^{3}$, respectively.

3) The critical-state friction angle of BOF slag samples was in the range between $45.5^{\circ}$ and $48.1^{\circ}$ based on large-scale direct shear tests results. The peak friction angles of aged BOF slag (with minus $9.5 \mathrm{~mm}$ gradation) samples prepared at about $90 \%$ relative compaction were equal to $47.3^{\circ}, 45.2^{\circ}$ and $43.5^{\circ}$ at effective confining stresses of 50, 110 and $200 \mathrm{kPa}$, respectively based on isotropically consolidated drained triaxial test (CIDTX) results. 4) Based on the leachate concentration levels of BOF slag samples obtained from the TCLP analysis, BOF slag is classified as Type III solid waste according to the Indiana restricted waste criterion.

5) BOF slag samples were classified as wellgraded sand with silt (SW-SM) and A-1-b based on the Unified Soil Classification System (USCS) and American Association of State Highway Transportation Officials (AASHTO) soil classification systems, respectively. The specific gravity of the EAF(L) slag was in the 2.73 to 3.04 range.
6) The optimum moisture content and maximum dry unit weight of EAF(L) slag samples were in the ranges of $10-13 \%$ and $16.8-20.0 \mathrm{kN} / \mathrm{m}^{3}$, respectively.

7) The critical-state friction angle of $\operatorname{EAF}(\mathrm{L})$ slag samples was approximately $40.6^{\circ}$ based on the large-scale direct shear tests results.

8) Based on the leachate concentration levels of EAF(L) slag samples obtained from the TCLP analysis, EAF(L) slag is classified as Type III solid waste according to the Indiana restricted waste criterion.

9) Aged BOF slag and Class-C fly ash mixtures showed excellent strength gain with time. The two-day unconfined compression strength of compacted BOF slag and Class-C-fly ash mixtures with 5 and $10 \%$ Class-C fly ash content by weight were 915 and $2873 \mathrm{kPa}$, respectively.

10) Fresh $E A F(L)$ slag and Class-C fly ash mixtures showed excellent strength gain with time. The two-day unconfined compression strength of compacted EAF(L) slag and Class-C fly ash mixtures with 5, 10 and 20\% Class-C fly ash content by weight were 842, 1804 and 4871 $\mathrm{kPa}$ respectively.

11) Results of long-term swelling tests on BOF slag and Class-C fly ash mixtures showed that the addition of $10 \%$ Class- $C$ fly ash suppresses the swelling of both fresh and aged BOF slag samples to negligible levels.

12) Results of long-term swelling tests on EAF(L) slag and Class-C fly ash mixtures showed that the addition of $10 \%$ Class-C fly ash suppresses the swelling of $\mathrm{EAF}(\mathrm{L})$ slag almost completely.

\section{Implementation}

The design parameters determined in this experimental study (such as specific gravity, optimum moisture content, maximum dry density, critical-state friction angle, peak friction angle and unconfined compressive strength) for BOF slag, EAF(L) slag and mixtures of steel slag and Class$C$ fly ash can be used in the design of various types of geotechnical projects, such as small roads and highway embankments. Based on the experimental results, we suggest the use of mixtures of BOF slag and 10\% Class-C fly ash and of EAF(L) slag and 5-10\% Class-C fly ash in subgrade stabilization projects. Use of mixtures of BOF slag and soil or BOF and Class-C fly ash could be explored in the context of embankment construction projects. Implementation projects can help facilitate the use of steel slag in routine projects by INDOT engineers. However, the short and long term environmental impact of using steel slags in geotechnical applications should be carefully assessed in the context of field implementation projects. 


\section{Contacts}

For more information:

Prof. Monica Prezzi

Principal Investigator

School of Civil Engineering

Purdue University

West Lafayette IN 47907

Phone: (765) 494-5034

E-mail: mprezzi@purdue.edu
Indiana Department of Transportation

Office of Research and Development

1205 Montgomery Street

P.O. Box 2279

West Lafayette, IN 47906

Phone: (765) 463-1521

Fax: (765) 497-1665

Purdue University

Joint Transportation Research Program

School of Civil Engineering

West Lafayette, IN 47907-1284

Phone: (765) 494-9310

Fax: (765) 496-7996

E-mail: jtrp@ecn.purdue.edu

http://www.purdue.edu/jtrp 
Final Report

FHWA/IN/JTRP-2009/32

\title{
USE OF STEEL SLAG IN SUBGRADE APPLICATIONS
}

\author{
by \\ Irem Zeynep Yildirim \\ Graduate Research Assistant \\ and \\ Monica Prezzi \\ Associate Professor \\ Principal Investigation \\ Geotechnical Engineering \\ School of Civil Engineering \\ Purdue University
Joint Transportation Research Program
Project No. C-36-50BB
File No. 6-19-27
SPR-3129
Prepared in Cooperation with the The U.S. Department of Transportation
Federal Highway Administration \\ Indiana Department of Transportation and
}

The contents of this report reflect the views of the authors who are responsible for the facts and the accuracy of the data presented herein. The contents do not necessarily reflect the official views or policies of the Federal Highway Administration and the Indiana Department of Transportation. This report does not constitute a standard, specification or regulation.

Purdue University

West Lafayette, Indiana

October 2009 
TECHNICAL REPORT STANDARD TITLE PAGE

\begin{tabular}{|c|c|c|c|c|}
\hline $\begin{array}{l}\text { 1. } \text { Report No. } \\
\text { FHWA/IN/JTRP-2009/32 }\end{array}$ & \multicolumn{2}{|c|}{ 2. Government Accession No. } & \multicolumn{2}{|c|}{ 3. Recipient's Catalog No. } \\
\hline \multirow{2}{*}{\multicolumn{3}{|c|}{$\begin{array}{l}\text { 4. Title and Subtitle } \\
\text { Use of Steel Slag in Subgrade Applications }\end{array}$}} & \multicolumn{2}{|l|}{$\begin{array}{l}\text { 5. } \quad \text { Report Date } \\
\text { October } 2009\end{array}$} \\
\hline & & & \multicolumn{2}{|c|}{ 6. Performing Organization Code } \\
\hline \multicolumn{2}{|c|}{$\begin{array}{l}\text { 9. Performing Organization Name and Address } \\
\text { Joint Transportation Research Program } \\
550 \text { Stadium Mall Drive } \\
\text { Purdue University } \\
\text { West Lafayette, IN 47907-2051 }\end{array}$} & & \multicolumn{2}{|l|}{ 10. Work Unit No. } \\
\hline \multicolumn{5}{|c|}{$\begin{array}{l}\text { 15. Supplementary Notes } \\
\text { Prepared in cooperation with the Indiana Department of Transportation and Federal Highway Administration. }\end{array}$} \\
\hline \multicolumn{5}{|c|}{ 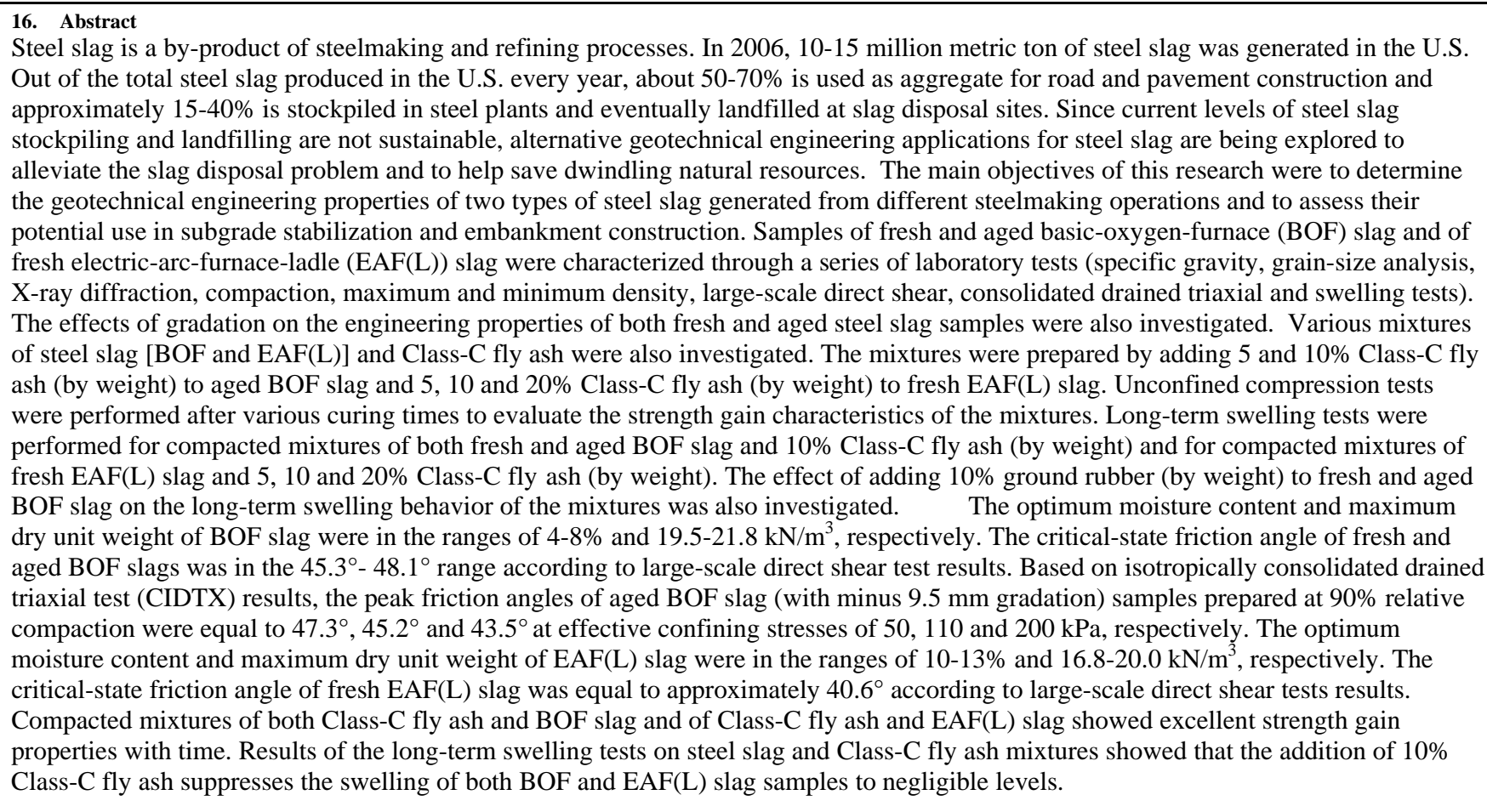 } \\
\hline \multicolumn{2}{|c|}{$\begin{array}{l}\text { Steel slag; sustainability, Class-C fly ash, recyclable } \\
\text { materials, subgrade stabilization }\end{array}$} & \multicolumn{3}{|c|}{$\begin{array}{l}\text { No restrictions. This document is available to the public through the } \\
\text { National Technical Information Service, Springfield, VA } 22161\end{array}$} \\
\hline 19. Security Classif. (of this report) & 20. Security C & his page) & 21. No. of Pages & 22. Price \\
\hline
\end{tabular}




\section{TABLE OF CONTENTS}

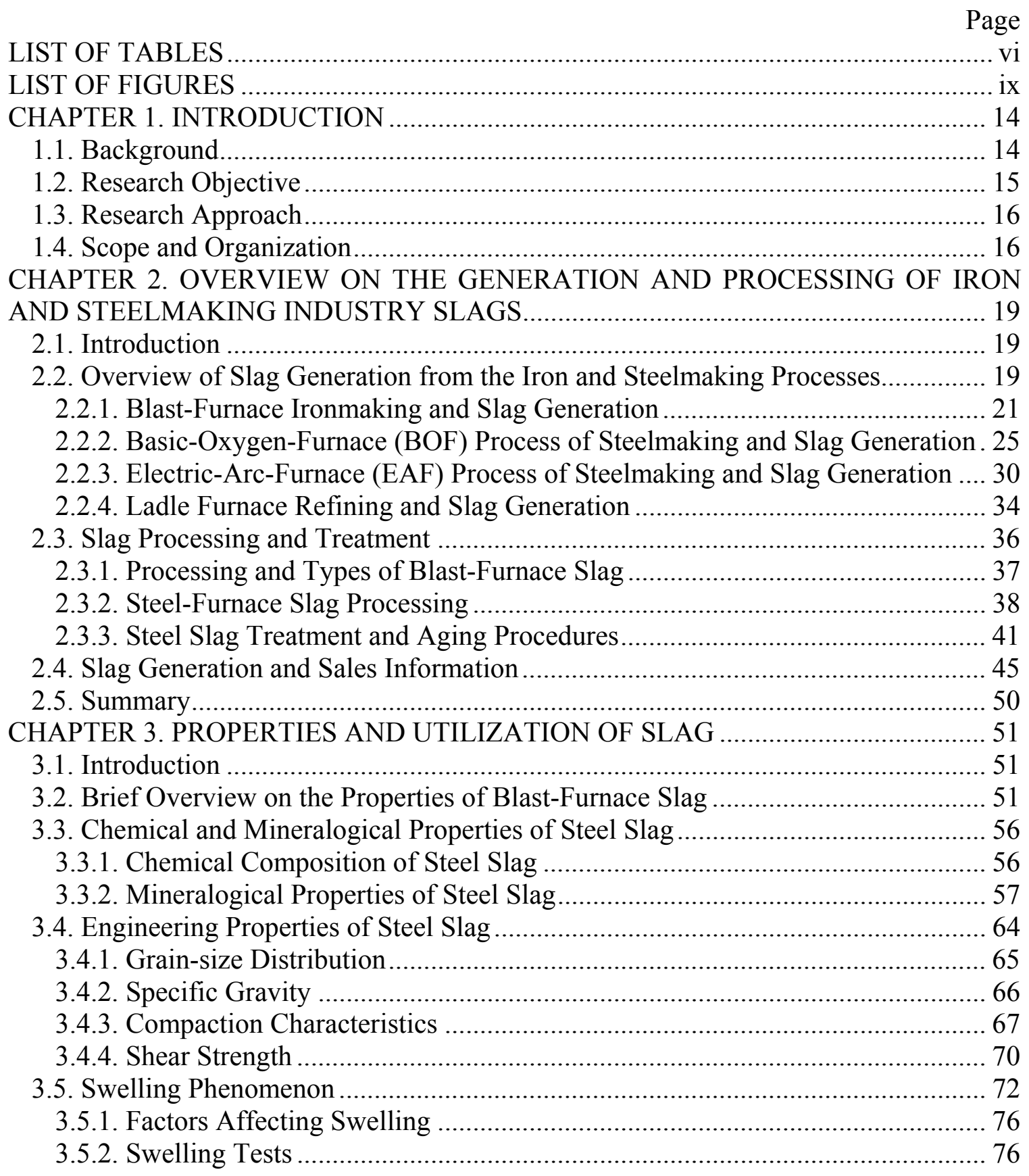


3.5.3. Recommendations and Specifications for Steel Slag Swelling......................... 81

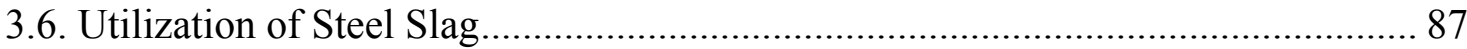

3.6.1. Use of Steel Slag in the Cement and Concrete Industry ................................. 88

3.6.2. Use of Steel Slag in Road Applications ......................................................... 90

3.6.3. Use of Steel Slag in Geotechnical Applications .............................................. 92

3.7. Environmental Issues Associated with Steel Slag ................................................ 93

3.7.1. Leaching ............................................................................................... 93

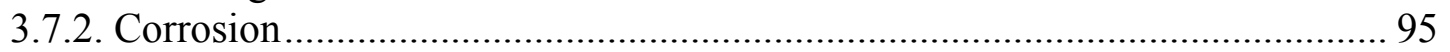

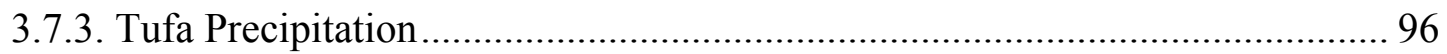

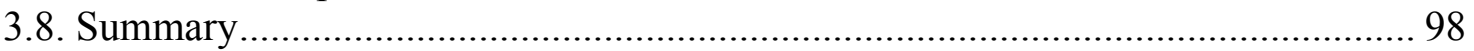

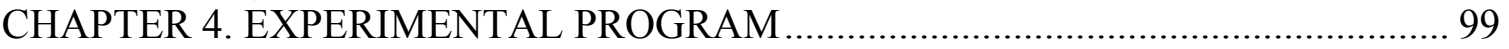

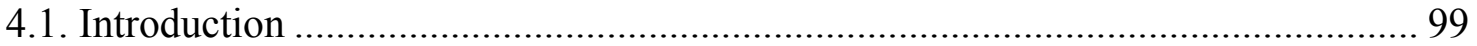

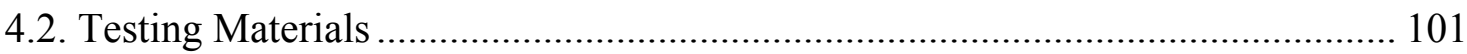

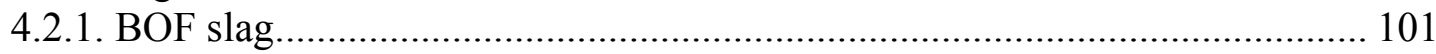

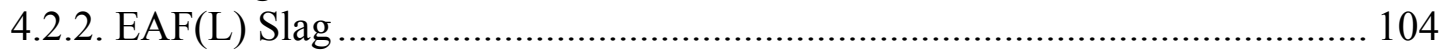

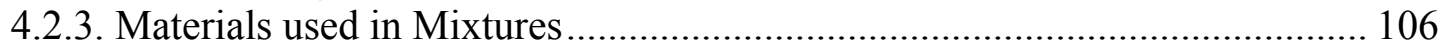

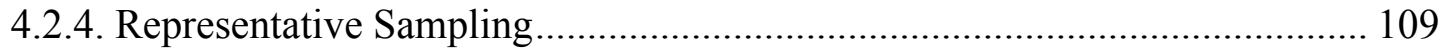

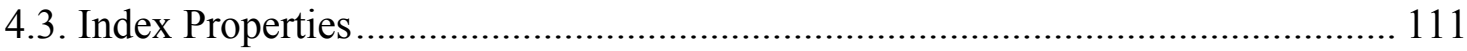

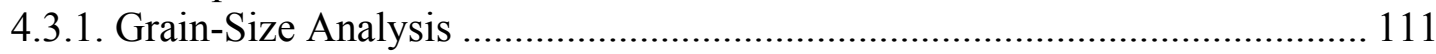

4.3.2. Atterberg Limits and Soil Classification....................................................... 112

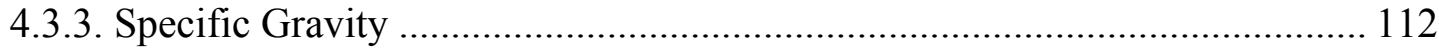

4.4. Examination of Mineralogical and Morphological Properties .............................. 117

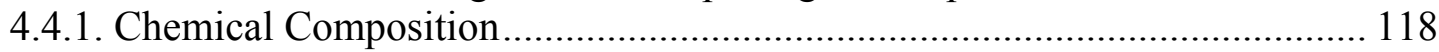

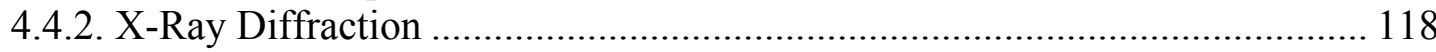

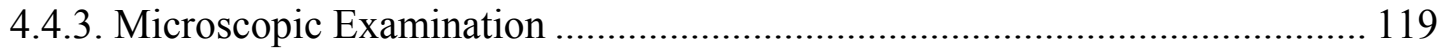

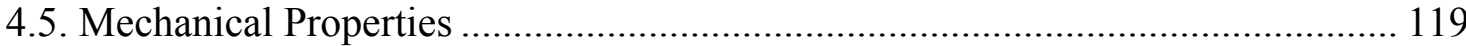

4.5.1. Maximum and Minimum Dry Density...................................................... 119

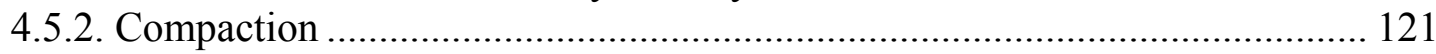

4.5.3. Large-Scale Direct Shear Tests ................................................................. 124

4.5.4. Consolidated Drained Triaxial Tests .......................................................... 132

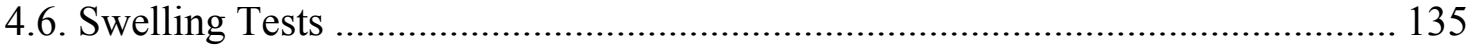

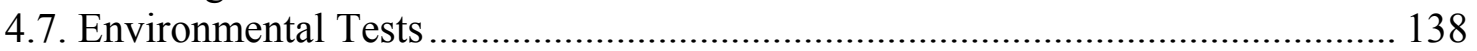

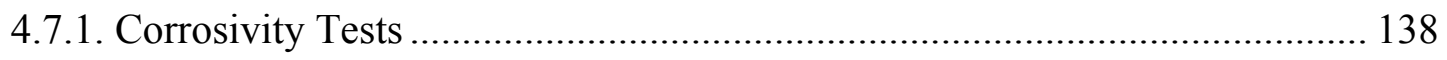

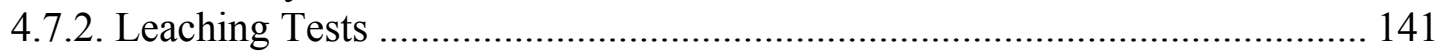

4.8. Tests on Mixtures of Steel Slag ................................................................... 142

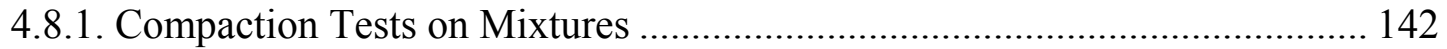

4.8.2. Unconfined Compression Tests on Mixtures................................................ 143

4.8.3. Swelling Tests on Mixtures........................................................................ 147

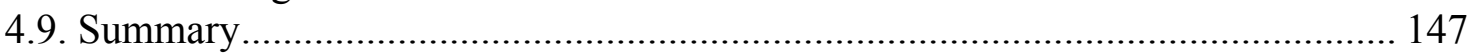

CHAPTER 5. ENGINEERING PROPERTIES OF BOF SLAGS ................................ 149

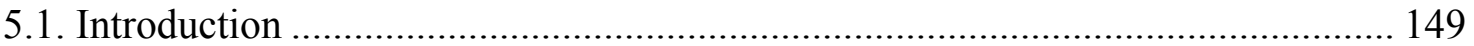

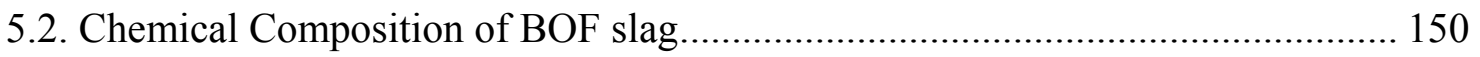

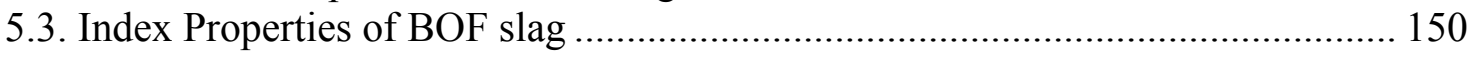

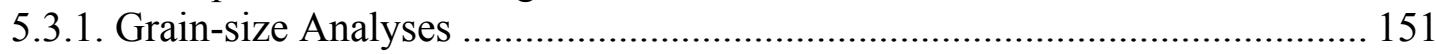

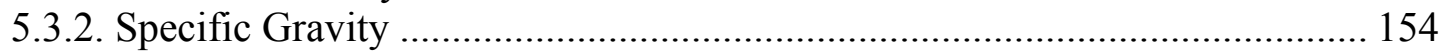


5.4. Mineralogical and Morphological Properties of BOF slag ................................... 156

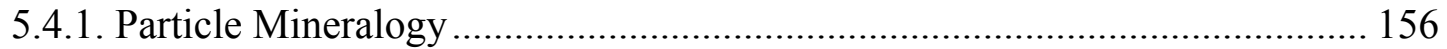

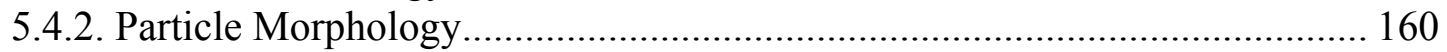

5.5. Geotechnical Properties of BOF slag …………............................................. 165

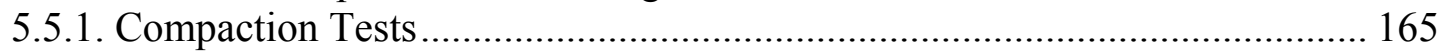

5.5.2. Maximum and Minimum Dry Density Tests ................................................ 169

5.5.3. Large-Scale Direct Shear Tests ................................................................. 170

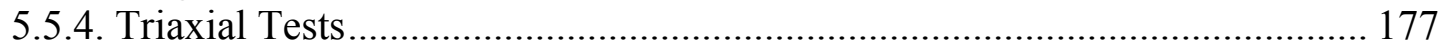

5.6. Long-term Swelling Response of BOF slag ............................................... 179

5.7. Corrosivity and Leaching Potential of BOF slag............................................... 182

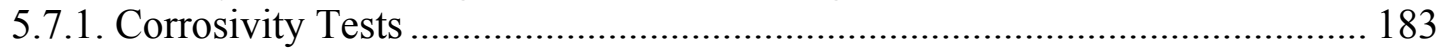

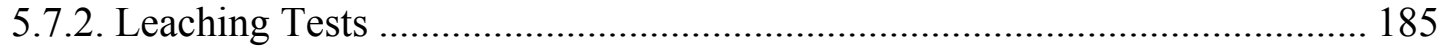

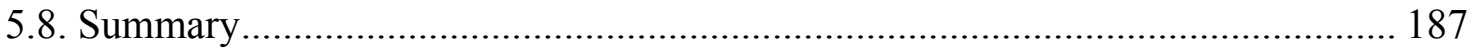

CHAPTER 6. ENGINEERING PROPERTIES OF EAF(L) SLAG …......................... 190

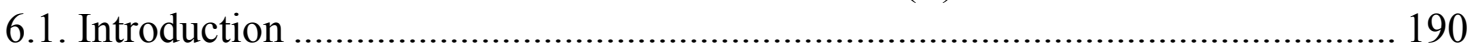

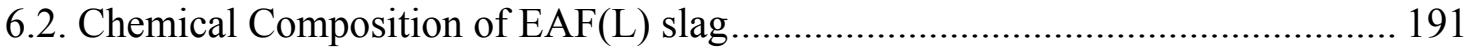

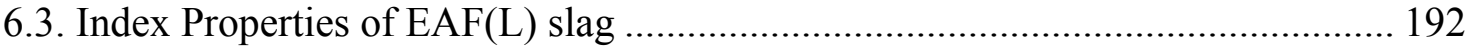

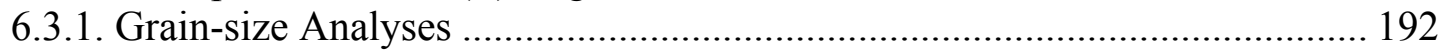

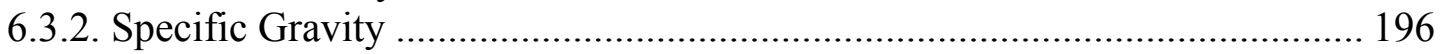

6.4. Mineralogical and Morphological Properties of EAF(L) slag............................... 198

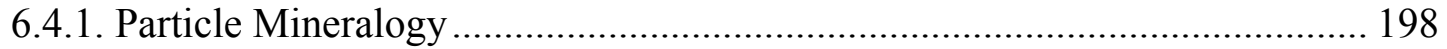

6.4.2. Particle Morphology............................................................................. 202

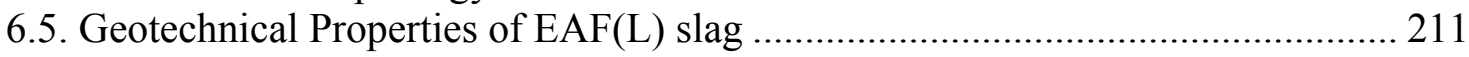

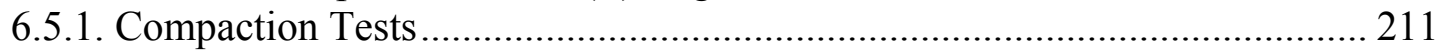

6.5.2. Maximum and Minimum Dry Density Tests ............................................... 214

6.5.3. Large-Scale Direct Shear Tests ................................................................... 215

6.6. Long-term Swelling Response of EAF(L) slag ............................................... 222

6.7. Corrosivity and Leaching Potential of EAF(L) slag.......................................... 225

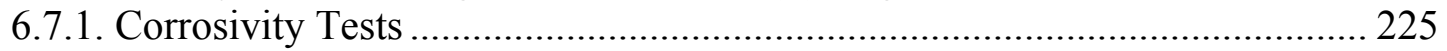

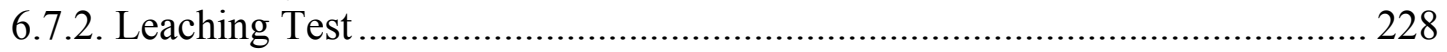

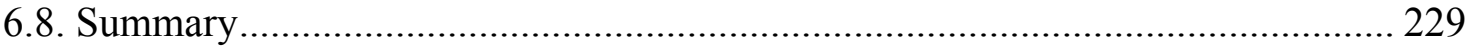

CHAPTER 7. ENGINEERING PROPERTIES OF STEEL SLAG MIXTURES.......... 232

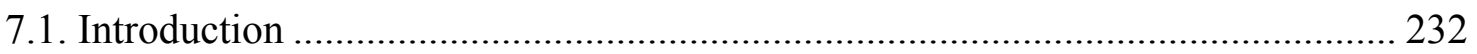

7.2. Compaction Characteristics of EAF(L) slag and Class-C Fly Ash Mixtures....... 233

7.3. Strength Gain Behavior of EAF(L) Slag and Class-C Fly Ash Mixtures ............ 234

7.4. Strength Gain Behavior of BOF Slag and Class-C Fly Ash Mixtures ................. 239

7.5. Long-term Swelling Response of EAF (L) Slag and Class-C Fly Ash Mixtures. 243

7.6. Long-term Swelling Response of BOF Slag Mixtures....................................... 246

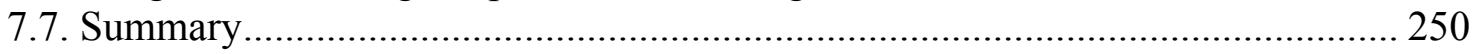

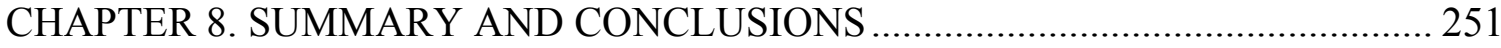

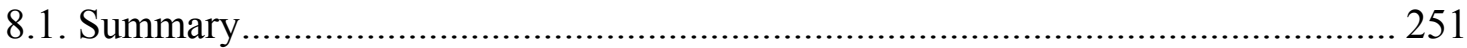

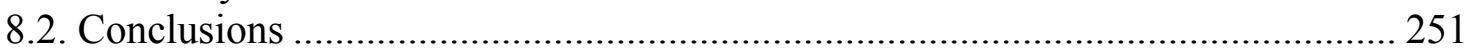

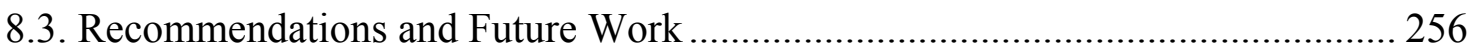

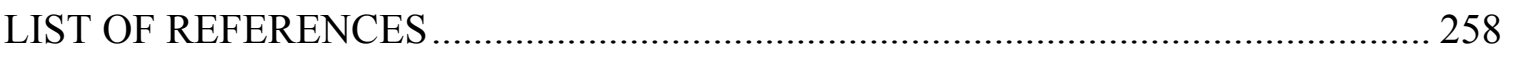




\section{LIST OF TABLES}

Table Page

Table 2.1 Slag generation and sales data (modified after USGS, 1993-2006) ............... 46

Table 3.1 Chemical composition of blast-furnace slags .......................................... 55

Table 3.2 Chemical composition of basic-oxygen-furnace slags ..................................5 59

Table 3.3 Chemical composition of electric-arc-furnace slags.................................... 61

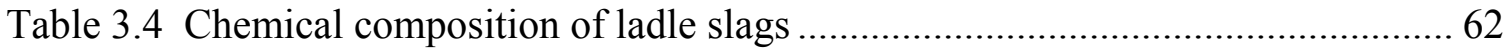

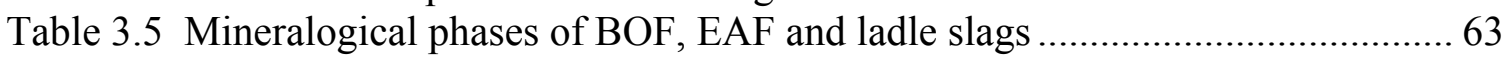

Table 3.6 Engineering properties of steel slag (modified after Lee 1974, Noureldin and

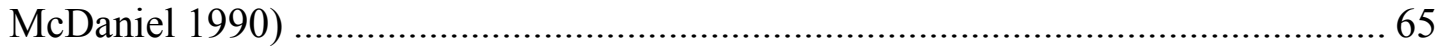

Table 3.7 Specific gravity values reported in the literature for steel slags ..................... 67

Table 3.8 European aggregate specification for steel slag based on volume expansion from steam tests (Motz and Geiseler, 2001) ........................................................ 85

Table 3.9 Volume change (based on autoclave) scale used by the Edw C. Levy Company to evaluate steel slag for aggregate applications (Yzenas 2008) ............................... 86

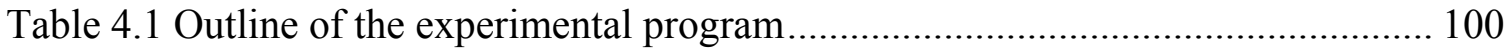

Table 4.2 Direct shear test matrix for BOF slag samples ......................................... 131

Table 4.3 Direct shear test matrix for EAF(L) slag .................................................. 132

Table 5.1 Chemical composition of Batch-1 Fresh BOF slag ................................... 150

Table 5.2 Summary of grain-size distribution analyses and classification of BOF slag

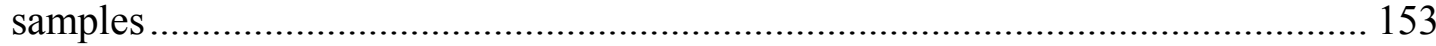

Table 5.3 Specific gravity and absorption values for the coarse fraction of BOF slag . 154

Table 5.4 Specific gravity of the fine fraction of BOF slag (particles smaller than

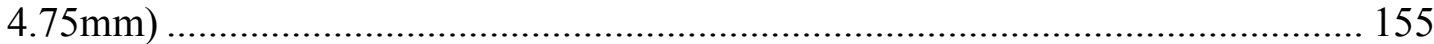

Table 5.5 Average specific gravity of BOF slag samples........................................ 156

Table 5.6 Mineralogical phases identified in fresh and aged BOF slags based on XRD

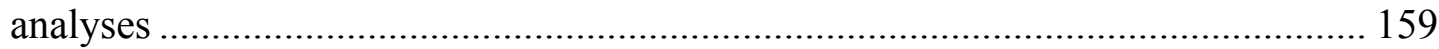

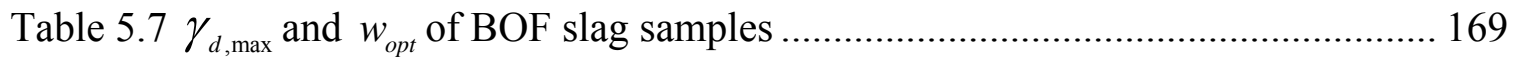

Table 5.8 Maximum and minimum dry unit weight test results ................................. 170

Table 5.9 Test matrix for direct shear testing of BOF slag samples............................ 172

Table 5.10 Summary of shear strength parameters obtained from large-scale direct shear

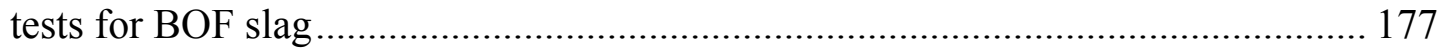

Table 5.11 Results of CID triaxial tests for Batch-3 Aged BOF slag samples (particles

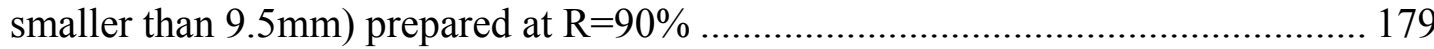

Table 5.12 Results of long-term swelling tests performed on BOF slag samples (fresh and

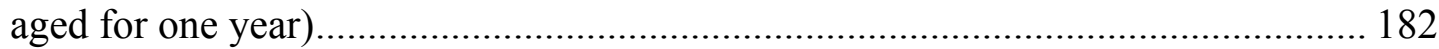

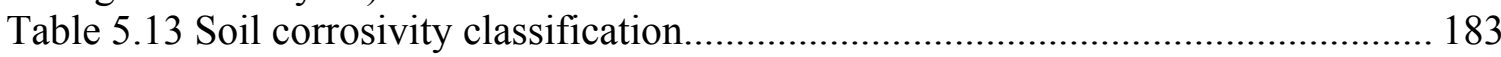


Table 5.14 Electrical resistivity test results for BOF slag samples............................. 184

Table 5.15 pH test results for soaked BOF slag samples....................................... 185

Table 5.16 TCLP (acidic leachate-mg/L) analysis of BOF slag ................................. 186

Table 5.17 Indiana restricted waste criteria based on TCLP test results ...................... 187

Table 6.1 Chemical composition of Batch-1 Fresh EAF(L) slag ................................ 191

Table 6.2 Summary of grain-size distribution analyses and classification of EAF(L) slag

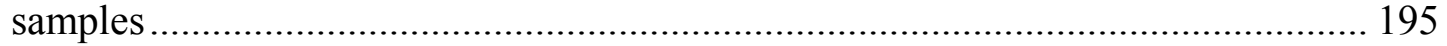

Table 6.3 Specific gravity and absorption values for the coarse fraction of EAF(L) slag 196

Table 6.4 Specific gravity of the fine fraction of EAF(L) slag (particles smaller than

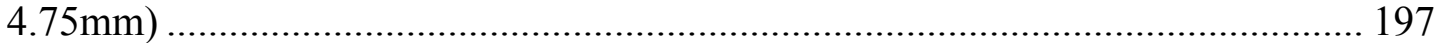

Table 6.5 Average specific gravity of EAF(L) slag samples..................................... 198

Table 6.6 Mineralogical phases identified in Batch-1 Fresh and Batch-2 Fresh EAF(L) slags samples based on XRD analyses ........................................................... 202

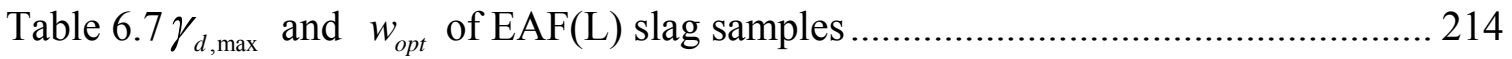

Table 6.8 Maximum and minimum dry unit weight test results ................................ 215

Table 6.9 Test matrix for direct shear testing of EAF(L) slag samples ....................... 216

Table 6.10 Summary of shear strength parameters obtained from large-scale direct shear

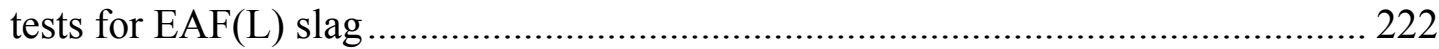

Table 6.11 Results of long-term swelling tests performed on EAF(L) slag samples (fresh

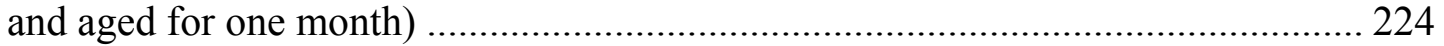

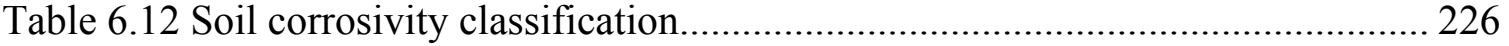

Table 6.13 Electrical resistivity test results for EAF(L) slag samples.........................226

Table $6.14 \mathrm{pH}$ measurements on soaked EAF(L) slag samples.................................. 227

Table 6.15 TCLP (acidic leachate-mg/L) analysis of EAF(L) slag ............................. 228

Table 6.16 Indiana restricted waste criteria based on TCLP tests .............................. 229

Table $7.1 \gamma_{d, \max }$ and $w_{\text {opt }}$ of EAF(L) slag and Class-C fly ash mixtures ................... 234

Table 7.2 Regression functions that represent the time vs. unconfined compressive strength gain behavior of EAF(L) slag and Class-C fly ash mixtures .................... 239

Table 7.3 Summary of unconfined compressive strength of EAF(L) slag and Class-C fly

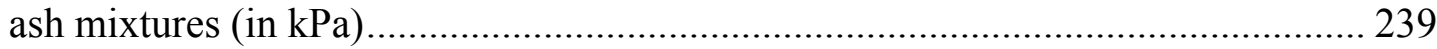

Table 7.4 Summary of unconfined compressive strength of EAF(L) slag and Class-C fly

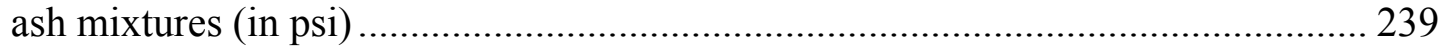

Table 7.5 Regression functions that that represent the time vs. unconfined compressive strength gain behavior of BOF slag and Class-C fly ash mixtures ........................ 243

Table 7.6 Summary of the unconfined compressive strength (in $\mathrm{kPa}$ ) of BOF slag and

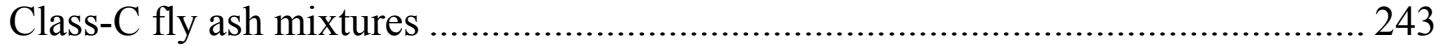

Table 7.7 Summary of the unconfined compressive strength (in psi) of compacted BOF slag and Class-C fly ash mixtures .................................................................... 243

Table 7.8 Volumetric strains obtained from the long-term swelling tests for fresh EAF(L) slag and mixtures of fresh EAF(L) slag and 5,10 and 20\% Class-C fly ash (by weight). 
Table 7.9 Swell-strains obtained from the long-term swelling tests for BOF slag and mixtures of BOF slag and 5,10 and 20\% Class-C fly ash and ground rubber (by weight) 


\section{LIST OF FIGURES}

Figure

Page

Figure 2.1 Flowchart of iron and steelmaking processes (modified after Schoenberger 2001 ; http://www.emt-india.com/process_main.htm). 20

Figure 2.2 Picture of two adjacent blast furnaces (Schoenberger 2001) ........................ 21

Figure 2.3 Picture of a blast-furnace slag pit (National Slag Association 2009)............. 22

Figure 2.4 Schematic of a blast-furnace process and ironmaking reactions (modified after Jastrzebski 1959) 24

Figure 2.5 Basic-oxygen furnace processes: (a) BOF being charged with molten iron, and

(b) BOF slag pit (after Schoenberger 2001; NSA 2009) ....................................... 27

Figure 2.6 Schematic representation of the basic-oxygen furnace process and the reactions involved in BOF steelmaking (modified after Schoenberger 2001 and

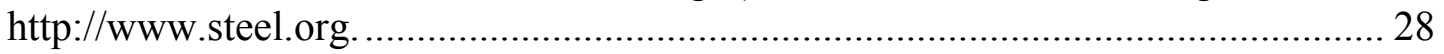

Figure 2.7 Picture of an electric-arc furnace (Whitesville Mill, Indiana)....................... 31

Figure 2.8 Schematic representation of the electric-arc-furnace steelmaking process and ladle refining (modified after http://www.steel.org; http://www.energymanagertraining.com/iron_steel/Iron_Steel_process.htm) .......... 35

Figure 2.9 Slag Processing: (a) Water spraying, (b) air cooling, (c) metal recovery and (d) sizing (Photographs were taken at the Whitesville Mill, Indiana)..................... 39

Figure 2.10 Use of :(a) granulated blast-furnace slag (b) air-cooled blast-furnace slag in 2006 based on sales data (modified after USGS (2006)) ...................................... 48

Figure 2.11 Use of steel slag in 2006 based on sales data (modified after USGS (2006)) 49

Figure 3.1 Types of blast-furnace slag: (a) air-cooled (b) pelletized (c) granulated (d)

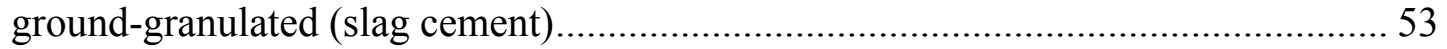

Figure 3.2 Typical shapes of regular and irregular compaction curves for different soil types (modified after Foster 1962; Lee and Suedkamp 1972) ................................. 69

Figure 3.3 Gravel-size steel slag particle with a lime pocket (Photograph was taken at Mittal Steel, Indiana Harbor West Steel Plant). 74

Figure 3.4 Autoclave expansion test assembly: (a) autoclave test machine (b) mold and dial gauge used for height measurements (courtesy of John Yzenas 2008) ............. 79

Figure 3.5 Schematic representation of steam test (BS EN 1744-1:1998) ..................... 80

Figure 3.6 Rate of corrosion versus pH (modified after Scully 1990)........................... 96

Figure 4.1.Location of the source plant for BOF slag ............................................. 102

Figure 4.2. BOF slag screened into three size ranges at the processing plant ............... 102 Figure 4.3 Representative BOF slag sample from Indiana Harbor Works Plant........... 103

Figure 4.4 Location of the source plant for EAF (L) slag ........................................ 105 
Figure 4.5 Cooling of EAF (L) slag: (a) EAF(L) slag being poured into the pits, and b) Solidified EAF (L) slag (Photographs taken at the Whitesville Mill) .................... 106 Figure 4.6 Representative EAF(L) slag sample from the Whitesville Mill................... 106 Figure 4.7 Class-C fly ash from NIPSCO Company, IN........................................... 108 Figure 4.8 Ground rubber (10/20) from Rubber Mulch Products, IN .......................... 109 Figure 4.9 Representative steel slag samples: (a) spreading of steel slag on tarp (b) thorough mixing (c) quartering $(\mathrm{d})$ storing in air-tight buckets ............................. 110

Figure 4.10 Reducing steel slag samples to smaller representative quantities using a soil splitter

Figure 4.11 De-airing process in the water pycnometer method ................................. 114

Figure 4.12 Soaked gravel-size particles from EAF (L) and BOF slag samples.......... 116

Figure 4.13 EAF(L) slag coarse aggregate: (a) during surface drying, and (b) measuring buoyant mass by suspending the container with slag particles in water ................. 117

Figure 4.14 Maximum dry density test set-up on the vibrating table ........................... 120

Figure 4.15 Compaction procedure for $\mathrm{EAF}(\mathrm{L})$ slag samples: a) spraying water to achieve the desired moisture content, b) compacting the sample in a 4-inch-diamter mold, c) trimming the compacted sample, d) measuring the compacted mass, e) recovering the sample with a hydraulic jack, and f) oven drying for moisture content measurement 123

Figure 4.16 Compaction of BOF slag sample: (a) placing BOF-slag sample in the 6" mold, and (b) applying blows with the Standard Proctor rammer ......................... 123

Figure 4.17 Isometric view of the large-scale direct shear machine........................... 125

Figure 4.18 Vertical loading system instrumentation details of large-scale direct shear machine: (a) vertical LVDT and (b) loading frame and the vertical load cell......... 126

Figure 4.19 Shearing mechanism and instrumentation details of the large-scale direct

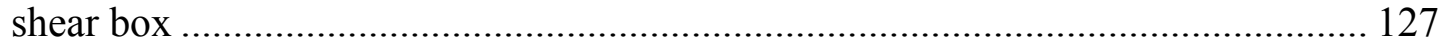

Figure 4.20 Preparation of a BOF-slag sample in the lower box: (a) mass measurement, (b) compaction, (c) leveling, (d) height measurement, and (e) scratching of the surface 128

Figure 4.21 Preparation and shearing of a BOF-slag sample in the upper-box: (a) placing the slag sample in the upper box, (b) compacting the layer, (c) placing the top cap on top of the final layer, and (d) sample before the start of the shearing process......... 129

Figure 4.22 Triaxial test set-up: (a) close view of a BOF-slag specimen before shearing, and (b) specimen after shearing in the $\mathrm{CKC}$ triaxial machine 134

Figure 4.23 Sample preparation in CBR mold: a) a spacer disc placed at the bottom of the CBR mold prior to compaction b) spacer disc is removed and a filter paper is placed on the top of the sample after compaction ............................................... 135

Figure 4.24 Components of the CBR swelling test set-up......................................... 136

Figure 4.25 Plastic soaking containers with a steel mesh placed at the bottom ............. 137

Figure 4.26 Long-term swelling test set-up .............................................................. 138

Figure 4.27 BOF slag sample preparation in the soil box for resistivity testing ........... 140

Figure 4.28 Electrical resistivity tests performed on (a) as-compacted BOF slag, and (b)

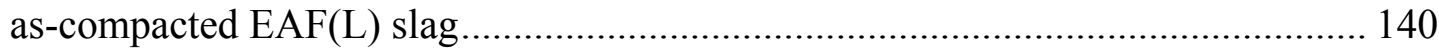

Figure $4.29 \mathrm{pH}$ measurement on a soaked BOF-slag ............................................. 141 
Figure 4.30 UC sample preparation steps prior to curing: (a) greasing the split mold, (b) preparing the dry steel slag and fly ash mixture, (c) spraying water to achieve the optimum moisture content of the sample, (d) compacting in layers in a mold $10 \mathrm{~cm}$ (4inch) in diameter and $20 \mathrm{~cm}$ (8inch ) in height, (e) measuring the mass of the compacted sample, and (f) placing the mold with the compacted sample in the moist room to allow curing for 1 day.... 145

Figure 4.31 UC sample preparation and testing after the samples were cured: (a) removing the sample from the mold, (b) labeling the samples with time and date, (c) curing of samples in the moist room for the designated curing times, and (d) testing the sample in a compression test machine 146

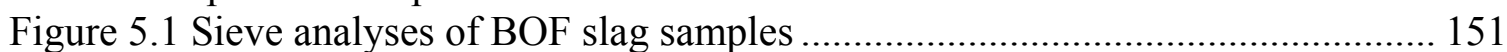

Figure 5.2 Grain-size distribution of Batch-1 Fresh BOF slag ................................... 152 Figure 5.3 Representative grain-size distribution curves for BOF slag samples ........... 153 Figure 5.4 X-ray diffraction patterns for fresh and aged BOF slag samples ................. 157 Figure 5.5 XRD analysis of Batch-1 Fresh BOF slag sample ..................................... 158

Figure 5.6 XRD analysis of Batch-3 Aged BOF slag sample................................... 158

Figure 5.7 Gravel-size fresh BOF slag particles ..................................................... 160

Figure 5.8 SEM micrographs of Batch-1 Fresh BOF slag sample: (a) particle shape, and

(b) surface texture and elemental analysis 161

Figure 5.9 SEM micrographs of Batch-2 Fresh BOF slag sample: (a) particle shape and elemental analysis of sand- and silt-size particles, and (b) surface texture

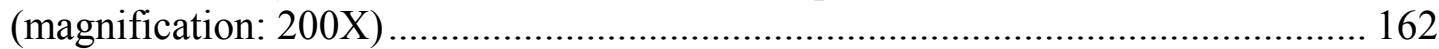

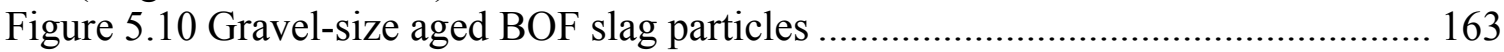

Figure 5.11 An agglomerated aged BOF slag particle............................................. 164

Figure 5.12 SEM micrographs of aged BOF slag particles: (a) particle shape and

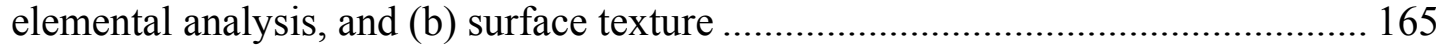

Figure 5.13 Compaction curves of BOF slag samples............................................... 166 Figure 5.14 Grain-size distribution curves prior and after compaction for fresh and aged BOF slags 168

Figure 5.15 Horizontal shear stress versus horizontal displacement for Batch-1 Fresh

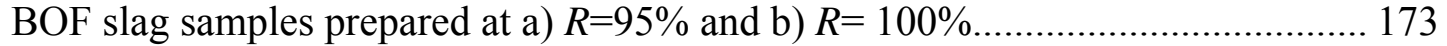

Figure 5.16 Shear strength parameters for Batch-1 Fresh BOF slag samples prepared at $R=95 \%$ and $R=100 \%$ : (a) critical-state and (b) peak-state ................................... 174

Figure 5.17 Horizontal shear stress versus horizontal displacement graphs for: (a) Batch2 Fresh BOF slag prepared at $R=95 \%$ (b) Batch-2 Aged BOF slag prepared at $R=95 \%$. 175

Figure 5.18 Shear strength parameters for Batch-2 Fresh BOF slag at $R=95 \%$ and Batch-2 Aged BOF slag at $R=96 \%$ : (a) critical-state, and (b) peak state .......................... 176 Figure 5.19 CID triaxial testing on Batch-3 Aged BOF slag (particles smaller than $9.5 \mathrm{~mm}$ ) prepared at $90 \%$ relative compaction: (a) axial strain vs. deviatoric stress,

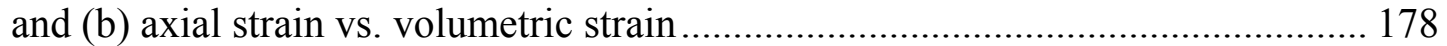

Figure 5.20 Time vs. volumetric strain curves for BOF slag samples......................... 180 Figure 6.1 Sieve analyses of EAF(L) slag samples ................................................. 193

Figure 6.2 Grain-size distribution curve for Batch-1 Fresh EAF(L) slag...................... 194

Figure 6.3 Representative grain-size distribution curves for EAF(L) slag samples ....... 195 
Figure 6.4 X-ray diffraction patterns for Batch-1 Fresh and Batch-2 Fresh EAF(L) slag

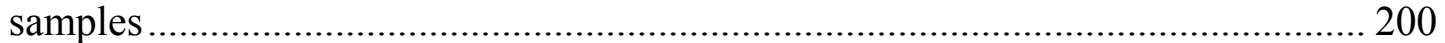

Figure 6.5 XRD analysis of Batch-1 Fresh EAF(L) slag sample ................................ 201

Figure 6.6 XRD analysis of Batch-2 Fresh EAF(L) slag sample ................................ 201

Figure 6.7 Gravel-size EAF(L) slag particles present in (a) Batch-1 Fresh EAF(L) slag sample and (b) Batch-2 Fresh EAF(L) slag sample ............................................. 203

Figure 6.8 Platy gravel-size particles present in (a) Batch-1 Fresh EAF(L) slag sample, and (b) Batch-2 Fresh EAF(L) slag sample ....................................................... 204

Figure 6.9 Porous structure evident in gravel-size particles of Batch-1 Fresh EAF(L) slag

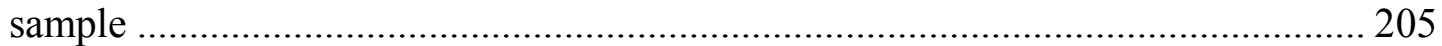

Figure 6.10 SEM micrographs of Batch-1 Fresh EAF(L) slag (a) sand- and silt-size particle shapes (magnification $=50 \mathrm{X}$ ) and (b) particles with their elemental analysis 206

Figure 6.11 SEM micrographs of Batch-1 Fresh EAF(L) slag: (a) surface texture of a sand-size particle (magnification=250X), (b) surface texture of a sand-size particle (magnification=1200X) and (c) crystalline structure and elemental analysis......... 208

Figure 6.12 SEM micrographs of Batch-2 Fresh EAF(L) slag: (a) sand- and silt-size particle shapes (magnification=50X) and (b) particles with their elemental analysis 209

Figure 6.13 SEM micrographs of Batch-2 Fresh EAF(L) slag: (a) surface texture of a sand-size particle (magnification $=800 \mathrm{X}$ ), (b) very rough surface texture of a sandsize particle (magnification=120X), (c) crystalline structure and elemental analysis

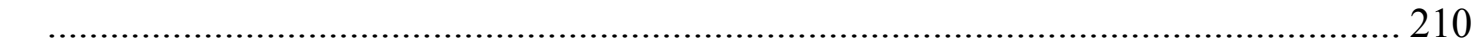

Figure 6.14 Compaction curves of fresh EAF(L) slag samples................................. 212

Figure 6.15 Grain-size distribution curves prior and after compaction of fresh EAF(L)

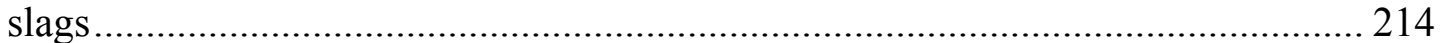

Figure 6.16 Horizontal displacement versus horizontal shear stress for Batch-1 Fresh

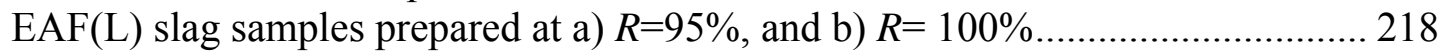

Figure 6.17 Shear strength parameters for Batch-1 Fresh EAF(L) slag samples prepared at $R=95 \%$ and $R=100 \%$ : (a) critical-state, and (b) peak-state ............................. 219

Figure 6.18 Horizontal displacement versus horizontal shear stress for Batch-2 Fresh

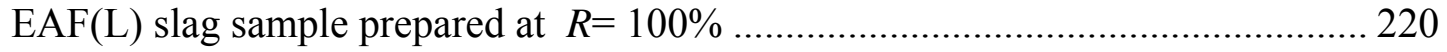

Figure 6.19 Shear strength parameters for Batch-2 Fresh EAF(L) slag prepared at $R=100 \%$ : (a) critical state, and (b) peak state .................................................. 221

Figure 6.20 Time vs. volumetric strain curves for EAF(L) slag samples..................... 223

Figure 7.1 Compaction curves for EAF(L) slag and Class-C fly ash mixtures ............. 233

Figure 7.2 Unconfined compression test results on compacted EAF(L) slag samples after

1 day, 2 days, 3 days and 7 days of curing times ........................................... 235

Figure 7.3 Unconfined compression test results on compacted EAF(L) slag and Class-C

fly ash mixtures with 5\% Class-C fly ash (by weight) for various curing times .... 235

Figure 7.4 Unconfined compression test results on compacted EAF(L) slag and Class-C fly ash mixtures with 10\% Class-C fly ash (by weight) for various curing times ... 236

Figure 7.5 Unconfined compression test results on compacted EAF(L) slag and Class-C fly ash mixtures with 20\% Class-C fly ash (by weight) for various curing times ... 236 
Figure 7.6 Curing time vs. unconfined compressive strength (in $\mathrm{kPa}$ ) of $\mathrm{EAF}(\mathrm{L})$ slag and EAF(L) slag and Class-C fly ash mixtures ....................................................... 237

Figure 7.7 Curing time vs. unconfined compressive strength (in psi) of compacted EAF(L) slag and EAF(L) slag and Class-C fly ash mixtures................................ 238

Figure 7.8 Unconfined compression test results on compacted BOF slag and Class-C fly ash mixtures with 5\% Class-C fly ash (by weight) for various curing times........... 241

Figure 7.9 Unconfined compression test results on compacted BOF slag and Class-C fly ash mixtures with $10 \%$ Class-C fly ash (by weight) for various curing times........ 241

Figure 7.10 Curing time vs. unconfined compressive strength (in $\mathrm{kPa}$ ) of compacted BOF slag and Class-C fly ash mixtures ........................................................... 242

Figure 7.11 Curing time vs. unconfined compressive strength (in psi) of compacted BOF

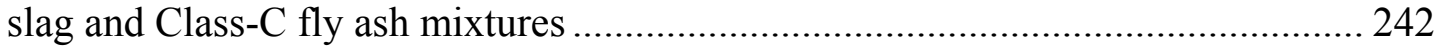

Figure 7.12 Time vs. volumetric strain curve for mixtures of EAF(L) slag and 5, 10 and $20 \%$ Class-C fly ash (by weight) ................................................................ 244

Figure 7.13 Time vs. volumetric strain for $\operatorname{EAF}(\mathrm{L})$ slag and mixtures of $\mathrm{EAF}(\mathrm{L})$ slag and 5, 10 and $20 \%$ Class-C fly ash (by weight). 245

Figure 7.14 Time vs. volumetric strain curves for mixtures of fresh and aged BOF slag prepared with $10 \%$ Class-C fly ash and 10\% ground rubber addition(by weight) .248

Figure 7.15 Time vs. volumetric strain curve for BOF slag and mixtures of BOF slag. 248 


\section{CHAPTER 1. INTRODUCTION}

\subsection{Background}

Slags are by-products of metallurgical processes. Steel- and ironmaking industries generate different types of slags. Blast furnace slag which is a by-product of ironmaking process has a high $\mathrm{SiO}_{2}$ content and hence, rapidly-cooled blast-furnace slag has an amorphous structure and pozzolanic properties. Due to its beneficial cementitious properties, blast-furnace slag generated each year is fully utilized by the cement and concrete industry. In contrast to blast-furnace slag, steel slags that generate from steelmaking and refining operations, are not widely known and fully utilized in practice. Typically, steel slags have a very crystalline structure (due to the slow cooling conditions applied during processing and their chemical composition that lack $\mathrm{SiO}_{2}$ ), and hence, they only show weak cementitious properties. In addition they can possess volumetric instability in presence of moisture. Coarse fraction (gravel-sizes) of steel slag is mainly used as road aggregates; however the problems related to its volumetric instability and lack of studies that explore the engineering properties of steel slag have impeded the utilization of steel slag in other applications in construction industry, specifically for the finer fraction (sand- and silt-sizes ) of steel slag.

In 2006, steel slag generation was estimated to be in 10-15 million metric ton (Mt) range in the U.S. and approximately 15 to $40 \%$ of the total steel slag output was not utilized. Traditionally unutilized steel slag is stockpiled in the steel plants, and eventually landfilled at slag disposal sites. Since the current methods of stockpiling and landfilling are not sustainable, disposal of steel slag has become a significant concern both to slagprocesser companies and to environmental agencies in the last decades. Use of steel slag in geotechnical engineering projects, such as in the construction of highway 
embankments or in subgrade stabilization projects, is advantageous because large volumes of steel slag can be utilized. Sustainability of steel slag in geotechnical applications will not only alleviate the steel slag disposal problem but also will offer a cost-effective substitute for conventional materials. In order to identify new applications for steel slag in the construction industry, there is a significant need to characterize steel slags, and to determine their engineering properties and long-term swelling potential.

\subsection{Research Objective}

The main objective of this study is to evaluate the feasibility of using steel slag as geo-materials and identifying beneficial uses of steel slag in geotechnical applications. For this purpose, two types of steel slag samples from two different steelmaking plants located in Indiana were investigated in this research. The steel slags tested include a basic-oxygen-furnace (BOF) slag and an electric-arc-furnace-ladle slag (EAF(L)). The engineering properties of these steel slags were determined through a systematic experimental program. The main goals of this research are as follows:

1. Characterization of BOF slag by determining its mineralogical, morphological, index and mechanical properties;

2. Characterization of $\mathrm{EAF}(\mathrm{L})$ slag by determining its mineralogical, morphological, index and mechanical properties;

3. Assessment of the corrosivity and leaching characteristics of EAF(L) slag and BOF slag for their potential use in geotechnical applications;

4. Assessment of the long-term swelling behavior of EAF(L) and BOF slag samples

5. Assessment of the strength gain characteristics and long-term swelling behavior of both mixtures of Class-C fly ash and BOF slag and mixtures of Class-C fly ash and $\operatorname{EAF}(\mathrm{L})$ slag

6. Identification of the potential geotechnical applications for $\mathrm{EAF}(\mathrm{L})$ and $\mathrm{BOF}$ slags 


\subsection{Research Approach}

BOF and $\mathrm{EAF}(\mathrm{L})$ slag samples were characterized through a series of tests which include, specific gravity, grain-size analysis, X-ray diffraction (XRD) analysis and SEM examinations. The mechanical properties of the BOF and $\mathrm{EAF}(\mathrm{L})$ slag samples were determined through compaction, maximum and minimum density, large-scale direct shear and triaxial tests. BOF and $\operatorname{EAF}(\mathrm{L})$ slag samples were classified based on the Indiana restricted waste criteria using the results of leaching and corrosivity tests. Swelling tests were performed on $\mathrm{BOF}$ and $\mathrm{EAF}(\mathrm{L})$ slag samples to asses their long-term swelling potential.

In order to enhance the mechanical properties and to alleviate the long-term swelling potential of BOF and $\operatorname{EAF}(\mathrm{L})$ slag samples, steel slag samples were mixed various percentages of Class-C fly ash and these steel slag mixtures were also evaluated in this research. The effect of 5 and $20 \%$ Class-C fly ash addition on the compaction characteristics of EAF (L) slag was investigated through standard Proctor compaction tests. Mixtures of steel slag were prepared by adding 5 and $10 \%$ Class-C fly ash by weight to BOF slag and 5, 10 and 20\% Class-C fly ash by weight to EAF(L) slag. The mixtures were compacted in a mold at their optimum moisture content and subjected to unconfined compression tests after various curing times to evaluate their strength gain characteristics. The effects of different percentages of Class-C fly ash and ground rubber addition to steel slag and also gradation on swelling potential of fresh and aged steel slag samples were investigated by performing long-term swelling tests. Long-term swelling tests were performed on compacted mixtures of both BOF slag and 10\% Class-C fly ash (by weight) and of $\operatorname{EAF}(\mathrm{L})$ slag and 5, 10 and 20\% Class-C fly ash (by weight). The effect of adding $10 \%$ ground rubber (by weight) to BOF slag on the long-term swelling behavior of the mixture was also investigated.

\subsection{Scope and Organization}

In this research, a comprehensive experimental program was undertaken to evaluate the feasibility of utilizing steel slag [BOF and $\mathrm{EAF}(\mathrm{L})$ slags] as geo-materials. In addition, various mixtures of steel slag and Class-C fly ash and of steel slag and ground rubber 
were also explored as options to enhance the mechanical properties and to mitigate swelling of slags.

This report presents the background information on the generation and processing of slags, the literature review on the utilization of steel slag, details of the experimental program and the experimental results. The report is organized in eight chapters, which are outlined below:

Chapter 1 provides a brief introduction.

Chapter 2 presents the background information on the generation and processing of slags produced by the iron and steelmaking industries in the U.S.

Chapter 3 presents a detailed literature review on the utilization of steel slag in various civil engineering applications. Environmental issues associated with using steel slag in geotechnical applications are also discussed.

Chapter 4 presents the experimental program and the details of the various types of tests performed in this study. The testing materials, equipment and experimental procedures followed in this research are described in detail in this Chapter.

Chapter 5 provides the experimental results for BOF slag. The test results include index, mineralogical, morphological and mechanical properties of BOF slag. Long-term swelling, corrosivity and leaching test results on BOF slag samples are also included.

Chapter 6 provides the experimental results for $\mathrm{EAF}(\mathrm{L})$ slag. The test results include index, mineralogical, morphological and mechanical properties of EAF(L) slag. Long-term swelling, corrosivity and leaching test results on EAF(L) slag samples are also included. 
Chapter 7 presents the experimental results for various steel slag [BOF and EAF(L) slag] mixtures. Unconfined compression, compaction, and longterm swelling test results for steel slag and Class-C fly ash mixtures are provided in this Chapter.

Chapter 8 includes the summary and conclusions of this research along with the recommendation for future research. 


\section{CHAPTER 2. OVERVIEW ON THE GENERATION AND PROCESSING OF IRON AND STEELMAKING INDUSTRY SLAGS}

\subsection{Introduction}

This chapter presents the background information on the generation and processing of slags from iron and steelmaking industries. At the beginning of the chapter, basic iron and steelmaking processes, and the generation of different types of slags from each of these processes are briefly explained. Subsequent to its generation, molten slag undergoes various processes or treatments that modify its engineering properties. These processes and treatments are also explained in this chapter. In addition, the statistical data on the generation and utilization of each type of slag (based on their sales in the US) is presented at the end of the chapter.

\subsection{Overview of Slag Generation from the Iron and Steelmaking Processes}

Slags are by-products of metallurgical processes of metal smelting from its ore or metal refining. The iron and steelmaking industry is the main source of slag generation both in the US and in the world. Iron is smelted from its ore in a blast furnace. There are two main types of steelmaking processes. The first is the basic-oxygen-furnace (BOF) steelmaking process by which iron is converted to steel. The second is the electric-arcfurnace (EAF) steelmaking process, which recycles mainly steel scraps. The steel from BOF and EAF can also go through a ladle refining unit to produce high-grade steels. Each of these processes generates different types of slags. Figure 2.1 shows a flow chart for the iron and steelmaking processes and the types of slag generated from each process. Slags are named based on the furnaces they are generated from. 


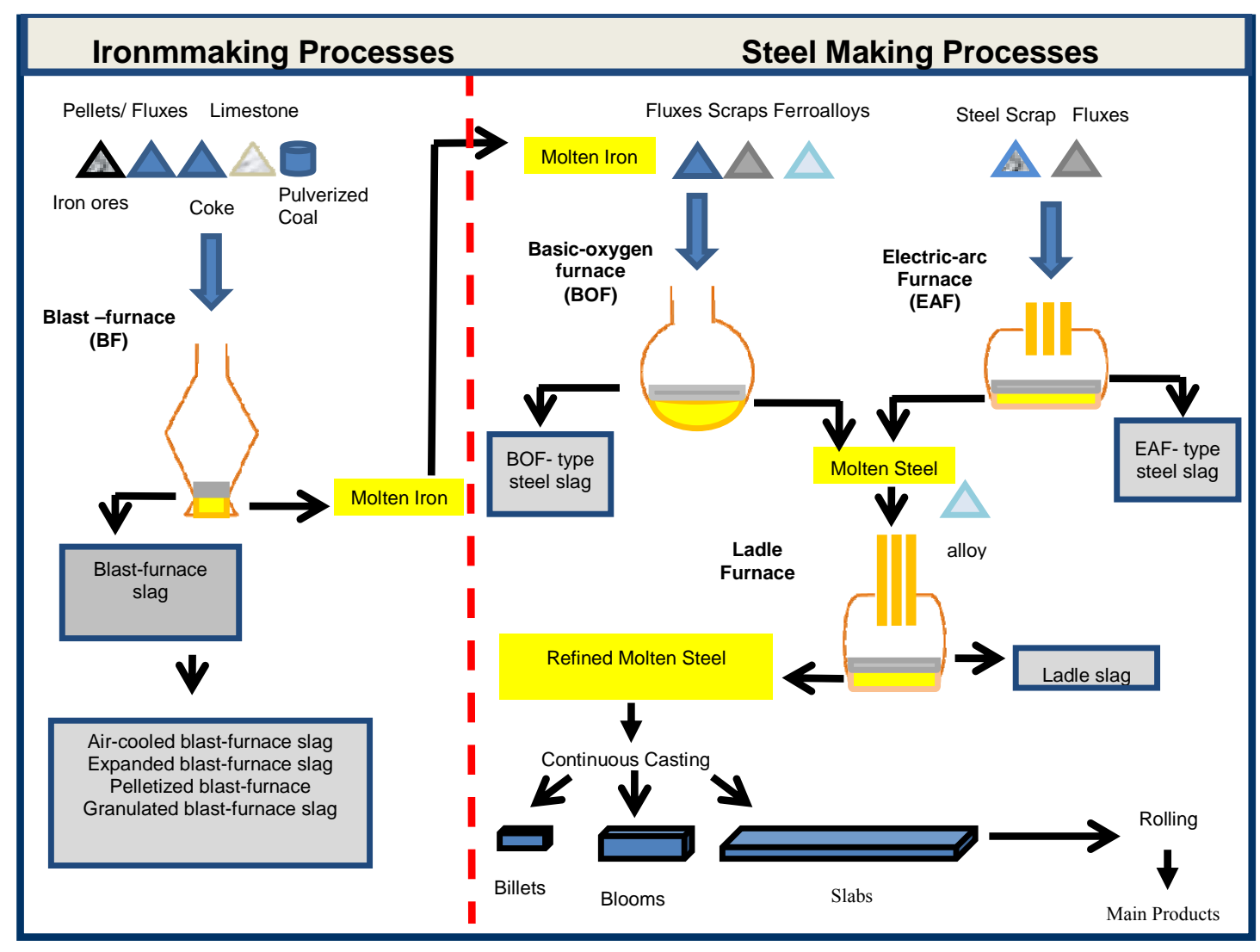

Figure 2.1 Flowchart of iron and steelmaking processes (modified after Schoenberger $2001 ;$ http://www.emt-india.com/process_main.htm)

The main types of slags that are generated from the iron and steelmaking industry can be summarized as follows:

- Blast-furnace slag (ironmmaking slag)

- Steel-furnace slag

o Basic-oxygen-furnace (BOF) slag

o Electric-arc-furnace (EAF) slag

o Ladle slag

The basic ironmaking and steelmaking processes and the type of steel slag generated from each process are explained briefly in the next section. 


\subsubsection{Blast-Furnace Ironmaking and Slag Generation}

A blast furnace is a type of metallurgical furnace that is used to produce a metal from its ore. The blast furnace is a tall vertical cylindrical structure that is lined internally with refractory brick and covered externally with a thick steel shell. Blast furnace plants are equipped with ore storage yards, bridges, rail hoppers and transfer cars to facilitate charging of the materials into the furnace. Figure 2.2 and Figure 2.3.show pictures of a blast furnace and a blast-furnace slag pit, respectively.

In the ironmaking process, blast furnace is continuously charged with ironbearing materials in the form of iron ore lumps, sinter and/or pellets, fluxing agents such as limestone and coke from the top of the furnace. An iron ore is an iron-rich rock from which iron is extracted for the production of steel. It contains a high concentration of iron oxides along with silica and alumina. The most common iron ores consist mainly of hematite $\left(\mathrm{Fe}_{2} \mathrm{O}_{3}\right)$ with minor amounts of magnetite $\left(\mathrm{Fe}_{3} \mathrm{O}_{4}\right)$. These iron oxides are chemically reduced and physically converted to liquid iron in the blast furnace. The fluxing agent - limestone $\left(\mathrm{CaCO}_{3}\right)$ - is added to the furnace to essentially remove the impurities present in the iron ore by converting these impurities into "slag".

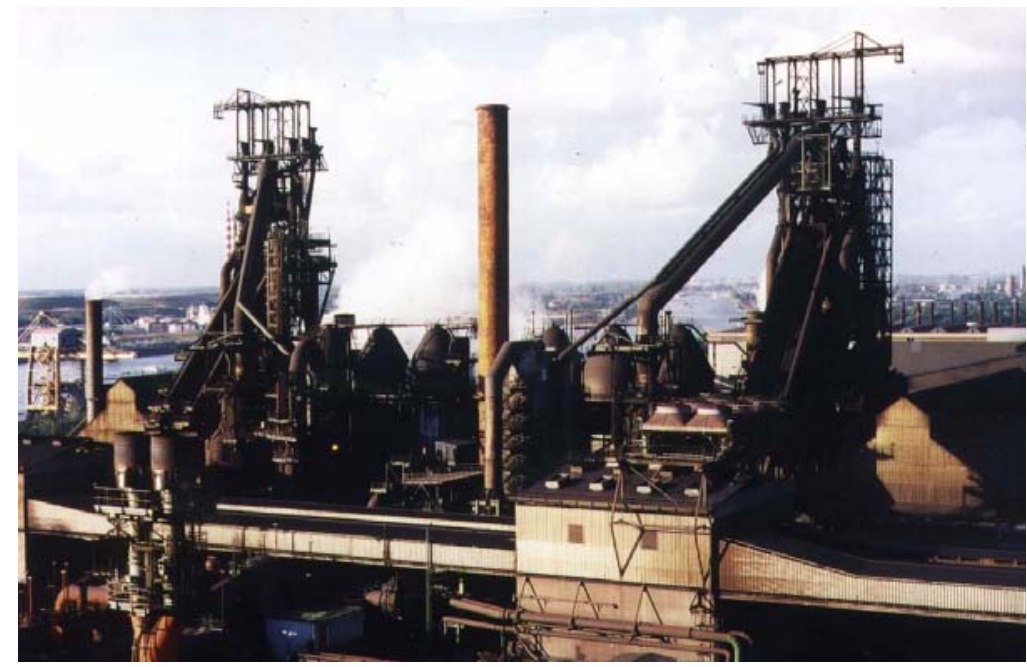

Figure 2.2 Picture of two adjacent blast furnaces (Schoenberger 2001) 


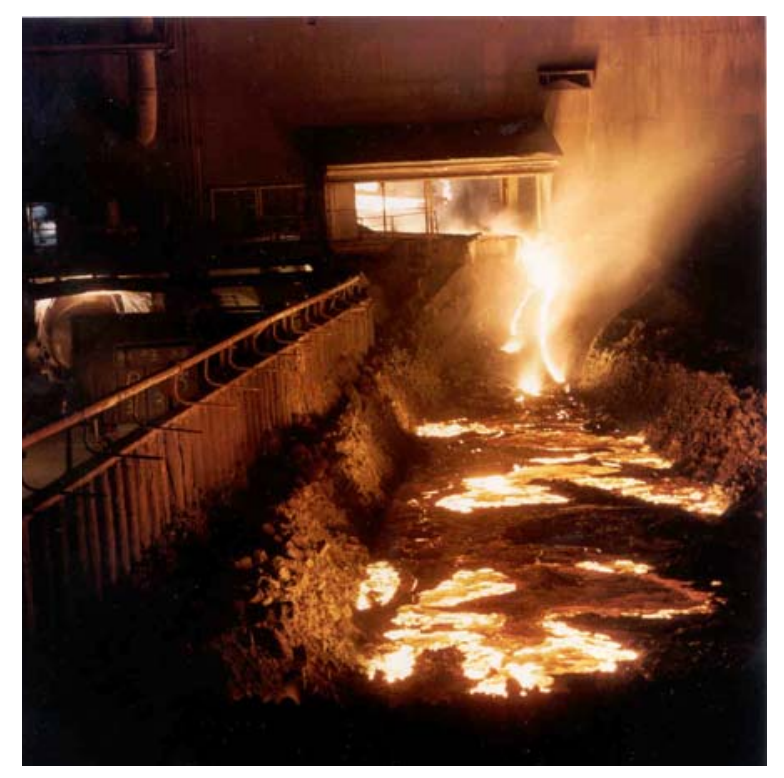

Figure 2.3 Picture of a blast-furnace slag pit (National Slag Association 2009)

As the iron-bearing materials and fluxing agents are charged from the top, a hot-air blast enriched with oxygen and auxiliary agents such as coal powder, oil and natural gas is simultaneously injected from the lower portion of the blast furnace. The furnace receives its name from this hot air "blast". Initially, the coke settles to the lower portion of the furnace and burns into the hot air blast leading to strong exothermic reactions releasing carbon dioxide $\left(\mathrm{CO}_{2}\right)$. At the bottom of the furnace, at high temperatures, carbon dioxide $\left(\mathrm{CO}_{2}\right)$ reacts with carbon $(\mathrm{C})$ to produce carbon monoxide $(\mathrm{CO})$. This released carbon monoxide is the main reducing agent in the furnace which converts iron oxides to metal iron. At high temperatures, carbon itself also acts as a reducing agent for iron oxides. The main reactions that take place in the blast-furnace can be summarized as follows:

$$
\begin{array}{ll}
\text { o } & \mathrm{C}+\mathrm{O}_{2} \rightarrow \mathrm{CO}_{2}+\text { Heat } \\
\text { o } & \mathrm{CO}_{2}+\mathrm{C} \rightarrow 2(\mathrm{CO}) \\
\mathrm{o} & \mathrm{CaCO}_{3} \rightarrow \mathrm{CaO}+\mathrm{CO}_{2} \\
\text { o } & \mathrm{Fe}_{2} \mathrm{O}_{3}+3 \mathrm{CO} \rightarrow 2 \mathrm{Fe}+3 \mathrm{CO}_{2} \\
\text { o } & \mathrm{Fe}_{3} \mathrm{O}_{4}+\mathrm{CO} \rightarrow \mathrm{CO}_{2}+3 \mathrm{FeO}
\end{array}
$$




$$
\begin{array}{cl}
\text { - } \mathrm{FeO}+\mathrm{CO} \rightarrow \mathrm{Fe}+\mathrm{CO}_{2} \\
\text { o } \mathrm{CaCO}_{3} \rightarrow \mathrm{CaO}+\mathrm{CO}_{2}
\end{array}
$$

As the iron oxides are reduced by these chemical reactions, iron starts to melt and drip as liquid iron through the coke to the bottom of the furnace. At the same time, the gases preheat the feed charge and the limestone is decomposed into calcium oxide and carbon dioxide. Calcium oxide formed by the decomposition of limestone reacts with the various impurities present in the iron-bearing materials (particularly silica and alumina) to form "slag." The slag that is generated from this ironmaking process is called "blastfurnace slag". Figure 2.4 shows a schematic of the blast-furnace process and a summary of the reactions involved.

Almost all of the silicates impurities present in the ore are removed by the fluxing agents forming blast-furnace slag. Consequently, the main chemical constituent of the blast furnace slag are calcium oxide $(\mathrm{CaO})$ from lime or dolomite, and silica $\left(\mathrm{SiO}_{2}\right)$ impurities from the ore. It also contains smaller amounts of alumina $\left(\mathrm{Al}_{2} \mathrm{O}_{3}\right)$ and magnesium oxide $(\mathrm{MgO})$ that enters the furnace with the iron ore, sinter, fluxing agent or coke. The iron-oxide content of blast furnace slag is typically less than $1 \%$ by weight. These constituents typically form silicates and aluminosilicates of calcium and magnesium. Typical mineralogy of a blast furnace slag consists of solid solutions of gehlenite $\left(2 \mathrm{CaO} \cdot \mathrm{Al}_{2} \mathrm{O}_{3} \cdot \mathrm{SiO}_{2}\right)$ and akermanite $\left(2 \mathrm{CaO} \cdot \mathrm{MgO} .2 \mathrm{SiO}_{2}\right)(\mathrm{Lee} 1974$; Robinson 2000; Rao 2006; NSA 2008). 


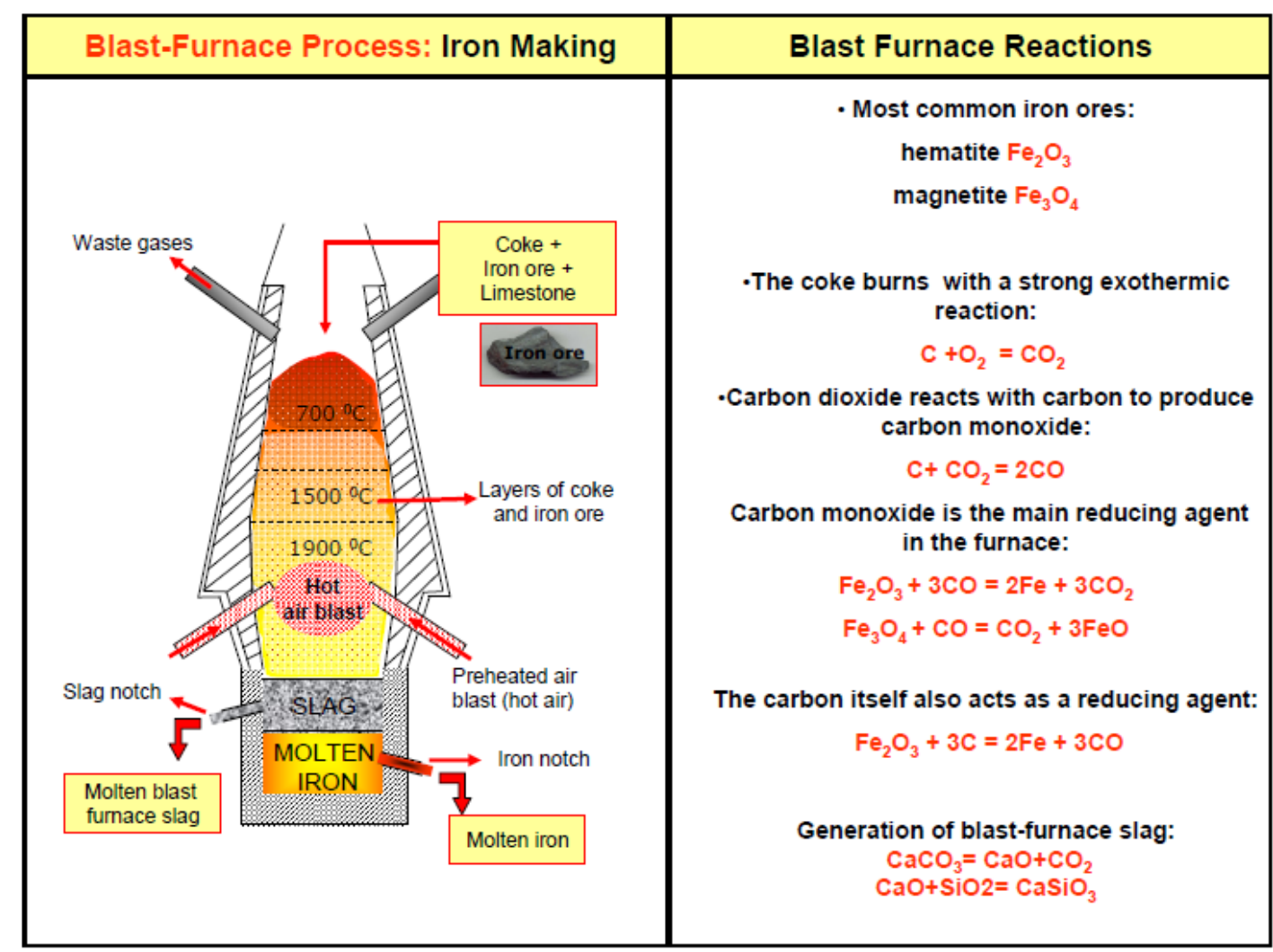

Figure 2.4 Schematic of a blast-furnace process and ironmaking reactions (modified after Jastrzebski 1959)

At the end of the process, the blast-furnace slag floats on top of the molten iron because its density is lower than the density of the molten iron. There are two separate notches at different elevations at the bottom section of the blast furnace. The upper (slag) notch and the lower (iron) notch facilitate the removal of the blast furnace slag and the molten iron, respectively. During the continuous blast-furnace process, at certain intervals of time (typically every 2 to 5 hours), the blast-furnace slag is tapped (poured out of the furnace) through the slag notch into ladles (a ladle is a steel bowl lined with refractory bricks) or slag pots, and the molten iron is tapped out from the iron notch into sand channels. The molten iron runs along these channels either directly to the casting bed or into large torpedo cars. In casting beds, pig iron (the hardened iron is referred to as pig iron because in the past the molten iron was cast into bars by pouring the molten iron into molds with fine sand beds; these iron bars were called as pigs because of their shapes) is re-melted 
and converted into cast iron. The molten iron that will be converted to steel is initially subjected to hot metal pretreatment in torpedo cars, and then transferred to the steel making facility. The blast-furnace slag is transferred to a slag pit with ladles or slag pot carriers and poured into the pit for cooling (See Figure 2.3).

The molten iron produced in the blast furnace has a high carbon content of approximately $4-5 \%$ by weight. This relatively high carbon content of the pig iron makes it very brittle and unsuitable for most commercial uses. Some portion of the pig iron produced in blast furnaces is used to make cast iron but the majority of pig iron undergoes several processes in order to produce different grades of steel. For this reason, conversion of iron ore to pig iron in a blast furnace can be viewed as the first step in the steel production process. Modern blast furnaces can produce up to 13,000 tons of iron per day (Lee 1974; Schoenberger 2001; Brandt and Warner 2005).

\subsubsection{Basic-Oxygen-Furnace (BOF) Process of Steelmaking and Slag Generation}

In the $20^{\text {th }}$ century, prior to the development of basic-oxygen furnaces, pig iron was converted to steel by open-hearth steelmaking process (also known as the SiemensMartin process). French engineer Pierre-Emile Martin in 1865 took out a license from Siemens Co. and developed the open-hearth steelmaking process in his furnace to convert iron to steel. The working principle of the open-hearth furnace was similar to modern steelmaking techniques, in which excess carbon and other impurities were burned out of the pig iron to produce steel. The open-hearth steelmaking process used gas or liquid fuel and had a capacity of producing 200 tons of steel in $\sim 6$ to 14 hours. The rate of steel making was relatively slow and the process was not fuel efficient. Therefore, most of the open hearth furnaces were closed in early 1990s and they were replaced with larger and cost effective basic-oxygen furnaces in the US (Brandt and Warner 2005; http://en.wikipedia.org/wiki/Open_hearth_furnace).

Modern integrated steel mills are huge steelmaking plants which have all the functions of primary steel production. These functions include conversion of ore to liquid iron, conversion of liquid iron to steel, solidification of liquid steel (casting), size reduction of solidified blocks (roughing rolling/billet rolling) and production of finished 
shapes (product rolling). Basic-oxygen furnaces are located at integrated steel mills in association with blast furnaces as they are charged with the molten iron produced in the blast furnace. The basic-oxygen furnace process (also known as the Linz-Donawitz process) is one of the modern steelmaking processes by which molten iron is converted to steel. The process was developed in 1948 at a steelworks near the Austrian towns of Linz and Donawitz (LD). The most common type of basic-oxygen furnaces is a pear-shaped refractory lined furnace which is also known as an LD converter. In modern steelworks, basic-oxygen furnaces can be charged with approximately 350 tons of molten iron at a time. The process of converting molten iron to steel in a basic-oxygen furnace takes approximately 40 minutes and hence is much more efficient than the traditional openhearth process of steelmaking. Furnaces are designed to be tilted during charging and tapping. Figure 2.5 (a) and (b) shows a picture of a basic-oxygen furnace while being charged with molten iron and a BOF slag pit, respectively (http://en.wikipedia.org/wiki/Steel_mill, Brandt and Warner 2005).

The entire process of basic-oxygen steelmaking is typically controlled by softwares which define the precise amounts of each feed thereby ensuring the chemical composition of the steel. Basic-oxygen furnaces are charged mainly with both molten iron and steel scraps. Typically, the proper basic-oxygen furnace charge balance consists of approximately $10-20 \%$ of steel scrap and $80-90 \%$ of molten iron. Some steelmaking plants as well use a steel scrap percentage as high as $40-50 \%$ in the BOF charge (Schoenberger 2001; personal communication with Jamie Hamilton from Multiserv). The presence of steel scraps in the basic-oxygen-furnace charge play an important role in cooling down the furnace and maintaining the temperature at $\sim 1600^{\circ} \mathrm{C}-1650^{\circ} \mathrm{C}$ for the required chemical reactions to take place. Depending on the chemical composition of the molten iron supplied from the blast furnace (in ladles), it is either sent directly to the basic-oxygen furnace to be used as charge or it undergoes a series of pretreatments in the ladles prior to that. The main pretreatments in the ladles include desulfurization, desiliconisation and dephosphorisation. The decision on the pretreatment of the molten iron depends on the chemical composition and quality of the molten iron and also on the 
required final quality of the steel that will be produced in the basic-oxygen furnace (Schoenberger 2001; http://en.wikipedia.org/wiki/Basic_oxygen_furnace).

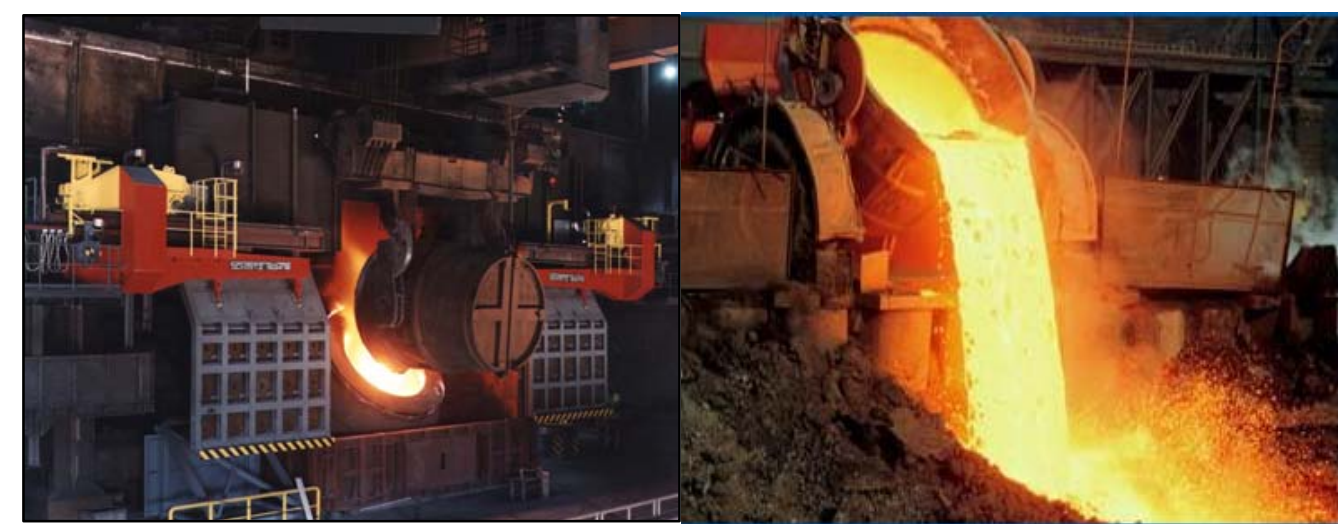

(a)

(b)

Figure 2.5 Basic-oxygen furnace processes: (a) BOF being charged with molten iron, and (b) BOF slag pit (after Schoenberger 2001; NSA 2009)

BOF process starts with charging of each feed into the furnace. Figure 2.6 shows a schematic representation of a basic-oxygen furnace and the main chemical reactions occurring in the furnace. Initially, steel scrap is charged to the furnace and, immediately after this charge, a ladle of molten iron ( 200 tons) is poured into the mouth of the basicoxygen furnace (on top of the steel scrap) with the help of a crane [See Figure 2.5 (a)]. Subsequently, a water-cooled oxygen lance is lowered into the furnace just above the surface of the metal as seen in Figure 2.6. The oxygen lance blows 99\% pure oxygen, which hits the mixture at supersonic speeds. In the following 20-25 min, intense oxidation reactions occur that remove impurities of the charge. Carbon dissolved in the steel is burned to form carbon monoxide, causing the temperature to rise to $1600-1700^{\circ} \mathrm{C}$. This temperature, which is monitored throughout the oxygen blowing period, causes the scrap to melt and lowers the carbon content of the molten iron (Schoenberger 2001; Brandt and Warner 2005; http://en.wikipedia.org/wiki/Basic_oxygen_furnace). 


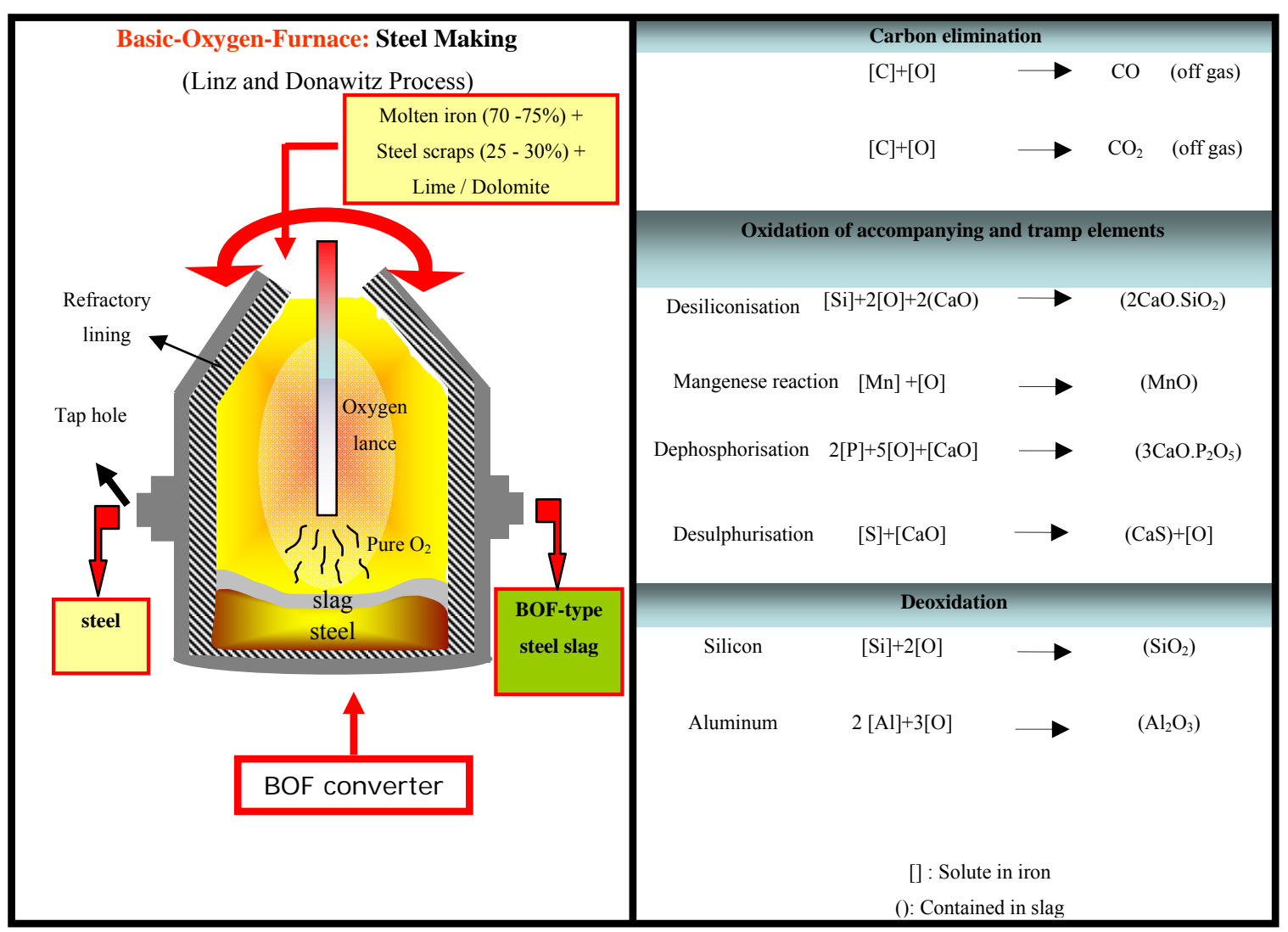

Figure 2.6 Schematic representation of the basic-oxygen furnace process and the reactions involved in BOF steelmaking (modified after Schoenberger 2001 and http://www.steel.org.

In order to remove the unwanted chemical elements, the furnace is also charged with fluxing agents such as lime $\left(\mathrm{CaO}\right.$ or dolomite $\left(\mathrm{Mg}\left(\mathrm{CaCO}_{3}\right)_{2}\right)$ during oxygen blowing. Carbon and other impurities combine with the burnt lime or dolomite to form slag, effectively reducing the amount of undesirable substances. Samples taken from the molten metal are tested near the end of the blowing cycle $(\sim 20 \mathrm{~min})$, and the chemical composition of the metal is determined. Once the desired chemical composition is achieved, the oxygen lance is pulled up from the furnace. Similar to the blast-furnace slag, the slag resulting from steelmaking also floats on top of the molten steel. The basicoxygen furnace is tilted in one direction in order to tap the steel into ladles. The steel produced can either undergo further refining in a secondary refining unit or be sent 
directly to a continuous caster where semi- finished shapes (blooms, billets, or slabs) are solidified in integrated steel mills.

After all the steel is removed from the basic-oxygen furnace, it is tilted again to pour the liquid slag into ladles. The slag generated from this steelmaking cycle is later processed, and the final product after processing is referred to as "basic-oxygen-furnace slag" (BOF slag). Several researchers and sources in the literature refer to this slag as "LD converter slag" since it is generated from the Linz-Donawitz process. The chemical reactions occurring during the removal of impurities determines the chemical composition of the basic-oxygen-furnace slag. The main chemical constituents of basicoxygen-furnace slag are $\mathrm{CaO}, \mathrm{FeO}$ and $\mathrm{SiO}_{2}$. During the conversion of molten iron into steel, a percentage of iron $(\mathrm{Fe})$ in the hot-metal cannot be recovered into the steel produced. This oxidized iron is observed in the chemical composition of the basicoxygen-furnace slag. Depending on the efficiency of the furnace, the iron content of basic-oxygen-furnace slag can vary between 10 to $40 \%$. $\mathrm{SiO}_{2}$ content of basic-oxygenfurnace slag is much lower compared to blast-furnace slag as most of the silica impurities are already trapped in the blast-furnace slag. Large quantities of lime or dolomotic lime are used during refining period of conversion from iron to steel hence the $\mathrm{CaO}$ content of the basic-oxygen-furnace slag is typically very high $(\mathrm{CaO}>35 \%)$. Even though, most of the lime $(\mathrm{CaO})$ or periclase $(\mathrm{MgO})$ exists in bound crystalline forms with other constituents; BOF slag as well can contain free (unbound) lime typically between (0-10 $\%$ ) and magnesia (typically between $0-10 \%)$. These free lime $(\mathrm{CaO})$ and magnesia $(\mathrm{MgO})$ hydrate expansively and these hydration reactions can cause the volumetric instability of the basic-oxygen-furnace slag. Chemical composition of basic-oxygenfurnace slag also contains oxides of other remaining impurities (such as Al, Mn, Ti, etc.). Dicalciumsilicate $\left(\mathrm{C}_{2} \mathrm{~S}\right.$ or $\left.2 \mathrm{CaO} . \mathrm{SiO}_{2}\right)$, wustite $(\mathrm{FeO})$, ferrites $\left(\mathrm{Fe}_{3} \mathrm{O}_{4}\right)$ and solid solutions of iron oxide $(\mathrm{FeO})$ and $(\mathrm{MgO})$ are typically observed in mineralogy of basic-oxygenfurnace slag (Robinson 2000; Schoenberger 2001; Juckes 2003; Shi 2004).

Currently, the basic-oxygen furnace processing is the predominant steelmaking technology, accounting for $60 \%$ of the world's total output of crude steel. In the US, this process accounts for $45 \%$ of the total output of crude steel, and this percentage is 
declining, primarily due to the replacement of basic-oxygen furnaces with electric-arcfurnaces (EAF), also known as mini mills, in which steel scrap is recycled to produce steel. The primary reason for the replacement of basic-oxygen furnaces with these mini mills was the day-by-day increasing need for recycling steel scrap to conserve natural resources throughout the world. The increase in the size of electric-arc furnaces in the last decades resulted in an increase in the rate of steel production in these furnaces which subsequently made these furnaces competitive in terms of cost as well. Overall, basicoxygen furnaces is an essential component of integrated steel mills and will continue to exist as the integrated steel mills continue to work, converting iron into steel (Schoenberger 2001; Brandt and Warner 2005; Seetharaman 2005; USGS 2006).

\subsubsection{Electric-Arc-Furnace (EAF) Process of Steelmaking and Slag Generation}

The first commercial electric-arc furnace plant was developed by Paul Heroult in the US, in 1907. However, the use of electric-arc furnaces to produce steel was not common until the Second World War and the steel produced in the electric-arc furnaces was only used to manufacture some specialty products such as machine tools and spring steel until then. In Europe during the World War II, EAFs were widely used to produce alloy steels and as the larger size electric-arc furnaces started to be built, the "electric steelmaking" started to expand. The electric-arc furnaces had a low capital cost of $\sim \$ 140-200$ per ton of annual installed capacity (compared to the $\sim \$ 1000$ per ton of annual installed capacity of an integrated steel mill), which made these furnaces competitive in the steelmaking market. Hence, the largest steel producers in the U.S. (such as Nucor Steel) started to build EAF furnaces in 1969. In the last decades, electric-arc furnaces (EAF) are increasingly replacing basic-oxygen furnaces in the U.S. (http://en.wikipedia.org/wiki/Electric_arc_furnace).

Electric-arc furnaces use high-power electric arcs, instead of gaseous fuels, to produce heat which melts recycled steel scrap and converts it to high-quality steel. Electric-arc furnaces are sometimes referred to as "mini mills". The electric-arc furnace steelmaking process is not dependent on the blast-furnace production. Mini mills do not have all the capabilities of primary steelmaking, as is the case in integrated steel mills. 
Typically, mini mills contain one or two electric-arc furnaces, a ladle furnace, a strip or billet continuous caster, a reheat furnace and a rolling mill.

Electric-arc furnaces are equipped with graphite electrodes and they look like giant kettles with a spout or an eccentric notch on one side. The roof of the electric-arc furnaces can pivot and swing to facilitate the loading of raw materials. Figure 2.7 shows a picture of an electric-arc furnace and a shaft for scrap charging. The main feed of electric-arc furnaces is steel scrap with some pig iron. Steel scrap, either as heavy melt (large slabs and beams) or in shredded form, are separated, graded and sorted into as many as 65 different classes of steel in scrap yards. Consequently, the chemical composition of the steel can be predicted based on the percentage of the different quality steel scraps charged into the furnace. Typically, scrap yards are located near the mini mills to supply the scrap. Scrap baskets are loaded carefully with different types of scrap according to their size and density to ensure that both the melting conditions in the furnace and the chemistry of the finished steel are within the targeted range (Schoenberger 2001; Brandt and Warner 2005).

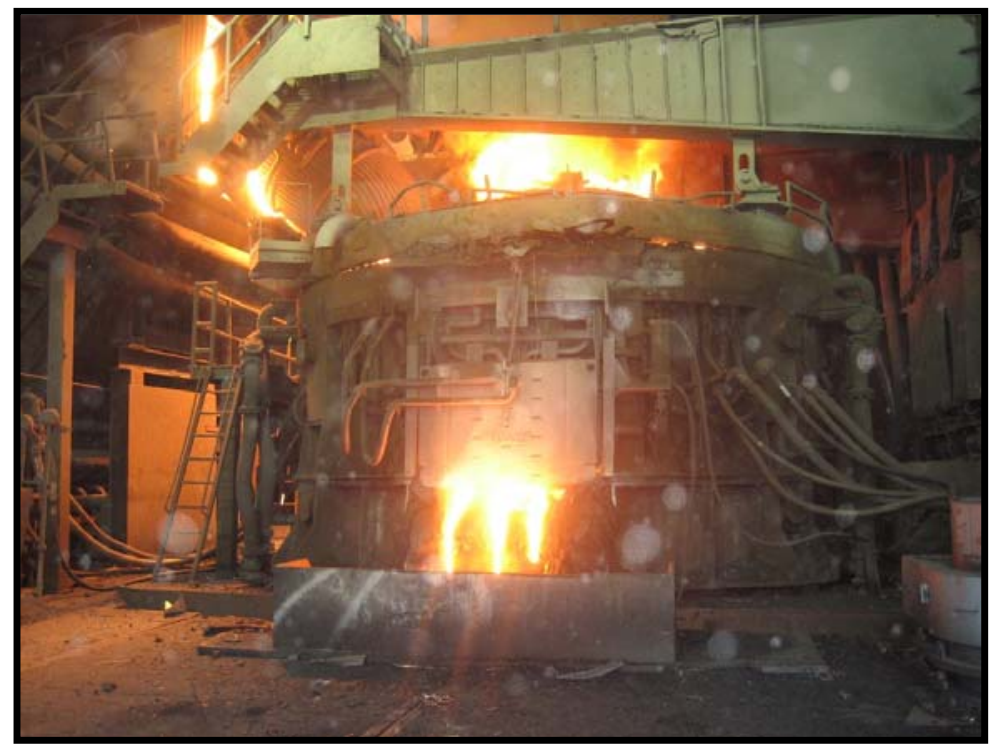

Figure 2.7 Picture of an electric-arc furnace (Whitesville Mill, Indiana) 
Electric-arc steelmaking process starts with charging the feed into the furnace. In order to facilitate charging from the top of the furnace, initially the roof of the electric-arc furnace is swung off (opened) and the electrodes are raised. Various types of steel scrap, is charged to the furnace using steel scrap baskets. After charging, typically smaller sizes of shreds are located on the top and heavy melt (large slabs) are located at the bottom of the furnace. Next, graphite electrodes (typically three of them), are lowered into the furnace through its roof. Then an arc is struck and the electricity travels through the electrodes and the metal itself. Heat is generated by this electric arc and the resistance of the metal to this flow of electricity. As the scrap melts, the electrodes are lowered/driven deeper trough the layers of scrap until they reach the heavy melt pieces at the bottom of the furnace. In some steel plants, during this process, oxygen is also injected through the lance to reduce the scrap. Oxygen reacts with the hot scrap producing an intense heat for cutting the scrap. As the melting process progresses, a pool of liquid steel is generated at the bottom of the furnace, and the process is stopped to allow loading of an additional basket of scrap. $\mathrm{CaO}$ in the form of burnt lime or dolomite is also introduced to the furnace either together with the scrap or they are blown into the furnace during melting. After several baskets of scraps have melted, heating continues, and the refining metallurgical operations (desulfurization, decarburization and dephospohorization) are performed. During this steel refining period, oxygen is injected into the molten steel through an oxygen lance. Some iron together with other impurities in the hot metal (including aluminum, silicon, manganese, phosphorus and carbon) are all oxidized during the oxygen injection. These oxidized components combine with lime $(\mathrm{CaO})$ to form slag. As steel is refined, carbon powder is also injected through the slag phase floating on the surface of the molten steel leading to the formation of carbon monoxide. Carbon monoxide gas thus formed causes the slag to foam, thereby increasing the efficiency to transfer the thermal energy. Typically, EAF is equipped with a slag door at the back of the furnace which facilitates the control of slag foaming operations and also slag removal in some cases. At the end of this process, a variety of alloying elements are also added to the furnace as needed to adjust the chemical composition of the steel 
(http://en.wikipedia.org/wiki/Electric_arc_furnace, Schoenberger 2001; Brandt and Warner 2005).

The slag generated from the electric-arc process is called as the "electric-arcfurnace slag". Electric-arc- furnace slag contains the lime $(\mathrm{CaO})$ together with both the impurities present in the hot metal and some portion of the iron oxidized during the oxygen injection period. Hence $\mathrm{CaO}, \mathrm{FeO}, \mathrm{SiO}_{2}$ and $\mathrm{Al}_{2} \mathrm{O}_{3}$ are the main components of electric-arc-furnace slag. Other minor components include the remaining oxidized impurities $\left(\mathrm{MgO}, \mathrm{MnO}, \mathrm{SO}_{3}\right.$ etc.). Mineralogical composition of EAF slag contains free $\mathrm{CaO}$ and $\mathrm{MgO}$ along with other complex minerals and solid solutions of $\mathrm{CaO}, \mathrm{FeO}$ and $\mathrm{MgO}$. When hydrated, the unbound lime and magnesia can cause volumetric expansion of EAF slag. Similar to the BOF process, slag formation is an important part of the EAF steelmaking process. Electric-arc-furnace slag also acts as a blanket covering the arcs and preventing damage to the roof and internal lining of the furnace.

Once the desired chemical composition of the steel is achieved, the furnace is tilted, and the slag and steel are tapped out of the furnace into separate ladles. Steel is poured into a ladle and typically transferred to a secondary steelmaking station for further refining. The molten slag is carried to a slag processing unit with ladles or slag pot carriers.

In electric-arc furnaces, up to 300 tons of steel can be manufactured per cycle. A cycle takes 3 to 7 hours to complete. The temperature in the furnace can be controlled more precisely in the EAF process than in the BOF process. As EAF steelmaking was costlier than the BOF process, initially it was only used for production of high quality steels. However, as the size of the electric-arc furnaces increased over the years, the EAF steelmaking process has become competitive in the production of different grades of steel and started to dominate the U.S. steel industry with a share of $55 \%$ of the total steel output in 2006 (Schoenberger 2001; Brandt and Warner 2005; Seetharaman 2005; USGS 2006). 


\subsubsection{Ladle Furnace Refining and Slag Generation}

After completion of primary steelmaking operations, steel produced from BOF or EAF can be further refined to obtain the desired chemical composition. These refining processes are called as "secondary steelmaking operations". Secondary refining processes are common in the production of high-grade steels. The most important functions of secondary refining are final desulfurization, degassing of oxygen, nitrogen, hydrogen etc., removal of the impurities and final decarburization for ultra-low carbon steel. Depending on the quality of the desired steel some or all of these refining processes are applied to the molten steel produced in EAF or BOF process. Ladle furnaces also function as a storage unit for the steel before the initiation of casting operations. Hence, they reduce the cost of high-graded steel production and allow flexibility in steelmaking operations (http://www.energymanagertraining.com/iron_steel/Iron_Steel_proc ess.htm; Schoenberger 2001;).

Most of the mini mills and integrated steel mills have ladle furnace refining stations that are used for secondary metallurgical processes. A schematic representation of the electric-arc-furnace process and a ladle refining unit associated with it are shown in Figure 2.8. 


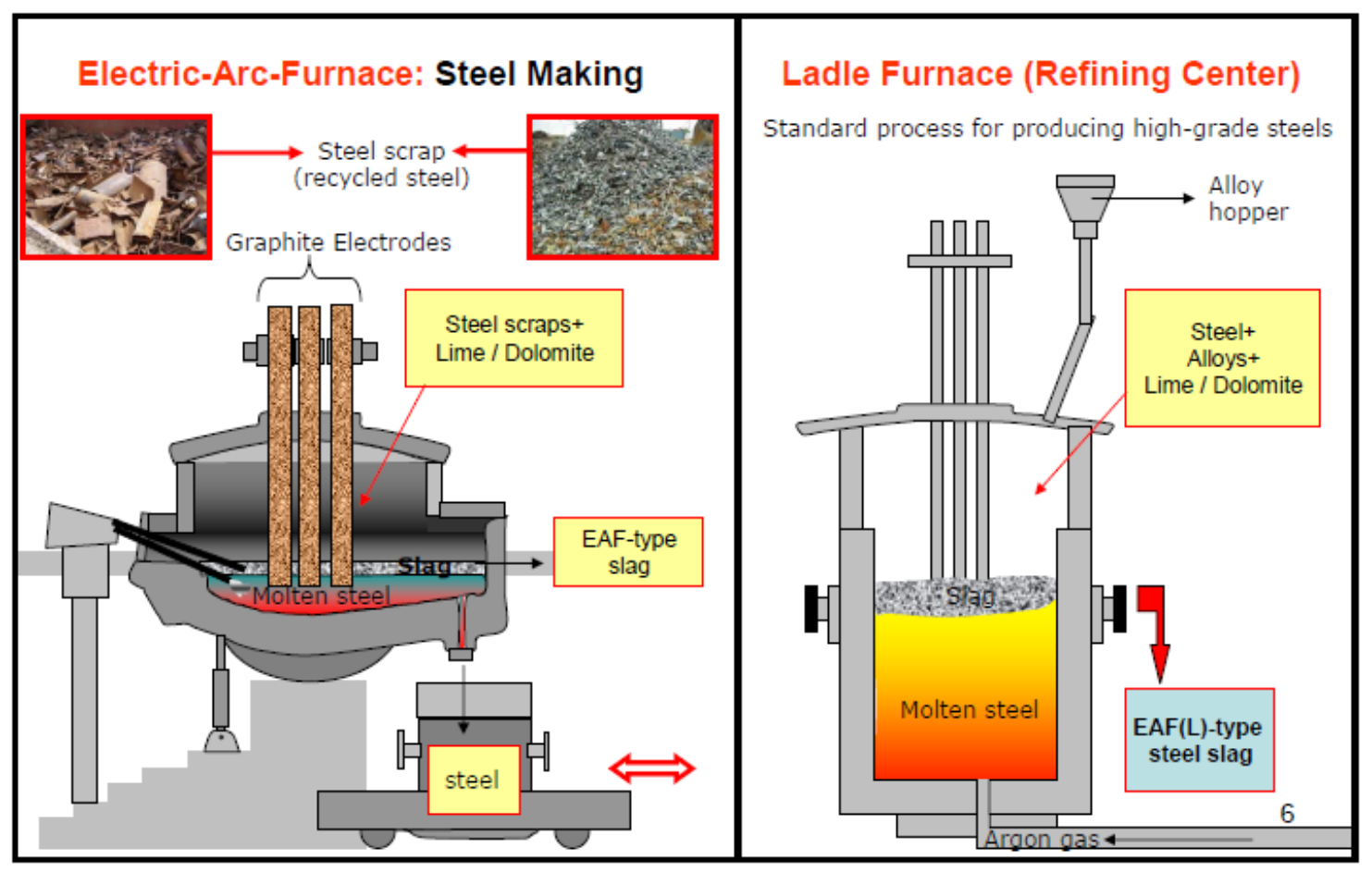

Figure 2.8 Schematic representation of the electric-arc-furnace steelmaking process and ladle refining (modified after http://www.steel.org; http://www.energymanagertraining.com/iron_steel/Iron_Steel_process.htm)

Ladle furnaces look like smaller versions of EAF furnaces as they also have three graphite electrodes which are connected to an arc transformer. Typically, the bottom of the ladle furnace has a pipeline through which argon gas is injected for stirring and homogenization of the liquid steel in the furnace. The graphite electrodes are lowered into the steel in order to heat it. The furnace is also facilitated with a lance for injecting desulfurizing agents $\left(\mathrm{Ca}, \mathrm{Mg}, \mathrm{CaSi}, \mathrm{CaC}_{2}, \mathrm{CaF}_{2}+\mathrm{CaO}\right)$. By injecting these agents, the sulfur concentration in the steel can be lowered to $0.0002 \%$ (Schoenberger 2001). The addition of silicon and aluminum during deoxidation forms silica $\left(\mathrm{SiO}_{2}\right)$ and alumina $\left(\mathrm{Al}_{2} \mathrm{O}_{3}\right)$; these oxides are later absorbed by the slag generated as a result of this refining process. In addition, in order to precisely adjust the chemical composition to produce different grades of steel, the desired alloys are also added to the molten steel through an alloy hopper connected to the ladle furnace. 
The steel slag generated in the ladles from this further steel refining process is named as the "ladle slag". Ladle slag not only facilitates the absorption of the deoxidation products, but also assists with the heat insulation and the protection of the refractory linings of the ladle furnace. Since ladle refining usually involves the addition of various fluxes and alloys, properties of ladle slag can be quite different from those of BOF and EAF slags. Compared to the slags generated from primary steelmaking (BOF and EAF) operations, ladle slag has a much lower $\mathrm{FeO}$ and a higher $\mathrm{Al}_{2} \mathrm{O}_{3}$ content. Typically, the most significant oxides in the composition of ladle slag are $\mathrm{CaO}, \mathrm{Al}_{2} \mathrm{O}_{3}, \mathrm{SiO}_{2}$, and $\mathrm{MgO}$. $\mathrm{CaO}$ is the most abundant component (typically higher than 45\%) in the chemical composition of ladle slag; hence typically it also contains free (unbound) lime. Regardless of the operations, one of the main phases is the ladle slag is the polymorphs of $\mathrm{C}_{2} \mathrm{~S}\left(\mathrm{Ca}_{2} \mathrm{SiO}_{4}\right)$. During cooling of slag, the conversion between the amorphs of $\mathrm{C}_{2} \mathrm{~S}(\beta-$ $\mathrm{C}_{2} \mathrm{~S}$ to $\gamma-\mathrm{C} 2 \mathrm{~S}$ ) result in an increase in volume and shattering of the crystals into dust. Therefore, ladle slag is also known as the "falling slag". Similar to EAF and BOF slags, ladle slag also shows volumetric instability mainly due to both the presence of free lime and the conversion between the amorphs of $\mathrm{C}_{2} \mathrm{~S}$ (Schoenberger 2001; Shi 2002; Manso et al. 2005).

\subsection{Slag Processing and Treatment}

After being tapped out of the furnace, slag goes through several processes. The main slag processing steps are as follows:

- Cooling

- Metal recovery

- Crushing

- Sizing/screening

- Grounding

- Stockpiling 
Cooling is an essential step in the processing of all types of slag. It is important because the method of cooling and hence the rate of cooling affect the physical and mineralogical properties of the material drastically. After cooling, depending on the type of slag and intended use, slag undergoes all or some of the processing steps listed above.

\subsubsection{Processing and Types of Blast-Furnace Slag}

Several different techniques are used to process and generate different kinds of blastfurnace slag. As the processing determines the crystal structure and the physical properties of the final product, blast-furnace slags are classified based on the processing technique used. Four main types of blast-furnace slags are:

- Air-cooled blast-furnace slag

- Expanded or foamed blast-furnace slag

- Pelletized blast-furnace slag

- Granulated blast-furnace slag

When liquid blast-furnace slag is poured into pits and air-cooled under current conditions, it solidifies very slowly developing a crystalline structure similar to igneous rock. This slowly cooled slag is called air-cooled blast-furnace slag. It has crystals with sizes ranging from macroscopic to as large as $3 \mathrm{~mm}$. This slag, which is hard and lumpy, is subsequently crushed and screened.

Foamed or expanded blast-furnace slag is formed when water, air or steam is introduced under controlled conditions into the molten slag as it is tipped into a special pit or container. The sudden generation of occluded gases and steam generates foaming and, therefore, the slag cooled in this manner is called expanded or foamed blast-furnace slag.

If the molten slag is cooled initially with water and then air-quenched in a spinning drum, pelletized blast-furnace slag is generated. At the end of the process, instead of a solidified mass, rounded pellets are produced. The rate of quenching can also be controlled. The faster the rate of cooling is, the smaller the size of the crystals is. Rapid quenching produces pellets with a vitreous phase. 
If the molten slag is cooled and solidified very quickly using high-pressure jets or water quenching, there is not enough time for any crystallization to occur and slag solidifies as a glassy material. Slag cooled in this manner consists of sand-size particles with some larger popcorn-like gravel-size particles. This material is known as granulated blast-furnace slag. When grounded into a cement-size powder it is called as the ground granulated blast-furnace slag. When mixed with alkaline activating agents such as lime, ground granulated blast-furnace slag shows hydraulic properties (Lee 1974; Emery 1980; Rao 2006; USGS 2006).

\subsubsection{Steel-Furnace Slag Processing}

Molten steel slag is transferred to slag pits typically with a slag pot carrier. The slag pot carrier is rotated in order to pour the molten slag into slag pits. After the slag is poured down into the pits, the steel slag is typically slowly cooled down with either air cooling or with both air-cooling and water-spraying methods. Water spraying helps in breaking down big pieces of solidified slag into smaller sizes. The solidified material is dug out from the pit at about every 8 hours to expose all areas of the pit to air and water. As this is not a controlled cooling process, the unprocessed slag (before metal recovery) shows quite varying grain-size distributions, with sizes larger than $250 \mathrm{~mm}$ (10 in.) together with the finer-gravel and sand-size particles.

After the steel slag is cooled down in the pits, the material is stockpiled for metal recovery and sizing processes. The metal recovery process aims to separate the metallic portion of the unprocessed slag. Initially, large chunks of magnetic materials (pieces larger than $>250 \mathrm{~mm}(10$ ") are separated by a crane-mounted magnet. The large metallic chunks are either crushed further and returned to the metal recovery unit or sold back to the mill for recycling as a raw-feed for the furnace. The remaining smaller-size slag particles are diverted to the metal recovery unit. In the metal recovery unit, the steel slag is carried with a conveyor belt through a drum-magnet system. The conveyor belt circles around the magnet that is enclosed in one side of the circular mill. As the belt moves around the circular mill, the magnet attracts and holds the smaller-size metallic particles. The metallic and nonmetallic particles of the raw steel slag materials are thus separated 
by this magnetic separation process. The terms "BOF slag", "EAF slag" and "Ladle slag" used in the literature actually refers to this nonmetallic portion of the processed slag. After the metal recovery process is completed, the final slag output is nearly $10-15 \%$ of the total steel output (Oss 2006).

The sizing process consists of separating the steel slag into two or three different size fractions by passing the material through several sieves. The fine fraction of the material is composed mainly of sand- and gravel-size particles. These two or three different size fractions can differ slightly from plant to plant, based on the intended applications for the slag. For example, steel slags obtained from the steel processing plants in the state of Indiana are broadly classifies into the following size categories:

- Minus $16 \mathrm{~mm}(\sim-5 / 8 ”)$ - Fine

- $16 \mathrm{~mm} \sim 64 \mathrm{~mm}(\sim 5 / 8 "-3 ”)$ - Medium

- $\quad 64 \mathrm{~mm} 204 \mathrm{~mm}(\sim 3 "-10 ”)$ - Coarse

Figure 1.9 shows sequentially the photographs of the slag processing procedures: (a) water spraying, (b) air cooling, (c) metal recovery, and (d) sizing, respectively.
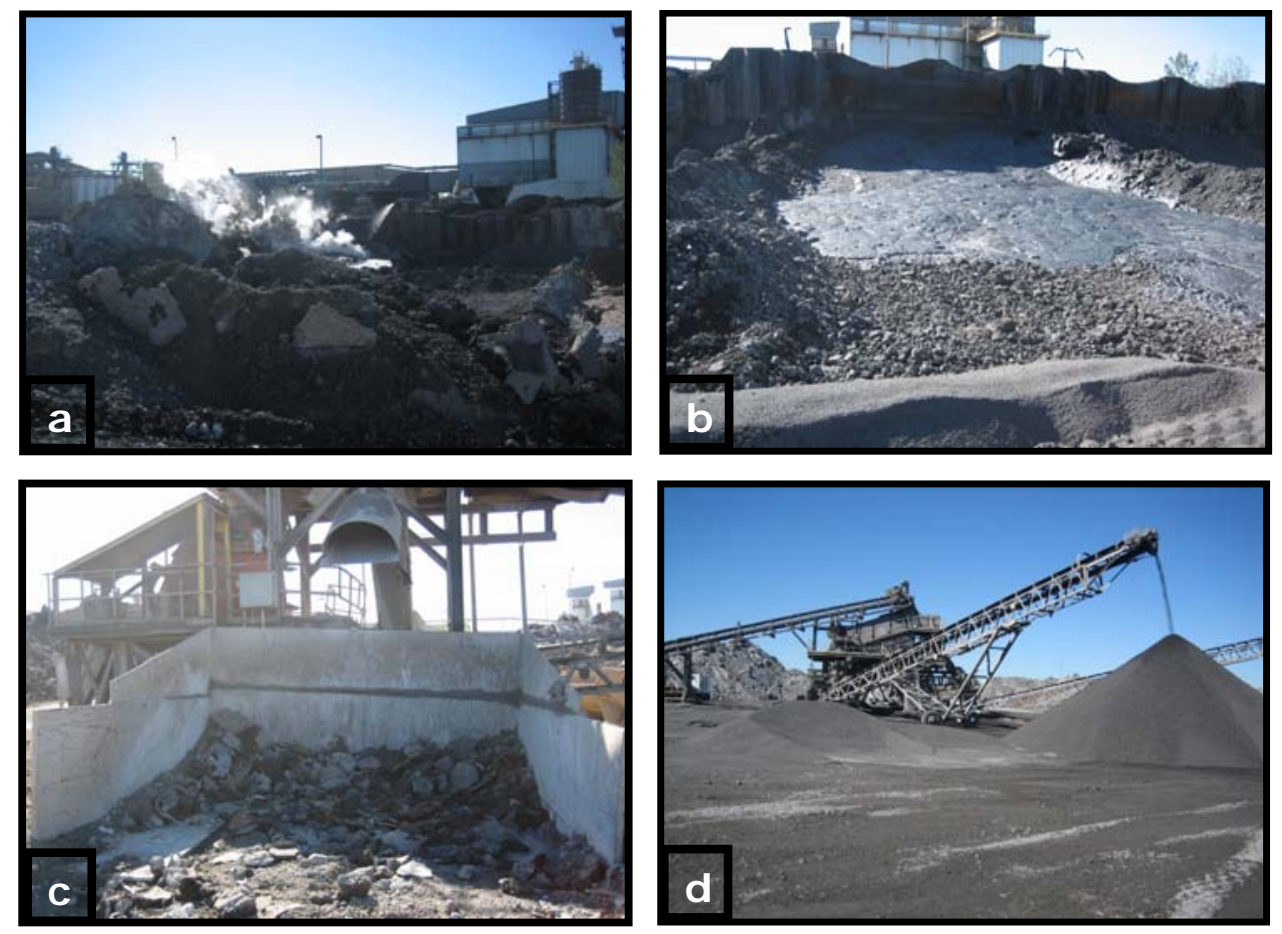

Figure 2.9 Slag Processing: (a) Water spraying, (b) air cooling, (c) metal recovery and (d) sizing (Photographs were taken at the Whitesville Mill, Indiana). 
In some steel plants, steel slag also goes through crushers before screening. When the plants produce asphalt material, such as asphalt chips, the slag is further crushed into appropriate aggregate gradations in primary and secondary crushing units. Very few slag processing plants that provide slag for the cement industry have also grinding units. The slag processing plants have similar facilities to that of aggregate plants, and standard aggregate tests (specific gravity, absorption, gradation etc.) are also performed on steel slag aggregates. After completion of the processing, steel slag is stockpiled separately according to their particle size ranges in the plant for their use in different applications. In most plants, these open-air stockpiles are stored in the designated storage areas for each slag until they are sold or transferred to slag disposal areas.

There are examples in the literature in which similar cooling techniques that are used to cool blast-furnace slag have also been applied for steel slag. Most of the times, these fast cooling techniques are reviewed in the context of treatment methods rather than processing of steel slag, as fast-cooling techniques are not commonly used for steel slag in practice. These cooling methods include air quenching, water quenching and instant chilling.

Air quenching is recently used for cooling steel slags in China (Ye and Liao 1999, Shi 2004). In this method, steel slag is poured into a slot where compressed air is blown with high pressure through an air nozzle from the bottom of the slot. The molten slag is cooled rapidly with the compressed air and turns into particles of $3-5 \mathrm{~mm}$ in size. As blown air also oxidizes some of the metals present in the molten steel slag, air-quenched steel slag is harder to grind than air-cooled or water-cooled slag. When steel slag is cooled down with water-quenching method, due to the high viscosity of steel slag water particles can get trapped in steel slag and this entrapped water can cause explosions. For this reason, the cooling conditions need to be controlled precisely when steel slag is cooled by water quenching. To prevent the explosion problem associated with the waterquenching method, an instant-chilling (also known as shallow-box chilling) method has been developed to cool steel slag in Japan recently (Montgomery and Wang 1992, Shi 2004). In this method, the molten slag is poured into shallow boxes, forming thin slag beds of $10 \mathrm{~mm}$ thickness. These slag beds are initially air-cooled, and then water is 
sprayed on the shallow boxes to reduce the slag temperature to $500^{\circ} \mathrm{C}$. Next, the slag is transported to a water-spraying station where it is further water sprayed for 4 minutes and the temperature drops further to $200^{\circ} \mathrm{C}$. Finally, the steel slag beds are placed in a water pool and cooled down to $60^{\circ} \mathrm{C}$. Cooling steel slag in these shallow beds in steps decreases the risk of water entrapment and the explosions substantially. The slag resulting from this treatment has particles in the $30-50 \mathrm{~mm}$ size range with a low free lime content of about $2-4 \%$ (Shi 2004).

As mentioned before, the cooling method used in slag processing has a significant impact on its resulting mineralogical properties (Montgomery and Wang 1992; Wang 1992; Shi 2002; Reddy et al. 2006). For example, Reddy et al. (2006), using XRD analysis, determined different phases for slowly-cooled and rapidly-quenched BOF slags. Fast-cooling techniques are routinely applied for blast furnace slags. However, compared to blast furnace slag, steel slag has a much lower $\mathrm{SiO}_{2}$ content in its chemical composition. Due to its chemical composition, steel slag does not vitrify even when it is rapidly cooled. In addition, incorporation of the fast-cooling units into the steel plants requires significant additional costs due to the difficulties resulting from high viscosity of steel slag. Even though, there are a few studies in the literature which show that fast cooling tends to enhance the mechanical properties of steel slag (and also decrease the content of deleterious components such as $\mathrm{CaO}$; in the U.S., most of the steel plants do not have fast-cooling units. Typically, steel slag is slowly chilled by water-spraying and air-cooling techniques.

\subsubsection{Steel Slag Treatment and Aging Procedures}

Unlike blast-furnace slag, steel slag shows volumetric instability mainly due to the presence of free magnesium oxide $(\mathrm{MgO})$ and lime $(\mathrm{CaO})$. In the presence of water, these compounds hydrate expansively. The dicalciumsilicate phase $\left(\mathrm{C}_{2} \mathrm{~S}\right)$ present in steel slag also can cause a reaction that causes expansion. $\mathrm{C}_{2} \mathrm{~S}$ exists in different forms $(\alpha, \alpha, \beta$ and $\gamma$ ). The transformation between these forms, $\beta-C_{2} S$ to $\gamma-C_{2} S$ (specifically in ladle slag), can also lead to volume expansion. 
The swelling nature of steel slag is detrimental to almost all civil engineering applications. Hence, the main purpose of treating slag is to decrease the volume instability caused by the expansive components of steel slag by changing its chemical and/or mineralogical properties. In the literature, there are examples of special steel slag treatment techniques that are used in some steel plants to minimize the undesirable volumetric instability of slag. These techniques include using additives, steam treatment, and aging. The terms "aging" or "weathering" of steel slag, refer to the open-air stock piling of steel slag to provide adequate exposure to moisture.

The Edw. C. Levy Company (slag processer company located in many locations in U.S.) used a spent pickle liquor treatment for steel slag in the 60s (Emery 1974). In this method, steel slag is pre-moistened with $\mathrm{H}_{2} \mathrm{SO}_{4}$, which accelerates the hydration of expansive components. The treated steel slag material is then stockpiled for at least one month before it is used as base material in pavement structures. This method has been found effective in accelerating aging and reducing the expansion rate of steel slag. Though, due to the environmental concerns, this treatment method is not very common today (Emery 1974). Another technique consists of adding silicate-rich materials to enable the formation of greater amounts of $\beta-\mathrm{C}_{2} \mathrm{~S}$ during cooling process. As this technique does not assist with the stabilization of other detrimental expansive components such as free lime, it has been shown to provide only a marginal effect in suppressing swelling (Emery 1974). In some plants, additives containing silicate and aluminates such as fly ash and blast-furnace slag are added to the molten steel slag to alter its chemical composition. In Japan, steel slag is exposed to a high-temperature steam treatment before use. This high-temperature steam treatment hydrates the expansive components of steel slag before it is used, decreasing swelling in situ substantially (Wang 1992).

Since the treatment methods listed above require the use of special equipment and labor intensive protocols in steel plants, they require substantial additional costs. For this reason, these treatments are not frequently used in practice. Traditionally, slowly cooled steel slag is stockpiled and kept in open air for aging under atmospheric conditions. 
Among the methods presented in the literature to minimize swelling, aging is the most commonly used procedure to suppress swelling of steel slag.

Aging is required to hydrate the free calcium and magnesium oxides present in the steel slag. Open-air stockpiling also facilitates the carbonation (absorption of $\mathrm{CO}_{2}$ from air) of these hydrated oxides. If steel slag is accumulated in huge stockpiles, it is hard to achieve homogenous aging of the material in the stockpiles. Emery (1974) pointed out that even aging for long periods in large dumps does not ensure the elimination of expansive behavior because adequate exposure to moisture is essential for hydration of $\mathrm{CaO}$ and $\mathrm{MgO}$. For this reason, the literature on steel slag contains recommendations on aging procedures.

According to ASTM D2940 on "Standard Specification for Graded Aggregate Material For Bases or Subbases for Highways or Airport", the steel slag aggregate that does not meet the limiting expansion specified in the standard (a maximum of $0.5 \%$ linear expansion after 7 days with the standard procedure described in ASTM D4792Standard Test Method for Potential Expansion of Aggregates from Hydration Reactions), should be aged or treated in order to reduce the potential expansion to a satisfactory level. To ensure proper aging of steel slag, several Department of Transportation (DOTs) in the U.S. have developed specifications and quality control measures for aging and stockpiling of steel slag for use in different applications.

According to the Ohio DOT specifications, the basic-oxygen-furnace steel slag that is to be used as asphalt aggregate should be graded and stockpiled into a maximum pile size of 23,000 metric ton (25,000 ton). During stockpiling operation, water should be sprayed on the steel slag stockpile, which should be maintained in moist condition during the entire stockpiling period. The stockpiling period is at least one month at moisture contents greater than the absorption of the aggregate. The Ohio DOT also requires frequent quality control checks due to the variability of the steel slag stockpiles. The supplier of steel slag aggregate is required to provide frequent test results for gradation, absorption, loss by washing and determination of deleterious components. The California DOT recommends the use of steel slag only as imported borrow, sub-base aggregate, base aggregate and aggregate in hot mix asphalt applications. The maximum quantity of 
slag that can be accumulated in one individual stockpile is specified as $10,000-50,000$ tons. The times corresponding to completion of the stockpiles, end of controlled aging and aggregate testing (grading, specific gravity, abrasion, crushing etc.) should be recorded precisely. Moisture tests should be performed at least once a weak and, if a moisture content of $6 \%$ or less is recorded, the time period corresponding to the low moisture content should be taken out from the recorded aging period. A minimum aging period of 3 months is required for steel slag according to the California DOT. Based on the Pennsylvania DOT specifications, steel slag aggregate that does not meet the expansion requirement (a maximum limiting expansion of $0.5 \%$ obtained using the Pennsylvania Test Method Specification: PTM-130) should be aged for 6 months. After the 6 months period, if steel slag still does not meet the expansion requirement, aging period should be prolonged and expansion tests should be repeated after every 2 months until swelling is suppressed to the satisfactory level. According to the Pennsylvania DOT steel slag that meets the requirements can be used for subbases, road shoulders, and bituminous surface courses (Emery 1984, NSA-186-1).

Several researches also recommended minimum aging periods for steel slag to be used in different applications. Das et al. (2007) indicated that experiments both in the laboratory and in stockpiles have shown that the free lime content will decrease to a constant near zero value after 9-12 months of aging. Emery (1974) proposes a minimum of one month of aging after crushing for steel slag that is to be used in asphalt mixes. Rohde et al. (2003) indicated that the origin, gradation and age of the steel slag stockpile affect the amount of steel slag expansion observed in unbound applications. The study recommended that EAF slag used as unbound aggregate be handled in a similar manner to that used to handle densely crushed rock, except that it should be stored on a drained paved surface. Their results showed that EAF slag should be weathered for at least 4 months in cone-shaped stockpiles of height equal to $3 \mathrm{~m}$ or lesser. In addition, special attention should be paid to protect the stockpile from contamination with refractory wastes. Rohde et al. (2003) performed expansion tests on EAF slag according to the test procedures described in ASTM D4792 and showed that the expansion of 4 months aged EAF slag was less than $0.5 \%$ (the limiting value recommended by ASTM 2940). USGS 
(2001) recommends aging or "curing" of steel slag for a period of 6 months, especially when it is used as a road base aggregate. Farrand and Emery (1995) indicated the importance of applying quality control procedures (gradation, material handling to avoid segregation etc.) on steel slag that will be used as aggregate in hot-mix asphalt mixes. Noureldin and McDaniel (1990) indicated that prior aging is not as critical for fine sizes of steel slag aggregate $(<13 \mathrm{~mm})$, as watering and screening processes during travel through the asphalt plant can allow for any immediate expansion. However a minimum aging period of 30 days is recommended for the coarser steel slag aggregates $(>19 \mathrm{~mm})$ that will be used in asphalt mixes.

\subsection{Slag Generation and Sales Information}

The weight of the steel slag tapped out of the furnaces is not always routinely measured by the iron and steelmaking industry. For this reason, the annual ferrous slag production data in the U.S. and in the world is estimated based on slag-to-metal output ratios. The slag generation fluctuates from plant to plant because the chemistry of the feed determines the quantity of slag generated per 1 ton of steel produced. Iron ores containing 60 to $66 \%$ iron, typically generate about 0.25 to 0.3 tons of blast-furnace slag per 1 ton of crude iron. Blast-furnace slag generation can be as high as 1-1.2 tons of slag per ton of crude iron if lower grades of ores are used as feed. Steel furnaces generate 0.2 tons of steel slag per ton of steel produced. Up to $50 \%$ of the steel slag produced is entrained metal which is recovered during the metal recovery process. The recovered metal is typically sent back to the furnaces and reused as a feed. The amount of steel slag generated after metal removal is about 10 to $15 \%$ of the total steel output (Oss 2006). USGS (2006) estimated the slag output in the U.S. based on the steel production data published by the American and Iron Steel Institute. In 2006, the estimated blast-furnace slag generation was in the range of 11-16 Mt (million metric tons) and 218 to-262 Mt in the U.S. and in the world respectively. Similarly, in 2006, the steel slag generation was estimated to be in 10-15 Mt range in the U.S. and in the 124-186 Mt range in the world. In 2006, USGS recorded 30 companies processing both new and old stockpiles of steel 
slag in the U.S. The processing of blast-furnace slag was carried out at 40 sites in 14 states, and steel slag was processed at 100 sites in 40 states.

Most of the slag processing companies receive steel slag for free, and after processing it, they sell it in the open market. The iron and steel producers receive a percentage of the revenue from the slag sales. However, depending on the slag processing and steel companies involved, financial agreements may differ. In some plants, substantial amounts of steel slag are fed back to the furnaces as a source of flux and iron. The estimated generation and sales data for iron and steel slag in recent years are compiled in Table 2.1

Table 2.1 Slag generation and sales data (modified after USGS, 1993-2006)

\begin{tabular}{|c|c|c|c|c|c|c|c|}
\hline \multicolumn{4}{|c|}{ Blast-furnace Slag } & \multicolumn{4}{|c|}{ Steel Slag } \\
\hline Years & U.S. Output* & World Output* & Sales in U.S. & Years & U.S. Output* & World Output* & Sales in U.S. \\
\hline 1993 & - & - & $12.3 \mathrm{Mt}$ & 1993 & - & - & $6.7 \mathrm{Mt}$ \\
\hline 1994 & $12-15 \mathrm{Mt}$ & - & $12.3 \mathrm{Mt}$ & 1994 & $9-14 \mathrm{Mt}$ & - & $7.8 \mathrm{Mt}$ \\
\hline 1995 & $12-13 \mathrm{Mt}$ & - & $13.8 \mathrm{Mt}$ & 1995 & $9-14 \mathrm{Mt}$ & - & $7.2 \mathrm{Mt}$ \\
\hline 1996 & $12 \mathrm{Mt}$ & - & $13.9 \mathrm{Mt}$ & 1996 & $15 \mathrm{Mt}$ & - & $6.6 \mathrm{Mt}$ \\
\hline 1997 & $13 \mathrm{Mt}$ & - & $11.9 \mathrm{Mt}$ & 1997 & $17 \mathrm{Mt}$ & - & 7.0 Mt \\
\hline 1998 & $11 \mathrm{Mt}$ & - & $12.2 \mathrm{Mt}$ & 1998 & $17 \mathrm{Mt}$ & - & $6.2 \mathrm{Mt}$ \\
\hline 1999 & $12 \mathrm{Mt}$ & - & $10.9 \mathrm{Mt}$ & 1999 & $11 \mathrm{Mt}$ & - & $6.2 \mathrm{Mt}$ \\
\hline 2000 & $12 \mathrm{Mt}$ & - & $11.2 \mathrm{Mt}$ & 2000 & $13 \mathrm{Mt}$ & - & $5.2 \mathrm{Mt}$ \\
\hline 2001 & - & - & $10.5 \mathrm{Mt}$ & 2001 & - & - & $6.5 \mathrm{Mt}$ \\
\hline 2002 & $10-12 \mathrm{Mt}$ & $150-180 \mathrm{Mt}$ & $11.0 \mathrm{Mt}$ & 2002 & $9-14 \mathrm{Mt}$ & $90-135 \mathrm{Mt}$ & $8.0 \mathrm{Mt}$ \\
\hline 2003 & $10-12 \mathrm{Mt}$ & $160-200 \mathrm{Mt}$ & $10.9 \mathrm{Mt}$ & 2003 & $9-14 \mathrm{Mt}$ & $96-145 \mathrm{Mt}$ & $8.8 \mathrm{Mt}$ \\
\hline 2004 & $12-14 \mathrm{Mt}$ & $200-240 \mathrm{Mt}$ & $12.2 \mathrm{Mt}$ & 2004 & $11-16 \mathrm{Mt}$ & $115-118 \mathrm{Mt}$ & $9.0 \mathrm{Mt}$ \\
\hline 2005 & $9-11 \mathrm{Mt}$ & $196-273 \mathrm{Mt}$ & $12.0 \mathrm{Mt}$ & 2005 & $10-14 \mathrm{Mt}$ & $113-170 \mathrm{Mt}$ & $8.7 \mathrm{Mt}$ \\
\hline 2006 & $9-11 \mathrm{Mt}$ & $218-261 \mathrm{Mt}$ & $11.6 \mathrm{Mt}$ & 2006 & $10-15 \mathrm{Mt}$ & $124-186 \mathrm{Mt}$ & $8.7 \mathrm{Mt}$ \\
\hline
\end{tabular}

Note: $\mathrm{Mt}=$ million metric tons, - data not available

* Values for slag outcome include a large estimated component based on USGS data. Steel slag data excludes the metallic portion removed during slag processing. 
In 2007, U.S. slag sales were estimated to be more than 20 million tons, which corresponds to approximately $\$ 400$ millions. Blast-furnace slag accounted for $60 \%$ of the total weight produced, valued at approximately $\$ 380$ million. The remainder of the sales was steel-furnace slag generated from both basic-oxygen and electric-arc furnaces. The states in the North Central and Mid-Atlantic regions - Illinois, Indiana, Michigan, Ohio, Maryland, New York, Pennsylvania and West Virginia - accounted for more than $80 \%$ of the slag sales in the last decade. Table 2.1 shows that there is an excess amount between the estimated generation and sales of steel slag. This excess amount of steel slag is the undocumented steel slag recycled in the furnaces and the steel slag dumped at disposal sites (USGS 2006).

Ground granulated blast-furnace slag (GGBFS) dominates the overall slag sales. It is widely used as a substitute for Portland cement in concrete or as a component of blended cements. Concretes incorporating GGBFS have equivalent or superior long term strength, lower permeability, and improved resistance to chemical attack. In 2006, the selling price of granulated blast-furnace slag ranged from $\$ 19.29$ to 94.80 per metric ton, with an average of $\$ 79.18$ per metric ton. The domestic sources for GGBFS in the U.S. are limited to a few blast furnaces. However, the demand for GGBFS is still growing because of its beneficial performance and environmental effects on the materials containing it. Because of the growing demand for GGBFS, new granulation cooling facilities have been constructed in two blast furnaces in the U.S. and imports of GGBFS from other countries have increased in the recent years (Oss 2006). The price of aircooled blast-furnace slag ranged from $\$ 3.03$ to $\$ 16.26$ per metric ton, with an average of $\$ 6.63$ per metric ton in 2006. Figure 2.10 (a) and (b) show the various uses of granulated blast-furnace slag and air-cooled blast-furnace slag based on the sales data obtained from USGS (2006). Granulated blast-furnace slag is used mainly by the cement industry (aircooled blast-furnace slag is used as aggregate in road bases and surfaces and in concrete).

Unlike blast-furnace slag, steel slag has not been widely recognized and utilized by the construction industry. Every year, substantial amounts of steel slag are stockpiled by the processing companies. Figure 2.11 shows the applications recorded for the steel slag sold in 2006 . 


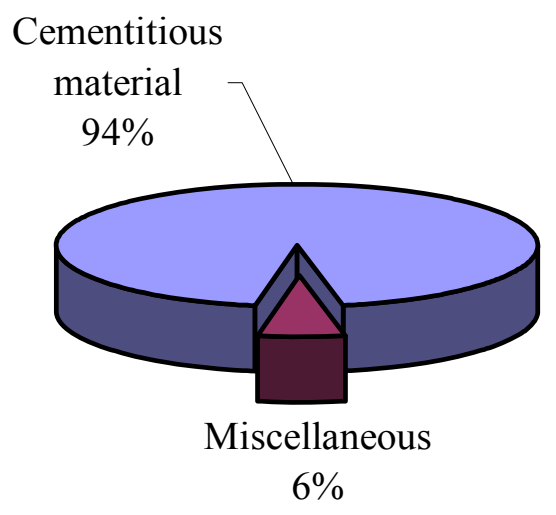

(a)

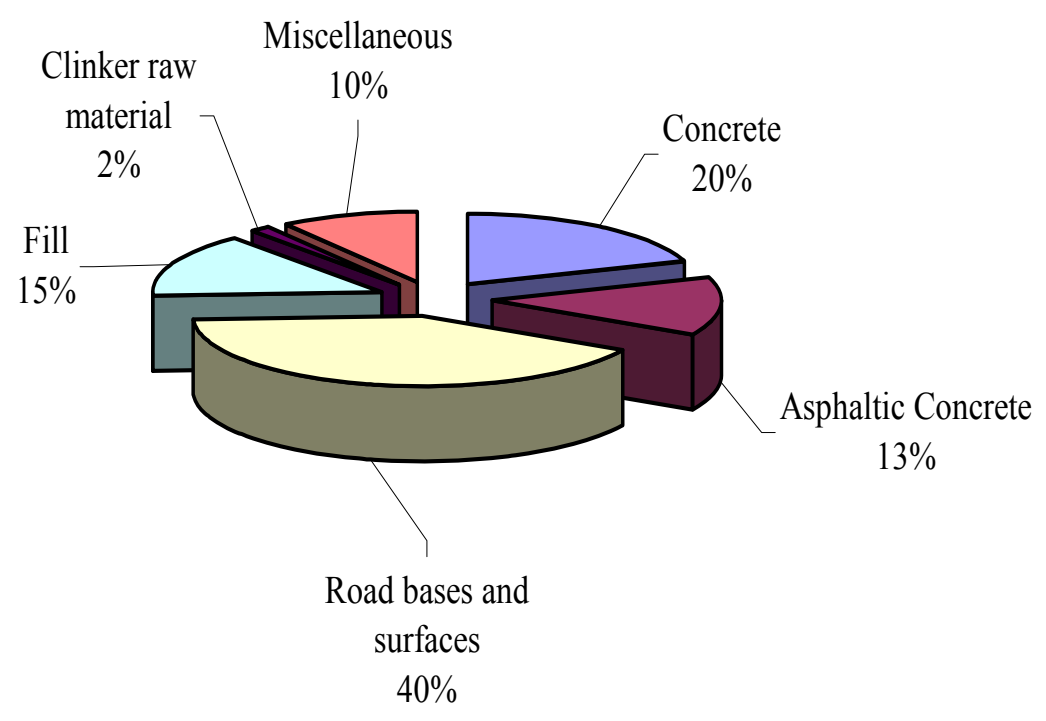

(b)

Note: Miscellaneous include use as rail road ballast, roofing, mineral wool, soil conditioner and other unspecified sales.

Figure 2.10 Use of :(a) granulated blast-furnace slag (b) air-cooled blast-furnace slag in 2006 based on sales data (modified after USGS (2006))

Steel slag is mainly used as road construction aggregate and as raw material for cement clinker manufacturing. However, applications for the steel slag, particularly for the finer gradations, remain still limited due to the potential for volumetric expansion problems. 
Bound applications which are very sensitive to volume change (e.g., concrete aggregate) are usually eliminated due the detrimental components in the steel slag chemical composition. Compared to blast-furnace slag, studies on the properties of steel slag and its application in the construction industry are scarce. The other determining factors affecting the volume of sales of steel slag is the competition with natural aggregates, the level of construction activity and the availability of long-term supply contracts.

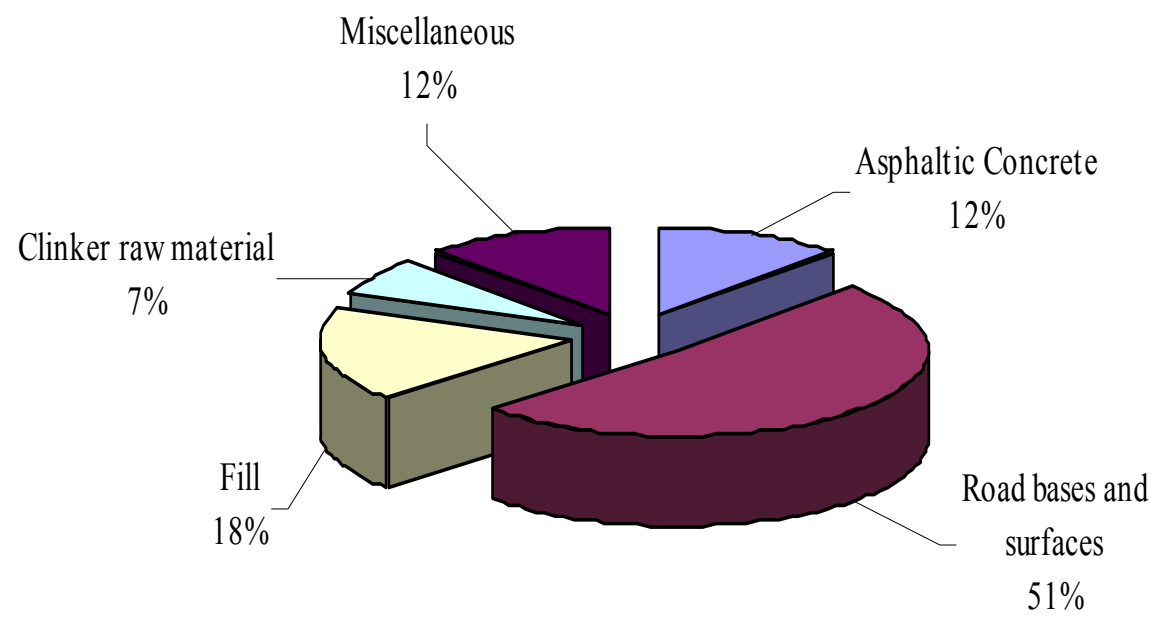

Note: Miscellaneous include use as rail road ballast, roofing, mineral wool, soil conditioner and other unspecified sales.

Figure 2.11 Use of steel slag in 2006 based on sales data (modified after USGS (2006))

In 2006, selling prices of steel slag ranged from $\$ 0.49$ to $\$ 13.16$ per metric ton, with an average of $\$ 4.58$ per metric ton. Since the unit sale (\$/metric ton) of steel slag are low and the dry unit weight of steel slag is typically higher than that of natural aggregates, it becomes uneconomical to transport large quantities of steel slag aggregate over long distances. However, use of steel slag in aggregate applications becomes competitive if there is a processing facility nearby the construction site.

The supply and availability of steel slag in the U.S. will continue to increase in the next decades because the numbers of electric-arc furnaces continue to increase and 
the existing stockpiles of steel slag do not seem to get drawn down. For this reason, ongoing research has been focusing on determining new applications for steel slag in the construction industry and on mitigating its potential volumetric expansion problems. The beneficial use of steel slag will decrease the problems related to stockpiling and land filling.

\subsection{Summary}

Slags are byproducts of metallurgical processes. Each furnace in the iron and steelmaking processes generates a different type of slag. Blast furnace slag is a by-product of iron making process and it is classified as air-cooled, pelletized, expanded (foamed) or granulated blast-furnace slag, based on its processing after generation. Blast furnace slag is widely recognized and utilized by the construction industry. Three types of steel slag that generate from steelmaking processes are basic-oxygen-furnace slag, electric-arcfurnace slag and ladle slag. Basic-oxygen-furnace (BOF) slag generates during conversion of the molten iron into steel in a basic-oxygen-furnace (also known as the LDconverter). Electric-arc furnace (EAF) slag is generated during recycling of steel scraps to produce steel in an electric-arc-furnace. Steel generated in a BOF or an EAF typically goes into a ladle furnace for further refining to produce different grades of steel slag. Slag generated from this refining process is called as the ladle slag. After being tapped out of the furnace, steel slag goes through several processes. These main processes include cooling, metal recovery, crushing, sizing and stockpiling. Steel slag shows expansive properties due to the presence of volumetrically unstable components in its chemical composition. Proper aging of steel slag can substantially reduce the volume instability. Compared to blast-furnace slag, studies on the properties of steel slag and its application in the construction industry are scarce. Every year, substantial amounts of steel slag are stockpiled by the slag processing companies or sent to slag disposal sites. Ongoing research is focusing on determining new applications for steel slag in the construction industry and on mitigating its swelling potential. 


\section{CHAPTER 3. PROPERTIES AND UTILIZATION OF SLAG}

\subsection{Introduction}

This chapter presents a detailed literature review on the properties and utilization of steel slag. More than 200 documents were reviewed on the chemical composition, mineralogical composition, engineering properties and utilization of different types of steel slag used in various civil engineering applications. A brief overview of the properties of blast-furnace slag is also presented. The literature on steel slags was thoroughly reviewed in the context of the following topics:

- Chemical, mineralogical and mechanical properties of different slags

- Swelling mechanism, swelling tests and related specifications for steel slags

- Utilization of steel slag in various civil engineering applications

- Environmental impact associated with steel slag utilization

\subsection{Brief Overview on the Properties of Blast-Furnace Slag}

Blast-furnace slag (BFS) is generated during the extraction of iron from its ore. Hence, it contains the impurities present in the iron ore that react with the $\mathrm{CaO}$ released during the decomposition of the fluxing agents (lime or dolomite). The chemical constituents of blast-furnace slag can vary depending on the nature of the ore, type and composition of the fluxing agents- and the coke. The chemical composition of blast-furnace slag from different sources is compiled in Table 3.2. The oxide contents of blast-furnace slag vary with its source. Table 3.1 shows that the $\mathrm{CaO}, \mathrm{SiO}_{2}, \mathrm{Al}_{2} \mathrm{O}_{3}$ and $\mathrm{MgO}$ contents in blastfurnace slag can vary between $33-45 \%, 27-39 \%, 8-22 \%$ and $3-16 \%$, respectively. Blastfurnace slag also contains other minor compounds such as $\mathrm{TiO}_{2}, \mathrm{SO}_{3}, \mathrm{P}_{2} \mathrm{O}_{5}$ and $\mathrm{MnO}$ (Lea 2004). 
Blast-furnace slags are mainly comprised of silicate phases, typically aluminosilicates of calcium and magnesium. However, the engineering properties of blast-furnace slag is not only influenced by its chemical composition but also by the procedures followed during processing of the molten slag. This is analogous to the mineral formation in rocks. Large grains with distinguishable minerals are prevalent in the intrusive igneous rocks which are formed by solidifying of the magma slowly within the rock mass. On the other hand, when magma reaches the surface and solidifies fast, there is not enough time for extensive mineral grouping and, hence extrusive igneous rocks show homogenous structures with small mineral groupings in between. Vitreous phases are observed in volcanic rocks when the magma ejecting from the volcano mix with water and cools very rapidly. Similar to the different structures observed in rocks, cooling rate associated with the slag processing technique determines whether crystalline or vitreous phases will be prevalent in the resulting slag. The structure of blast-furnace slag can vary from crystalline to amorphous (glassy) depending on its processing. Based on the processing technique selected, blast-furnace slags are classified as air-cooled, pelletized, expanded (foamed) and ground-granulated blast-furnace slag (refer to section 1.2.5 for details on processing techniques involved in the manufacturing of these slag types). Figure 3.1 (a), (b), (c) and (d) show photographs of air-cooled, pelletized, granulated and groundgranulated blast-furnace slags, respectively (Lee 1974; Rao 2006; NSA 2008). Each of these types of blast-furnace slag has different engineering properties.

The main mineralogical constituent of crystallized (air-cooled) blast-furnace slag is melilite. Melilite is the name of an isomorphous series of solid solutions that also includes gehlenite $\left(2 \mathrm{CaO} \cdot \mathrm{Al}_{2} \mathrm{O}_{3} \cdot \mathrm{SiO}_{2}\right)$ and akermanite $\left(2 \mathrm{CaO} \cdot \mathrm{MgO} \cdot 2 \mathrm{SiO}_{2}\right)$. The other minerals that typically occur in blast-furnace slag include different forms $\left(\alpha, \alpha^{\prime}, \beta, \gamma\right)$ of dicalcium silicate $\left(2 \mathrm{CaO} \mathrm{SiO}_{2}\right.$, represented as $\left.\mathrm{C}_{2} \mathrm{~S}\right)$, merwinite $\left(\mathrm{Ca}_{3} \mathrm{Mg}\left(\mathrm{SiO}_{4}\right)_{4}\right)$, monticellite $\left(\mathrm{CaO} \cdot \mathrm{MgO} \cdot \mathrm{SiO}_{2}\right)$ and wollastonite $\left(\mathrm{CaO}^{\mathrm{SiO}} \mathrm{Si}_{2}\right)$. It also contains other minor mineral phases that include compounds of calcium, sulphur, iron, manganese and other trace elements. Granulated and some pelletized blast-furnace slags are predominantly amorphous containing very small amounts of crystalline phases (Taylor 1990; Lea 2004). 

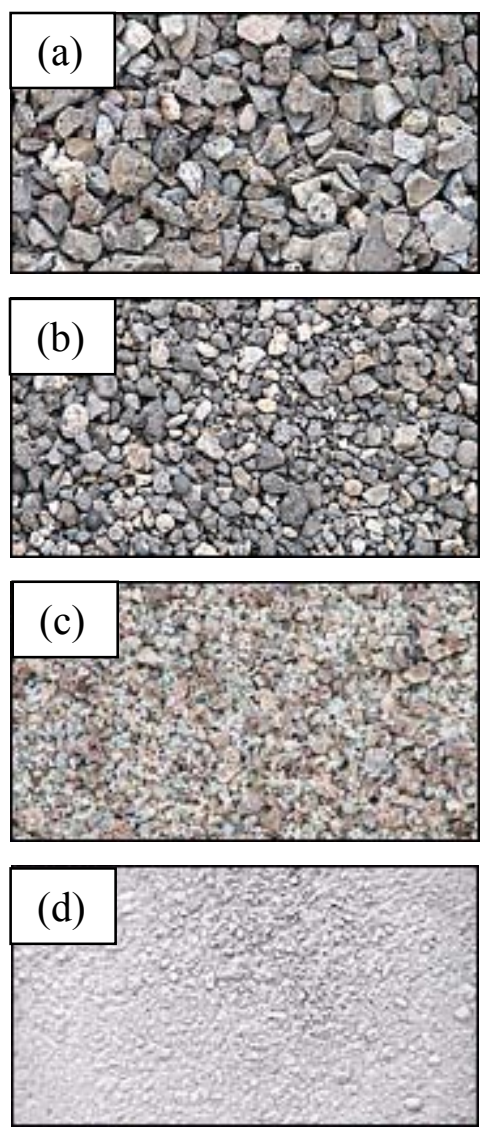

Figure 3.1 Types of blast-furnace slag: (a) air-cooled (b) pelletized (c) granulated (d) ground-granulated (slag cement)

Air-cooled blast-furnace slag (ACBFS) has a very crystalline structure, as the cooling rate is fairly slow. The hard lumps of slag are crushed down to sizes in order to meet the gradations specified by ASTM C33, ASTM D692 and ASTM D448 for its use as aggregate in concrete, asphalt and road base material. The structure of ACBFS varies from vesicular to dense, with the presence of fractures. Particles have textures with different degrees of roughness and angular shapes. The typical unit weight of ACBFS is $12-13 \mathrm{kN} / \mathrm{m}^{3}$, which is lower than that of most natural aggregates. However, there are reported values of dry unit weight as high as $19 \mathrm{kN} / \mathrm{m}^{3}$ for iron contents higher than the usual. The specific gravity of the blast-furnace slag ranges from 2 to 2.5 , with an absorption value ranging from 1 to $6 \%$. The friction angle of ACBFS is reported to be in the range of $40^{\circ}-45^{\circ}$ (the ranges of confining stresses are not specified for the reported 
friction angles). ACBFS is used as road stones, concrete aggregate, filter media and railway ballast. When melted, it can also be made into mineral wool. ACBFS particles with vesicular structure have a rough surface enabling it to easily bond with cement paste and thus making it a favorable aggregate for use by the concrete industry (Lee 1974; Noureldin and McDaniel 1990; Rao 2006). Compared to ACBFS, expanded blast-furnace slag (EBFS) has a more vesicular structure and hence a higher porosity. The compacted dry unit weight of expanded blast-furnace slag typically lies in the range of $8-10 \mathrm{kN} / \mathrm{m}^{3}$, which corresponds to $70 \%$ of the dry unit weight of ACBFS. The particles of EBFS are angular with a very rough texture. For these reasons, expanded blast-furnace slag is very suitable as an aggregate for lightweight concrete. It is also used as a structural element for roof screeds and bridge decks. In general, expanded blast-furnace slag is predominantly glassy and, therefore, when finely ground, it also possesses hydraulic properties similar to ground-granulated blast-furnace slag (Noureldin and McDaniel 1990; Rao 2006).

Pelletized blast-furnace slag (PBFS) has very distinguishable properties from other types of blast-furnace slag. PBFS particles are rounded in shape and smooth in texture. Compared to EBFS, PBFS has lower porosity and water absorption but higher bulk density. Depending on the quenching rate, PBFS can be produced in either crystallized or glassy forms depending on its intended application either as an aggregate or as a cementitious material, respectively. Pellet sizes can range from $0.1 \mathrm{~mm}$ to $13 \mathrm{~mm}$. According to Emery (1980), loose dry unit weight values for pelletized blast-furnace slag range from 8.2 to $10.4 \mathrm{kN} / \mathrm{m}^{3}$.

Granulated slag (GS) is a glassy material, typically with sand-to-gravel-size particles. When milled into a powder of cement-size particles, it exhibits pozzolanic properties. The temperature before granulation, chemical composition and fines content of GS determine its hydraulic reactivity. Ground-granulated blast-furnace slag is used as a supplementary cementitious material in the production of high-quality cement that is known as Portland blast-furnace slag cement (PBFSC). AASHTO M302-06 specifies the properties of ground-granulated blast-furnace slag for use in concrete and mortars (Emery 1980; Noureldin and McDaniel 1990; Mathur et al. 1999; AASHTO M302-06 2006). 
Table 3.1 Chemical composition of blast-furnace slags

\begin{tabular}{|c|c|c|c|c|c|c|c|c|c|c|c|c|}
\hline \multicolumn{13}{|c|}{ Oxide Composition (\%) } \\
\hline Reference & $\mathrm{CaO}$ & $\mathrm{SiO}_{2}$ & $\mathrm{Al}_{2} \mathrm{O}_{3}$ & $\mathrm{MgO}$ & $\mathrm{FeO}$ & $\mathrm{Fe}_{2} \mathrm{O}_{3}$ & $\mathrm{Fe}_{\text {total }}$ & $\mathrm{SO}_{3}$ & $\mathrm{MnO}$ & $\mathrm{TiO}_{2}$ & $\mathrm{P}_{2} \mathrm{O}_{5}$ & L.O.I. ${ }^{\mathrm{a}}$ \\
\hline Cramer et al. (2005) ${ }^{b}$ & 37.62 & 37.22 & 7.78 & 10.98 & - & 1.01 & - & 2.53 & 0.56 & 0.43 & $<0.01$ & 0.56 \\
\hline Das et al. (2007) & 37.40 & 37.14 & 9.15 & 11.70 & - & 1.05 & - & 0.37 & - & - & - & 2.25 \\
\hline Emery (1974) & $36-45$ & $33-42$ & $10-16$ & $3-16$ & - & - & $0.3-2$ & 1.30 & $0.2-1.5$ & - & - & - \\
\hline Kneller et al. (1994) & $36-45$ & $33-42$ & $10-16$ & $3-12$ & $0.3-2.0$ & - & $0.2-1.5$ & 1.30 & - & - & - & - \\
\hline Kumar et al. (2008) ${ }^{b}$ & 33.0 & 33.1 & 21.6 & 8.8 & - & 0.87 & - & - & - & - & - & - \\
\hline Lee (1974) & $36-43$ & $28-36$ & $12-22$ & $4-11$ & - & - & $0.3-1.7$ & $1.0-2.0$ & - & - & - & - \\
\hline Miklos (2000) & $39-42$ & $33-39$ & $9-13$ & $6-9$ & $\sim 0$ & - & - & $1.2-1.4$ & $0.1-0.5$ & $0.4-3.0$ & $\sim 0$ & - \\
\hline Mymrin et al.(2001) & 36.1 & 35.2 & 10.6 & 3.5 & - & - & 4 & 3.7 & 2 & - & - & - \\
\hline NSA (2008) & $34.0-42.7$ & $26.6-38.0$ & $6.9-11.7$ & $9.9-14.9$ & - & $0.3-0.6$ & - & $1.0-1.8$ & $0.15-0.76$ & - & - & - \\
\hline $\begin{array}{l}\text { Rasheeduzzafar et al. } \\
\qquad(1991)\end{array}$ & 43.70 & 35.40 & 7.80 & 8.50 & - & 0.52 & - & 1.13 & - & - & - & - \\
\hline Sobolev $(2005)^{b}$ & 35.9 & 37.4 & 10.9 & 8.1 & - & 0.6 & - & 2.1 & - & - & - & - \\
\hline Taylor (1990) & $37.9-44.4$ & $31.9-37.3$ & $10.3-16.0$ & $3.6-8.7$ & $0.29-9.32$ & - & - & $0-0.19$ & $0.34-1.31$ & $0.49-0.65$ & $0-0.34$ & $0-1.04$ \\
\hline Wild et al. (1998) ${ }^{b}$ & 41.99 & 35.34 & 11.59 & 8.04 & - & 0.35 & - & 0.23 & 0.45 & - & - & - \\
\hline
\end{tabular}




\subsection{Chemical and Mineralogical Properties of Steel Slag}

All ferrous slags that are generated from the iron and steelmaking industries (blastfurnace, basic-oxygen-furnace, electric-arc-furnace and ladle slags) contain a percentage of $\mathrm{CaO}$ (from the fluxing agents) along with undesirable impurities. However, the mineralogy and mechanical properties of steel slag depend on the proportion of the main chemical constituents in the steel slag and on the techniques used in slag processing. Therefore, the chemical, mineralogical and mechanical properties of steelmaking (EAF, BOF and ladle) slags are very different from those of blast-furnace slag.

\subsubsection{Chemical Composition of Steel Slag}

BOF and EAF slags are both formed during basic steelmaking operations. Therefore, in general, the chemical and mineralogical composition of BOF and EAF slags are similar. Calcium oxide and iron oxide form the two major chemical constituents of both EAF and BOF slags. Ladle slag is generated during the steel refining process in which several alloys are added to the ladle furnace to produce different grades of steel. For this reason, the chemical constituents of ladle slag differ from those of BOF and EAF slags. Table 3.2 provides the chemical composition of basic-oxygen-furnace (BOF) slags compiled from the literature. The iron oxide $\left(\mathrm{FeO} / \mathrm{Fe}_{2} \mathrm{O}_{3}\right)$ content of $\mathrm{BOF}$ slag can be as high as $38 \%$ (refer to Table 3.2); this is the amount of oxidized iron that can not be recovered into steel during the conversion of molten iron into steel. Prior to the BOF process, most of the silica impurities in the iron ore react with $\mathrm{CaO}$ to form blast-furnace slag and, as a result, $\mathrm{BOF}$ slag has a lower $\mathrm{SiO}_{2}$ content than BFS. The silica $\left(\mathrm{SiO}_{2}\right)$ content of $\mathrm{BOF}$ slag ranges from $7-18 \%$. The $\mathrm{Al}_{2} \mathrm{O}_{3}$ and $\mathrm{MgO}$ contents are in the $0.5-4 \%$ and $0.4-14 \%$ ranges, respectively, whereas the free lime content can be as high as $12 \%$. The chemical composition of electric-arc-furnace (EAF) slags is summarized in Table 3.3. EAF slag has chemical composition similar to that of BOF slag (refer to Table 3.3). Unlike the basic-oxygen-furnace steelmaking, the electric-arc-furnace steelmaking is essentially a recycling process of steel from steel scraps. The chemical composition of electric-arc- 
furnace slag depends significantly on the properties of the recycled steel. Therefore, compared to BOF slags, the main chemical constituents of EAF slags vary widely. Typically, the $\mathrm{FeO}, \mathrm{CaO}, \mathrm{SiO}_{2}, \mathrm{Al}_{2} \mathrm{O}_{3}$ and $\mathrm{MgO}$ contents of EAF slags are in the $10-40 \%$, $22-60 \%, 6-34 \%, 3-14 \%$ and 3-13\% ranges, respectively. The FeO content of EAF slags generated from stainless steel production can be as low as 2\% (Shen et al. 2004).

Information on the chemical composition of ladle slags (LS) is scarce in the literature. The data obtained from a few sources are compiled in Table 3.4. During the steel refining process, different alloys are fed into the ladle furnace in order to obtain the desired grade of steel. Hence, the chemical composition of ladle slag is highly dependent on the grade of steel produced. As a result, compared to BOF and EAF slags, the chemical composition of ladle slag is highly variable. The major difference in the chemical composition of ladle slag and BOF and EAF slags is the FeO content. Typically, the FeO content of ladle slag is much lower $(<10 \%)$ than those of EAF and BOF slags. On the other hand, the $\mathrm{Al}_{2} \mathrm{O}_{3}$ and $\mathrm{CaO}$ contents are typically higher for ladle slags. The $\mathrm{CaO}$ and iron oxide $\left(\mathrm{FeO} / \mathrm{Fe}_{2} \mathrm{O}_{3}\right)$ contents of $\mathrm{LS}$ are higher than $45 \%$ and less than $10 \%$, respectively (refer to Table 3.4 ).

\subsubsection{Mineralogical Properties of Steel Slag}

Crystallization of slag is a function of both its chemical composition and cooling rate. Silica rich blast-furnace slag vitrifies (forms a glassy phase) easily when it is rapidly cooled. Steel slag has a lower silica content than blast-furnace slag and, hence, steel slag seldom vitrifies even when rapidly cooled. Tossavanien et al. (2007) studied the effect of the cooling rate on the mineralogy of BOF, EAF and ladle slag samples with different proportions of major chemical constituents and showed that ladle slag became almost completely amorphous by granulation, with the exception of only one crystalline phase of periclase $(\mathrm{MgO})$. On the other hand, granulated BOF and EAF slag samples showed very complex crystalline structures similar to that of slowly cooled BOF and EAF slag samples. The ladle slag tested had significantly more $\mathrm{Al}_{2} \mathrm{O}_{3}$ than the BOF and EAF slag samples. Reddy et al. (2006) have also identified very crystalline structure in quenched 
BOF slag from XRD analysis. These studies indicate that even when rapidly cooled in general steel slag tend to crystallize due to its chemical composition.

Several studies on the mineralogical composition of steel slags are reported in the literature. X-ray diffraction analysis of steel slag samples shows a complex structure with many overlapping peaks reflecting the crystalline phases present in steel slag. These crystalline phases appear mainly due to the chemical composition of steel slag and the slow cooling rate applied during processing (Monaco and Wu 1994; Shi 2002; Manso et al. 2005; Reddy et al. 2006; Tsakiridis et al. 2008). Variations in the feed (charge) into the furnaces occur from one steelmaking plant to the other, and hence, it is natural to observe variations in the chemical constituents of steel slags produced at different steelmaking plants. A variety of mineral phases were identified and reported in the literature for EAF, BOF and ladle slags (refer to Table 3.5).

Several researchers have summarized the mineral phases that are commonly observed in steel slags. These mineral phases include merwinite $\left(3 \mathrm{CaO} \cdot \mathrm{MgO} .2 \mathrm{SiO}_{2}\right)$, olivine (2MgO.2 FeO. $\left.\mathrm{SiO}_{2}\right), \beta-\mathrm{C}_{2} \mathrm{~S}\left(2 \mathrm{CaO} . \mathrm{SiO}_{2}\right), \alpha-\mathrm{C}_{2} \mathrm{~S}, \mathrm{C}_{4} \mathrm{AF}\left(4 \mathrm{CaO} . \mathrm{Al}_{2} \mathrm{O} 3 . \mathrm{FeO}_{3}\right), \mathrm{C}_{2} \mathrm{~F}$ (2CaO. $\left.\mathrm{Fe}_{2} \mathrm{O}_{3}\right), \mathrm{CaO}$ (free lime), $\mathrm{MgO}, \mathrm{FeO}, \mathrm{C}_{3} \mathrm{~S}\left(3 \mathrm{CaO} . \mathrm{SiO}_{2}\right)$ and $\mathrm{RO}$ phase (a solid solution of CaO-FeO-MnO-MgO). (see Table 3.5) (Qian et al. 2002a; Qian et al. 2002b; Shi 2004). Since BOF and EAF slags both have high iron oxide contents in their chemistry, solid solutions of FeO (wustite) are typically observed as one of the main mineral phases. Ladle slag has a lower FeO content, and therefore, polymorphs of $\mathrm{C}_{2} \mathrm{~S}$ are frequently observed as the main phase (Geiseler 1996; Shi 2002; Shi 2004; Tsakiridis et al. 2008). 
Table 3.2 Chemical composition of basic-oxygen-furnace slags

\begin{tabular}{|c|c|c|c|c|c|c|c|c|c|c|c|c|c|c|}
\hline \multicolumn{15}{|c|}{ Oxide Composition (\%) } \\
\hline Reference & $\mathrm{CaO}$ & $\mathrm{SiO}_{2}$ & $\mathrm{Al}_{2} \mathrm{O}_{3}$ & $\mathrm{MgO}$ & $\mathrm{FeO}$ & $\mathrm{Fe}_{2} \mathrm{O}_{3}$ & $\mathrm{Fe}_{\text {total }}$ & $\mathrm{SO}_{3}$ & $\mathrm{MnO}$ & $\mathrm{TiO}_{2}$ & $\mathrm{P}_{2} \mathrm{O}_{5}$ & $\mathrm{Cr}_{2} \mathrm{O}_{5}$ & L.O.I. ${ }^{\mathrm{a}}$ & $\begin{array}{l}\text { aree } \\
\mathrm{CaO}\end{array}$ \\
\hline Altun et al. (2002) & 37.02 & 18.01 & 2.61 & 14.10 & - & 14.10 & - & 0.35 & - & - & - & - & 1.25 & - \\
\hline Chaurand et al. (2007) & 41.30 & 12.50 & 2.40 & 4.30 & - & 31.20 & - & - & 6.10 & 0.80 & 1.10 & - & - & - \\
\hline Das et al. (2007) & 47.88 & 12.16 & 1.22 & 0.82 & 26.30 & - & - & 0.28 & 0.28 & - & 3.33 & - & 7.54 & - \\
\hline Emery (1974) & 41.30 & 15.60 & 2.20 & 6.90 & - & - & 20.0 & - & 8.90 & 0.50 & - & - & - & 3.3 \\
\hline Juckes $(2003)^{b}$ & $36.4-45.8$ & $10.7-15.2$ & $1-3.4$ & $4.1-7.8$ & - & - & $18.6-24.2$ & $0.07-0.21$ & $2.7-4.3$ & - & $1-1.5$ & - & - & $2.5-12$ \\
\hline Kneller et al. (1994) & $36-49$ & $7.2-18.2$ & $0.42-3.0$ & $5-12$ & $15-30$ & - & - & $0.05-0.5$ & - & - & $0.03-0.9$ & - & - & - \\
\hline Mahieux et al (2009) & 47.50 & 11.80 & 2.00 & 6.30 & - & 22.60 & - & - & 1.90 & 0.50 & 2.70 & - & 3.60 & - \\
\hline Miklos (2000) & $42-52$ & $9-13$ & $0.5-3$ & $1-8$ & $15-35$ & - & - & $\sim 0.25$ & $3-10$ & $\sim 0$ & $1.5-4$ & $<2$ & - & $3-13$ \\
\hline \multicolumn{15}{|l|}{ Motz et al.(2001) } \\
\hline low $\mathrm{MgO}$ & $45-55$ & $12-18$ & $<3$ & $<3$ & - & - & $14-20$ & - & $<5$ & - & $<2$ & - & - & $<10$ \\
\hline \multicolumn{15}{|l|}{ Motz et al. (2001) } \\
\hline high $\mathrm{MgO}$ & $42-50$ & $12-15$ & $<3$ & $5-8$ & - & - & $15-20$ & - & $<5$ & - & $<2$ & - & - & $<10$ \\
\hline NSA (2008) & 41.30 & 15.60 & 2.20 & 6.90 & - & - & 20.00 & - & 8.90 & 0.50 & - & - & - & 3.3 \\
\hline Nicolae et al. (2007) & 40.10 & 17.80 & 2.04 & 6.32 & 12.92 & 6.58 & - & 0.46 & 6.52 & - & 1.13 & - & - & 3.9 \\
\hline Poh et al. (2006) & 41.44 & 15.26 & 4.35 & 8.06 & 13.95 & 9.24 & - & - & 5.20 & 0.72 & 1.15 & - & - & 3.9 \\
\hline
\end{tabular}


Table 3.2 Chemical composition of basic-oxygen-furnace slags (continued)

\begin{tabular}{|c|c|c|c|c|c|c|c|c|c|c|c|c|c|c|}
\hline \multicolumn{15}{|c|}{ Oxide Composition (\%) } \\
\hline Reference & $\mathrm{CaO}$ & $\mathrm{SiO}_{2}$ & $\mathrm{Al}_{2} \mathrm{O}_{3}$ & $\mathrm{MgO}$ & $\mathrm{FeO}$ & $\mathrm{Fe}_{2} \mathrm{O}_{3}$ & $\mathrm{Fe}_{\text {total }}$ & $\mathrm{SO}_{3}$ & $\mathrm{MnO}$ & $\mathrm{TiO}_{2}$ & $\mathrm{P}_{2} \mathrm{O}_{5}$ & $\mathrm{Cr}_{2} \mathrm{O}_{5}$ & L.O.I. ${ }^{\mathrm{a}}$ & $\begin{array}{l}\text { Free } \\
\mathrm{CaO}\end{array}$ \\
\hline Poh et al. (2006) & 52.19 & 10.78 & 1.34 & 5.04 & 17.16 & 10.14 & 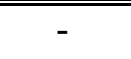 & 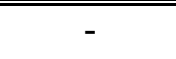 & 2.45 & 0.55 & 1.28 & 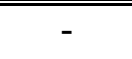 & 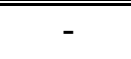 & 10.2 \\
\hline Poh et al. (2006) & 40.98 & 11.98 & 2.82 & 7.50 & 16.09 & 10.06 & - & - & 3.78 & 0.58 & 0.89 & - & - & 5.8 \\
\hline Reddy et al. (2006) & 52.30 & 15.30 & 1.30 & 1.10 & - & - & 16.20 & - & 0.39 & - & 3.10 & 0.20 & - & 10.0 \\
\hline Shen et al. (2009) & 39.30 & 7.75 & 0.98 & 8.56 & - & 38.06 & - & 0.02 & 4.24 & 0.94 & - & - & - & - \\
\hline Shi (2004) & $30-55$ & $8-20$ & $1-6$ & $5-15$ & $10-35$ & - & - & $0.05-0.15$ & $2-8$ & $0.4-2$ & $0.2-2$ & $0.1-0.5$ & - & - \\
\hline Topkaya et al. (2004) & $31-35$ & $17-22$ & $2.5-4.5$ & $7.5-9$ & - & - & $25-30$ & - & $5-8$ & - & - & - & - & - \\
\hline Tossavainen (2006) & 45.00 & 11.10 & 1.90 & 9.60 & 10.70 & 10.90 & - & - & 3.10 & - & - & - & - & - \\
\hline Wachsmuth et 1.(1981) & $36-49$ & $6-14$ & - & 5.00 & - & - & $19-34$ & - & 2.00 & - & - & - & - & $0.3-9.2$ \\
\hline Xue et al. (2006) & 45.41 & 13.71 & 3.80 & 6.25 & 21.85 & 3.24 & - & - & 3.27 & - & 1.42 & - & - & - \\
\hline
\end{tabular}

${ }^{\mathrm{a}}$ L.O.I. $=$ Loss of ignition

${ }^{\mathrm{b}}$ The range of values are compiled based on the chemical composition data from 4 different sources in Great Britain provided by Juckes (2003)

- data not available 
Table 3.3 Chemical composition of electric-arc-furnace slags

\begin{tabular}{|c|c|c|c|c|c|c|c|c|c|c|c|c|c|}
\hline \multicolumn{14}{|c|}{ Oxide Composition (\%) } \\
\hline Reference & $\mathrm{CaO} \quad \mathrm{SiO}_{2}$ & $\mathrm{Al}_{2} \mathrm{O}_{3}$ & $\mathrm{MgO}$ & $\mathrm{FeO}$ & $\mathrm{Fe}_{2} \mathrm{O}_{3}$ & $\mathrm{Fe}_{\text {total }}$ & $\mathrm{SO}_{3}$ & $\mathrm{MnO}$ & $\mathrm{TiO}_{2}$ & $\mathrm{P}_{2} \mathrm{O}_{5}$ & $\mathrm{Cr}_{2} \mathrm{O}_{5}$ & $\mathrm{~K}_{2} \mathrm{O}$ & $\begin{array}{l}\text { Free } \\
\mathrm{CaO}\end{array}$ \\
\hline Barra et al. (2001) & 29.4916 .11 & 7.56 & 4.96 & - & 32.56 & - & 0.63 & 4.53 & 0.78 & 0.55 & 1.42 & 0.13 & - \\
\hline Kneller et al. (1994) & $48.3 \quad 13.9$ & 2.8 & 9.9 & 15 & - & - & 0.06 & - & - & 0.88 & - & - & - \\
\hline Lekakh et al.(2008) & $32.1 \quad 19.4$ & 8.6 & 9.4 & - & - & 26.4 & 0.6 & 6.8 & 0.4 & - & - & - & - \\
\hline Luxan et al. (2000) & 29.116 .04 & 14.07 & 3.35 & 27.41 & - & - & - & 15.58 & 0.54 & 1.24 & 0.70 & 1.80 & - \\
\hline Luxan et al. (2000) & 24.4015 .35 & 12.21 & 2.91 & 34.36 & - & - & - & 5.57 & 0.56 & 1.19 & 0.99 & 1.52 & - \\
\hline Manso et al.(2004) & $23-328-15$ & $3.5-7.04$ & $4.8-6.6$ & $67-35$ & $11-40$ & - & - & $2.5-4.5$ & - & - & - & - & $0-4.0$ \\
\hline Manso et al. (2006) & $23.9 \quad 15.3$ & 7.4 & 5.1 & - & - & 42.5 & 0.1 & 4.5 & - & - & - & - & 0.45 \\
\hline Miklos (2000) & $30-4010-20$ & $<10$ & $<10$ & $15-35$ & - & - & $<0.25$ & $<10$ & $\sim 0$ & $<2$ & $<2$ & - & $<1.5$ \\
\hline Motz and Geisler (2001) & $25-4010-17$ & $4-7$ & $4-15$ & - & - & $18-29$ & - & $<6$ & - & $<1.5$ & - & - & $<3$ \\
\hline Nicolae et al. (2007) & 40.7817 .81 & 4.23 & 8.53 & 9.25 & 3.97 & - & 0.30 & 9.79 & - & 0.74 & 1.42 & - & - \\
\hline Qian et al. (2002a) & 38.9217 .52 & 4.47 & 12.86 & 9.83 & 10.15 & - & - & 3.98 & - & 0.27 & - & - & - \\
\hline Qian et al. (2002a) & 30.1516 .63 & 7.7 & 10.66 & 15.48 & 11.33 & - & - & 0.94 & - & 0.36 & - & - & - \\
\hline Qian et al. (2002a) & 21.5818 .60 & 8.47 & 8.69 & 32.27 & 7.32 & - & - & 1.21 & - & 0.58 & - & - & - \\
\hline Shi (2004) & $35-609-20$ & $2-9$ & $5-15$ & $15-30$ & - & - & $0.08-0.2$ & $23.0-8.0$ & - & $0.01-0.25$ & $0.1-1$ & - & - \\
\hline Tossavainen (2006) & $45.5 \quad 32.2$ & 3.7 & 5.2 & 3.3 & 1 & - & - & 2 & - & - & - & - & - \\
\hline Tossavainen (2006) & $38.8 \quad 14.1$ & 6.7 & 3.9 & 5.6 & 20.3 & - & - & 5 & - & - & - & - & - \\
\hline Tsakiridis et al.(2008) & 35.717 .53 & 6.25 & 6.45 & - & 26.36 & - & - & 2.5 & 0.76 & - & - & 0.26 & - \\
\hline
\end{tabular}


Table 3.4 Chemical composition of ladle slags

\begin{tabular}{|c|c|c|c|c|c|c|c|c|c|c|c|c|c|}
\hline \multicolumn{14}{|c|}{ Oxide Composition (\%) } \\
\hline Reference & $\mathrm{CaO}$ & $\mathrm{SiO}_{2}$ & $\mathrm{Al}_{2} \mathrm{O}_{3}$ & $\mathrm{MgO}$ & $\mathrm{FeO}$ & $\mathrm{Fe}_{2} \mathrm{O}_{3}$ & $\mathrm{Fe}_{\text {total }}$ & $\mathrm{SO}_{3}$ & $\mathrm{MnO}$ & $\mathrm{TiO}_{2}$ & $\mathrm{P}_{2} \mathrm{O}_{5}$ & $\mathrm{Cr}_{2} \mathrm{O}_{5}$ & $\begin{array}{l}\text { Free } \\
\mathrm{CaO}\end{array}$ \\
\hline Munso et al. (2005) & 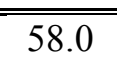 & 17 & 12.0 & 10.0 & - & - & - & 1.0 & 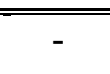 & - & "- & - & - \\
\hline Nicolae et al. (2007) & 49.56 & 14.73 & 25.55 & 7.88 & 0.44 & 0.22 & 0.17 & 0.8 & 0.39 & - & 0.2 & 0 & - \\
\hline Qian et al. (2002a) & 49.51 & 19.59 & 12.32 & 7.36 & - & 0.92 & - & - & 1.35 & - & 0.43 & - & 2.47 \\
\hline Shi (2004) & $30-60$ & $2-35$ & $5-35$ & $1-10$ & $0.1-15$ & - & - & $0.1-1$ & $0-5.0$ & - & $0.1-0.4$ & $0-0.5$ & - \\
\hline Shi (2002) & 55.90 & 26.40 & 4.70 & 4.20 & - & 1.00 & 4.40 & 2.30 & 0.50 & 0.3 & - & - & - \\
\hline Tossavainen (2006) & 42.5 & 14.2 & 22.9 & 12.6 & 0.5 & 1.1 & 0.4 & - & 0.2 & - & - & - & - \\
\hline Xuequan et al. (1999) & 48.19 & 12.12 & 2.58 & 6.44 & - & 8.52 & - & 0.43 & - & - & 1.27 & - & - \\
\hline Xuequan et al. (1999) ${ }^{b}$ & $45-60$ & $10-15$ & $1-5$ & $3-13$ & $7-20$ & $3-9$ & - & - & - & - & $1-4$ & - & - \\
\hline
\end{tabular}

${ }^{\mathrm{a}}$ L.O.I. $=$ Loss of ignition

${ }^{b}$ Xuequan et al. (1999) reports chemical composition of steel slag from refining process (not specified as ladle)

-data not available 
Table 3.5 Mineralogical phases of BOF, EAF and ladle slags

\begin{tabular}{|c|c|c|}
\hline Reference & Slag & Mineralogical Phases \\
\hline Barra et al. (2001) & EAF & $\mathrm{CaCO}_{3}, \mathrm{FeO}, \mathrm{MgO}, \mathrm{Fe}_{2} \mathrm{O}_{3}, \mathrm{Ca}_{2} \mathrm{Al}\left(\mathrm{AlSiO}_{7}\right), \mathrm{Ca}_{2} \mathrm{SiO}_{4}$ \\
\hline Geiseler (1995) & - & $\begin{array}{l}2 \mathrm{CaO} . \mathrm{SiO}_{2}, 3 \mathrm{CaO} \cdot \mathrm{SiO}_{2}, 2 \mathrm{CaO} \cdot \mathrm{Fe}_{2} \mathrm{O}_{3}, \mathrm{FeO},(\mathrm{Ca}, \mathrm{Fe}) \mathrm{O} \\
\text { (calciowustite), }(\mathrm{Mg}, \mathrm{Fe}) \mathrm{O} \text { (magnesiowustite), free } \mathrm{MgO}, \mathrm{CaO}\end{array}$ \\
\hline Juckes (2003) & BOF & $\mathrm{C}_{3} \mathrm{~S}, \mathrm{C}_{2} \mathrm{~S}, \mathrm{C}_{2} \mathrm{~F}$, RO phase (FeO-MgO-CaO-FeO), $\mathrm{MgO}, \mathrm{CaO}$ \\
\hline Luxan et al. (2000) & EAF & $\begin{array}{c}\left.\mathrm{Ca}_{2} \mathrm{SiO}_{5}, \mathrm{Ca}_{2} \mathrm{Al}(\mathrm{AlSiO})_{7}\right), \mathrm{Fe}_{2} \mathrm{O}_{3}, \mathrm{Ca}_{14} \mathrm{Mg}_{2}\left(\mathrm{SiO}_{4}\right)_{8}, \mathrm{MgFe}_{2} \mathrm{O}_{4} \\
\mathrm{Mn}_{3} \mathrm{O}_{4}, \mathrm{MnO}_{2}\end{array}$ \\
\hline Manso et al. (2005) & Ladle & $\begin{array}{c}\mathrm{Al}_{2} \mathrm{O}_{4} \mathrm{Mg}, \mathrm{Ca}(\mathrm{OH})_{2}, \mathrm{Si}_{2} \mathrm{O}_{6} \mathrm{CaMg}, \mathrm{MgO}, \mathrm{Si}_{2} \mathrm{O}_{6} \mathrm{CaMg}, \mathrm{Ca}_{3} \mathrm{SiO}_{5}, \\
\beta-\mathrm{Ca}_{2} \mathrm{SiO}_{4}, \gamma-\mathrm{Ca}_{2} \mathrm{SiO}_{4}, \mathrm{SO}_{4} \mathrm{Ca}\end{array}$ \\
\hline Murphy et al. (1997) & - & $\begin{array}{l}3 \mathrm{CaO} \cdot \mathrm{SiO}_{2}, 2 \mathrm{CaO} \cdot \mathrm{SiO}_{2}, \beta-\mathrm{Ca} 2 \mathrm{SiO} 4, \alpha-\mathrm{Ca}_{2} \mathrm{SiO}_{4}, \\
2 \mathrm{CaO} \cdot \mathrm{Fe}_{2} \mathrm{O}_{3}, 4 \mathrm{CaO} \cdot \mathrm{Al}_{2} \mathrm{O}_{3} \cdot \mathrm{Fe}_{2} \mathrm{O}_{3}, \mathrm{FeO}, \mathrm{MgO}, \mathrm{CaO}\end{array}$ \\
\hline Nicolae et al. (2007) & $\mathrm{BOF}$ & 2CaO.Al2O3.SiO2, Fe2O3, $\mathrm{CaO}, \mathrm{FeO}$ \\
\hline Nicolae et al. (2007) & EAF & $\mathrm{MnO}_{2}, \mathrm{MnO}, \mathrm{Fe}_{2} \mathrm{SiO}_{4}, \mathrm{Fe}_{7} \mathrm{SiO}_{10}$ \\
\hline Nicolae et al. (2007) & Ladle & $\mathrm{CaO} . \mathrm{SiO}_{2}, \mathrm{CaOAl}_{2} \mathrm{O}_{3} .2 \mathrm{SiO}_{2}, \mathrm{CaS}, \mathrm{Al}_{2} \mathrm{O}_{3}$ \\
\hline Qian et al. (2002a) & EAF & $\gamma-\mathrm{Ca}_{2} \mathrm{SiO}_{4}, \mathrm{C}_{3} \mathrm{MS}_{2}, \mathrm{CFMS}, \mathrm{FeO}-\mathrm{MnO}-\mathrm{MgO}$ solid solution \\
\hline Qian et al. (2002a) & Ladle & $\gamma-\mathrm{Ca}_{2} \mathrm{SiO}_{4}, \mathrm{C}_{3} \mathrm{MS}_{2}, \mathrm{MgO}$ \\
\hline Reddy et al. (2006) & $\mathrm{BOF}$ & $2 \mathrm{CaO} . \mathrm{Fe}_{2} \mathrm{O}_{3}, 2 \mathrm{CaO} . \mathrm{P}_{2} \mathrm{O}_{5}, 2 \mathrm{CaO} . \mathrm{SiO}_{2}, \mathrm{CaO}$ \\
\hline Reddy et al. (2006) & $\mathrm{BOF}^{\mathrm{q}}$ & $2 \mathrm{CaO} . \mathrm{Fe}_{2} \mathrm{O}_{3}, 3 \mathrm{CaO} . \mathrm{SiO}_{2}, 2 \mathrm{CaO} \cdot \mathrm{SiO}_{2}, \mathrm{Fe}_{2} \mathrm{O}_{3}$ \\
\hline Tossavanien et al. (2007) & Ladle & $\mathrm{Ca}_{12} \mathrm{Al}_{14} \mathrm{O}_{33}, \mathrm{MgO} . \beta-\mathrm{Ca}_{2} \mathrm{SiO}_{4}, \gamma-\mathrm{Ca}_{2} \mathrm{SiO}_{4}, \mathrm{Ca}_{2} \mathrm{Al}_{2} \mathrm{SiO}_{7}$ \\
\hline Tossavanien et al. (2007) & $\mathrm{BOF}$ & $\beta-\mathrm{Ca}_{2} \mathrm{SiO}_{4}, \mathrm{FeO}-\mathrm{MnO}-\mathrm{MgO}$ solid solution, $\mathrm{MgO}$ \\
\hline Tossavanien et al. (2007) & EAF & $\begin{array}{c}\mathrm{Ca}_{3} \mathrm{Mg}\left(\mathrm{SiO}_{4}\right)_{2}, \beta-\mathrm{Ca}_{2} \mathrm{SiO}_{4} \text {, Spinel solid solution } \\
(\mathrm{Mg}, \mathrm{Mn})(\mathrm{Cr}, \mathrm{Al})_{2} \mathrm{O}_{4}, \text { wsutite-type solid } \\
\text { solution }((\mathrm{Fe}, \mathrm{Mg}, \mathrm{Mn}) \mathrm{O}), \mathrm{Ca}_{2}(\mathrm{Al}, \mathrm{Fe})_{2} \mathrm{O}_{5}\end{array}$ \\
\hline Tsakiridis et al.(2008) & EAF & $\begin{array}{c}\mathrm{Ca}_{2} \mathrm{SiO}_{4}, 4 \mathrm{CaO} \cdot \mathrm{Al}_{2} \mathrm{O}_{3} \cdot \mathrm{Fe}_{2} \mathrm{O}_{3}, \mathrm{Ca}_{2} \mathrm{Al}(\mathrm{AlSiO})_{7}, \mathrm{Ca}_{3} \mathrm{SiO}_{5} \\
2 \mathrm{CaO} \cdot \mathrm{Al}_{2} \mathrm{O}_{3} \cdot \mathrm{SiO}_{2}, \mathrm{FeO}, \mathrm{Fe}_{3} \mathrm{O}_{4}, \mathrm{MgO}, \mathrm{SiO}_{2}\end{array}$ \\
\hline Wachsmuth et al. (1981) & BOF & $\mathrm{Ca}_{2} \mathrm{SiO}_{4}, \mathrm{Ca}_{3} \mathrm{SiO}_{5}, \mathrm{FeO}, 2 \mathrm{CaO} . \mathrm{Fe}_{2} \mathrm{O}_{3}$ \\
\hline
\end{tabular}

-type of steel slag is not provided ${ }^{\mathrm{q}}$ quenched 
Even though the chemical composition of steel slag imitates that of cement, the type of mineral phases and their quantities in steel slag are very different from those of Portland cement. Portland cement contains four significant mineral phases which are the source of their strong cementitious reactions. These phases are tricalcium silicate $\left(\mathrm{C}_{3} \mathrm{~S}\right)$, dicalcium silicate $\left(\mathrm{C}_{2} \mathrm{~S}\right)$, tricalcium aluminate $\left(\mathrm{C}_{3} \mathrm{~A}\right)$ and tetracalcium-alumino ferrite $\left(\mathrm{C}_{4} \mathrm{AF}\right)$. These important mineral phases are not present in sufficient quantities in steel slag. The main differences in the mineralogy of steel slag and cement result from the abundance of iron oxide and free lime and the lack of silica in the chemical composition of steel slag. One of the predominant phases in steel slag is solid solutions of wsutite $(\mathrm{FeO})$, which do not possess hydraulic properties. Moreover, these solid solutions typically have a tendency to hold the $\mathrm{CaO}$ needed in the formation of hydraulic minerals such as $\mathrm{C}_{2} \mathrm{~S}$ or $\mathrm{C}_{3} \mathrm{~S}$. Particularly, the $\mathrm{C}_{3} \mathrm{~S}$ phase, which is the source of the long-term strength of Portland cement concrete, is either one of the minor phases or in some cases it does not even appear in the mineralogical composition of steel slags. Under suitable conditions, iron oxide present in the form of hematite $\left(\mathrm{Fe}_{2} \mathrm{O}_{3}\right)$ can form calcium ferrite phases that can show hydraulic properties. Similarly, the presence of even small amounts of dicalcium silicate $\left(\mathrm{C}_{2} \mathrm{~S}\right)$ indicates light cementitious properties. However, unless activated with additives, steel slags typically show much weaker cementitious properties than Portland cement and usually are regarded as a very weak Portland cement clinker. The magnitude of the cementitious properties of steel slags is influenced mainly by the percentage of each chemical constituent, the conditions existing at the time of slag formation in the furnaces, and the rate of cooling. The cementitious properties of steel slag tend to increase with an increase in their basicity (Murphy et al. 1997; Shi 2002; Shi 2004; Reddy et al. 2006).

\subsection{Engineering Properties of Steel Slag}

There is very limited information on the engineering properties of steel slags in the literature. Noureldin and Mc Daniel (1990) and Lee (1974) reported on some of the engineering properties of steel slags. The values reported by these researchers are summarized in Table 3.6 
Table 3.6 Engineering properties of steel slag (modified after Lee 1974, Noureldin and McDaniel 1990)

\begin{tabular}{cc}
\hline Engineering Properties of steel slag & \\
\hline Specific Gravity & $3.1-3.6$ \\
Angle of Internal Friction & $40^{\circ}-50^{\circ}$ \\
California Bearing Ratio (CBR) & up to 300 \\
Los Angeles Abrasion (ASTM C131) & $20-25 \%$ \\
Maximum Dry Unit Weight (kN/m $\left.{ }^{3}\right)$ & $15.7-18.9$ \\
Porosity (\%) & up to 3 \\
Water Absorption (\%) & $0.2-2$ \\
Sodium Sulfate Soundness Losses (ASTM C88) & $<12 \%$ \\
Hardness (measured by Moh's scale of mineral hardness) & $6-7$ \\
\hline
\end{tabular}

Most of the studies in the literature focus mainly on the chemical composition and mineralogy of steel slag to assess its cementitious properties rather than its mechanical properties. The geotechnical properties of steel slag, such as its compaction characteristics and shear strength parameters have not been studied, indicating a clear need for research in this area.

\subsubsection{Grain-size Distribution}

Grain-size distribution is one of the most important characteristics of granular materials that affect their mechanical properties. As steel slag is generated as a by-product of the steelmaking process, its generation can not be controlled precisely. Molten slag solidifies in the slag pits and, subsequently, breaks down into smaller size particles during the cooling process. During this natural particle break down process, steel slag particles of varying dimensions - from as large as boulder size to as small as silt-size are generated. Thus, steel slags show a variable gradation with a wide range of particle sizes.

Steel slags are eventually screened into two or three different gradations (from coarse to fine) in the processing plants. The coarse gradation consists mainly of cobble- 
size particles (sizes ranging from $64 \mathrm{~mm}$ to $200 \mathrm{~mm}$ ), and the medium gradation consists of gravel-size particles (particle sizes up to $64 \mathrm{~mm}$ ). The fine gradation is similar to that of well-graded sand with varying percentages of gravel (retained by the No. 4 sieve; 4.75 $\mathrm{mm}$ ) and silt-size particles (passing the No. 200 sieve; 0.075mm). Typically, the percentage of silt-size particles is in the range of 10-15\% (Barra et al. 2001; Rohde et al. 2003). As explained in Chapter 2, the plants that produce asphalt material have steel-slag processors that can crush and adjust the medium- and coarse-size gradation of the steel slag generated to meet the specifications of the appropriate aggregate gradations. The finer gradation that is not utilized gets stockpiled at the plants. This research focuses on determining the properties of this under-utilized finer gradation of steel slag and exploring the possible applications of this fine gradation in geotechnical engineering.

\subsubsection{Specific Gravity}

Specific gravity $\mathrm{G}_{\mathrm{s}}$ is defined as the ratio of the density of a unit volume of a material to the density of a unit volume of water. The specific gravity of steel slags depends on their chemical composition, mineralogy and particle structure. Due to the presence of high iron oxide contents, steel slags have specific gravity values larger than those of natural soils/aggregates. Several researchers have reported specific gravity values of EAF and BOF slags, and the values range from 3.1 to 3.8 (refer to Table 3.7). The large range of $\mathrm{G}_{\mathrm{s}}$ values in Table 3.7 indicates the varying iron oxide contents in the chemical composition of steel slags. In addition, particle structure also has a marginal affect on the specific gravity of steel slag. In general, steel slag particles have a dense structure with low particle porosity. However, steel slags may occasionally contain gravel or pebble size particles (depending on the chemical composition and the cooling process) with large inaccessible voids leading to relatively lower specific gravity values. 
Table 3.7 Specific gravity values reported in the literature for steel slags

\begin{tabular}{ccc}
\hline Reference & Slag Type & $\mathrm{G}_{\mathrm{s}}$ \\
\hline \hline Altun and Yilmaz (2002) & BOF & $3.5-3.6$ \\
Barra et al.(2001) & EAF & 3.5 \\
Geiseler (1996) & BOF & $3.1-3.7$ \\
Geiseler (1996) & EAF & $3.2-3.8$ \\
Lee (1974) & - & $3.1-3.5$ \\
Luxan et al. (2000) & EAF & $3.1-3.4$ \\
Mahieux et al. (2009) & BOF & 3.3 \\
Manso et al. (2006) & EAF & $3.3-3.7$ \\
Mathur et al. (1999) & - & 3.22 \\
Motz and Geiseler (2001) & BOF & 3.3 \\
Motz and Geiseler (2001) & EAF & 3.5 \\
Noureldin and Mc Daniel (1990) & - & $3.2-3.6$ \\
Rohde et al. (2003) & EAF & $3.4-3.5$ \\
Shen et al. (2009) & BOF & $3.4-3.5$ \\
Wang (1992) & BOF & $3.1-3.3$ \\
Xue et al. (2006) & BOF & 3.3 \\
\hline
\end{tabular}

\subsubsection{Compaction Characteristics}

Compaction is the densification of soils through the expulsion of air from the soil mass under the application of mechanical energy (dynamic or static loads). Compaction improves the engineering properties of soils significantly. As a result of compaction, the permeability and compressibility of soils decrease substantially, and the shear strength increases. The compaction effort can be applied through rolling, tamping or vibration. There are several factors that affect the compaction characteristics of soils. The main factors include the type of soil, moisture content and the compaction effort. Laboratory compaction tests aim to determine the moisture-density relationship of soils. The coordinates of the peak point in the moisture-density relationship corresponds to the maximum dry density and the optimum moisture content. The compaction mechanisms 
for coarse grained and fine grained soils are different from each other (Foster 1962; Kim 2003).

When fine-grained soils are compacted in their dry state, soil particles can not easily achieve a dense state due to friction. As water is added to the soil mass and compaction is performed at low moisture contents, a thin water film is formed around the soil particles. These thin water films around the particles do not contribute to lubrication of particles. Addition of more water breaks these thin water films. Water then starts to act as a lubricant between the soil particles during compaction, facilitating the rearrangement of particles into denser states until the maximum dry density is achieved at the optimum moisture content. Beyond the optimum moisture content, water tends to separate and push the soil particles apart from each other rather than assisting them to come closer, and, accordingly, the soil dry unit weight values tend to drop. Therefore, the moisturedensity relationship for fine-grained soils typically has a single peak (Foster 1962).

In the case of free-draining coarse-grained soils (sand and gravels), the compaction mechanism tends to be different and more complex than that of fine-grained soils. At moisture content values in which the soil is partially saturated, surface tension forces develop between the particles. During compaction, these surface tension forces prevent the soil particles from moving closer. Therefore, the maximum dry unit weight is typically observed at the dry state for free-draining soils. Addition of water tends to decrease the compacted dry unit weight until the surface tension forces break. After the surface tension forces break, further addition of water facilitates lubrication of the particles, and, accordingly, the dry unit weight values start to increase, typically reaching a maximum at a fully-saturated state. This mechanism commonly seen in granular soils is referred to as the "bulking" phenomenon (Foster 1962; Lambe and Whitman 1972; Kim 2003). This type of compaction curves has been observed not only for natural soils and but also for other free-draining geo-materials such as bottom ash and slag (Evans 2007; Huang and Lovell 1990).

The shapes of compaction curves (moisture-density relation) for soils do not always necessarily fall into the two categories explained above. For some fine-grained and coarse-grained soils, somewhat irregularly-shaped compaction curves (with 1 and 1/2 
peak, 2 peaks, and without distinct peaks) were also observed in laboratory tests and field trials. Figure 3.2 shows the typical shapes of regular and irregular compaction curves observed for different soil types. Several researchers have investigated the causes of irregularly-shaped compaction curves and discussed the effects of gradation, Atterberg limits, particle shape, mineralogy and surface tension on these kinds of curves (Lee and Suedkamp 1972; Lee 1976). Studies in the literature have indicated similar irregular (oddly shaped) compaction curves for some blast-furnaces slags. The Pennsylvania Department of Transportation studied the compaction characteristics of granulated blastfurnace slags and observed oddly-shaped curves with 1 and 1/2 and 2 peaks (Lee and Suedkamp 1972; Lee 1976). Occasionally, compaction may result in a substantial change in the gradation of materials that degrade easily. This particle degradation during compaction can also cause irregularity in the moisture-density relationship. Therefore, it is important to quantify and determine the effect of particle degradation on the compaction characteristics of a material (Hale et al. 1981).

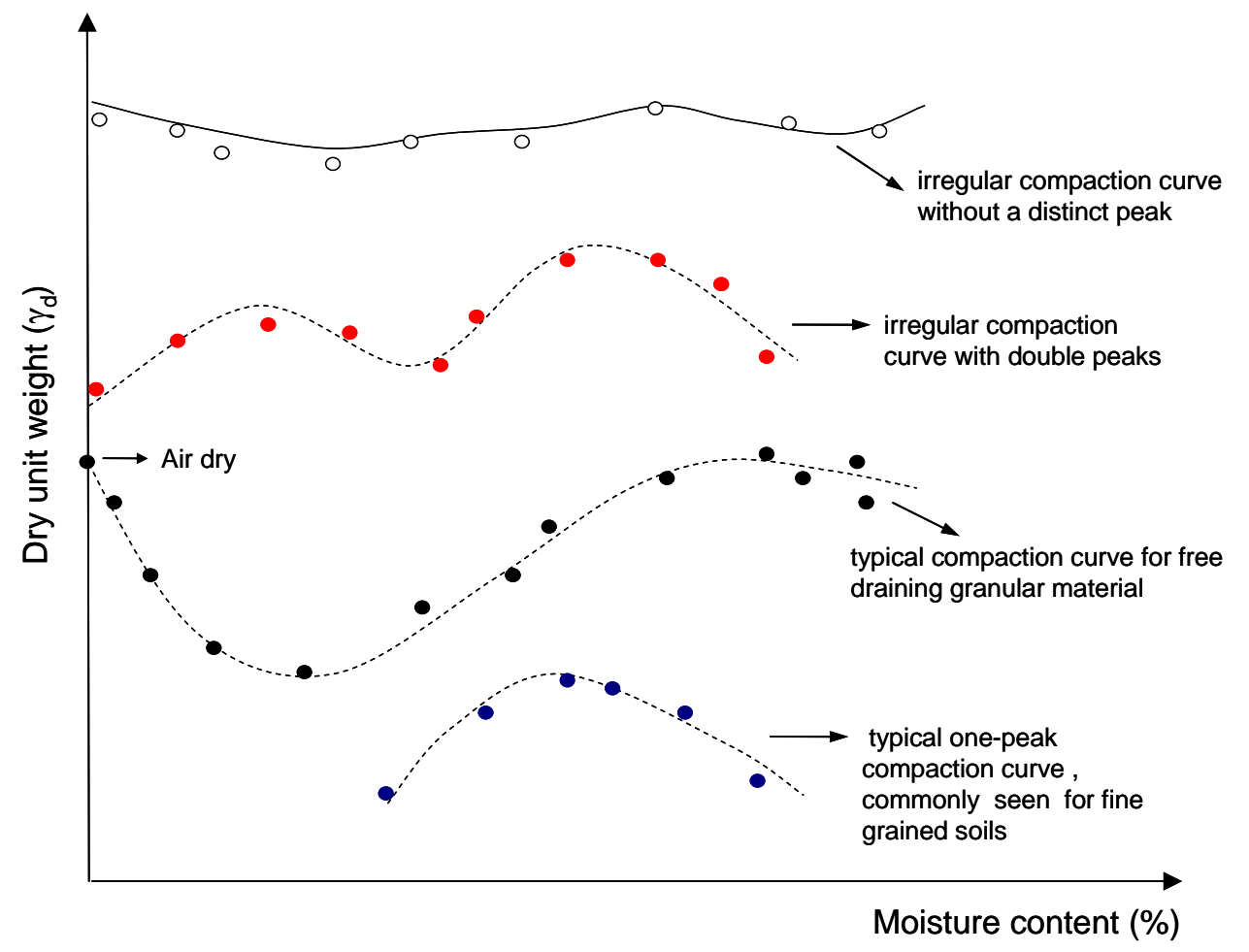

Figure 3.2 Typical shapes of regular and irregular compaction curves for different soil types (modified after Foster 1962; Lee and Suedkamp 1972) 
Even the fine gradations of steel slag typically have a significant percentage of gravelsize particles and can be classified as a coarse-grained material. Therefore, the characteristic compaction curves for steel slags are typically more similar to those of coarse-grained soils rather than those of fine-grained soils. Studies on the compaction characteristics of steel slag are very scarce since properties of steel slag have not been explored for geotechnical applications. Very few researchers studied the moisture-density relationships of steel slags. Based on laboratory compaction tests on steel slag (type of steel slag not specified) Ghionna et al. (1996) reported a maximum dry unit weight of 26 $\mathrm{kN} / \mathrm{m}^{3}$ and a corresponding optimum moisture content of approximately $4-6 \%$ The dry unit weight values measured in situ by these authors showed some scatter, with a mean value of $23 \mathrm{kN} / \mathrm{m}^{3}$. Raposo (2005) presented the compaction characteristics of BOF slag. The compaction curves showed irregular shapes with two smooth peaks with a maximum dry unit weight of $\sim 23-24 \mathrm{kN} / \mathrm{m}^{3}$ at moisture contents of approximately $4 \%$ and $12 \%$. Rohde et al. (2003) presented standard Proctor compaction tests results on EAF slag samples with different gradations; both regular (single-peak) and irregular compaction curves were observed for different gradations of EAF slag. Optimum moisture content and maximum dry unit weight of EAF slag samples were in the range of 3-6\% and 23$26 \mathrm{kN} / \mathrm{m}^{3}$. Andreas et al. (2005) presented the standard Proctor compaction test results on ladle slag-EAF slag mixture that contained 35\% EAF slag by weight. The dry unit weight and moisture content couples displayed a single peak compaction curve, with a maximum dry unit weight of $22 \mathrm{kN} / \mathrm{m}^{3}$ at approximately $13 \%$ moisture content. Due to its high specific gravity (typically above 3 ) and gradation (typically well-graded) the reported values for maximum dry unit weight of steel slags is higher than that of natural aggregates.

\subsubsection{Shear Strength}

Frictional soils subjected to confining stresses develop shear strength from particle friction, interlocking and rearrangement. Shear strength is a fundamental soil property that determines the capability of soils to resist loads. Shear strength of soil is influenced by many factors related to intrinsic soil properties, soil state and environmental 
conditions. Intrinsic soil properties are related to the nature and characteristic of soil particles (mineral composition, particle angularity, surface roughness, grain-size distribution, etc.). Soil state is the state at which a soil element exists. Factors related to soil state include relative density, stress state $\left(\sigma_{v}^{\prime}\right.$ and $\sigma_{h}^{\prime}$ ), soil fabric (particle arrangement) and inter particle cementation. Environmental factors include the loading path and moisture content. Typically, triaxial and direct shear tests are performed in the laboratory to determine the shear strength parameters of soils. From results of these laboratory tests, peak friction angles $\left(\phi_{p}\right)$ and critical-state friction angles $\left(\phi_{c}\right)$ can be obtained. The peak friction angle corresponds to the friction angle that is measured at the peak of a stress-strain curve, whereas the critical-state friction angle corresponds to the friction angle measured at an equilibrium state in which there is no longer sample volume change and the stress-strain curve reaches a plateau.

The peak behavior observed in a soil stress-strain curve is the result of dilatancy. Dilatancy is the tendency of particles to undergo volume increase due to climbing of particles over each other during shearing. Dilatancy is a function of both intrinsic soil properties and soil state. As an example, particle angularity is an intrinsic soil parameter that affects dilatancy. Angular soil particles tend to resist rearrangement more than rounded particles, increasing the dilatancy component of $\phi_{p}$. Factors related to soil state, such as relative density and confining stress applied on the soil mass, also influence dilatancy. The higher the relative density of the soil, the higher the tendency of the particles to dilate is. On the other hand, at high confining stresses, the tendency of soil particles to dilate is suppressed. Hence, peak friction angles tend to increase with increases in relative density and decreases in confining stress. The peak friction angle is not an intrinsic soil property of a material as it depends significantly on soil state.

As mentioned previously, the critical state corresponds to an equilibrium condition at which soil is sheared at constant stress, confining pressure and volume (at critical state, there is no need for dilation or contraction anymore). The critical-state friction angle $\phi_{c}$ is one of the most important shear strength parameters of soils as it 
depends solely on intrinsic soil properties. Unlike $\phi_{p}, \phi_{c}$ is not dependent on the factors related to soil state, such as confinement or relative density (Salgado 2008).

Steel slags have mineralogical composition different than that of natural soils. In addition to particle size, shape and texture, the types of minerals present in a given material have an impact on interparticle friction; this can be estimated from sliding of one sheet of mineral on another sheet of the same mineral. Interparticle friction affects both $\phi_{c}$ and $\phi_{p}$. Steel slag has higher interparticle friction than natural soils. Typically, steel slag has a well-graded grain-size distribution, with particle shapes varying from subrounded to angular. In addition, steel slag particles have very rough surfaces. For all these reasons compared to most natural sands, steel slags exhibit superior frictional properties. Well-documented experimental studies on determination of shear strength parameters of steel slags are scarce. A few researchers reported steel slag friction angles between $40^{\circ}$ and $50^{\circ}$ (Lee 1974; Noureldin and McDaniel 1990). However, these studies did not provide information on the gradation of the tested steel slag and on the experimental set-up used to obtain these values. Also, it is not specified if the values reported for friction angles are critical-state or peak friction angles. Well-documented experimental studies investigating the shear strength parameters of steel slags within the critical-state framework are needed.

\subsection{Swelling Phenomenon}

Due to the presence of unstable phases in its mineralogy, steel slags can show volumetric instability. The following expansive reactions were reported by several researchers as the causes of steel slag expansion:

- Expansion of free lime $(\mathrm{CaO})$

$$
\text { O } \mathrm{CaO}+\mathrm{H}_{2} \mathrm{O} \rightarrow \mathrm{Ca}(\mathrm{OH})_{2}
$$

- Expansion of free periclase $(\mathrm{MgO})$

$$
\text { - } \mathrm{MgO}+\mathrm{H}_{2} \mathrm{O} \rightarrow \mathrm{Mg}(\mathrm{OH})_{2}
$$

- Conversion of dicalciumsilicate $\left(\mathrm{C}_{2} \mathrm{~S}\right)$ 


$$
\text { O } \beta-C_{2} S \rightarrow \alpha-C_{2} S
$$

- Carbonation of $\mathrm{CaO}$ and $\mathrm{Mg}$ silicates

$$
\begin{array}{ll}
\mathrm{O} & \mathrm{Ca}(\mathrm{OH})_{2}+\mathrm{CO}_{2} \rightarrow \mathrm{CaCO}_{3}+\mathrm{H}_{2} \mathrm{O} \\
\mathrm{O} & \mathrm{Mg}(\mathrm{OH})_{2}+\mathrm{CO}_{2} \rightarrow \mathrm{MgCO}_{3}+\mathrm{H}_{2} \mathrm{O}
\end{array}
$$

- Oxidation of iron

According to the literature, the main cause of steel slag swelling is the presence of free $\mathrm{CaO}$ in its mineralogy. In the presence of water, free lime forms portlandite $\left(\mathrm{Ca}(\mathrm{OH})_{2}\right)$. Portlandide has a lower density than calcium oxide, and, hence, this reaction results in volume increase. There are two main sources for free lime in steel slags: 1) undissolved (residual) lumps originated from the raw material fed to the furnace, and 2) lime that is precipitated during the cooling process or during the conversion of $\mathrm{C}_{3} \mathrm{~S}$ to $\mathrm{C}_{2} \mathrm{~S}$. Ramachandran et al. (1964) studied the hydration mechanism of $\mathrm{CaO}$ and showed that when it is immersed in water, compacted $\mathrm{CaO}$ can hydrate almost completely in a few days with a volume increase as high as $100 \%$. This study has also demonstrated that hydration of free lime by exposure to water vapor causes more expansion than hydration caused by exposure to water due to the effect of temperature. The fact that lime hydrates fast suggests that during the slag weathering process, almost all of the lime in the slag would hydrate in a few days if it is given access to water. However, residual lime can be embedded in small pockets in gravel-size steel slag particles. Figure 3.3 shows a photograph of a BOF-type steel slag particle with a lime pocket (seen in white) buried inside the particle. Some of the lime pockets may not hydrate at all if they do not have access to water through the fractures extending to them. If there are fractures in the particles extending to these lime pockets, then hydration progresses. When hydrated, sometimes even a small lime pocket can open up a fracture extending across the entire particle, which might result in disproportionate expansion of the aggregate as a whole and, in some cases, disintegration of the particles. Contribution of residual lime to volume expansion of steel slag is generally higher than that of precipitated lime (Kneller et al. 1994; Juckes 2003; Shi 2004). 


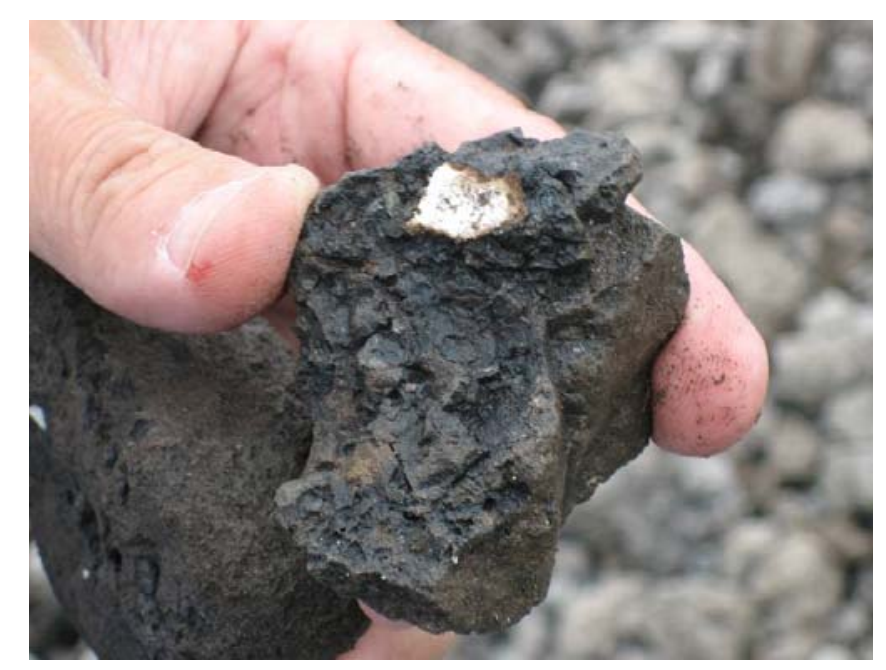

Figure 3.3 Gravel-size steel slag particle with a lime pocket (Photograph was taken at Mittal Steel, Indiana Harbor West Steel Plant)

Several studies have showed that the actual expansion of slag is more than the theoretical expansion calculated for the free lime content present in it; this suggests not only that disintegration of the slag particles occurs but also that other expansive compounds, such as $\mathrm{MgO}$, are present.. Unlike $\mathrm{CaO}$, free $\mathrm{MgO}$ hydrates at a much slower rate, causing significant volume changes for months or years. Crawford and Burn (1969) reported on a case history of a building damage observed 1 year after its construction due to expansive reactions that occurred in an open-hearth-furnace steel slag backfill. The long-term expansion of the backfill material was attributed to the high $\mathrm{MgO}$ content of the openhearth-furnace slag. Slags generated from modern steelmaking technologies generally have lower $\mathrm{MgO}$ content than open-hearth-furnace steel slags. However, if dolomite $\left(\mathrm{CaMg}\left(\mathrm{CO}_{3}\right)_{2}\right)$ is used as a fluxing agent instead of lime, the free $\mathrm{MgO}$ content in steel slag increases, and, therefore, the possibility of volumetric expansion of modern steelmaking slags should be considered as well. For this reason, Geiseler et al. (1994) classified the steelmaking slags based on their $\mathrm{MgO}$ content and suggested threshold values for the $\mathrm{MgO}$ content for different applications. All of the $\mathrm{MgO}$ content in steel slags is not free. $\mathrm{MgO}$ is also commonly present in solid solutions along with $\mathrm{FeO}$ and $\mathrm{MnO}$ (in the form of mix crystals). If the mix crystals in the solid solution have a $\mathrm{MgO}$ content higher than $40 \%$, they are capable of swelling as well. However, in most of the 
cases, these mix crystals are embedded in a more inert coat of other crystals with a lower $\mathrm{MgO}$ content and, hence, they are protected from hydration reactions. Therefore, the free $\mathrm{MgO}$ (periclase) content of steel slag is the main cause of long-term swelling rather than the solid solutions of $\mathrm{MgO}$ (Crawford and Burn 1969; Verhasselt and Choquet 1989; Geiseler 1994; Motz and Geiseler 2001; Juckes 2003).

Another reaction that causes volumetric expansion involves the dicalciumsilicate $\left(\mathrm{C}_{2} \mathrm{~S}\right)$ phase. The $\mathrm{C}_{2} \mathrm{~S}$ phase is commonly present in all types of steel slags and, in particular, is abundant typically as the main phase in ladle slags. $\mathrm{C}_{2} \mathrm{~S}$ exists in four welldefined polymorphs: $\alpha, \alpha, \beta$ and $\gamma \cdot \alpha-\mathrm{C}_{2} \mathrm{~S}$ is stable at high temperatures $\left(>630^{\circ} \mathrm{C}\right)$. When steel slag cools from high temperatures down to $630^{\circ} \mathrm{C}$, initially $\alpha-\mathrm{C}_{2} \mathrm{~S}$ converts to $\beta-\mathrm{C}_{2} \mathrm{~S}$. As cooling progresses, temperature further drops to $500^{\circ} \mathrm{C}$. At temperatures below $500^{\circ} \mathrm{C}$ $\beta-\mathrm{C}_{2} \mathrm{~S}$ starts transforming into $\gamma-\mathrm{C}_{2} \mathrm{~S}$. This transformation produces volumetric expansion of up to $10 \%$. If the steel slag cooling process is slow, crystals break, and this reaction results in a significant amount of dust. This phase conversion and associated dusting are very typical for ladle slags. For this reason, ladle slags are commonly called "self dusting" or "falling" slags. In BOF slags, the $\beta-\mathrm{C}_{2} \mathrm{~S}$ phase is observed to be more stable due to its phosphorus content (Shi 2002; Juckes 2003).

Oxidation and carbonation of steel slag can also be the cause of expansive reactions. If steel slag is weathered in open-air stockpiles, hydroxides of magnesium and calcium can carbonate by absorbing $\mathrm{CO}_{2}$ from the air. Carbonation has been observed under microscopy as crusts on outer surfaces of steel slag particles and as linings to fractures created during hydration. Carbonation reactions also contribute to swelling of steel slag. A similar expansive reaction is reported in the literature for iron oxide. $\mathrm{FeO}$ can oxidize leading to the formation of iron oxides $\left(\mathrm{Fe}_{2} \mathrm{O}_{3}, \mathrm{Fe}_{3} \mathrm{O}_{4}, \mathrm{Fe}(\mathrm{OH})_{2}\right)$. All of these reactions are expansive reactions. However, there is limited information in the literature about the magnitude of expansion resulting from these reactions. Compared to the swelling caused by hydration reactions, the contribution of carbonation and oxidizing reactions to swelling are likely to be negligible (Jukes 2003). 


\subsubsection{Factors Affecting Swelling}

There are several factors that determine the swelling characteristics of steel slag. The chemical composition and mineralogy of steel slag are the main factors that determine the degree of volumetric expansion, but gradation, degree of compaction, confinement and other environmental conditions also play important roles on the expansion potential.

Crawford and Burn (1969) summarized the factors that affect steel slag expansion: i) initial density, ii) confining pressure, iii) degree of saturation and iv) percentage of expansive compounds. Gradation and degree of compaction are important factors because they determine the porosity and, hence the degree of packing of particles within the steel slag matrix in unbound applications (embankment, road base, etc.). Particle packing is important because, in some cases expansion of individual fragments can be accommodated within the porosity of the compacted material. Confinement of the steel slag material tends to suppress volumetric expansion. In order to quantify the volumetric expansion of slag samples, gradation, weathering time, degree of compaction (maximum dry unit weight) and confining stress should be determined (Crawford and Burn 1969; Emery 1974; Juckes 2003; Rohde et al. 2003).

Environmental conditions, such as access to water, steam, heat, or/and pressure. also affect the rate of swelling. In order for swelling to initiate, steel slag particles need to have free access to some degree of moisture (that can be present in the form of water or steam). Compared to water, steam expedites the hydration of $\mathrm{CaO}$ and $\mathrm{MgO}$. Temperature and pressure also have a significant effect on the swelling rate. The swelling rate of steel slag increases with increases in temperature and pressure. The degree of steel slag swelling is also affected by the presence of salts and minerals in the water that reacts with the steel slag. The effect of water chemistry is expected to be marginal compared to other environmental factors (Ramachandran et al. 1964; Motz and Geiseler 2001; Juckes 2003).

\subsubsection{Swelling Tests}

In order to effectively utilize steel slag in both bound and unbound applications, it is important to assess its swelling potential. For this purpose, several swelling test methods 
have been developed and used to assess the expansion potential of steel slag. These test methods can be grouped into two main groups: i) long-term swelling tests and ii) accelerated swelling tests. In the long-term swelling tests, steel slag samples are typically immersed in water, and swelling is monitored at room temperature for a long period of time (a minimum of 3-6 months). In accelerated swelling tests, compacted steel slag samples are exposed to hot water or steam in order to accelerate the swelling rate, and swelling is monitored for a shorter period of time (typically ranging from 2 to 14 days). In both types of swelling test (long-term and accelerated) methods, steel slag samples are typically compacted in cylindrical molds, and the one-dimensional volume change of laterally constrained samples is measured. Both long-term and accelerated tests commonly used to assess the swelling behavior of steel slags are briefly described in the following.

\section{Long-term Swelling Tests (ASTM D1883)}

Several researchers have performed swelling tests on steel slag samples at room temperature to assess the rate of expansion (Crawford and Burn 1969; Juckes 2003; Poh et al. 2006). Different testing equipment and samples sizes have been used by different researchers, however, the principle of the test is the same for all the studies available in the literature. Samples are initially compacted to the desired dry unit weight in cylindrical molds of different sizes (5-cm-, 10-cm-, 15-cm-, 38-cm- diameter); typically the molds used for standard Proctor or CBR tests (ASTM D1883 recommends the use of the standard CBR mold). After sample preparation is completed, the samples are immersed in water tanks and maintained at room temperature with free access to water from both the top and bottom of the sample. One-dimensional swelling of the compacted slag samples is measured by LVDTs or dial gauges mounted at the top of the sample. Swell measurements are taken for a period varying from days to several months depending on the rate of swelling; specifically, for steel slag samples with free $\mathrm{MgO}$ content, the tests should be monitored for months as the conversion of $\mathrm{MgO}$ to periclase $\left(\mathrm{Mg}(\mathrm{OH})_{2}\right)$ takes place at a slow rate. For unbound applications, swelling tests performed at room temperature seems to represent the field conditions better than other swelling testing 
methods that involve application of high temperature or/and high pressure (ASTM D1883; Juckes 2003).

Water-Bath Swelling Test (ASTM D4792)

The test procedure described in ASTM D4792 (Standard Test Method for Potential Expansion of Aggregates from Hydration Reactions) was developed based on the test procedures developed by Emery (1974) and the Pennsylvania Test Method (PTM-130). In the U.S., this testing method is commonly used to measure the expansion of industrial by-products that are used as aggregates. In ASTM D4792, samples are compacted in standard CBR-molds that are equipped with dial gauges, following the same procedures described in ASTM 1883. In order to accelerate swelling, molds are placed in a hot-water bath maintained at a temperature of $70 \pm 3^{\circ} \mathrm{C}$ for 7 days. The rate of swelling usually stabilizes in a period of 7 days. However, if there is no pronounced decrease in the rate of swelling after 7 days, tests are continued for longer periods (up to 2 weeks) to obtain additional data. The percent expansion is calculated from each day's measurements; a graph of percent expansion versus elapsed time (in days) is then prepared once the test is completed (ASTM D4792; Emery 1974; Rohde et al. 2003).

\section{Autoclave Expansion Test (ASTM C151-05)}

The autoclave test is a very quick and common expansion test that uses both elevated temperature and pressure to accelerate expansive reactions. Aggregate samples are first compacted in molds, and initial sample height measurements are taken. Next, samples are placed in the autoclave machine and kept at a pressure of (2068 $\mathrm{kPa}) 300 \mathrm{psi}$ and at temperature of $420^{\circ} \mathrm{C}$ for 3 hours. After 3 hours, samples are cooled, and height measurements are taken again using a micrometer assembly. The percent expansion is calculated using the initial and final height measurements. Figure 3.4 (a) and (b) show the photographs of the autoclave machine and the mold with the dial gauge used for the swelling measurements, respectively. 

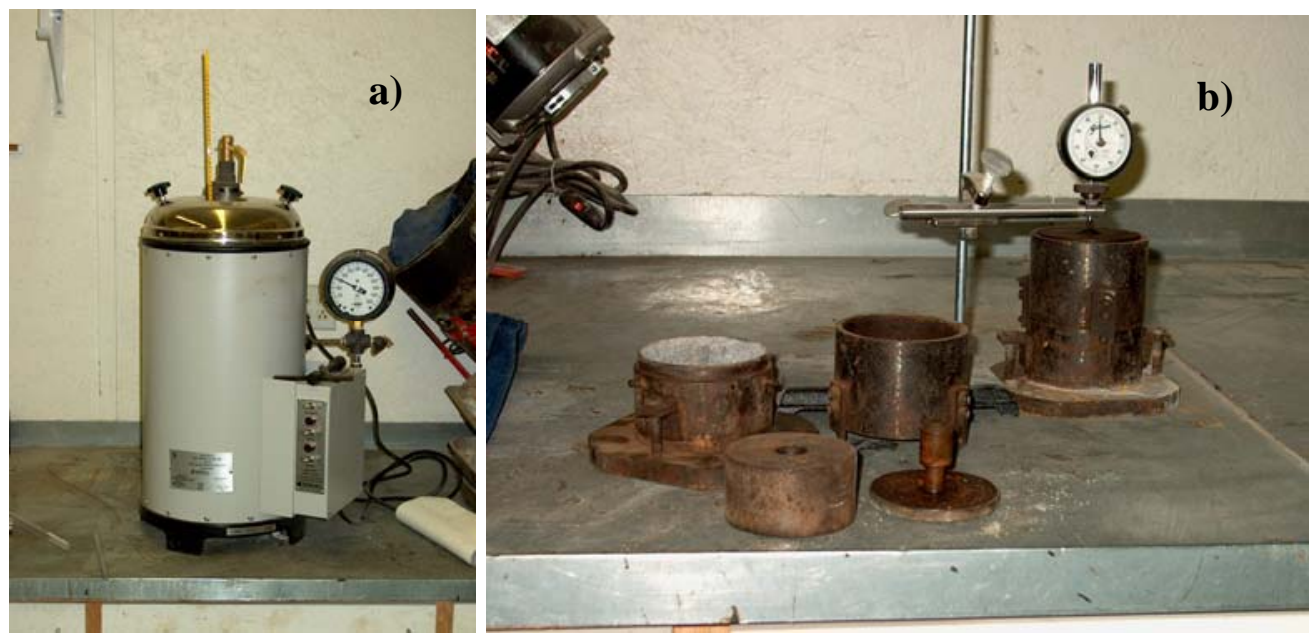

Figure 3.4 Autoclave expansion test assembly: (a) autoclave test machine (b) mold and dial gauge used for height measurements (courtesy of John Yzenas 2008)

In general, the expansion rate measured with the autoclave tests is typically 10 times higher than that obtained with the water-bath test procedure (ASTM D4792). The severe autoclave conditions imposed in this test can cause disintegration of the steel slag particles. For this reason, results obtained from this test do not correlate well with actual field performance. However, the autoclave test is advantageous because it provides results for volumetric stability and integrity of aggregates quickly (ASTM C151-03, Yzenas 2008).

\section{European Steam Test (EN 1744-1)}

The European steam test is an accelerated swelling test which is widely used in Europe to check the quality of steel slag used in aggregate applications. The method is incorporated in the British standard BS EN 1744-1:1998, "Tests for chemical properties of aggregateschemical analysis" that was published officially by the European Committee for Standardization (CEN) in 1998. According to this test procedure, a steel slag sample with a grain-size distribution in a given range (particle sizes ranging from 0 to $22 \mathrm{~mm}$ ) is compacted in a cylindrical mold of $21 \mathrm{~cm}(\sim 8 \mathrm{inch})$ in diameter and $10 \mathrm{~cm}(\sim 4 \mathrm{inch})$ in height. Next, a flow of steam at a temperature of about $100^{\circ} \mathrm{C}$ is applied to the compacted 
sample from the bottom in a steam unit. The expansion of the compacted sample is measured with a dial gauge located at the top of sample. Figure 3.5 shows a schematic representation of the apparatus used in the European steam test.

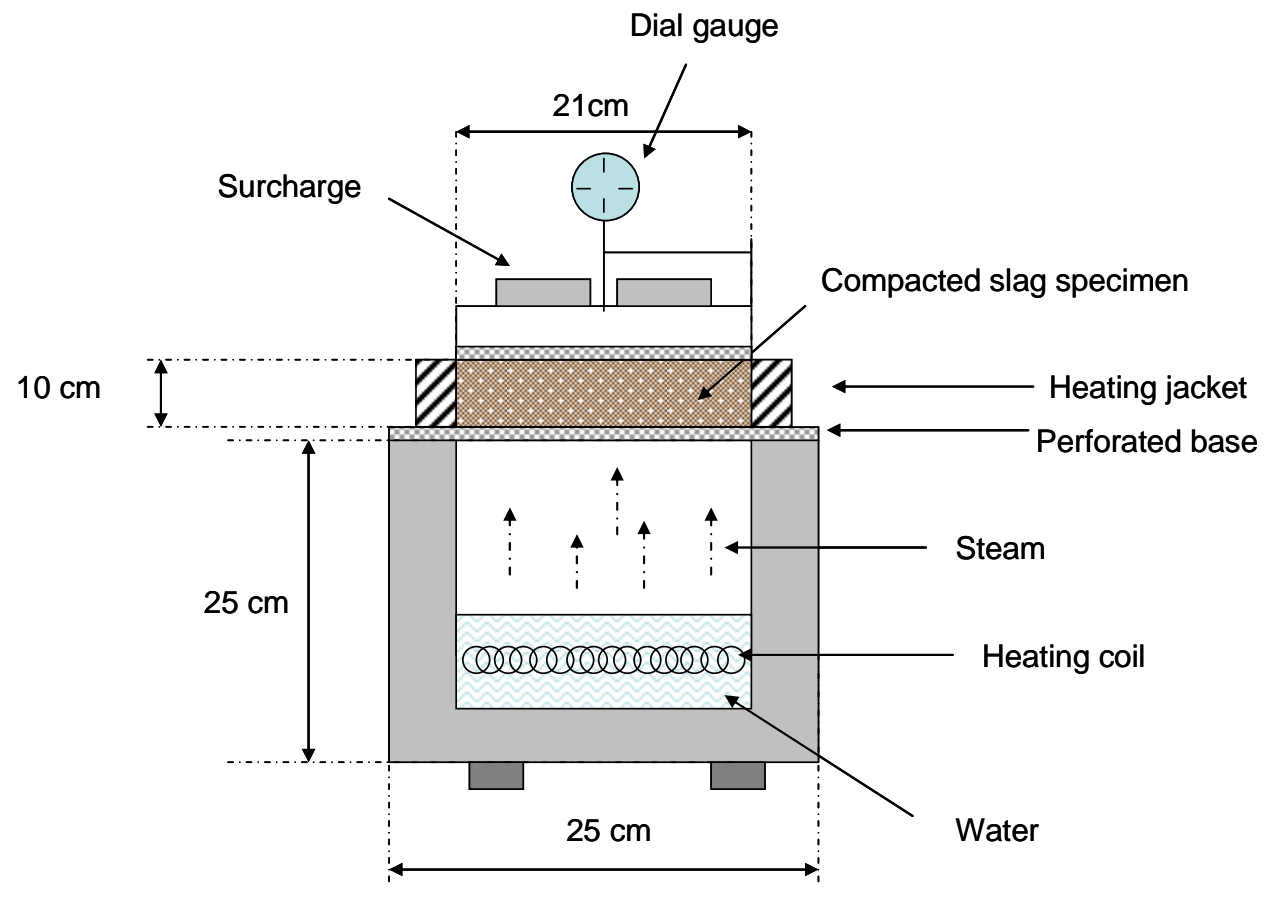

Figure 3.5 Schematic representation of steam test (BS EN 1744-1:1998)

The sample volume change typically stabilizes in $24 \mathrm{~h}$ to $168 \mathrm{~h}$, and the maximum expansion is recorded. Results of steam tests have shown that for BOF slag with an $\mathrm{MgO}$ content less than 5\%, a testing time of $24 \mathrm{~h}$ is sufficient (Motz and Geiseler 2001). EAF and BOF slags that have an $\mathrm{MgO}$ content higher than 5\% should be tested for $168 \mathrm{~h}$ since the hydration of $\mathrm{MgO}$ takes more time than that of free lime. The steam test procedure avoids some of the unrealistic test conditions present in the other test methods. For example, the steam test avoids the unrealistic conditions induced by high pressures in autoclave tests. In addition, the steam test also eliminates the wash off effects (dissolving of expansive compounds in water) that may be present in water-bath swelling tests. Swelling measurements from the steam test are expected to be higher than those of longterm tests. (BS EN 1744-1:1998; Motz and Geiseler 2001). 
Juckes et al. (2003) discussed the different types of expansion tests performed on steel slag and pointed out that the field performance of steel slag may be very different from that expected based on the results obtained from laboratory testing. Both long-term and accelerated swelling test methods have advantages and disadvantages associated with them. Short-term accelerated swelling tests are quick and provide the maximum expansion for a given steel slag sample. However, as the rate of swelling is expected to be much lower under ambient atmospheric conditions than that observed during the shortterm accelerated testing performed on slag samples in the laboratory, the expansion values measured in the field for unbound applications are likely to be much lower than that measured during laboratory testing. In contrast, long-term swelling tests can better simulate the in situ conditions and hence provide a more accurate swelling rate for unbound applications. However, long-term swelling tests require test monitoring for several months to be able to predict the swelling rate. We can take advantage of both testing procedures to assess the overall expansive behavior of the samples by determining the rate of swelling from long-term laboratory tests and coupling this rate with a limiting absolute volumetric strain (\%) obtained from the accelerated tests. In order to better correlate the results of laboratory testing with field performance it is essential to choose test methods and conditions that are consistent with the intended application for the steel slag. As an example, steam test procedure represents the field conditions better if the steel slag aggregate is used in bound asphalt pavements (Motz and Geiseler 2001; Juckes 2003). On the other hand, long-term swelling tests complemented with real scale field data seem to be the more appropriate to assess the swelling of steel slag used in unbound applications.

\subsubsection{Recommendations and Specifications for Steel Slag Swelling}

There is a definite lack of detailed experimental studies that determine the engineering properties of steel slag as it pertains to its swelling potential. Therefore, it is difficult to reconcile specifications for steel slag swelling. Each swelling test method provides a different maximum expansion value for the same steel slag. Hence, the limiting values of 
expansion that should not be exceeded for a specific application depends also on the type of swelling test performed. It is important to understand and choose the correct test method that best simulates the conditions of the intended application. Also, the long-term performance of infrastructure constructed with steel slag should be monitored. In the absence of these studies, it is difficult to establish quantitative measures that can be the basis for reliable swelling-related specifications for different steel slag applications. However, there are some studies in the literature that recommend limiting values on initial free $\mathrm{CaO}$ and $\mathrm{MgO}$ contents for steel slag to be used in bound or unbound applications. There are also some specifications and studies that provide limiting values of percent expansion based on test data obtained from certain swelling tests.

Crawford and Burn (1969) reported a case history of a concrete slab that was cast on a compacted fill containing a mixture of blast-furnace slag and open-hearth-furnace slag. Due to the expansive nature of this steel slag, $9 \%$ vertical volume change was observed 5 years after construction. At that time, since no test methods and specifications were available, use of fresh steel slag as backfill material was found to be indiscriminate, especially where long-term volume changes can not be tolerated.

Verhasselt and Choquet (1989) set a threshold value as $4.5 \%$ for free $\mathrm{CaO}$ (lime) content of steel slag aggregates to be used in unbound road layers; this value was later adopted in the specifications of the Belgian Roads Administration. They also recommended that the value of maximum permissible linear expansion (volumetric strain) be limited to $1 \%$ from accelerated water bath tests for safe use of steel slag in unbound applications. These researchers also suggested placing a sand layer between or on top of the unbound BOF slag layers. Voids in the sand layers can accommodate the swelling induced by the steel slag aggregates and, hence, potential damage to pavement structures is minimized. The thickness of the sand layer to accommodate swelling of steel slag in unbound applications depends on the thickness of the steel slag layer; however, a sand layer with a minimum thickness of $15-20 \mathrm{~cm}$ is recommended by these researchers. Field studies showed that swelling-related surface defects were totally eliminated on roads when 30-cm-thick layers of unbound sand were interposed between layers of a steel slag fill (Verhasselt and Choquet; 1989). 
Wang (1992) developed an empirical correlation between the free lime content and the expansion potential of steel slags . The study focused on unbound applications of steel slag and investigated whether the voids present in the granular media can absorb partially the volume expansion of steel slag aggregates used in unbound applications. Expansion tests were performed on two different types of steel slag. A surcharge of 2.5 $\mathrm{kPa}$ was applied on each sample. It was assumed that the volume steel slag expansion was solely due to the presence of free lime. The following empirical relation was derived

$$
F \leq \frac{(P)\left(\rho_{s}-\rho_{0}\right)}{0.383 \gamma_{s}^{2}}
$$

where $F$ is the initial free lime $(\mathrm{CaO})$ content in percentage, $\rho_{s}$ is the density of solids $\left(\mathrm{g} / \mathrm{cm}^{3}\right), \rho_{0}$ is the compacted bulk density of $\operatorname{slag}\left(\mathrm{g} / \mathrm{cm}^{3}\right)$, and $P$ is the porosity of the sample in percentage. This criterion shows that if the free $\mathrm{CaO}$ content is lower than the value calculated for the right hand term of Equation (3.1), then the voids in the compacted sample can accommodate the expansion of free lime, and the slag will not expand macroscopically if used in unbound applications. However, this expression has not been validated for all types of steel slag, and the relationship can vary depending on the surcharge load used in the tests and the physical properties of the steel slag. It should be noted that the contribution of $\mathrm{MgO}$ to swelling was neglected in this study (Wang 2002; Emery and Wang 2004).

Geiseler (1994) pointed out that for certain applications of steel slag there is no need for restriction on volume expansion. These applications include use of steel slag in unbound traffic roads, parking areas, and landscaping applications. According to this author, the free lime content of the steel slag can be used as the classification criterion, especially for fresh (not weathered in stockpiles) steel slags with low $\mathrm{MgO}$ content $(<5 \%)$ that will be used in unbound layers of roads. Geiseler (1994) also proposed limits of 7\% and $4 \%$ for the free lime content of fresh steel slag for use in unbound layers and in bituminous (asphaltic) road layers, respectively. 
There are a few setbacks in setting a limiting value only for the initial free lime content as a criterion for utilization of steel slag. First of all, size and nature of free-lime grains exerts a major effect on swelling of steel slag, and hence, similar initial free lime contents can lead to linear expansions varying by factors of 2 to 3 (Juckes 2003). In addition, a criterion based solely on the free lime content of the steel slag ignores the presence of free $\mathrm{MgO}$. Presence of $\mathrm{MgO}$ is a major concern for swelling of steel slags with high $\mathrm{MgO}$ contents (Motz and Geiseler 2001).

Motz and Geiseler (2001) suggested that a restriction on the free lime content of fresh steel slag samples with low $\mathrm{MgO}$ content is appropriate. However, for steel slags with high $\mathrm{MgO}$ content, determination of the free lime content is not sufficient for the assessment of their volume stability. As there is no reliable test method to determine the free $\mathrm{MgO}$ content of steel slags, the study suggested the use of the steam test for quality control of steel slags with high $\mathrm{MgO}$ contents. When steel slag is used as a bituminousbound aggregate, the binder protects the free lime and $\mathrm{MgO}$ from direct contact with water; however, the steel slag aggregates are still permeable to water vapor. For this reason, the steam test is commonly applied on steel slag aggregates that are used in asphalt layers. Steel slag aggregates can be categorized into four main groups (from VA to VD) according to the European standard TC 154 based on the percent expansion obtained with the steam test. Table 3.8 shows the European classification of steel slags based on the limiting maximum volume change values as determined from steam tests for both bound and unbound applications. Based on the German experience, steel slag aggregates are suitable for unbound layers and asphalt layers if they satisfy the requirements of group VA. In order to satisfy the criteria to be classified as Class VA, the maximum expansion of the steel slag samples should be limited to $3.5 \%$ for bituminous mixes and 5\% for unbound mixtures (the test takes $24 \mathrm{hr}$ test for steel slags with $\mathrm{MgO}<5 \%$ and $168 \mathrm{hr}$ test for steel slags with $\mathrm{MgO}>5 \%$ ). As field performance is crucial in the evaluation of steel slag for different applications, the European specifications define a separate group for steel slag that has been proven satisfactory based on field experience. Class $V_{D}$ covers the steel slags which have shown satisfactory performance, 
and, in this case, there is no need of performing tests to assess the the volume change behavior of this field-tested material.

Farrand and Emery (1995) indicated that the volume expansion of steel slag aggregates should be evaluated by performance-based tests rather than by chemical analysis and quality control measures are necessary to cover all aspects of steel slag aggregate production to make sure aggregates of suitable quality are delivered to the user.

Table 3.8 European aggregate specification for steel slag based on volume expansion from steam tests (Motz and Geiseler, 2001)

\begin{tabular}{|c|c|c|c|c|c|}
\hline \multirow[b]{2}{*}{ Type of slag } & \multirow{2}{*}{$\begin{array}{l}\mathrm{MgO} \\
\text { content }\end{array}$} & \multicolumn{2}{|c|}{ Limit max expansion by volume } & \multirow{2}{*}{$\begin{array}{c}\text { Testing time } \\
\text { (h) }\end{array}$} & \multirow[b]{2}{*}{ Category } \\
\hline & & $\begin{array}{c}\text { Aggregates for bound } \\
\text { mixes }\end{array}$ & $\begin{array}{l}\text { Aggregates for } \\
\text { un bound mixes }\end{array}$ & & \\
\hline $\mathrm{BOF} / \mathrm{EAF}$ slag & $\leq 5 \%$ & $3.5 \%$ & $5 \%$ & 24 & \multirow{2}{*}{$\mathrm{V}_{\mathrm{A}}$} \\
\hline BOF/EAF slag & $>5 \%$ & $3.5 \%$ & $5 \%$ & 168 & \\
\hline $\mathrm{BOF} / \mathrm{EAF}$ slag & $\leq 5 \%$ & $6.5 \%$ & $7.5 \%$ & 24 & \multirow{2}{*}{$\mathrm{V}_{\mathrm{B}}$} \\
\hline $\mathrm{BOF} / \mathrm{EAF}$ slag & $>5 \%$ & $6.5 \%$ & $7.5 \%$ & 168 & \\
\hline $\mathrm{BOF} / \mathrm{EAF}$ slag & $\leq 5 \%$ & $10 \%$ & $10 \%$ & 24 & \multirow{2}{*}{$\mathrm{V}_{\mathrm{C}}$} \\
\hline $\mathrm{BOF} / \mathrm{EAF}$ slag & $>5 \%$ & $10 \%$ & $10 \%$ & 168 & \\
\hline BOF/EAF slag & $\leq 5 \%$ & \multicolumn{3}{|c|}{ No requirement } & $\mathrm{V}_{\mathrm{D}}$ \\
\hline
\end{tabular}

The Edw. C. Levy Company has used the autoclave expansion tests for over 30 years to measure the expansion of steel slags. John Yzenas (2008) from Levy developed a scale to evaluate the suitability of steel slag for aggregate applications based on the autoclave test results. This scale used by Edw C. Levy Company is presented in Table 3.9.

A recent study by DePree and Ferry (2008) presented a case study in which mitigation strategies were developed in a redevelopment site underlain by over $1,000,000$ $\mathrm{m}^{3}$ of fill that contains significant amount of EAF and open-hearth-furnace slags. To mitigate swelling, non-slag fill zones (of $\sim 3-5 \mathrm{~m}$ in thickness) were placed beneath roadways under some lightly loaded structures and behind retaining walls to accommodate swelling. The study also indicated that excessive compaction of steel slag 
may be counter-productive as the resulting lower void ratios might lead to higher swelling.

Table 3.9 Volume change (based on autoclave) scale used by the Edw C. Levy Company to evaluate steel slag for aggregate applications (Yzenas 2008)

\begin{tabular}{cl}
$\begin{array}{c}\text { \% Expansion from } \\
\text { Autoclave Test }\end{array}$ & \multicolumn{1}{c}{ Shipping Guide :Material Suitability for Aggregate } \\
Applications
\end{tabular}

In the U.S., ASTM D2940 ("Standard Specification for Graded Aggregate Material for Bases or Subbases for Highways or Airports") covers the swelling criterion for steel slags for aggregate applications. This standard defines suitable aggregates as “Aggregates that contain components subject to hydration, such as steel slags, shall be obtained from sources approved by the engineer on the basis of either a satisfactory performance record, or of aging or other treatment known to reduce potential expansion to a satisfactory level, or of expansion values not greater than $0.50 \%$ at seven days when tested in accordance with Test Method D4792". ASTM D2940 sets the expansion limit at 0.5\% for water bath swelling tests performed in accordance with ASTM D4792. 


\subsection{Utilization of Steel Slag}

Research that focuses on engineering properties of steel slags is scarce. The case histories available in the literature detailing some of the unsuccessful attempts of using steel slag seem to have decreased the confidence level in promoting its utilization for various applications. Therefore, in comparison to other recyclable materials, such as flyash, bottom-ash, tire shreds, cement kiln dust or foundry sand, steel slag is underutilized. Several researches have summarized the main applications for steel slag (Geiseler 1994; Proctor et al. 2000; Shen and Forssberg 2003, Dippenaar 2004). The reported applications of steel slag from the literature include:

Civil engineering applications:

- Cement production

- Concrete aggregate

- Asphalt aggregate

- Road bases and sub-bases

- Soil stabilization

Miscellaneous applications:

- Steelmaking

- Fertilizer production

- Linings for waterways

- Landfill daily covers

- Railroad ballast

- Miscellaneous environmental applications

Some portion of the steel slag is utilized in miscellaneous applications. As an example, a significant portion of BOF slag is recycled in the steelmaking process as a direct charge into the blast furnace or basic-oxygen furnace. Topkaya et al. (2004) studied the effects of BOF slag charging into blast and basic-oxygen furnaces on the operation and efficiency of the furnaces. Another application of steel slag is as a soil fertilizer. Steel 
slags (BOF slag, EAF slag and ladle slag) contain high phosphorous contents $\left(\mathrm{P}_{2} \mathrm{O}_{5}>4 \%\right)$ and thus have been used as a soil fertilizer. However, the decrease in the phosphorus content of modern steelmaking slags has limited this application in recent times. In Europe, coarse steel slag aggregate has also been used as a liner for waterways in road construction and as railroad ballast (Lee 1974; Geiseler 1994). In the U.S., a minor percentage of the excess steel slag is used in the construction of daily covers for landfills. Steel slag has also been used in the brick making industry (Shih et al. 2004).

Several studies in the literature focused on possible environmental applications for steel slag. These applications include use of slags in acid mine drainages as neutralizers, constructed wetlands and filter beds as a solution for phosphate removal, soil aquifer treatments for organic and inorganic substance removal (Sakadevan and Bavor 1998; Ziemkiewicz 1998; Cha et al. 2006; Jha et al. 2004; Drizo et al. 2006; Xue et al. 2009). Several researchers have also studied the environmental use of steel slag in carbon sequestration for calcium carbonate production (Huijgen et al. 2005; Teir et al. 2007; Stolaroff et al. 2005).

A significant percentage of steel slag that has been generated is utilized in civil engineering applications. The main civil engineering applications of steel slag can be divided into three main categories based on their use: 1) cement and concrete industry, 2) road construction, and 3) geotechnical applications, such as embankment construction and soil stabilization. The documented studies on these applications are briefly summarized in the following sections.

\subsubsection{Use of Steel Slag in the Cement and Concrete Industry}

Most of the experimental studies on steel slag focus on its applications in the cement and concrete industry. The cement and concrete industry utilizes steel slag in two major applications, either as a concrete aggregate or in the manufacture of cement.

Many publications are available in the literature focusing on the chemistry and hydraulic reactivity of different types of steel slags for their use as a hydraulic binder (Murphy et al. 1997; Luxan et al. 2000; Shi 2002; Rojas and Rojas 2000; Reddy et al. 2006). Steel slag can be incorporated in cement manufacturing in two different ways. 
Firstly, steel slag is used as a raw material for cement clinker; hence it is calcined in the kiln together with other raw materials. Secondly, it is grounded and blended with ready clinker as a cement additive (Wang 1992).

Several researchers focused on the utilization of steel slag as a raw material for cement clinker. Tsakiridis et al. (2008) showed that the addition of $10.5 \%$ steel slag (by weight) in the clinker raw material did not affect the sintering or hydration process of the resulting cement. The setting time, water demand, and expansion behavior of the resulting cement were found to be similar to those of ordinary Portland cement. Renfrew and Perkins (2004) carried out a study in a California-based cement plant where steel slag was added to the clinker manufacturing line. This study indicated that due to the steel slag chemical composition and the nature of its generation (the high temperatures used in the steel furnaces), compared to other raw materials, steel slag requires less fuel consumption for its conversion to cement clinker. Since 2002, the California-based cement plant maintained a slag utilization rate of $7 \%$ percent of the clinker produced, with a $5 \%$ increase in production rate and a decrease in fuel consumption (Renfrew and Perkins 2004).

Several researchers studied the use of steel slag as a cement additive (Conjeaud et al. 1981; Tufekci et al. 1997; Murphy et al. 1997; Altun and Yilmaz 2002; Qian et al. 2002a). These experimental studies have proved that different types of steel slag can be blended with cement (up to $20-45 \%$ by weight) and used as a partial replacement for cement without significantly affecting the strength and performance of the resulting cement. Xuequan et al. (1999) produced a new kind of composite cement made of clinker, steel slag and fly ash. Mahieux et al. (2009) developed a mixture of groundgranulated blast-furnace slag, weathered BOF slag and a catalyst for using as a hydraulic road binder.

Properties of concretes incorporating steel slag aggregate have been investigated by several researchers (Montgomery and Wang 1992; Maslehuddin et al. 2003; Manso et al. 2004; Anastasiou and Papayianni 2006; Manso et al. 2006; Patel 2006). Results presented by Manso et al. (2004) and Manso et al. (2006) showed that despite a slight reduction in their durability, the strength of concrete incorporating EAF slag aggregate is 
similar to the strength of concretes incorporating natural aggregates. Qasrawi et al. (2009) also showed that when fine natural aggregates in concrete mixes are replaced with 30$50 \%$ (by weight) of fine steel slag aggregate (with low $\mathrm{CaO}$ content), both compressive and tensile strength of concrete improved. Since steel slag is heavier than natural aggregates, concrete produced using steel slag aggregate is typically heavier than concrete prepared using natural aggregates.

Several researchers also indicated the importance of proper processing sequence. Crushing, homogenizing, weathering, and proper aging processes are required for steel slag to be used as a concrete aggregate. The expansive characteristics of steel slag should also be assessed prior to using it as a concrete aggregate since it can be detrimental to concrete structures (Manso et al. 2004; Manso et al. 2006; Patel 2006).

\subsubsection{Use of Steel Slag in Road Applications}

Steel slags have been utilized successfully both as bound and unbound layers of pavement structures. Steel slag is used as aggregate either in bound surface layers of pavements or in unbound sub-base or base layers of roads.

Several studies in the literature have shown the satisfactory performance of steel slag when used in road bases and sub-bases. Rohde et al. (2003) have investigated the use of weathered EAF slag as a base material for low-volume roads. The study concluded that the resilient modulus of EAF slag is much higher than that of natural aggregates, and in addition, that the use of EAF slag as a base material in low-volume roads can substantially lower the overall cost of roads. Aiban (2006) showed that road bases that incorporate mixtures of steel slag and natural aggregates (marl and sand) with $30 \%$ to $85 \%$ steel slag by weight exhibit satisfactory CBR values (as high as $455 \%$ ). Mixing of steel slag with other materials (fly ash, cement, blast furnace slag, etc.) was also investigated by several researchers for use as road base material. Mathur et al. (1999) studied the performance of mixtures of blast-furnace slag, weathered steel slag, granulated slag, fly ash and lime for use in sub-base or base course layers of low-volume traffic roads as a substitute for naturally available aggregates. Pamukcu and Tuncan (1993) evaluated the properties of cement-stabilized steel slag aggregate used as sub-base 
and base layers. The study showed that steel slag mixtures exhibited strength values comparable to that of natural aggregates stabilized with cement. Kamon et al. (1993) showed that when treated with kaolinite and CAS (Carbonated-Alumina Salts), EAF slag (obtained from stainless steel production), showed strong strength gain behavior and hence a potential use as subbase. Shen et al. (2009) investigated the properties of a mixture of steel slag, fly ash and phosphogypusm for road-base applications. The longterm shear strength values and water stability indices measured for this mixture were much higher than those of cement-stabilized granular materials. Mymrin et al. (2005) showed that use of cement-activated steel slag and natural soil mixtures as road base layers can lower road construction cost because of the decrease in the road base layer thickness.

There has been extensive research in the past decade focusing on the suitability of steel slags both as a coarse and a fine aggregate in asphalt mixes. Despite some unsuccessful case histories, the studies available in the literature are in agreement that steel slag aggregates (both from EAF and BOF processes) can be utilized in asphalt mixes if proper quality control measures are taken to ensure their volume stability. Steel slag aggregate used in asphalt mixes should have uniform density and quality (Farrand and Emery 1995; Bagampadde et al. 1999; Xue et al. 2006; Wu et al. 2007). Several researchers have indicated that the expansive nature of steel slag can be controlled by the asphalt content. Increasing the asphalt content can aid in the formation of a coating around the steel slag particles, preventing water access to expansive compounds. Based on results of expansion tests performed in accordance with PTM-130, Kandhal and Hoffman (1997) showed that there is no correlation between the content of fine steel slag aggregate in asphalt mixtures and the hot-mix expansion. This is probably due to the fact that the aggregates are very well coated with asphalt (Kandhal and Hoffman 1997).

Skid resistance is a measure of the minimum force at which a tire prevented from rotation slides on the pavement surface. Development of sufficient skid resistance is an important requirement of road safety. In this regard, steel slag is a favorable aggregate for bound asphalt applications as steel slag aggregates are angular and have a very rough surface texture. Therefore, pavement surfaces incorporating steel slag have shown 
superior skid characteristics than asphalt surfaces incorporating natural aggregates (Stock et al. 2006; Asi 2007). Two recent studies by Shen et al. (2009), and Ahmedzade and Sengoz (2009) proposed the use of BOF slag as coarse aggregate in asphalt mixes. Experimental results from these studies have shown satisfactory engineering properties of steel slags, such as high Marshal stability, low abrasion, high skid resistance and high rutting resistance. Wu et al. (2007) studied the use of a porous EAF slag aggregate in asphalt mixes and indicated that the use of EAF slag aggregate aged for 3 years in preparing stone-mastic asphalt mixtures is promising. Test roads incorporating EAF slag continued to show excellent performance after 2 years in service (Wu et al. 2007).

\subsubsection{Use of Steel Slag in Geotechnical Applications}

Studies evaluating the geotechnical properties of steel slag are very limited. This may be due to the undesirable properties of steel slag, that is, its volume instability and high specific gravity. However, steel slags possess other very favorable properties (selfcementation, high friction angle, etc.), and a few studies in the literature have shown promising applications of steel slags and indicated the potential for using steel slags in geotechnical applications.

Pamukcu and Tuncan (1993) showed that mixtures of cement, lime, fly ash and steel slag have satisfactory unconfined compression strength after curing. The study indicated that it is viable to use steel slag mixtures as pavement subgrades. Bock and Bergh (2004) presented the results of a case study in Belgium; in this case study, a hydraulic bound mixture containing 78\% EAF slag (0-20mm size range), 18\% natural sand and $4 \%$ cement (by weight) was used as the foundation layer of a large industrial storage area. Barra et al. (2001) studied blending of EAF slag (0-5mm size range, with $\mathrm{MgO} \leq 5 \%$ ) with cement-stabilized soils. A clayey soil common in Barcelona stabilized with $8-12 \%$ cement by weight was blended with EAF slag in different proportions in order to improve its strength. Due to the superior mechanical properties of EAF slag and the bonding effect created by its reaction with water, a significant improvement in strength was observed in the stabilized soil. This study also showed that the use of steel slag in soil stabilization projects can substantially reduce the cost due to the reduced need 
of cement. Poh et al. (2006) showed that there is potential in utilizing BOF slag fines in stabilization of fine-grained soils when activators are used. Ghionna et al. (1996) studied the possibility of using steel slag as structural fill material in landfill embankments. A trial embankment was constructed with steel slag. The study indicated that diluting steel slag with inert materials, such as gravel and sand, can reduce the swelling potential. Plate load tests performed on the embankment showed satisfactory elastic modulus values (as high as $55 \mathrm{MPa})$.

\subsection{Environmental Issues Associated with Steel Slag}

There are several environmental issues associated with the use of steel slag in civil engineering applications. The main environmental concerns related to the use of steel slag include:

- heavy metal concentration

- corrosivity

- carbonation potential

\subsubsection{Leaching}

Steel slags contain heavy metals (antimony, arsenic, barium, beryllium, cadmium, chromium, cobalt, copper, lead, mercury, nickel, selenium, thallium, vanadium, etc.) at concentrations higher than those in most soils. Even though these metals are available as minor constituents of steel slag, possible leaching of these heavy metals into groundwater have prevented the use of steel slags in various civil engineering applications (Fallman 1999; Proctor et al. 2000).

Proctor et al. (2000) studied the chemical properties and leaching potential of blast-furnace, basic-oxygen-furnace and electric-arc-furnace slag samples collected from 58 active mills, accounting for more than $47 \%$ of the steel production in North America. Steel slag samples with different aggregate sizes were crushed and combined together to obtain homogenous samples from each source. The data obtained from this very comprehensive study have been analyzed using statistical methods, and human and 
environmental health risk assessment studies were performed. The United States Environmental Protection Agency (EPA) tests procedures were applied to compare the heavy metal concentration of steel slag to background concentrations of these metals in soils. In order to evaluate the leaching of heavy metals from steel slag, steel slag samples were tested in accordance with the Toxicity Leaching Procedure (TCLP). Even though the background concentrations of metals were much higher in steel slag than in natural soils, the TCLP test results indicated that none of the steel slag samples exceeded the EPA standards for hazardous materials. None of the slag types that were tested for the maximum concentrations of the contaminants measured in the leachates have exceeded the limiting values for drinking water standards. These positive results were attributed to the fact that the metals are tightly bound in steel slag and are not released easily even under acidic conditions. It was concluded that the slag leachates are unlikely to cause groundwater contamination at a level that exceeds the drinking water standards (Proctor et al. 2000). Several other studies focused on leaching of the most common heavy metals, such as chromium, vanadium and barium, from steel slag (Fallman 1999; Lind et al. 2001; Chaurand et al. 2006; Chaurand et al. 2007). Chaurand et al. (2006) showed that use of BOF slag aggregate in road construction may result in a significant release of vanadium. Study by Macsik and Jacobsson (1996) suggested that due to chemical stabilization, the release of contaminants decrease when BOF slag is used as a mechanical stabilizing agent in cement-stabilized soils.

Several researchers studied the hydrology and geochemistry of aquifers that are affected by mineral precipitation from steel slag layers at disposal sites in Indiana. Most of the trace elements in the groundwater were below the reported contaminant limits. The most common solid precipitates were calcite, dolomite, iron-oxide and gypsum. The studies on the precipitates of steel slag indicated that sequestration of heavy metals (trace elements) in the solid precipitates increase at high-pH environments. There is still need for research to assess the chemical properties of solid precipitates from steel slag and their solubility potential (Bayless et al. 1998, Bayless and Schultz 2003; Mayes et al. 2008). 
Steel slag leachates are also characterized by their high alkalinity. Elevated $\mathrm{pH}$ values were observed in slag leachates and also in groundwater affected by steel slag disposal sites. $\mathrm{pH}$ levels are elevated in steel slag affected waters, mainly due to the leaching of alkaline substances from steel slag into the water. Therefore the effect of changes in $\mathrm{pH}$ on the ecosystem in the vicinity of slag disposal sites should be evaluated with caution (Yan et al.1998; Bayless and Schulz 2003; Roadcap et al. 2005, Mayes et al. 2006).

\subsubsection{Corrosion}

The deterioration or disintegration of a material by a chemical or electrochemical reaction with its environment is defined as corrosion. Metals loose electrons when they react with water and oxygen, leading to the occurrence of corrosion. The electrochemical corrosion reaction involves an anode and a cathode. At the anode, positively charged metal ions are formed, whereas negatively charged hydroxyl ions are formed from dissolved oxygen at the cathode. Flow of electricity between these two charged ends can be generated on a single metallic surface or between dissimilar metals. Due to microscopic cracks or impurities, there are numerous sites available on the surface of metals that facilitate the flow of the ions leading to corrosion.

Corrosion of a metal is affected by the properties of the surrounding environment. The corrosivity of a soil is its tendency to facilitate corrosive reactions in a metal it is in contact with. Corrosivity of a soil is a function of its $\mathrm{pH}$, electrical conductivity, oxygen concentration, moisture content, chemical composition, density and organic material content. One of the main factors that affect corrosion is the electrical conductivity of soils. The corrosion potential increases with increasing electrical conductivity. Typically, the presence of soluble salts in soils increases the electrical conductivity, whereas air voids decrease the electrical conductivity. $\mathrm{pH}$ is another factor that determines the corrosivity of soils. Scully (1990) presented a relation between the rate of corrosion and the $\mathrm{pH}$ of the surrounding environment (see Figure 3.6). The graph implies that the rate of corrosion is low in neutral environments, whereas both very acidic and alkaline environments tend to increase the rate of corrosion. 
As a result of the basic constituents in the chemical composition of steel slag and its electrical conductivity, steel slag tends to show higher corrosivity than natural soils. Especially when steel slag is used in unbound applications (embankment, road bases, etc.), the corrosion potential of steel slag should be evaluated carefully. If the steel slag shows corrosive properties, metal structures that are in contact with steel slag should be constructed with special care and proper precautions should be taken. Use of galvanized steel pipes is one of the most common and effective ways of corrosion protection (Scully 1990; NSA 172-13).

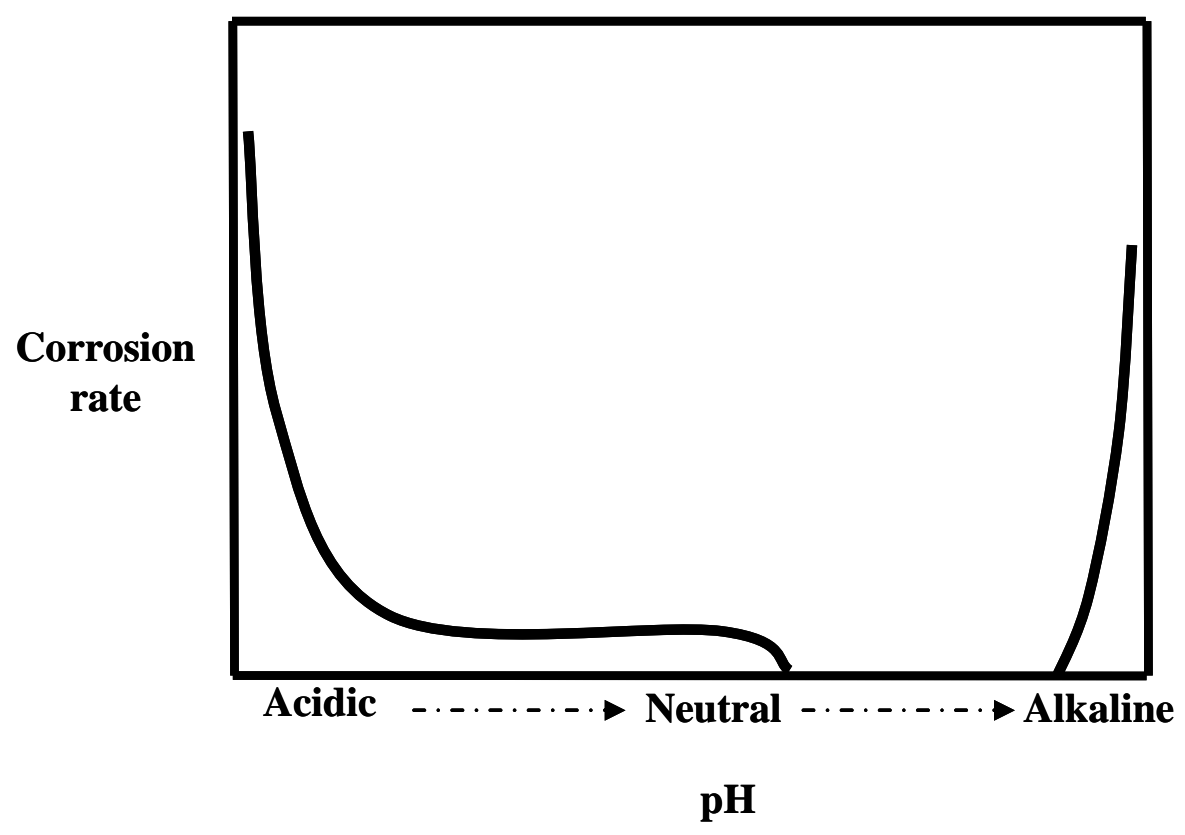

Figure 3.6 Rate of corrosion versus pH (modified after Scully 1990)

\subsubsection{Tufa Precipitation}

During the aging (weathering) process, $\mathrm{CaO}$ and $\mathrm{MgO}$ hydrates to form $\mathrm{Ca}(\mathrm{OH})_{2}$ and $\mathrm{Mg}(\mathrm{OH})_{2}$. If exposed, along with alkaline silicates of $\mathrm{Ca}$ and $\mathrm{Mg}$ in the steel slag, these hydrated compounds can react with carbon dioxide $\left(\mathrm{CO}_{2}\right)$ from the atmosphere and/or automobile exhausts during aging in stockpiles. This $\mathrm{CO}_{2}$ sequestration reaction is known as "carbonation". The carbonation behavior of steel slag has been addressed by several researchers (Johnson 2000; Monkman and Shao 2006; Huijgen et al. 2005; Lekakh et al. 2008). The major carbonation reactions can be summarized as follows: 


$$
\begin{array}{cl}
\mathrm{O} & (\mathrm{Ca}, \mathrm{Mg}) \mathrm{SiO}_{3}+\mathrm{CO}_{2} \rightarrow(\mathrm{Ca}, \mathrm{Mg}) \mathrm{CO}_{3}+\mathrm{SiO}_{2} \\
\mathrm{o} & \mathrm{Ca}(\mathrm{OH})_{2}+\mathrm{CO}_{2}+\mathrm{H}_{2} \mathrm{O} \rightarrow \mathrm{CaCO}_{3}+2 \mathrm{H}_{2} \mathrm{O} \\
\mathrm{O} & \mathrm{Mg}(\mathrm{OH})_{2}+\mathrm{CO}_{2}+\mathrm{H}_{2} \mathrm{O} \rightarrow \mathrm{MgCO}_{3}+2 \mathrm{H}_{2} \mathrm{O}
\end{array}
$$

A few case studies have addressed the presence of tufa-like materials clogging pavement drains in roads which incorporate steel slag as road base or sub-base. Tufa precipitation is the outcome of steel slag carbonation reactions that occurs under the pavement surface. High concentrations of carbon dioxide $\left(\mathrm{CO}_{2}\right)$ in the atmosphere or from automobile exhaust react with rainwater to form carbonic acid $\left(\mathrm{H}_{2} \mathrm{CO}_{3}\right)$. This carbonic acid reacts with the hydrated lime $\left(\mathrm{Ca}(\mathrm{OH})_{2}\right)$ in the drain water to form calcium bicarbonate $\left(\mathrm{Ca}\left(\mathrm{HCO}_{3}\right)_{2}\right)$, which is more soluble in water. As water evaporates from the solution, calcium carbonate $\left(\mathrm{CaCO}_{3}\right)$ precipitates. Gupta et al. (1994) explained the tufa precipitation with the following reactions:

$$
\begin{array}{ll}
\mathrm{o} & \mathrm{CaO}+\mathrm{H}_{2} \mathrm{O} \rightarrow \mathrm{Ca}(\mathrm{OH})_{2} \\
\mathrm{o} & \mathrm{CO}_{2}+\mathrm{H}_{2} \mathrm{O} \leftrightarrow \mathrm{H}_{2} \mathrm{CO}_{3} \\
\mathrm{o} & 2 \mathrm{H}_{2} \mathrm{CO}_{3}+\mathrm{Ca}(\mathrm{OH})_{2} \leftrightarrow \mathrm{Ca}\left(\mathrm{HCO}_{3}\right)_{2}+2 \mathrm{H}_{2} \mathrm{O} \\
\mathrm{o} & \mathrm{Ca}\left(\mathrm{HCO}_{3}\right)_{2} \leftrightarrow \mathrm{CaCO}_{2}(\downarrow)+\mathrm{H}_{2} \mathrm{O}(\uparrow)+\mathrm{CO}_{2}(\uparrow)
\end{array}
$$

A few researchers presented findings from case studies in which tufa precipitation was observed in roads constructed with steel slag aggregate. These studies showed that the amount of tufa precipitated from steel slag depends on the free lime content, size, surface area, pore size distribution, porosity and the degree of aging of steel slag aggregates. Tufa-forming reactions indicate that the carbon dioxide concentration, temperature and humidity control the rate of tufa precipitation in drains and basins of highways. At cold temperatures, carbon dioxide tends to remain in solution. Therefore, the rate of tufa precipitation is typically higher in the summer months. It is recommended to age steel slag properly in stockpiles to eliminate or at least reduce the possibility of formation of tufa (Boyer 1994; Gupta et al. 1994). 


\subsection{Summary}

This chapter summarizes the engineering properties of steel slag. The environmental issues associated with the use of steel slag are also presented at the end of the chapter. The chemical composition and engineering properties of steel slag differ substantially from those of blast-furnace slag. Typically, steel slag has a very crystalline structure and a complex mineralogical composition. Some of the constituents in the steel slag mineralogy can cause volumetric instability. Several expansion test procedures were developed to test the expansive nature of steel slags. Data on the mechanical properties of steel slag is scarce in the literature. The main civil engineering applications of steel slag include its use in the cement and concrete industry and in road construction. Research on geotechnical applications of steel slag is very limited. The main environmental issues associated with the use of steel slags are leaching, carbonation and corrosion. 


\section{CHAPTER 4. EXPERIMENTAL PROGRAM}

\subsection{Introduction}

Determination of the engineering properties of steel slags is necessary in the development of design guidelines for use of steel slags in various applications. However, very limited information is available in the literature on the physical and mechanical properties of steel slags. The experimental program of the present research was designed to fill this knowledge gap in the literature. The major objective of the experimental program was to thoroughly investigate the engineering properties of BOF and EAF (L) slags in order to explore new applications where these materials can be utilized as a geo material. Firstly, experiments were performed to determine their index, mineralogical, morphological and mechanical properties. Next, long-term swelling tests were performed on steel slag samples to evaluate their long-term swelling behavior. In addition, corrosivity and leaching tests were also performed to evaluate the environmental effects of using steel slag in geotechnical applications. To enhance the engineering properties of these materials, steel slag samples were mixed with other recyclable materials, such as Class-C fly ash and ground-rubber. Several tests were performed on mixtures of steel slag and Class-C fly ash and on mixtures of steel slag and ground-rubber. A brief outline of the experimental program is presented in Table 4.1. 
Table 4.1 Outline of the experimental program

\begin{tabular}{c|c}
\hline \multicolumn{2}{c}{ Experimental Program } \\
\hline \hline Properties & Experiments \\
\hline Index & Grain-size distribution \\
Soil classification \\
Specific gravity
\end{tabular}

This chapter focuses on the testing materials, experimental equipment and experimental procedures followed in this research. In the beginning of the chapter, different types of steel slag samples tested in this research and their sources are briefly presented. Materials used in preparing the mixtures of steel slag and recyclable materials are presented in this 
section as well. Next, the experimental testing procedure and testing equipment used for each test in the experimental program are described in detail.

\subsection{Testing Materials}

Two types of steel slag generated from two separate steelmaking processes were tested in this research. The two main types of steel slag tested in this study are:

1. Basic-oxygen-furnace (BOF) slag

2. Electric-arc-furnace-ladle $(\mathrm{EAF}(\mathrm{L}))$ slag

\subsubsection{BOF slag}

Mittal Steel, Indiana Harbour Works West Plant, which is located in Highland, IN (east of Chicago, on the south shore of Michigan Lake), is the source plant for the BOF slag used in this research. This plant is one of the largest integrated steel mills of this region. Figure 4.1 shows the location of the source plant. At this plant, which has a gross annual capacity of 3.5 million tons, two basic-oxygen furnaces operate continuously to produce liquid steel. Lime is used as the fluxing agent in this plant, and the amount of slag generated is approximately $12 \%$ of the total steel output. BOF slag processing operations are performed by Multiserv Ltd., Harsco Corporation at Indiana Harbour Works West Plant. Multiserv has its own processing unit associated within this facility. BOF slag is cooled down slowly in the pits by spraying water. Next, the cooled BOF slag goes through metal recovery and screening processes, as detailed in Chapter 2 . The processed steel slag is stockpiled in the processing plant according to three different particle size ranges. These particle size ranges are shown in Figure 4.2. 


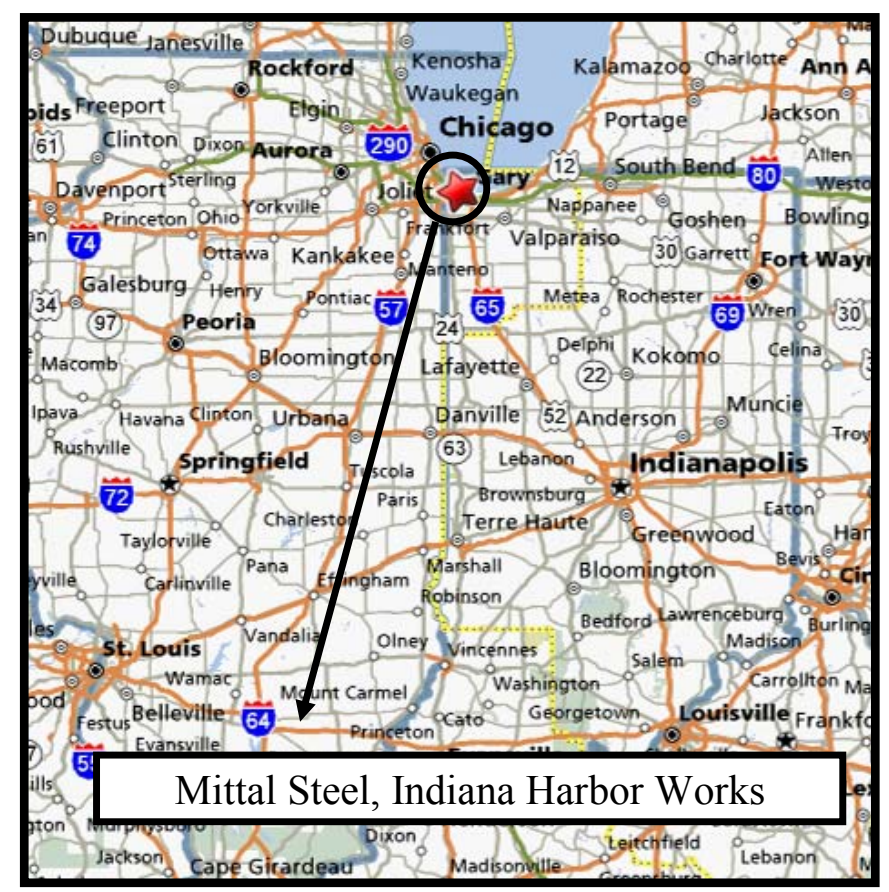

Figure 4.1.Location of the source plant for BOF slag
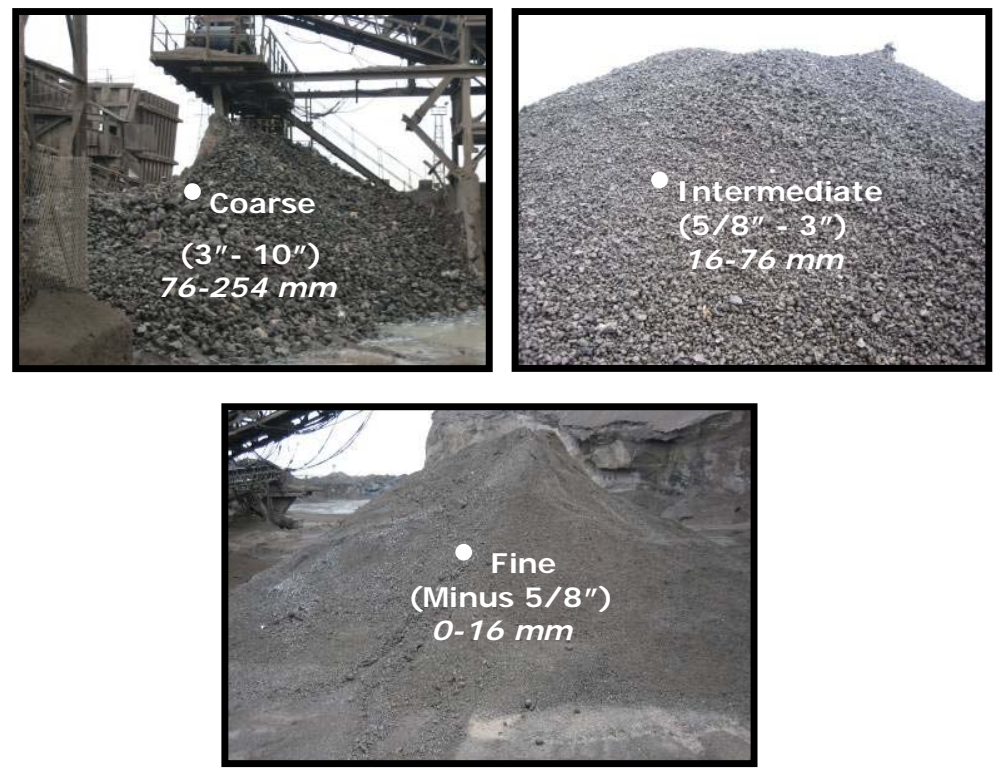

Figure 4.2. BOF slag screened into three size ranges at the processing plant 
This research focused on the underutilized fine gradation of steel slag with particle sizes smaller than $16 \mathrm{~mm}$ (minus $\sim 5 / 8 \mathrm{inch}$ ). Multiserv provided representative (minus $16 \mathrm{~mm}$ ) BOF slag samples from three different batches of production. This allowed an assessment of the variability in slag generation from batch-to-batch and an evaluation of the effect of minor changes in gradation on the resulting mechanical properties of BOF steel slag. Furthermore, both fresh and aged BOF steel slag samples were also supplied by Multiserv such that the affect of aging on swelling mitigation could be investigated. Each batch was named from 1 to 3 (Batch-1, Batch-2, and Batch-3) based on their order of arrival to Purdue: November 2006, October 2007 and December 2007, respectively. The initial batch (Batch-1) consisted of fresh BOF slag samples obtained in two 55 gallon barrels. The second batch (Batch-2) consisted of one aged BOF slag sample and one fresh BOF slag sample; each sample was received in a 55 gallon barrel. The third batch had two 55 gallon barrels of aged BOF slag samples. Even though all the batches of BOF slag samples contained particles sizes smaller than $16 \mathrm{~mm}$, small variations in the grain-size distributions of these samples were observed from one batch to another. Hence, the grain-size distribution associated with each batch is presented in this report. A representative BOF slag sample from the first batch is shown in Figure 4.3.

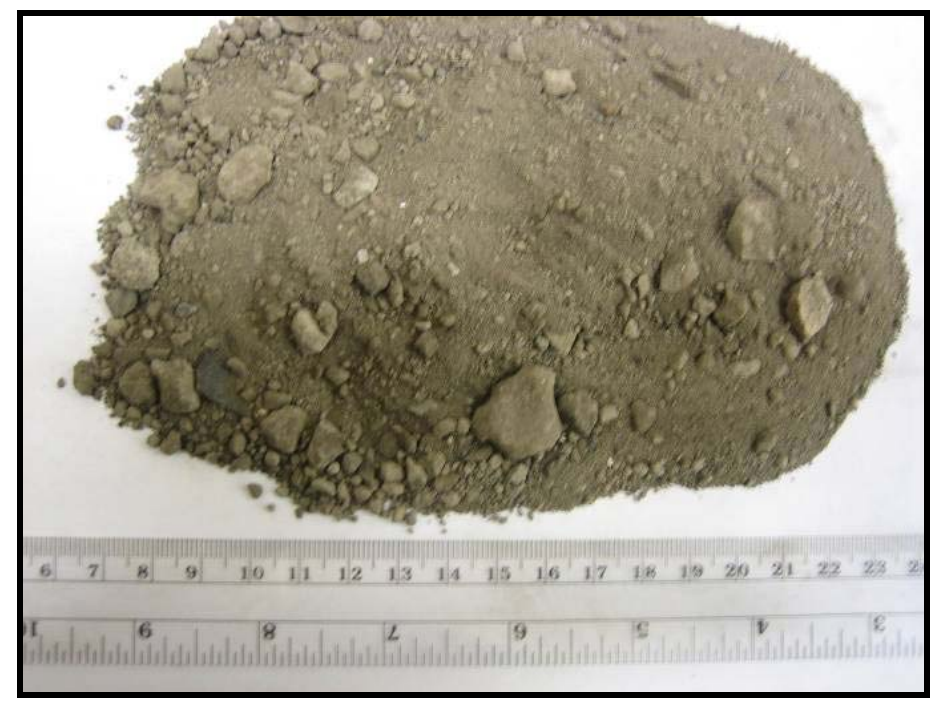

Figure 4.3 Representative BOF slag sample from Indiana Harbor Works Plant 
In summary, four different batches of BOF slag were tested in this research. The fresh and aged batches of BOF slag are categorized and named as:

- Batch-1 Fresh BOF slag (B-1 Fresh BOF slag)

- Batch-2 Fresh BOF slag (B-2 Fresh BOF slag)

- Batch-2 Aged BOF slag (B-2 Aged BOF slag)

- Batch-3 Aged BOF slag (B-3 Aged BOF slag)

\subsection{2. $\mathrm{EAF}(\mathrm{L})$ Slag}

The Whitesville Steel Mill at Nucor Steel, which is located in Crawfordsville, Indiana, is the source for the EAF (L) slag samples used in this study. Figure 4.4 shows the location of the plant. The Whitesville mill operates two electric-arc furnaces, with a steel production capacity of approximately 40,000 ton per week. The steel generated from the electric-arc-furnace process goes to a ladle refining unit. The EAF (L) slag generated from this refining process is cooled down under ambient air conditions. Figure 4.5(a) and (b) show photographs of EAF(L)slag being poured into the pit and its solidification, respectively. The solidified $\mathrm{EAF}(\mathrm{L})$ slag undergoes magnetic separation, and primary and secondary crushing and sizing. The slag is then stockpiled in the plant according to three to four different size ranges.

The Edw. C. Levy Co., which operates at the Whitesville Mill, handles and processes both electric-arc-furnace slag and ladle slag. The EAF ladle slag generated at the Whitesville Mill is the second testing material for this research. This slag is referred to as $\operatorname{EAF}(\mathrm{L})$ slag, as it is the ladle slag generated from the refining of the steel from the electric-arc furnace. Edward C. Levy Co. provided representative EAF (L) slag samples (consisting of particles smaller than $9.5 \mathrm{~mm}$ ) used in this research. The first batch of fresh EAF (L) slag samples was received in November 2006, and the second batch of EAF(L) slag samples was received in October 2007. The second batch consisted of both fresh and 
aged $\mathrm{EAF}(\mathrm{L})$ slag samples (aged for one month). All the tests were performed on fresh EAF(L) slag samples from the first and second batches. EAF(L) slag samples aged for one month were only used for performing swelling tests. Figure 4.6 show a photograph of a representative EAF (L) slag sample received from the Whitesville Mill. EAF(L) slag samples tested in this research are categorized as follows:

- Batch-1 (B-1) Fresh EAF(L) slag

- Batch-2 (B-2) Fresh EAF(L) slag

- Batch-2 (B-2) Aged EAF(L) slag

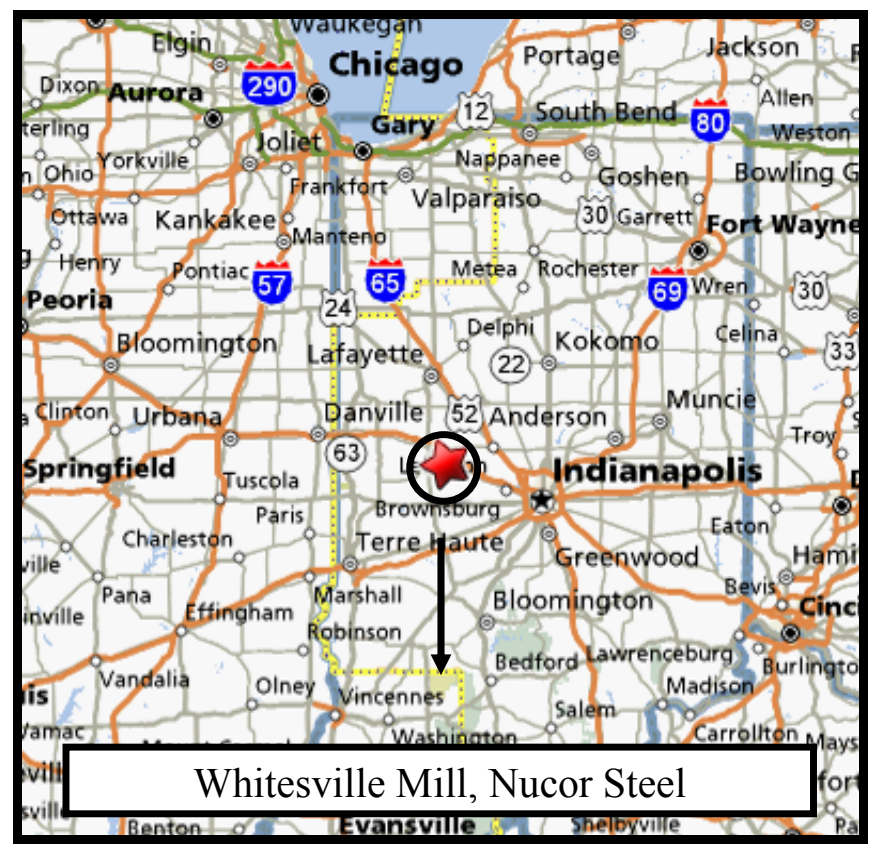

Figure 4.4 Location of the source plant for EAF (L) slag 


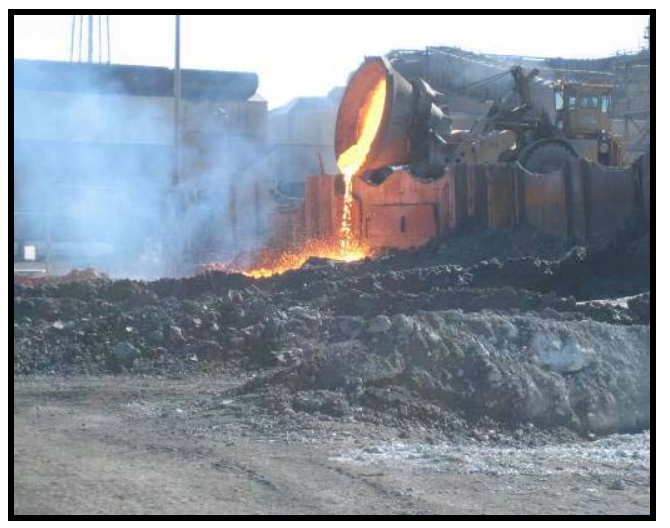

(a)

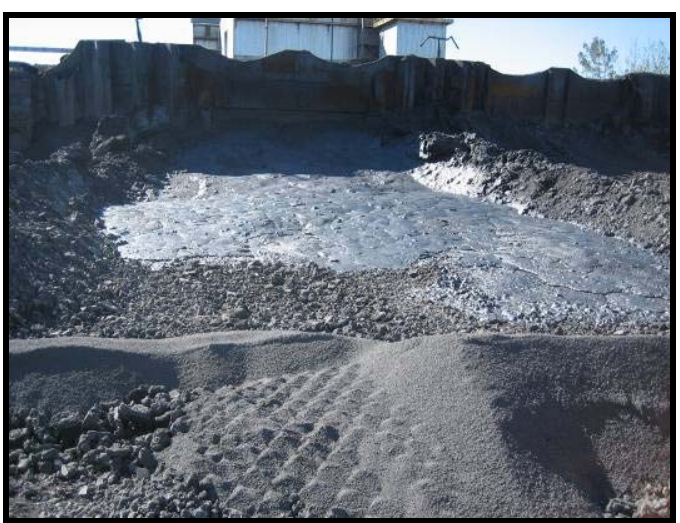

(b)

Figure 4.5 Cooling of EAF (L) slag: (a) EAF(L) slag being poured into the pits, and b) Solidified EAF (L) slag (Photographs taken at the Whitesville Mill)

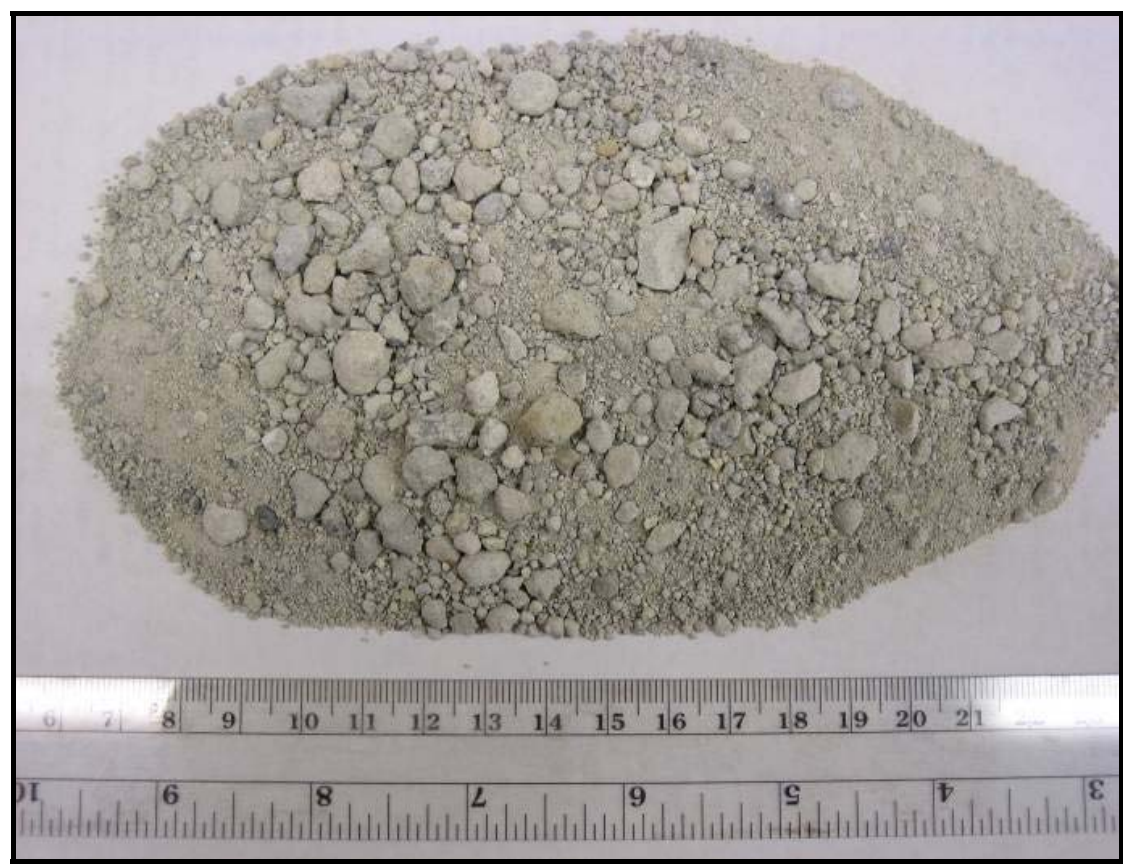

Figure 4.6 Representative EAF(L) slag sample from the Whitesville Mill

\subsubsection{Materials used in Mixtures}

The effectiveness of mixtures of either Class-C fly ash or ground-rubber with steel slag (both BOF and $\mathrm{EAF}(\mathrm{L})$ slag) in not only improving the mechanical properties and but also in mitigating the swelling of steel slag was also investigated in this research. The 
compaction characteristics, the rate of unconfined compressive strength gain and the swelling behavior of Class-C fly ash and steel slag mixtures were evaluated. The effect of adding ground-rubber to steel slag in suppressing the swelling response of steel slag was also assessed. The fly ash and ground-rubber used in the mixtures are presented next.

\section{Class-C Fly ash}

Fly ash is a coal combustion by-product that is generated in large quantities in power plants. Fly ash is classified as Class-C or Class-F based on the quality of the coal burned. When older, harder bituminous coal or anthracite is used, Class-F fly ash is generated, whereas Class-C fly ash is generated when younger, lighter lignite or sub bituminous coal is burned. Class-C fly ash has a higher free lime $(\mathrm{CaO})$ content than Class-F fly ash, and, for this reason, unlike Class-F fly ash, it possesses self-cementing properties. Fly ash can be classified as Class- $\mathrm{C}$ or Class-F based on their chemical composition, as specified in ASTM C618.

Even though BOF and $\mathrm{EAF}(\mathrm{L})$ slags have a high $\mathrm{CaO}$ content, only a small percentage of the $\mathrm{CaO}$ is free to react with silica $\left(\mathrm{SiO}_{2}\right)$ to form cementitious compounds. Furthermore, steel slag lacks the glassy silica phase that is required for pozzolanic reactions to occur. One of the main chemical constituent of Class-C fly ash is silica $\left(\mathrm{SiO}_{2}\right)$. In addition, Class-C fly ash also contains reactive free lime. Therefore, Class-C fly ash can be an activator for cementitious reactions to occur in steel slags.

In this research, steel slag and Class-C fly ash mixtures were tested for their compaction and strength gain characteristics. The effects of Class-C fly ash addition on the swelling potential of $\mathrm{BOF}$ and $\mathrm{EAF}(\mathrm{L})$ slags were also investigated. NIPSCO (Northern Indiana Public Service Company) provided the Class-C fly ash samples. Figure 4.7 shows a representative sample of the Class-C fly ash used in this study. 


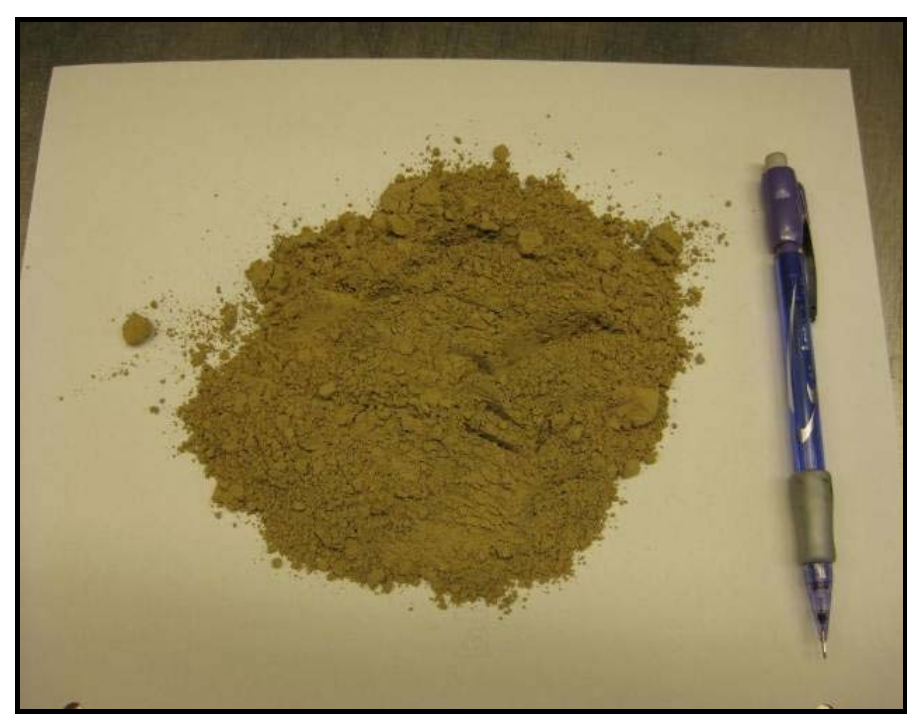

Figure 4.7 Class-C fly ash from NIPSCO Company, IN.

\section{Ground rubber}

Every year a large number of waste tires are generated in the U.S. Problems related to the disposal of tires have created a significant need for their beneficial utilization. Typically, tires are shredded into various sizes for use in different applications. There are several companies operating in many states that handle tire shredding operations. The size of tire pieces can range from large shreds to rubber dust.

Due to its incompressible properties, tire rubber dust has shown potential in mitigating swelling of expansive clays (Seda et al. 2007). In this research, the effect of ground rubber addition on the swelling potential of BOF slag was investigated. Rubber Mulch Products Company, IN supplied the ground-rubber (with particle sizes ranging between $0.85 \mathrm{~mm}$ and $2 \mathrm{~mm}$ ). Figure 4.8 shows a photograph of a representative sample of the ground rubber used in this study. 


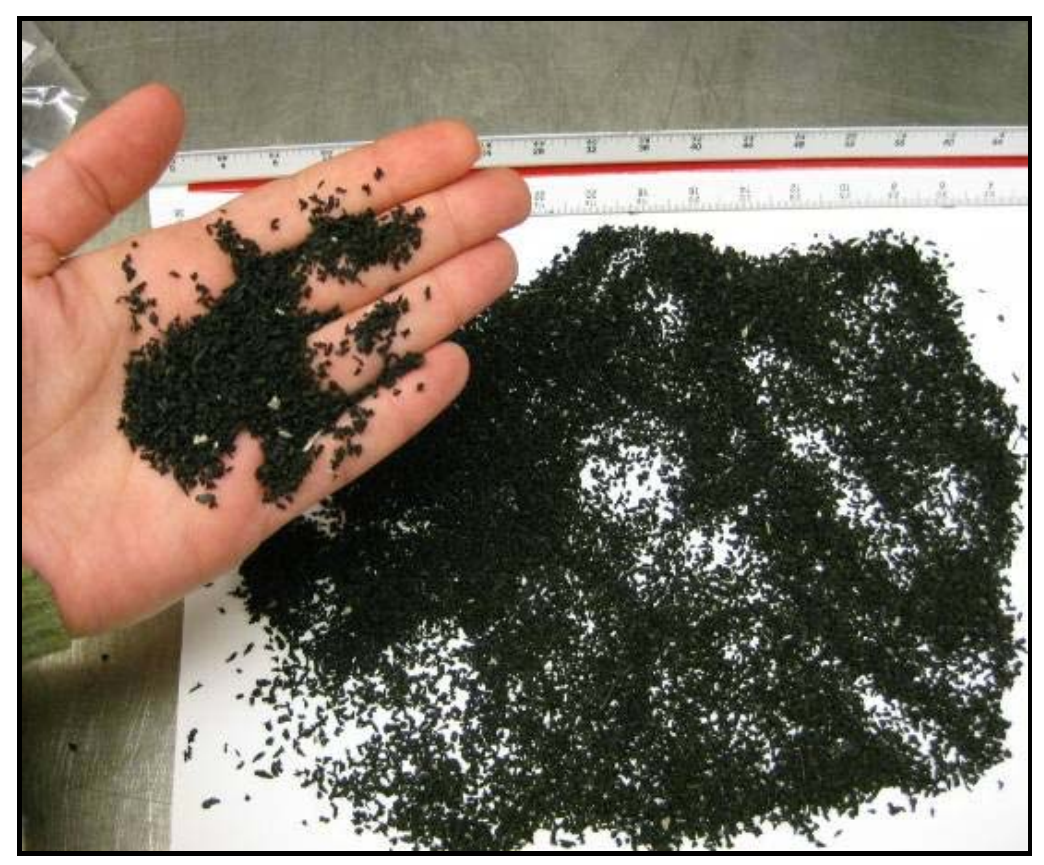

Figure 4.8 Ground rubber (10/20) from Rubber Mulch Products, IN

\subsubsection{Representative Sampling}

The slag processing companies supplied representative steel slag samples from both fresh and aged stockpiles. The steel slag samples were received in 55 gallon barrels. In order to obtain representative samples from these barrels, the procedures outlined in ASTM C70298 (Standard Practice for Reducing Samples of Aggregate to Testing Size) were followed. Figure 4.9 shows the main steps involved in obtaining representative samples from the barrels. The steel slag received in each barrel was initially dumped onto a large tarp sheet. The steel slag sample was then mixed thoroughly to eliminate the effect of possible segregation that may have occurred during transportation. Next, the steel slag was distributed on the tarp, and the quartering technique was then used to obtain smaller representative samples. The representative samples were stored in air-tight buckets for later testing. 

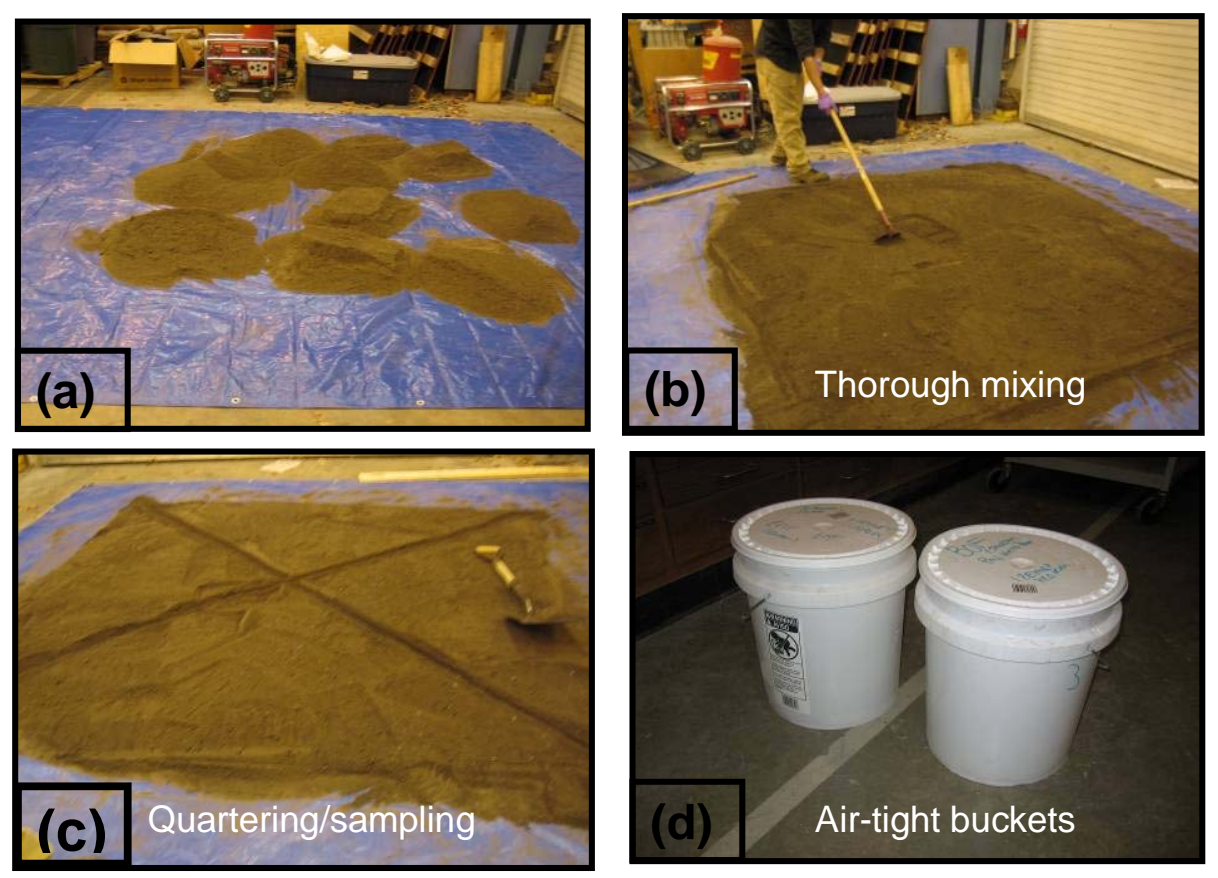

Figure 4.9 Representative steel slag samples: (a) spreading of steel slag on tarp (b) thorough mixing (c) quartering (d) storing in air-tight buckets

When smaller quantities of soil samples were required for testing, a soil splitter was used for obtaining representative samples from the air-tight buckets. A soil splitter can split a quantity of steel slag into two identical gradations. By repeating the splitting method for each gradation, smaller quantities of representative samples were obtained when required. Figure 4.10 shows the soil splitter used in the laboratory for sampling of BOF and $\mathrm{EAF}(\mathrm{L})$ slag from the buckets. In this manner, steel slag samples were reduced to representative testing sizes. 


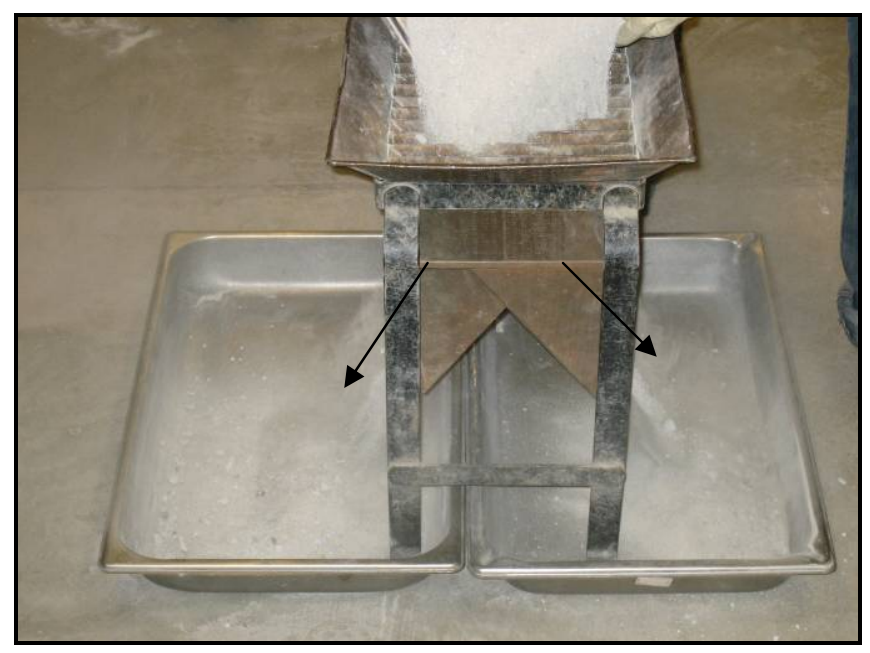

Figure 4.10 Reducing steel slag samples to smaller representative quantities using a soil splitter

\subsection{Index Properties}

Grain-size distribution analysis and specific gravity tests were performed for both the BOF and EAF(L) slags. Atterberg limit tests were also performed on the fine gradation of each sample. BOF and $\operatorname{EAF}(\mathrm{L})$ slags were classified based on the Unified Soil Classification (USCS) and American Association of State Highway and Transportation Officials (AASHTO) soil classification systems. The details of these tests are provided next.

\subsubsection{Grain-Size Analysis}

The grain-size distributions of $\mathrm{BOF}$ and $\mathrm{EAF}(\mathrm{L})$ slags were determined in accordance with ASTM D422-63, which is the standard method for particle-size analysis for soils. Sieve analysis was performed on all batches of both BOF and EAF (L) slag samples. In addition to the standard set of sieves (No.4, 10, 20, 40, 60, 100, 140 and 200) specified in the ASTM standard, sieves with $25.4 \mathrm{~mm}(1$ ”), $19 \mathrm{~mm}$ (3/4”) and $9.5 \mathrm{~mm}$ (3/8”) opening sizes were also used to obtain the gradation for the gravel-size fraction. Sieving was performed using a mechanical shaker. Batch-1 Fresh BOF and Batch-1 Fresh EAF (L) 
slag samples were sieved through the No. 40 sieve and hydrometer analysis was performed on particle sizes smaller than $0.425 \mathrm{~mm}$.

\subsubsection{Atterberg Limits and Soil Classification}

Fines from both BOF and EAF (L) slag samples were tested for their plastic properties. Slag particles passing through the No. $40(0.425 \mathrm{~mm})$ sieve were tested for Atterberg limits in accordance with ASTM D4318-D 05. Steel slag samples from each batch were classified according to the USCS, following ASTM D2487-83. The AASHTO soil classification system is commonly used for soils and aggregates mixtures for highway construction and, hence, steel slag samples were also classified based on ASSHTO M 145 .

\subsubsection{Specific Gravity}

According to ASTM D854-06 (Standard Test method for Specific gravity of Soil Solids by Water Pycnometer), only particle sizes smaller than $4.75 \mathrm{~mm}$ can be tested with the water pycnometer method. Steel slag samples had significant percentages of gravel-size particles in their gradation ranging from 14 to $35 \%$. Therefore, both BOF and EAF(L) slag samples were sieved prior to performing the specific gravity tests. The finer fraction passing the No. 4 sieve (particle sizes smaller than $4.75 \mathrm{~mm}$ ) of these samples was tested by the water-pycnometer method, and the specific gravity of the coarser fraction retained by the No. 4 sieve (particle sizes larger than $4.75 \mathrm{~mm}$ ) was determined in accordance with ASTM C127 [Standard Test Method for density (Specific gravity), Relative density and Absorption of the Coarse Aggregate]. The specific gravity of a representative sample (that includes both coarse and fine particles) was obtained by calculating the weighted average of the specific gravity values determined for the fine and coarse fractions in accordance with ASTM D854-06: 


$$
G_{\operatorname{avg} @ 20^{\circ} \mathrm{C}}=\frac{1}{\frac{P}{100 \cdot G_{1 @ 20^{\circ} \mathrm{C}}}+\frac{R}{100 \cdot G_{2 @ 20^{\circ} \mathrm{C}}}}
$$

where; $\mathrm{P}=$ percent of solid particles passing the $4.75-\mathrm{mm}$ sieve; $\mathrm{R}=$ percent of solid particles retained on the $4.75-\mathrm{mm}$ sieve $G_{1 @ 20^{\circ} \mathrm{C}}=$ specific gravity of solids passing the 4.75-mm sieve, as determined by ASTM D854-06 and corrected to $20^{\circ} \mathrm{C} ; \mathrm{G}_{2 @ 20^{\circ} \mathrm{C}}=$ apparent specific gravity of solid particles retained on the $4.75-\mathrm{mm}$ sieve, as determined by ASTM C127 and corrected to $20^{\circ} \mathrm{C}$; The specific gravity test procedures for the fine and coarse steel slag particles are explained next.

\section{Specific Gravity of the Fine Aggregate}

The specific gravity $\left(G_{1 @ 20^{\circ} \mathrm{C}}\right)$ of the steel slag particles with sizes smaller than $4.75 \mathrm{~mm}$ was obtained using the water pycnometer method in accordance with ASTM D854-06. The mass of the pycnometer filled only with de-aired water up to a known volume was recorded at different temperatures in order to calibrate the pycnometer in accordance with ASTM D854-06. Initial mass of the oven-dried steel slag sample was recorded and next, the steel slag sample was placed in the empty pycnometer that was calibrated previously. After adding de-aired water to about $2 / 3^{\text {rd }}$ of the volume of the pycnometer, the de-airing process was initiated. De-airing is an essential step in the water pycnometer method as entrapped air can cause erroneous volume measurements. De-airing was performed by both heating and air vacuuming techniques. Figure 4.11 shows a photograph taken during the de-airing of the $\operatorname{EAF}(\mathrm{L})$ slag slurry. 


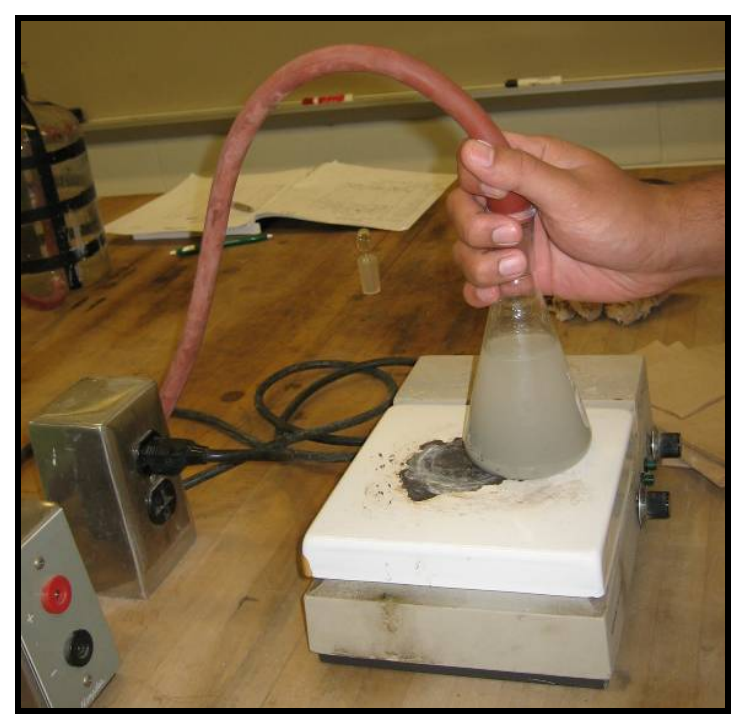

Figure 4.11 De-airing process in the water pycnometer method

The samples were agitated gently to aid the de-airing process. Following the de-airing process, the pycnometer was again filled with de-aired water up to a known volume, and the mass of the pycnometer, water and solids was measured after the temperature of the pycnometer equalized with the temperature of the room. Due to the possibility of loss of fines during the vacuuming process, the slurry was oven dried, and the mass of the dried steel slag sample was recorded again. All mass measurements were taken using a balance with $0.01 \mathrm{~g}$ precision. The temperature of the room was recorded for each test and, when necessary, the specific gravity values were corrected for temperature in accordance with ASTM D854-06. The specific gravity of the steel slag particles was calculated as follows:

$$
\begin{aligned}
& G_{t}=\frac{M_{s}}{\left(M_{\rho w, t}-\left(M_{\rho w s, t}-M_{s}\right)\right.} \\
& G_{1 @ 20^{\circ} \mathrm{C}}=K \cdot G_{t}
\end{aligned}
$$

where $G_{t}=$ specific gravity of the solid particles passing the $4.75-\mathrm{mm}$ sieve at the test temperature; $M_{s}=$ the mass of the oven-dried solids; $M_{\rho w, t}=$ the mass of the 
pycnometer and water at the test temperature; $M_{\rho w s, t}=$ the mass of pycnometer, water and solids at the test temperature; $G_{1 @ 20^{\circ} \mathrm{C}}=$ specific gravity of the solid particles passing the $4.75-\mathrm{mm}$ sieve at $20^{\circ} \mathrm{C} ; \mathrm{K}=$ temperature coefficient (provided in ASTM D854-06)

\section{Specific Gravity and Absorption of the Coarse Aggregate}

The procedures described in ASTM C127 (Standard Test Method for density (Specific gravity), Relative density and Absorption of the Coarse Aggregate) were followed to determine the specific gravity of gravel-size steel slag particles. Oven- dried samples were initially soaked in water for $24 \mathrm{~h}$. Figure 4.12 shows a picture of coarse particles (sizes larger than $4.75 \mathrm{~mm}$ ) of the BOF and $\mathrm{EAF}(\mathrm{L})$ slag during the soaking process. Once the soaking period was completed, the surfaces of the samples were dried with a cloth, and the mass of the surface-dried saturated samples was measured. Next, the samples were placed in a wire-mesh container and immersed in water, and the buoyant mass of the steel slag samples was measured. Figure 4.13 (a) and (b) show the surface drying procedure and the measurement of the buoyant mass, respectively. The final mass measurement (in air) was taken after the samples were dried in the oven. From these measurements and the density of distilled water, the oven-dry specific gravity $\left(G_{s, O D}\right)$,

saturated surface-dry specific gravity $\left(G_{s, S S D}\right)$, apparent specific gravity $\left(G_{s, \text { apparent }}\right)$ and water absorption of the coarse aggregates was determined for each steel slag sample as follows:

$$
\begin{array}{lc}
G_{s, O D}=[(A /(B-C)] & \text { Eq. } 4.4 \\
G_{s, S S D}=[B /(B-C)] & \text { Eq. } 4.5 \\
G_{s, \text { apparent }}=[(A /(A-C)] & \text { Eq. } 4.6 \\
G_{2 @ 20^{\circ} C}=K \cdot G_{s, \text { apparent }} & \text { Eq. } 4.7 \\
\text { Absorption, } \%=[(B-A) / A] \times 100 & \text { Eq. } 4.8
\end{array}
$$
where $A=$ mass of oven dry test sample on air; $B=$ mass of saturated-surface-dry test sample in air; $C=$ apparent mass of saturated test sample in water; $G_{2 @ 20^{\circ} \mathrm{C}}=$ apparent 
specific gravity of solid particles retained on the $4.75-\mathrm{mm}$ sieve, as determined by ASTM $\mathrm{C} 127$ and corrected to $20^{\circ} \mathrm{C}$.

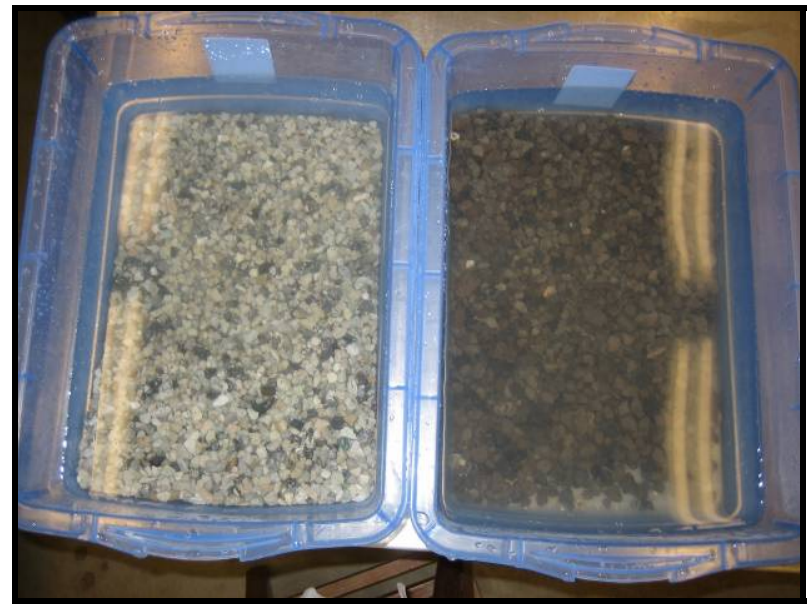

Figure 4.12 Soaked gravel-size particles from EAF (L) and BOF slag samples

The oven-dry, saturated-surface-dry and apparent density of the aggregates can be calculated by multiplying the corresponding specific gravity values by density of water at the test temperature. The oven-dry density corresponds to the mass of the oven-dried aggregate per unit volume of accessible (permeable) and inaccessible pores within a particle. Similarly, the saturated-surface-dry density is the mass of the saturated surfacedried aggregate per unit volume of accessible and inaccessible pores within the particle. The apparent density is the mass per unit volume of the inaccessible portion of the aggregate particles. 


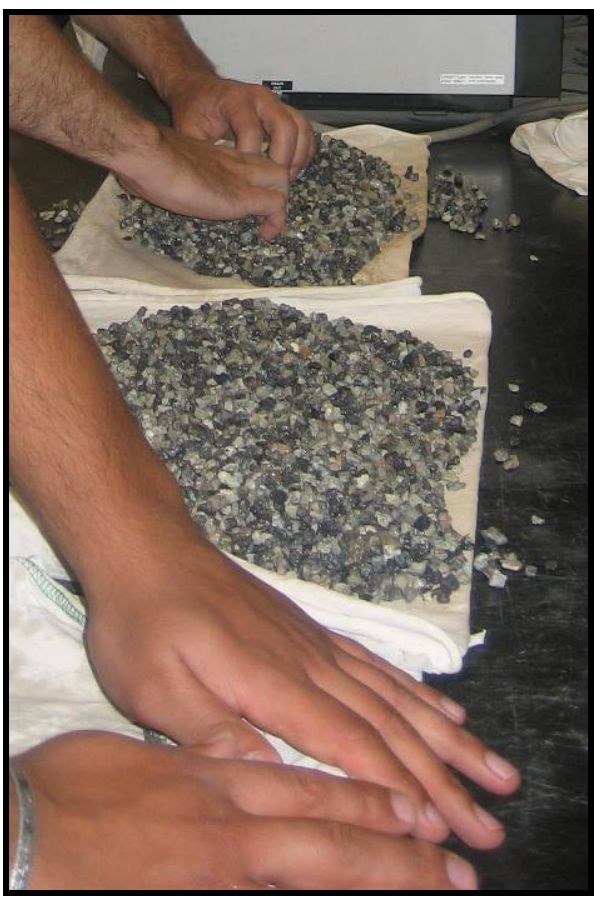

(a)

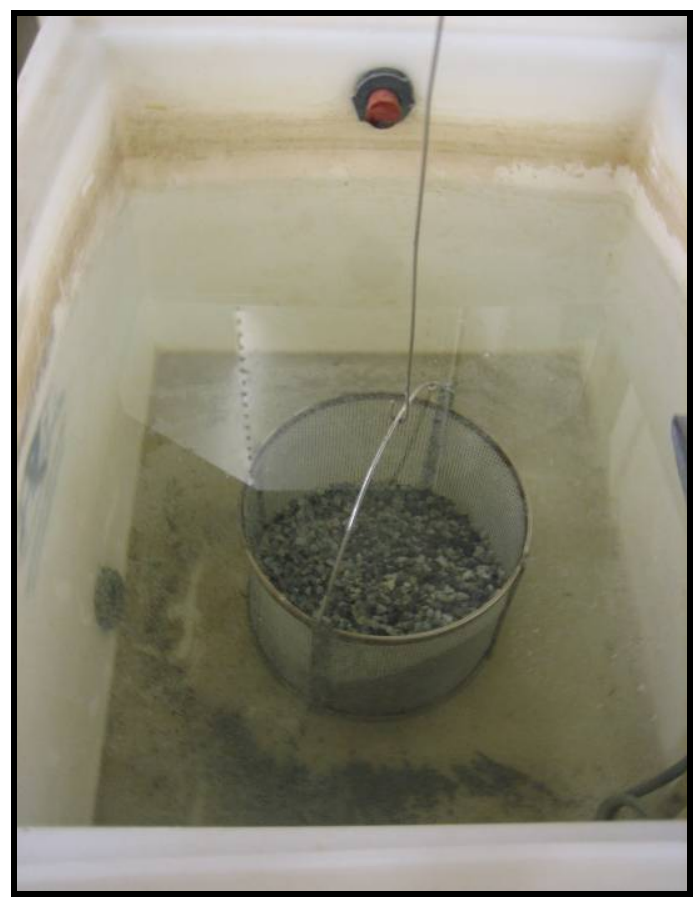

(b)

Figure 4.13 EAF(L) slag coarse aggregate: (a) during surface drying, and (b) measuring buoyant mass by suspending the container with slag particles in water

ASTM C127 is typically used by material engineers to determine the specific gravity and density of coarse aggregates for concrete. Usually, the natural aggregates used in concrete have their accessible pores saturated with water even though their surfaces are dry. For this reason, saturated-surface-dry density is typically used for the coarse aggregates in concrete mix calculations. Similarly, the water absorption of the aggregate is important in the determination of the net water-cement ratio in concrete mixtures. For geotechnical applications, the apparent specific gravity and hence apparent density, is of importance because the mass of aggregate per volume is calculated based on the volume that captures only the inaccessible pores and excludes the accessible ones.

\subsection{Examination of Mineralogical and Morphological Properties}

The chemical composition, mineralogy and morphology of the steel slag particles can influence both the cementitious characteristics and mechanical properties of steel slag. 
The mineralogical and morphological characteristics of both fresh and aged steel slag samples were investigated. X-ray diffraction analysis was used to determine the mineralogical constituents of BOF and $\mathrm{EAF}(\mathrm{L})$ slag samples. The morphological properties of the particles were evaluated by optical microscopy and SEM.

\subsubsection{Chemical Composition}

Determination of the chemical constituents of steel slags is essential to assess their mineralogical composition and to evaluate their cementitious properties. The oxide composition of both $\mathrm{EAF}(\mathrm{L})$ and BOF slag samples were determined by the slag processing companies (Multiserv and Edward C. Levy Co.) using X-ray fluorescence (XRF) analysis.

\subsubsection{X-Ray Diffraction}

X-ray powder diffractometry is a powerful tool to identify the crystal structure and the mineralogical constituents of a compound. X-ray diffraction analyses were carried out with a Siemens D-500 diffractometer using copper radiation. Representative oven-dried steel slag samples (with both gravel-size and finer particles) were crushed until a powder passing the No. 200 (0.075 $\mathrm{mm}$ opening) sieve was attained. The powder samples were step-scanned from 5 to $65^{\circ}(2 \theta)$ in increments of $0.02^{\circ}$ and 1 s count time. The X-ray diffraction pattern was analyzed by assigning each peak observed to one (or more) of the probable crystalline phases (minerals) using both the Jade software and the Joint Committee for Powder Diffraction Standards, Hanawalt System (JCPDS). X-ray diffraction analyses were performed on both fresh and aged BOF slag samples and on fresh $\mathrm{EAF(L)} \mathrm{slag} \mathrm{samples.} \mathrm{Only} \mathrm{qualitative} \mathrm{analyses} \mathrm{were} \mathrm{performed} \mathrm{due} \mathrm{to} \mathrm{the}$ complexity of the crystalline phases and the presence of overlapping peaks. The main and probable minor mineral phases were determined for each slag sample tested. 


\subsubsection{Microscopic Examination}

Steel slag samples were subjected to microscopic examination in order to characterize their particle shape, angularity, and surface texture. The examination was performed with the use of a scanning electron microscope (manufactured by ASPEX, Model Personal SEM) and a light microscope (manufactured by Nikon). The shape and surface texture of gravel-size particles were visible to the naked eye. The medium sand-size particles were examined under the light microscope. Finer sand and silt-size particles were examined under SEM. Typically, samples tend to build up electrostatic charge during the SEM analysis (which impedes sharply contrasted images required to detect the objects from the background) unless they are coated with a conductive film. To prevent charging of steel slag particles, the steel slag particles were coated with palladium with the Hummer 6.2 sputtering system, and the coated particles were examined on a two-sided copper tape. SEM images were captured on both photomicrographs and digital files.

\subsection{Mechanical Properties}

The laboratory tests performed on EAF and BOF slags were the maximum and minimum dry unit weight, compaction, large-scale direct shear and triaxial tests. The details of these mechanical property tests are presented next.

\subsubsection{Maximum and Minimum Dry Density}

The maximum and minimum dry density tests were performed on oven-dried EAF (L) and BOF slag samples from all batches. As per ASTM D4254, the minimum density tests were performed using a 15.2-cm-diameter mold with a total volume of $2830 \mathrm{~cm}^{3}$. To achieve the loosest possible condition, the mold was filled with a hand scoop several

times. Special attention was paid to minimize not only particle segregation while filling the mold but also disturbance that might be caused during trimming of the top of sample. After trimming, the mass of the mold was measured to determine the minimum dry density and hence the corresponding minimum dry unit weight $\left(\gamma_{d, \min }\right)$. The maximum dry density tests were performed using the same mold in accordance with ASTM D4253- 
00. The mold was assembled with the collar and mounted on to an electromagnetic, vertically vibrating table (manufactured by Syntron Bulk Handling Equipment) with a frequency of $60 \mathrm{~Hz}$. Figure 4.14 shows the maximum dry density test set-up. A surcharge weight corresponding to a stress value of approximately $14 \mathrm{kPa}$ was placed on top of the sample.

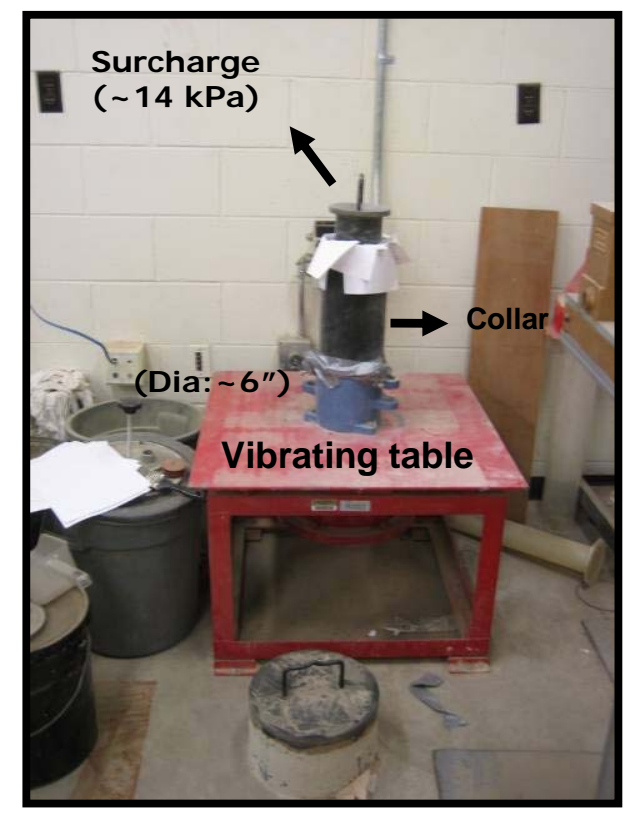

Figure 4.14 Maximum dry density test set-up on the vibrating table

In order to avoid the loss of fines during vibration, a large filter paper was placed on top of the sample, and an electric tape was wrapped around the connection of the collar with the mold. The loss of fines during vibration was reduced significantly by these precautions. Tests were repeated on the vibratory table several times to achieve the maximum dry density and hence, the corresponding maximum dry unit weight $\left(\gamma_{d, \max }\right)$. Maximum and minimum void ratio of steel slag samples were calculated as follows:

$$
\begin{aligned}
& e_{\text {max }}=\frac{\rho_{w} G_{s}}{\rho_{d, \text { min }}}-1 \\
& e_{\text {min }}=\frac{\rho_{w .} G_{s}}{\rho_{d, \text { max }}}-1
\end{aligned}
$$


where $e_{\max }=$ maximum void ratio; $e_{\min }=$ minimum void ratio; $\rho_{w .}=$ density of water; $G_{s}=$ specific gravity, $\rho_{d, \min }=$ minimum dry density, $\rho_{d, \max }=$ maximum dry density. Relative density $\left(D_{R}\right)$, which is a measure of the relative compactness of a granular material -compared to possible densest and loosest states- can be calculated using the $e_{\min }$ and $e_{\max }$ as follows:

$D_{R}=\frac{e_{\max }-e}{e_{\max }-e_{\min }}$

where, e is the void ratio of the compacted granular material.

\subsubsection{Compaction}

Moisture-density relationships of all $\mathrm{EAF}(\mathrm{L})$ and BOF slag samples were determined by Standard Proctor compaction tests, as described in ASTM D698-00a. EAF (L) slag samples were compacted in a 10-cm-diameter (4-inch-diameter) mold in three layers with 25 blows per layer using a standard Proctor rammer (Method A of ASTM D698). Some of the BOF slag samples contained more than 30\% gravel-size particles. As per the standard, the BOF slag samples were compacted in a 15-cm-diameter (6-inch-diameter) mold in three layers with 56 blows per layer using a standard Proctor rammer (Method C of ASTM D698). During compaction, the Standard Proctor rammer of $24.4 \mathrm{~N}$ was dropped from a height of $30.5 \mathrm{~cm}$.

Steel slag samples were tested at a wide range of moisture content values to obtain their compaction characteristics. Oven-dried samples were moistened by the water-spraying technique until the desired moisture content was achieved. Special attention was paid to ensure thorough mixing of the steel slag with water prior to compaction. Compaction was performed by distributing the rammer blows evenly on the surface of each layer. Each compacted layer was scratched carefully before placing the next slag layer. After recording the mass of the compacted soil, the tested samples were recovered using a hydraulic jack and dried in the oven for moisture content determination. Before placing the samples in the oven, the intact samples were broken 
into pieces to facilitate drying. The main steps of the compaction procedure for $\mathrm{EAF}(\mathrm{L})$ slag are: water spraying, compaction in the 10-cm-diameter (4-inch-diameter) mold, trimming, mass measurement, sample recovery with the hydraulic jack and oven drying [see Figure 4.15 (a),(b),(c),(d), (e) and (f)]. Due to the presence of a high percentage of gravel-size particles, BOF slag samples were compacted in a 15-cm-diameter (6-inchdiameter) mold following similar procedures. Figure 4.16 (a) and (b) shows placement of the BOF slag layer in the 15-cm-diameter mold and the compaction of a layer, respectively.

Due to the impact of the rammer blows, particles can degrade during the compaction process. Degradation studies were performed on EAF(L) and BOF slag samples. The main objective of the degradation studies was to determine whether there were any changes in the gradation of the samples due to crushing caused by compaction. Degradation analysis was performed on samples prepared at the optimum moisture content and maximum dry unit weight. The grain-size analysis of the sample was done prior to compaction. After compaction, the compacted steel slag sample was recovered from the compaction mold, dried in the oven, and subjected to sieve analysis once more. As a result of the degradation studies, the changes in the gradations of EAF and BOF slag samples due to the impact of rammer blows were determined.
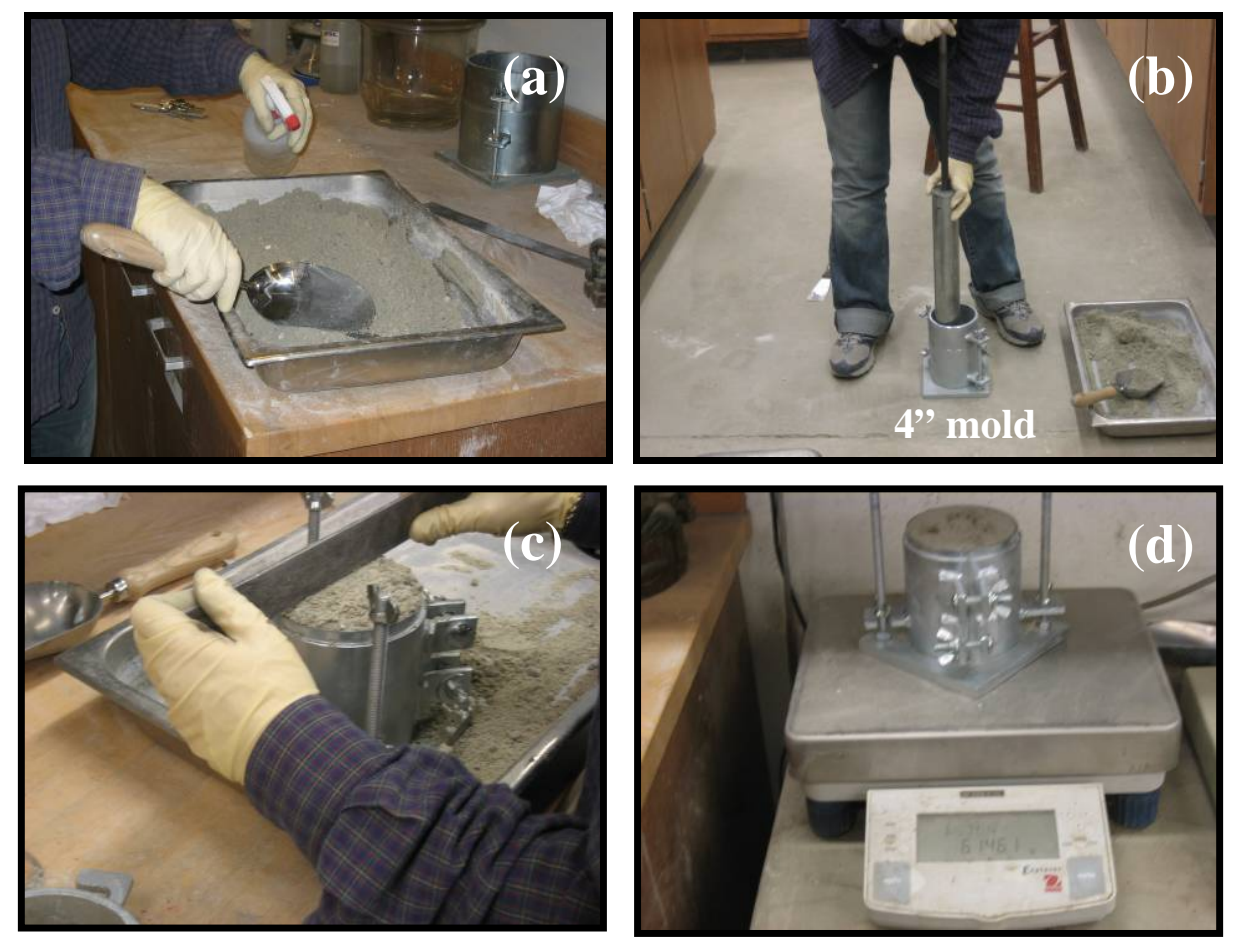

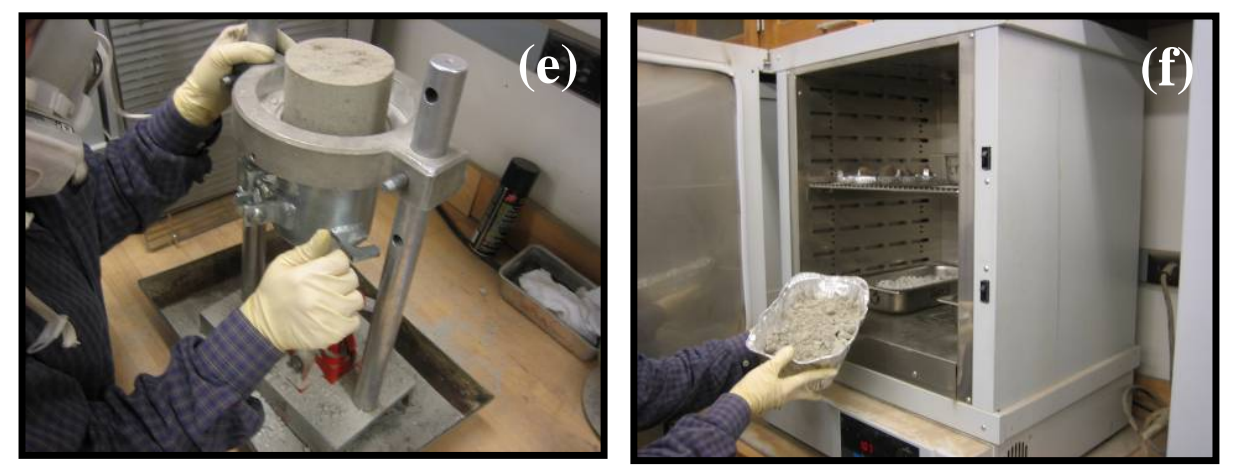

Figure 4.15 Compaction procedure for EAF(L) slag samples: a) spraying water to achieve the desired moisture content, b) compacting the sample in a 4-inch-diamter mold, c) trimming the compacted sample, d) measuring the compacted mass, e) recovering the sample with a hydraulic jack, and f) oven drying for moisture content measurement
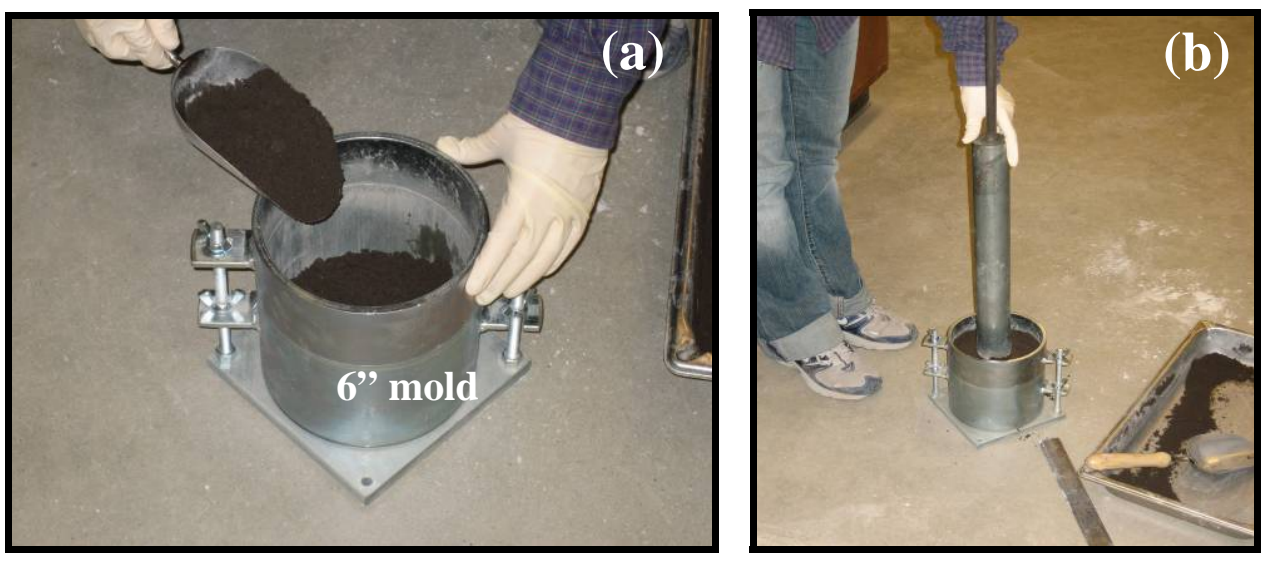

Figure 4.16 Compaction of BOF slag sample: (a) placing BOF-slag sample in the 6" mold, and (b) applying blows with the Standard Proctor rammer

In addition to relative density $\left(D_{R}\right)$, relative compaction $(R)$ is also used as a common measure of density for granular materials. Relative compaction $(R)$ is defined as follows:

$$
R=\frac{\gamma_{d}}{\gamma_{d, \max }}
$$


where $\gamma_{d}=$ compacted dry unit weight and $\gamma_{d, \max }=$ maximum dry unit weight obtained from the standard Proctor test. Both relative density and relative compaction can be used to control field compaction. As loss of fines and segregation of the particles during the vibratory compaction can lead to difficulties in obtaining reliable values of maximum and minimum density for materials that contain a wide range of particle sizes (both fines and gravels) such as steel slag, the present study uses relative compaction $(R)$ as a measure to control the densities of testing samples.

\subsubsection{Large-Scale Direct Shear Tests}

Large-scale direct shear tests were performed on both BOF and EAF(L) slag samples to determine their shear strength parameters. In order to eliminate boundary effects, ASTM D 3080-04 (The Standard Test Method for Direct Shear Test of Soils under Consolidated Drained Conditions) recommends use of a box size of at least 10 times the maximum particle size. Therefore, use of the conventional-size direct shear box was not feasible due to the presence of gravel-size particles in the steel slag samples and tests were performed in a large-scale direct shear machine with a box size of $30.5 \mathrm{~cm}$ x $30.5 \mathrm{~cm} \times 20 \mathrm{~cm}$ in the laboratory of the Indiana Department of Transportation Research Division, West Lafayette, IN.

\section{Equipment and Instrumentation}

A large-scale direct shear machine, Model Shear Track III (manufactured by GEOCOMP Products and Laboratory Systems Corp.) was used in this research. Figure 4.17 shows an isometric view of the large-scale direct shear box. The large-scale direct shear machine contains two embedded control systems that generate the vertical and horizontal forces on the sample and measure the vertical and horizontal displacements. There are two LCDs and keypads on the front panel which allow the users to manually control the operation of the load frame and monitor the system. This automated system is connected to a computer which allows the user to control the test and monitor the plots displayed using the Shear Track III system software. 
The machine is equipped with transducers: two LVDTs (Linear Variable Differential Transformer) to measure the lateral displacement of the lower box and the vertical displacement of the top cap, and two load cells to measure the normal load applied on top of the sample and the shear load across the horizontal shear plane. The data from the transducers provide real-time control of the load frame. Based on the data from the sensors, the computer sends commands several times per second to the embedded controllers, which in turn generate signals to the micro-stepping motors (both horizontal and vertical), resulting in smooth vertical and horizontal motions. Figure 4.18 shows the vertical LVDT and the load cell attached to the direct shear machine.

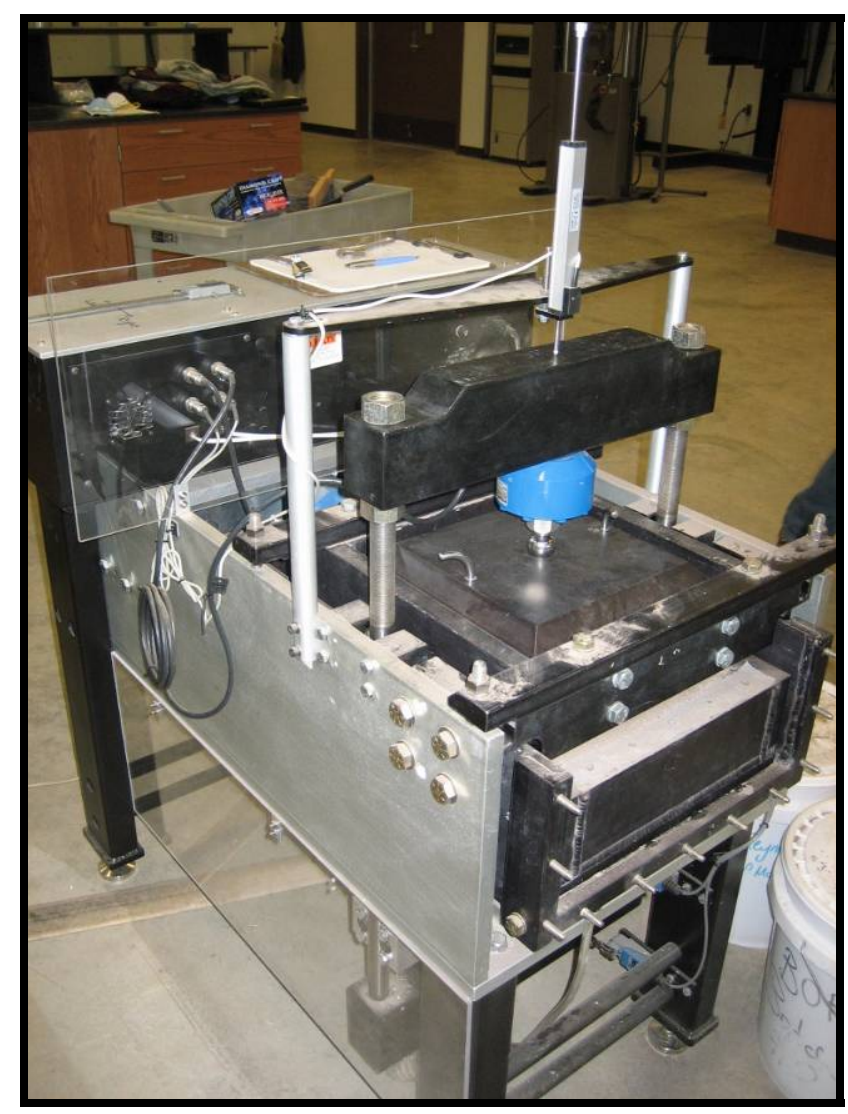

Figure 4.17 Isometric view of the large-scale direct shear machine 
The vertical loading system consists of a loading frame and a load cell with a capacity of approximately $50 \mathrm{kN}$ (4.5 tons). The load cell is placed on a cylindrical metal at the center of the top cap that applies the normal load uniformly on top of the sample. An LVDT with a $10 \mathrm{~cm}$ range is mounted on top of the loading frame above the center of the sample to measure the vertical displacement.

The lateral shearing system consists of a horizontal motor and a horizontal load cell with a capacity of approximately $50 \mathrm{kN}$ (4.5 tons). Similar to the vertical system, the horizontal deformations were measured using an LVDT with a range of $10 \mathrm{~cm}$. Figure 4.19 shows the instrumentation details of the lateral system.

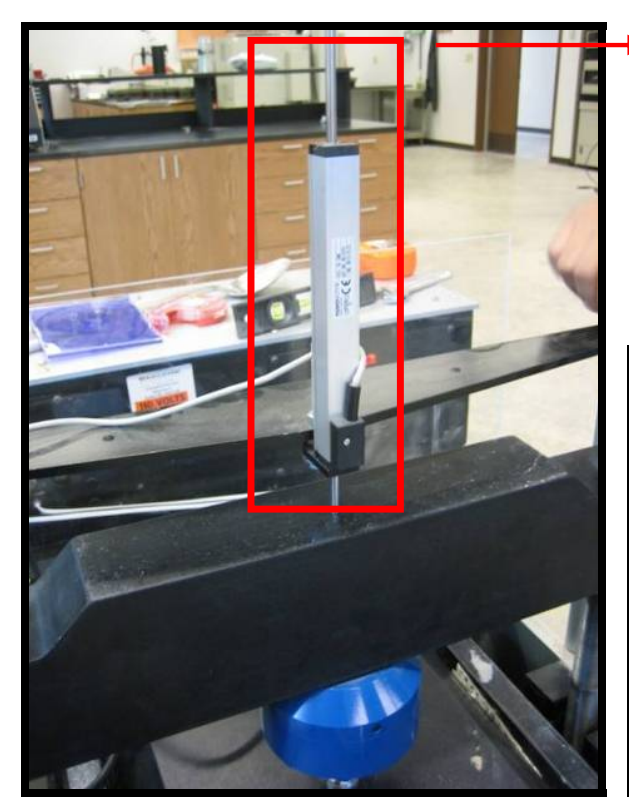

(a)
Vertical LVDT (Range: 100 mm) Load Cell

\section{(Capacity: $50 \mathrm{kN}$ ) Loading frame}

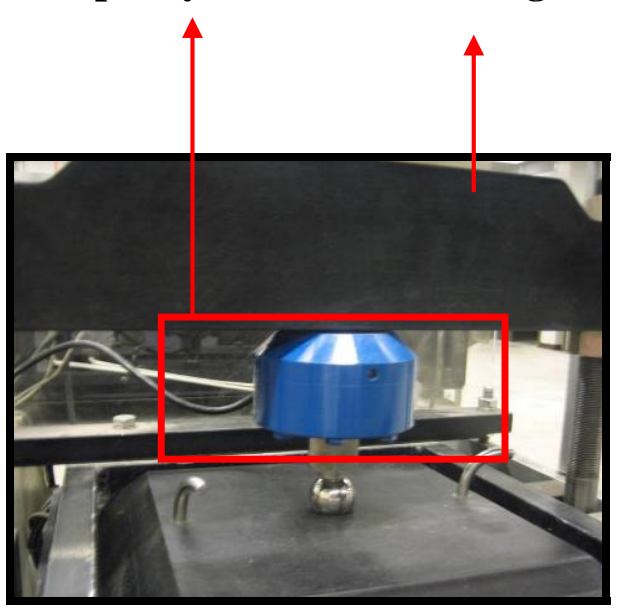

(b)

Figure 4.18 Vertical loading system instrumentation details of large-scale direct shear machine: (a) vertical LVDT and (b) loading frame and the vertical load cell 


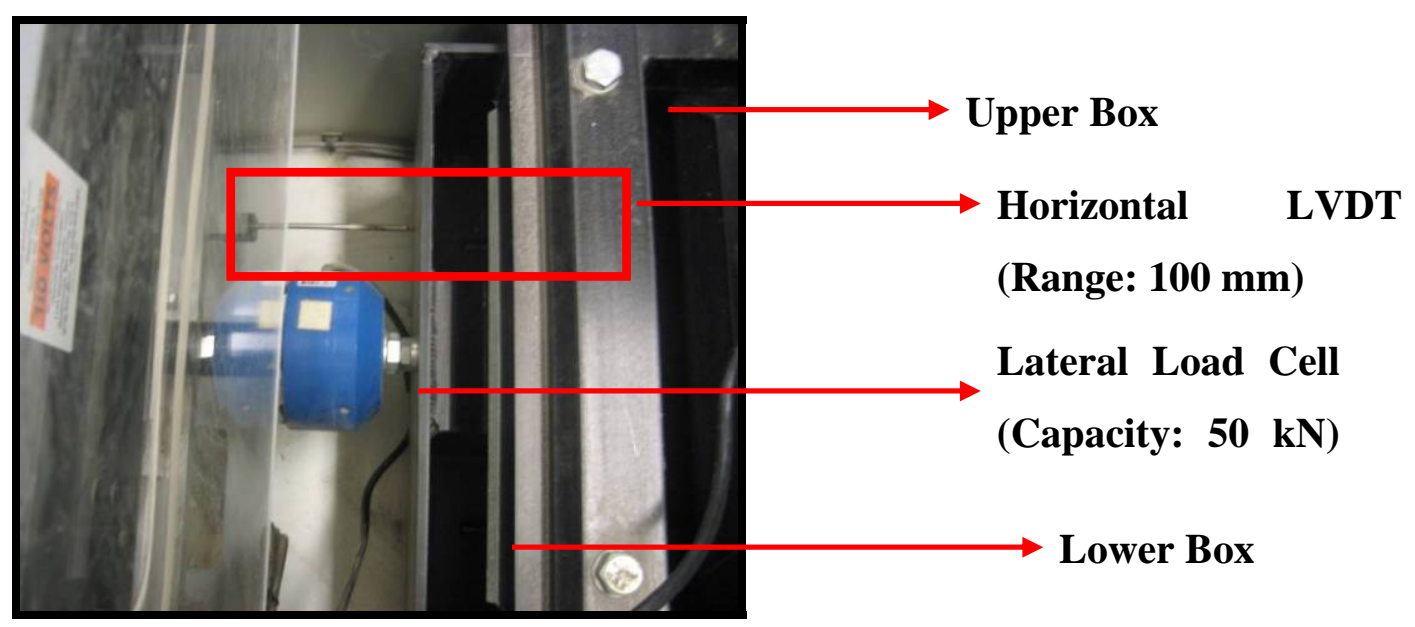

Figure 4.19 Shearing mechanism and instrumentation details of the large-scale direct shear box

\section{Sample Preparation and Testing}

The amount of steel slag required to fill the direct shear box was calculated based on the target moisture content and relative compaction values for each test. For each test, about $28-34 \mathrm{~kg}$ of material was prepared in the $\pm 1 \%$ range of the desired moisture content by adding water to the oven-dry slag samples. A standard Proctor energy was applied to achieve the maximum dry density for the steel slag sample placed inside the direct shear box. Materials were compacted in five layers with approximately 230 blows per layer using a standard Proctor rammer of mass equal to $2.5 \mathrm{~kg}$. After compacting each layer, the surface of the layer was leveled, and the height of the layer was measured to ensure homogenous compaction. Before placement of the next layer, the surface of the layer was scratched to make sure that there was good adherence between layers. Figure 4.20 shows the steps involved in sample preparation: measuring the mass of slag sample for each layer, compacting a layer in the lower box, leveling the surface of the layer, measuring the height of the layer, and scratching the surface of the compacted layer of a BOF-slag sample. 

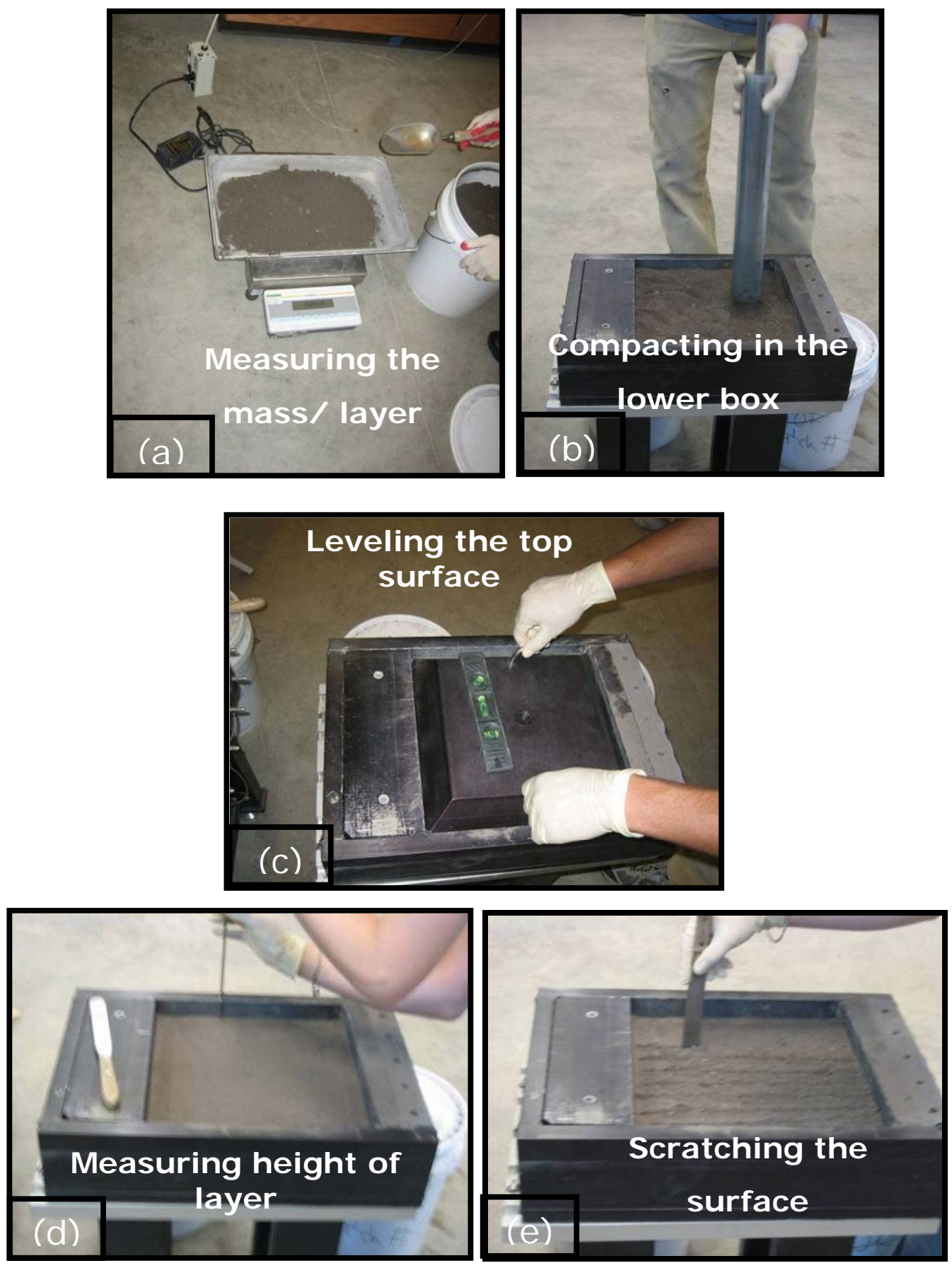

Figure 4.20 Preparation of a BOF-slag sample in the lower box: (a) mass measurement, (b) compaction, (c) leveling, (d) height measurement, and (e) scratching of the surface 
During compaction of the bottom two layers, the lower box was positioned outside the shear machine to protect the direct shear machine from any damage that might be caused by the impact of the rammer blows during compaction. After the bottom two layers were compacted in the lower box, the lower box was moved to the test position in the Shear Track III large direct shear machine. The upper box was then placed on top of the lower box. The next three layers were compacted following the same compaction procedure. After leveling of the final layer, the top cap was placed centrally on top of the sample. The loading frame and the load cell were then lowered onto the top cap. Figure 4.21 shows sample preparation in the top box, placement of a slag layer, compaction of a layer, placement of the top cap, and shearing.
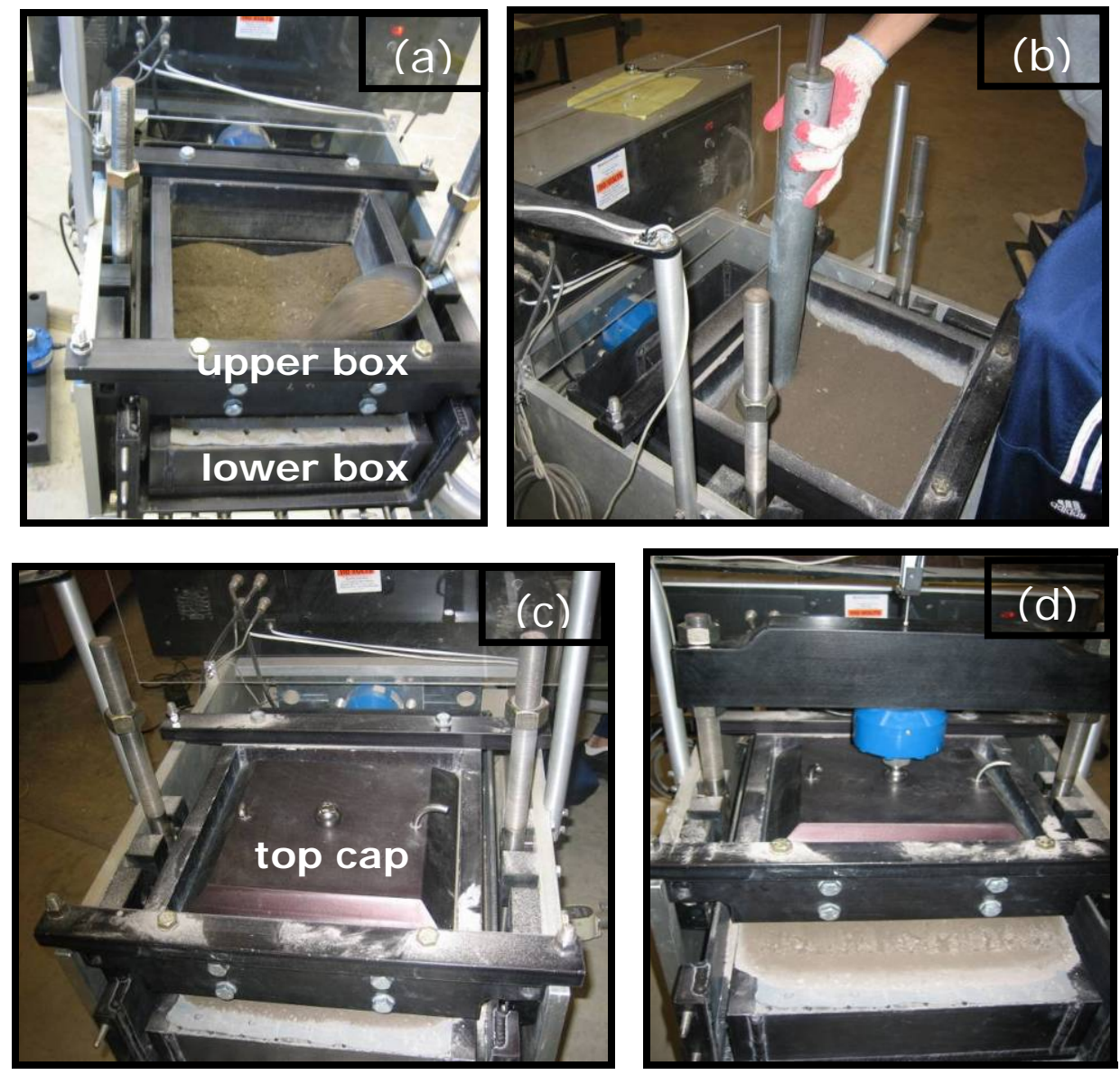

Figure 4.21 Preparation and shearing of a BOF-slag sample in the upper-box: (a) placing the slag sample in the upper box, (b) compacting the layer, (c) placing the top cap on top of the final layer, and (d) sample before the start of the shearing process 
In order to facilitate placement of the top cap on top of the sample, the top of the final layer was about 3-4 $\mathrm{cm}$ below the top of the box and, thus, the total sample height was equal to $16-17 \mathrm{~cm}$. Before shearing, the sample was consolidated under the desired normal stress which was applied for about 20 minutes until the settlements measured by the vertical LVDT became stable. Normal stresses of $50 \mathrm{kPa}, 100 \mathrm{kPa}, 200 \mathrm{kPa}$ and 300 (or 250) $\mathrm{kPa}$ were used in the tests. For each test, new samples were prepared at the start of each test (samples were not reused). After the consolidation stage, the samples were sheared by laterally displacing the lower box at a rate of $0.75 \mathrm{~mm} / \mathrm{min}$. The test was terminated when the lateral displacement reached $80 \mathrm{~mm}$.

The details of the test matrix for the large-scale direct shear tests on BOF slag and EAF(L) slag samples are shown in Table 4.2 and Table 4.3 respectively. Based on the large-scale direct shear test results, the effects of gradation, relative compaction, aging, and moisture content on shear strength parameters of BOF and EAF(L) slag samples were investigated. A total of 28 large-scale direct shear tests were performed on steel slag samples. 
Table 4.2 Direct shear test matrix for BOF slag samples

\begin{tabular}{|c|c|c|c|}
\hline $\begin{array}{c}\text { Material } \\
\text { Description }\end{array}$ & $\begin{array}{l}\text { Moisture } \\
\text { content } \\
\text { (w) }\end{array}$ & $\begin{array}{c}\text { Relative } \\
\text { Compaction } \\
(R)^{\mathrm{a}}\end{array}$ & $\begin{array}{c}\text { Confining } \\
\text { Stress } \\
(\mathrm{kPa})\end{array}$ \\
\hline $\begin{array}{c}\text { Batch-1 Fresh } \\
\text { BOF slag }\end{array}$ & $4 \%$ & $100 \%$ & $\begin{array}{c}50 \\
100 \\
200 \\
300\end{array}$ \\
\hline $\begin{array}{c}\text { Batch-1 Fresh } \\
\text { BOF slag }\end{array}$ & $7-8 \%$ & $95 \%$ & $\begin{array}{c}50 \\
100 \\
200 \\
300\end{array}$ \\
\hline $\begin{array}{c}\text { Batch-2 Fresh } \\
\text { BOF slag }\end{array}$ & $7-8 \%$ & $100 \%$ & $\begin{array}{c}50 \\
100 \\
200 \\
300\end{array}$ \\
\hline $\begin{array}{c}\text { Batch-2 Aged } \\
\text { BOF slag }\end{array}$ & $7-8 \%$ & $96 \%$ & $\begin{array}{c}50 \\
100 \\
200 \\
250\end{array}$ \\
\hline
\end{tabular}

a $R=\frac{\gamma_{d}}{\gamma_{d, \max }}$, where $\gamma_{d}=$ compacted dry unit weight of the sample,

$\gamma_{d, \max }=$ maximum compacted dry unit weight obtained from the standard Proctor compaction tests 
Table 4.3 Direct shear test matrix for $\mathrm{EAF}(\mathrm{L})$ slag

\begin{tabular}{cccc}
\hline $\begin{array}{c}\text { Material } \\
\text { Description }\end{array}$ & $\begin{array}{c}\text { Moisture } \\
\text { content } \\
(\mathrm{w})\end{array}$ & $\begin{array}{c}\text { Relative } \\
\text { Compaction } \\
(R)^{\mathrm{a}}\end{array}$ & $\begin{array}{c}\text { Confining } \\
\text { Stress } \\
(\mathrm{kPa})\end{array}$ \\
\hline \hline & & & 50 \\
Batch-1 Fresh & $14 \%$ & $100 \%$ & 100 \\
EAF(L) slag & & & 200 \\
& & & 300 \\
\hline Batch-1 Fresh & $10 \%$ & $96 \%$ & 50 \\
EAF(L) slag & & & 200 \\
& & & 300 \\
Batch-2 Fresh & $10 \%$ & $95 \%$ & 50 \\
EAF(L) slag & & & 100 \\
& & & 300 \\
\hline
\end{tabular}

a $R=\frac{\gamma_{d}}{\gamma_{d, \max }}$, where $\gamma_{d}=$ compacted dry unit weight of the sample,

$\gamma_{d, \max }=$ maximum compacted dry unit weight obtained from the standard Proctor compaction tests

\subsubsection{Consolidated Drained Triaxial Tests}

In order to complement the results of large-scale direct shear tests, isotropically consolidated drained (CID) triaxial tests were performed on Batch-3, aged BOF slag samples. The main objective of these tests was to better understand the shear stress-strain and volumetric response of aged BOF slag samples. An automated CKC triaxial testing apparatus was used to perform the CID triaxial tests. The CKC system consists of a loading frame, a triaxial cell, a loading piston, a volume-change measuring device with pressure transducers, a dual pneumatic loading unit, a signal conditioning unit, a process 
interface unit, a PC computer, and a printer. The axial load was applied through a doubleacting oil piston of $139.7 \mathrm{~mm}$ in diameter and measured using a load cell. The chamber pressure, effective pressure, and volume change during shearing of the sample were measured with three separate transducers. The computer-controlled system automatically records the shear stress-strain histories.

The BOF slag was sieved through a sieve with an opening size of $9.5 \mathrm{~mm}(3 / 8$ ”). The BOF slag particles passing this sieve were oven-dried, and water was uniformly added to the samples to achieve the optimum moisture content determined from the standard Proctor compaction tests. Next, the slag sample was compacted in ten layers in a split mold of $72 \mathrm{~mm}$ (2.8 inch) in diameter placed on a lubricated platen using a manual sleeve compaction rammer. Due to the presence of particles with sharp edges, a slightly thicker membrane of $0.6 \mathrm{~mm}$ in thickness was used to avoid tearing of the membrane during the compaction process. The number of blows per layer was calibrated for each layer after several trials to ensure homogenous compaction. A compacted dry density corresponding to $90-95 \%$ relative compaction was targeted. In order to remove air pockets that might be present in the compacted specimen, a vacuum of $10 \mathrm{inHg}(33 \mathrm{kPa})$ was applied at the bottom of the sample for about $30 \mathrm{~min}$. Following the application of vacuum, the split mold was carefully removed, causing no disturbance to the compacted specimen. The height and diameter measurements were taken using a caliper and a $\pi$ tape, respectively. After closing the vacuum line, the triaxial cell was assembled. Following the placement of the top cap, the pressure line was connected to the chamber top valve, and the pressure source was turned on. The $\mathrm{CO}_{2}$ percolation technique could not be used to aid saturation of the samples due to carbonation reactions with the steel slag. Therefore, the samples were flushed with de-aired water for at least 6 hrs to ensure saturation. The progress of water flushing from the bottom of the sample could be observed with the color change in the sample as the water particles traveled up through the sample. A minimum of 1 liter of water was flushed through each sample prior to the application of backpressure. The backpressure was increased slowly in $10 \mathrm{kPa}$ increments until a back pressure of $50 \mathrm{kPa}$ was reached. An effective stress value of $10 \mathrm{kPa}$ was maintained during backpressure saturation by increasing the cell pressure simultaneously 
with the backpressure. A period of time was allowed for the backpressure to dissolve the gas bubbles and, during this time, the sample was allowed to absorb more de-aired water through the volume change device. The B-value was checked after this saturation period, and when needed the backpressure was increased in steps of $10 \mathrm{kPa}$ up to 250-300 $\mathrm{kPa}$ following the same procedures until a B-value higher than 0.93 was achieved. Considering the stiffness and the self-cementing properties of the steel slag samples, B values larger than 0.93 were assumed to be satisfactory to ensure the saturation of the samples. Figure 4.22 (a) and (b) show photographs of a sample before and after shearing in the CKC triaxial cell.
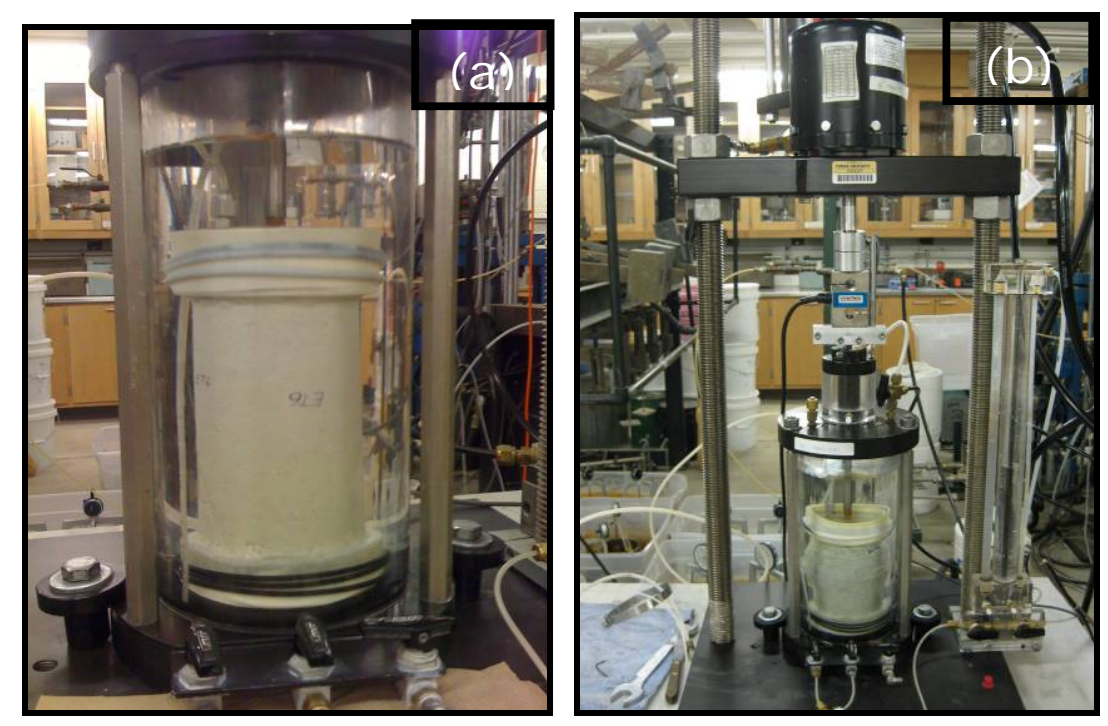

Figure 4.22 Triaxial test set-up: (a) close view of a BOF-slag specimen before shearing, and (b) specimen after shearing in the CKC triaxial machine

At the end of the backpressure saturation stage, the samples were isotropically consolidated to the desired effective confining stresses (50 kPa, $110 \mathrm{kPa}, 200 \mathrm{kPa})$ in steps of $10 \mathrm{kPa}$. For each stress increment, the specimens were consolidated for 20 minutes to fully dissipate the excess pore pressures. Each specimen was sheared at its consolidation stress under a strain-controlled rate of $0.1 \% / \mathrm{min}$. The axial strain, volumetric strain, pore pressure and deviatoric stresses were automatically recorded; the 
plots of shear stress versus axial strain and of volumetric strain versus axial strain were generated by the CKC software during the test and displayed on the computer screen.

\section{6. $\underline{\text { Swelling Tests }}$}

Swelling tests were performed on both $\mathrm{EAF}(\mathrm{L})$ and BOF slag samples in accordance with ASTM 1883-9905 to assess their long-term expansion characteristics. Prior to compaction, a standard cylindrical spacer disc of $15.2 \mathrm{~cm}(6$ inch) in diameter and $6.1 \mathrm{~cm}$ (2.4 inch) in height was placed at the bottom of the CBR molds of $15.2 \mathrm{~cm}(6 \mathrm{inch})$ in diameter and $17.8 \mathrm{~cm}$ (7 inch) in height. Steel slag samples were compacted at their optimum moisture content, in three layers with an energy equivalent to the standard Proctor energy. After compaction of each layer, by applying 56 blows/layer using the standard Proctor rammer, the samples were trimmed, and a filter paper was placed on the trimmed surface of each sample. Next, the compacted samples were flipped on to perforated base plates, and the spacer disks were removed from the top. A filter paper was placed on the top of each sample (see Figure 4.23). The height of each sample was approximately equal to $11.6 \mathrm{~cm}$ (4.6 inch). The compacted dry unit weight of each sample was determined from the mass measurements.

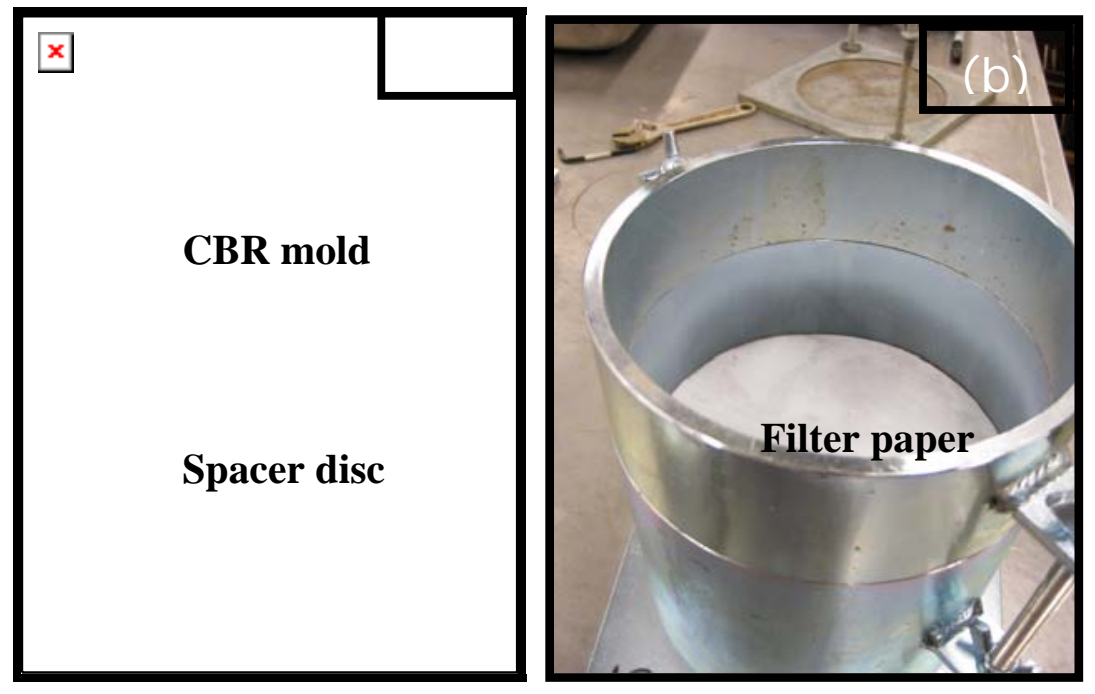

Figure 4.23 Sample preparation in CBR mold: a) a spacer disc placed at the bottom of the $\mathrm{CBR}$ mold prior to compaction b) spacer disc is removed and a filter paper is placed on the top of the sample after compaction 
Collars were then mounted on the molds. Annular surcharge weights having a total mass of approximately $4.54 \mathrm{~kg}$ were placed on the perforated swell plates that are connected to adjustable stems. Next the perforated swell plates (together with the annular surcharge weights on the top) were placed on the top of the samples (see Figure 4.24). The one-dimensional vertical swelling of the samples were measured by dial gauges with ranges of $25.4 \mathrm{~mm}$ (1-inch) and $12.5 \mathrm{~mm}(0.5$-inch) with a least count equal to 0.001 $\mathrm{mm}$ and $0.0005 \mathrm{~mm}$, respectively. The dial gauges were mounted using tripods and placed on the collar of the CBR molds. Extension rods were used to lengthen the core of the dial gauges to touch the adjustable stem of the perforated plates placed on top of the samples. Figure 4.24 shows the components of the CBR mold set-up with the dial gauge.

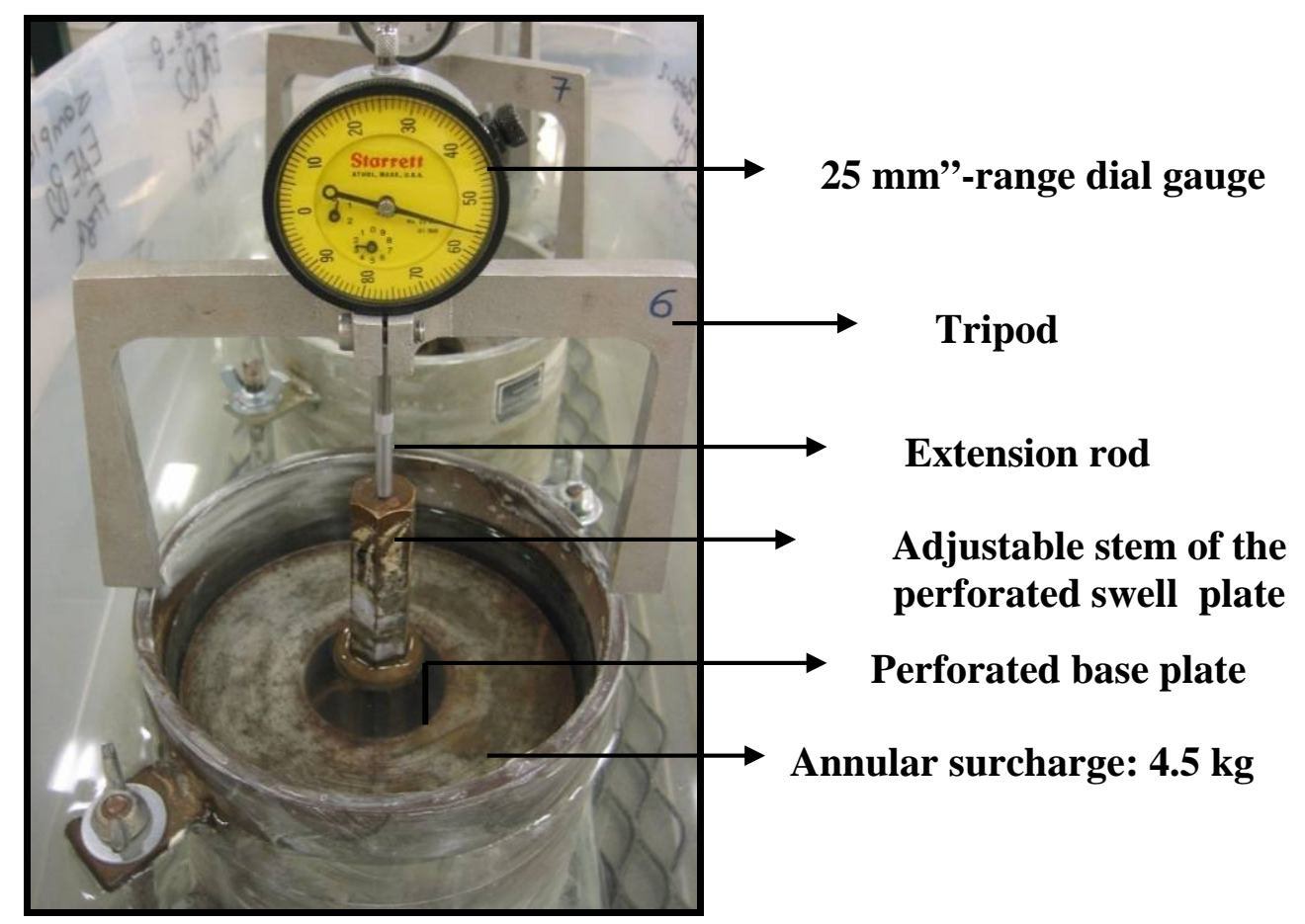

Figure 4.24 Components of the CBR swelling test set-up

In order to allow the steel slag samples to have access to water from the perforated base plates, stainless steel (304 SS) meshes with sizes of $25 \mathrm{~cm}$ by $71 \mathrm{~cm}$ by $37 \mathrm{~cm}$ (10inch x28inch x14inch) and $28 \mathrm{~cm}$ by $43 \mathrm{~cm}$ by $37 \mathrm{~cm}$ (11inch x17inch $\mathrm{x} 14$ inch) 
were placed at the bottom of the soaking containers. Figure 4.25 shows one of the plastic soaking containers $(28 \mathrm{~cm}$ by $43 \mathrm{~cm}$ by $37 \mathrm{~cm})$ and the steel mesh.

Following sample preparation, CBR molds were placed in the soaking containers. Immediately after soaking completely the CBR molds in water, initial zero readings were read from the dial gauges. Using a stop watch, readings were taken from the dial gauges at $1 \mathrm{~min}, 2 \mathrm{~min}, 4 \mathrm{~min}, 10 \mathrm{~min}, 15 \mathrm{~min}, 20 \mathrm{~min}, 30 \mathrm{~min}, 1 \mathrm{hr}, 2 \mathrm{hr}, 4 \mathrm{hr}, 8 \mathrm{hr}$ and $24 \mathrm{hrs}$ after the zero reading. After the first day of soaking, readings were taken at every $24 \mathrm{hrs}$. Swelling of steel slag samples were monitored for more than 16 months. Swelling tests were performed on both fresh and aged BOF and EAF(L) slag samples with different gradations to evaluate the effects of aging and particle size on the long-term expansion of the samples. Figure 4.26 shows a photograph of the test specimens placed in the soaking containers for long-term swell monitoring.

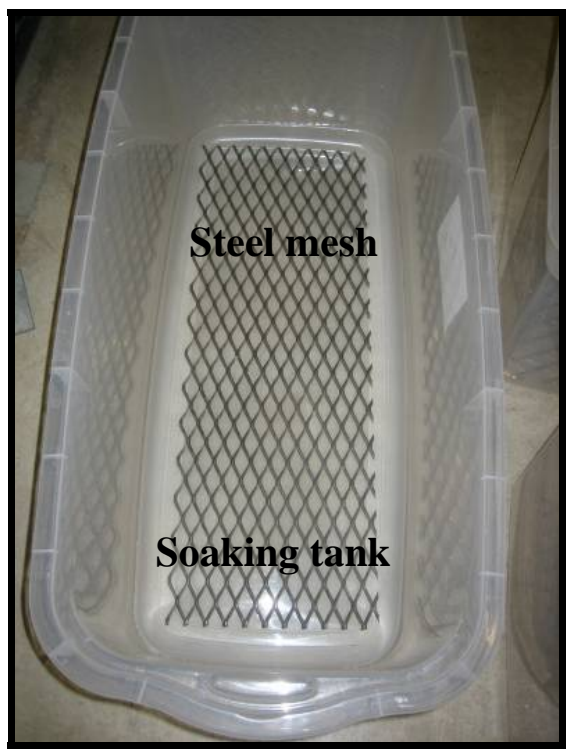

Figure 4.25 Plastic soaking containers with a steel mesh placed at the bottom 


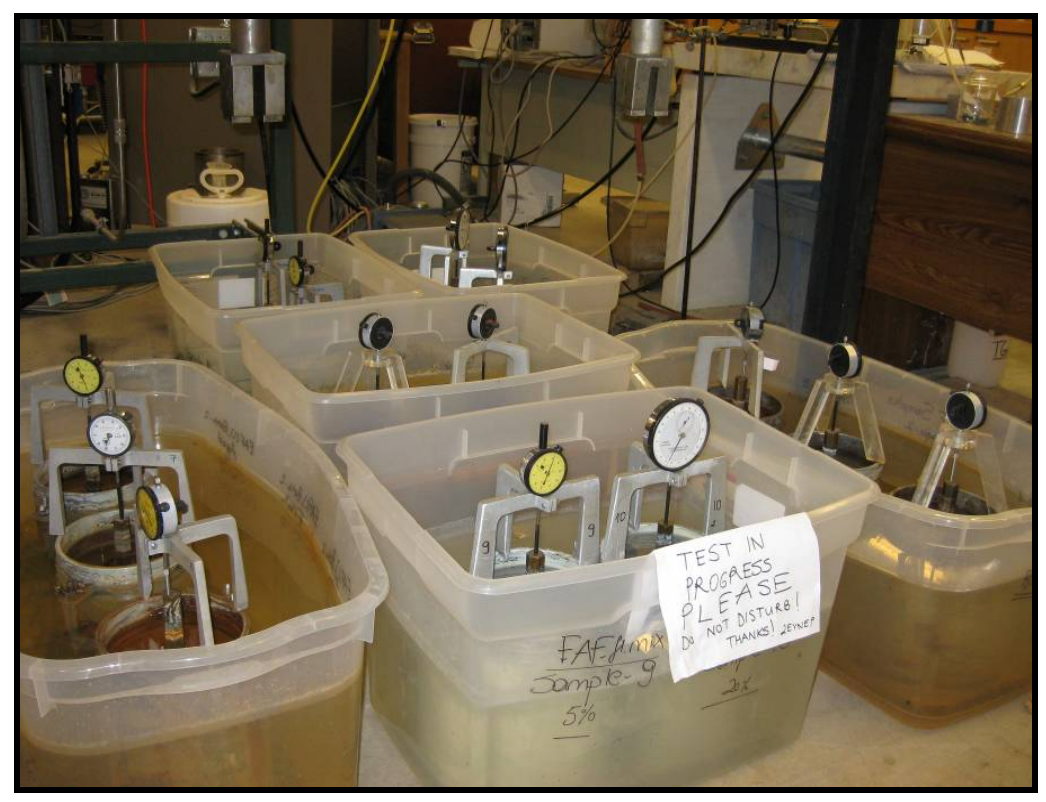

Figure 4.26 Long-term swelling test set-up

\subsection{Environmental Tests}

According to the United States Environmental Protection Agency (EPA) regulations, a waste is considered hazardous if it exhibits one or more of the hazardous characteristics of ignitability, corrosivity, reactivity, and toxicity. In order to assess the environmental effects of using steel slag in geotechnical applications, environmental tests were performed to assess the leaching and corrosion potential of both BOF and EAF(L) slag samples.

\subsubsection{Corrosivity Tests}

Corrosivity is a characteristic of a material (or of an environment) that indicates the likelihood of corrosion of a metal in contact with it. Metal structures such as rebars present in concrete used in highway structures, steel pipes used in drainage systems of retaining walls, steel water pipes or steel strips in reinforced earth walls are all susceptible to corrosion when the surrounding material has a corrosive nature.

In order to evaluate the corrosive nature of steel slag samples, parameters that are indicators of the corrosion potential - electrical resistivity $(\mathrm{R})$ and $\mathrm{pH}$ - were determined. 
The corrosion potential of $\mathrm{BOF}$ and $\mathrm{EAF}(\mathrm{L})$ slag were determined by evaluating these parameters.

\section{Electrical Resistivity}

The electrical resistivity test (popularly known as the soil resistivity test) is a common method used by geotechnical engineers to evaluate soil corrosivity. Corrosion of a metal is affected by the variation in potential that exist at different points or areas on the surface of a metal. Similarly, the electric resistance between opposite faces of a unit cube of a material can be obtained by measuring the potential drop between metal electrodes placed in the material. The electrical resistivity test uses this principle.

As-compacted and soaked samples from all batches of BOF and EAF(L) slag were tested for electrical resistivity according to ASTM G57-95a. Resistivity measurements were made using a Nilsson Model 400, 4-pin soil resistance meter (manufactured by Nilsson Electrical Laboratory Inc.) in a soil box of $3.8 \mathrm{~cm} \mathrm{x} 22 \mathrm{~cm} \mathrm{x}$ $3.1 \mathrm{~cm}$ in size with 4 insulated electrodes.

Steel slag samples were prepared at their optimum moisture content and compacted in the soil box by moist tamping until a compacted dry unit weight corresponding to $95 \%$ relative compaction was achieved. Special care was taken to level the top surface of the steel slag in the box; any voids present in the sample were filled. Figure 4.27 shows a photograph taken at the time of compaction of a BOF slag sample in the soil box for resistivity testing. Following sample preparation, two of the electrodes were connected to the two outer sides of the soil box, and the remaining two were connected to the box through the holes available along the longer sides of the soil box. All of the inner and outer electrodes were connected to the resistivity meter as shown (see Figure 4.28), and the resistivity of the as-compacted sample measured by the resistance meter was recorded (in ohm-centimeters). Then, the as-compacted sample was soaked in water for about $4 \mathrm{hrs}$ to ensure full saturation, and the electrical resistivity of the soaked sample was measured following the same procedure. 


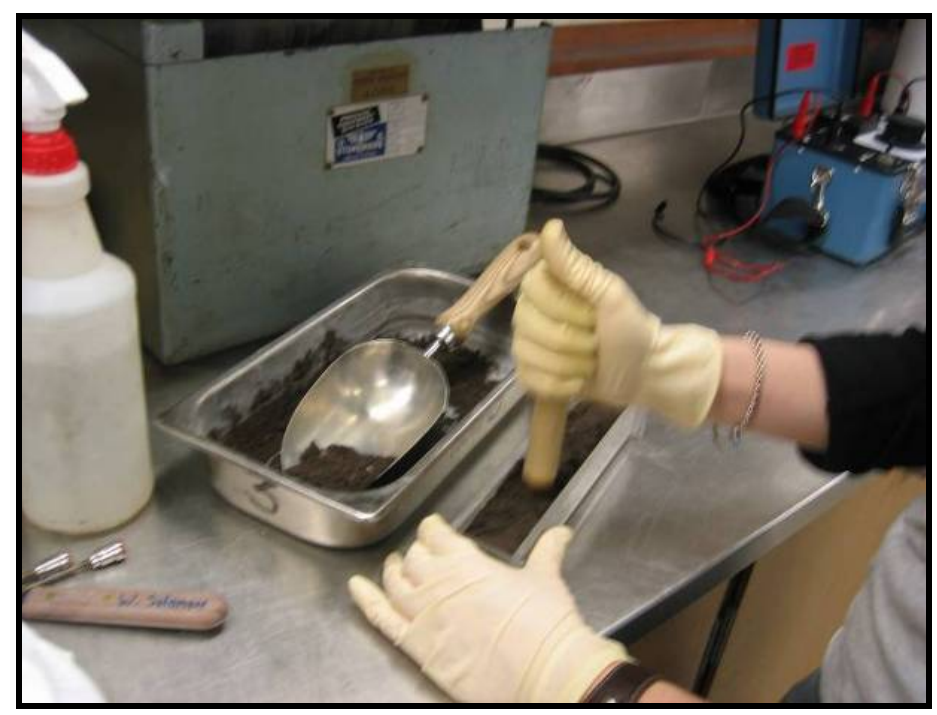

Figure 4.27 BOF slag sample preparation in the soil box for resistivity testing
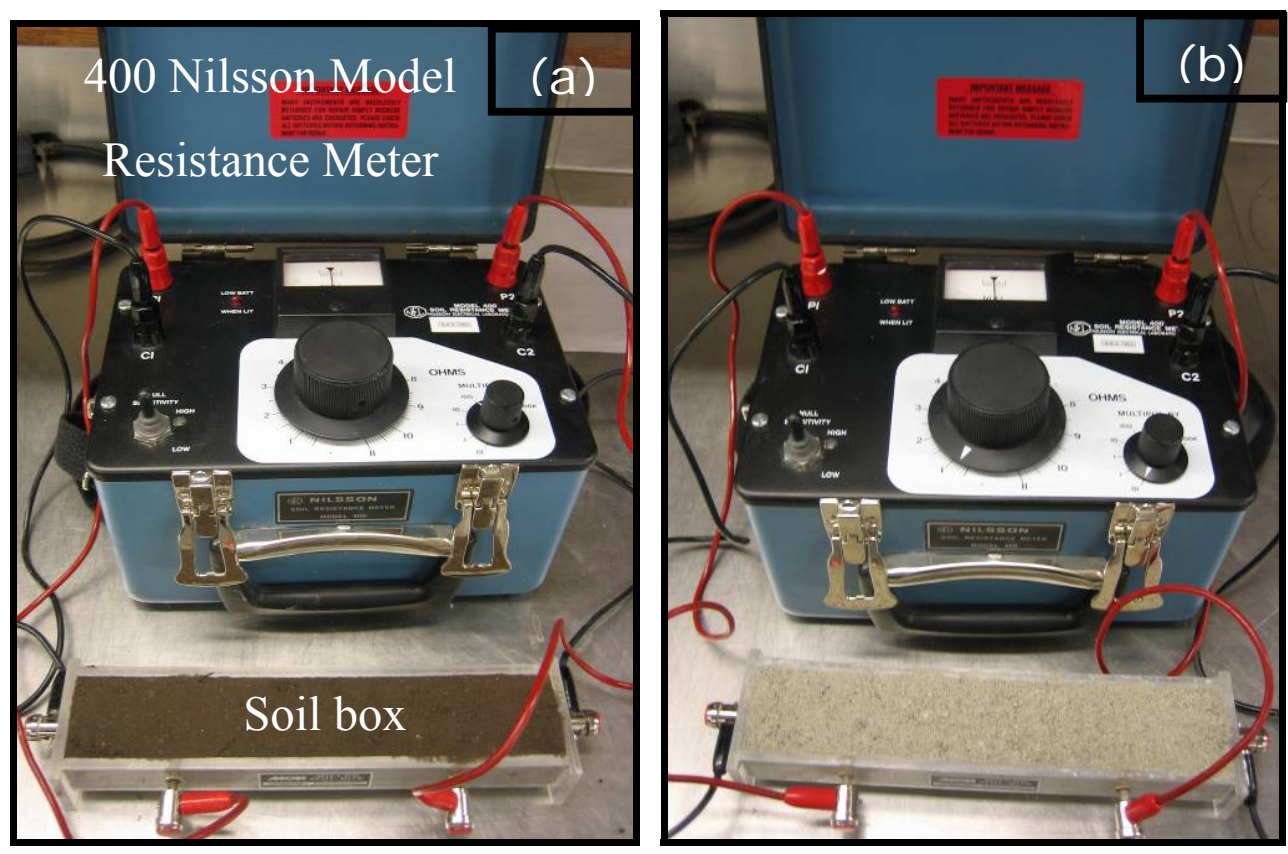

Figure 4.28 Electrical resistivity tests performed on (a) as-compacted BOF slag, and (b) as-compacted $\mathrm{EAF}(\mathrm{L})$ slag 
$\underline{p H}$

The main objective of the $\mathrm{pH}$ tests was to supplement the electrical resistivity measurements in evaluating the corrosivity of the steel slag samples. In accordance with ASTM G 51, pH tests were performed on the saturated specimens of both BOF and EAF (L) slag in the soil box. The $\mathrm{pH}$ probe, connected to an electronic $\mathrm{pH}$ meter (manufactured by Corning Instruments), was inserted into the sample to take the $\mathrm{pH}$ measurement (refer to Figure 4.29). The $\mathrm{pH}$ measurements together with the resistivity measurements were considered in evaluating the corrosion potential of steel slag samples.

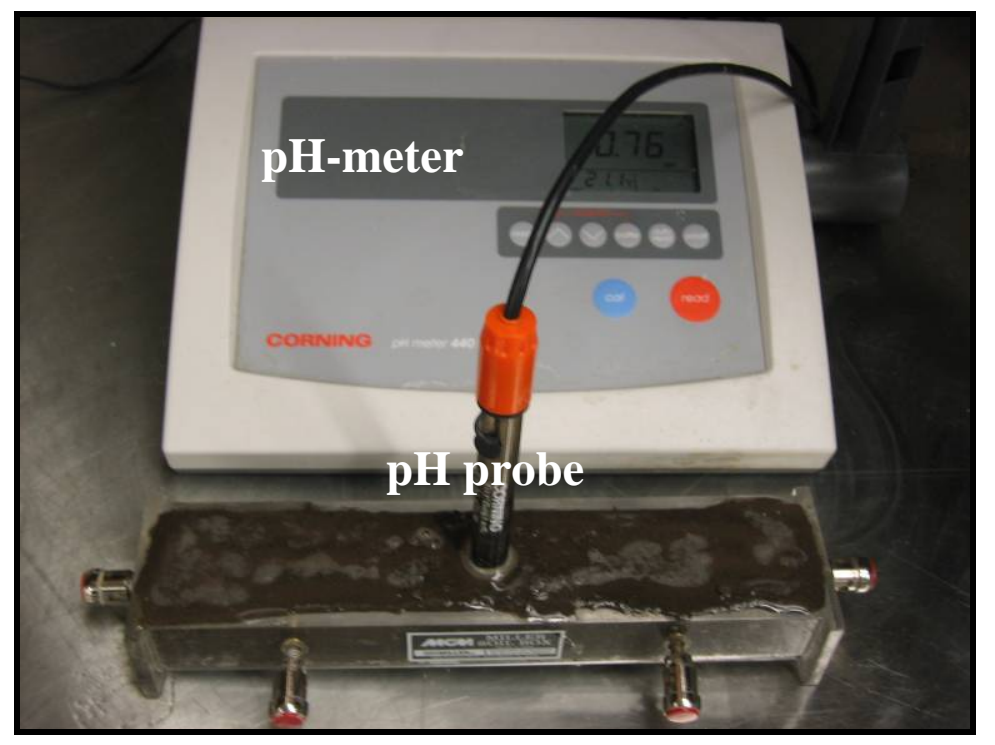

Figure $4.29 \mathrm{pH}$ measurement on a soaked BOF-slag

\subsubsection{Leaching Tests}

Steel slag is typically classified as a solid waste based on EPA regulations. However, the possibility of leaching of heavy metals (arsenic, barium, cadmium, chromium, lead, etc.) into the groundwater should be evaluated when steel slag is used as a geo-material. Typically, the Extraction Procedure (EP) Toxicity Test and the Toxicity Characteristic Leaching Analysis (TCLP) are performed to determine the concentrations of the contaminants identified by the EPA in the steel slag leachates. The TCLP test consists of two major steps: extracting the contaminants using an acetic acid solution and 
determining the concentration of these contaminants. The TCLP test simulates the worst case scenario for leaching of contaminants from a landfill in acidic conditions. Many industrial wastes are not disposed in acidic conditions. Therefore, in some cases neutral leachate tests, such as the EP Water Tests (Indiana Water Leach Test), can provide a more realistic assessment of the leaching potential of wastes in the environment.

Fresh $\mathrm{EAF}(\mathrm{L})$ and BOF slag samples were tested for their leaching potential by the Severn Trent Laboratories, Inc. located in Valparaiso, IN. Representative steel slag samples were supplied to this laboratory by the slag processor companies. TCLP analysis was performed with an Inductively Coupled Argon Plasma (ICAP) in accordance with the test methods outlined in EPA 6010 B and EPA 7470 which are used to determine heavy metal contaminants in leachates. The other contaminant concentrations were determined by neutral leachate tests. Based on the TCLP analysis, steel slag samples were classified according to the Indiana Administrative Code Restricted Waste Site Type Criteria (Indiana Administrative Code, 329 IAC 2-9-3).

\subsection{Tests on Mixtures of Steel Slag}

Experimental tests were performed on mixtures of Class-C fly ash and steel slag (BOF and $\mathrm{EAF}(\mathrm{L})$ slag) to assess their compaction, long-term swelling, and strength gain characteristics. The effect of ground rubber addition to BOF slag on the swelling response of the mixtures was also assessed.

\subsubsection{Compaction Tests on Mixtures}

The effect of Class-C fly ash addition on the compaction curves of EAF(L) slag was investigated using standard Proctor compaction tests. Tests were performed on mixtures of EAF(L) containing 5 and 20\% Class-C fly ash (by weight). Prior to compaction, dry mixtures were prepared by thoroughly mixing 5 and 20\% Class-C fly ash with $\mathrm{EAF}(\mathrm{L})$ slag to ensure proper blending of the fly ash in the steel slag matrix. In order to define the compaction curve of the mixtures tested, compaction test measurements were made at six 
different moisture content values. Tests were performed in 10-cm-diameter (4-inchdiameter) molds in accordance with ASTM D698-00a.

\subsubsection{Unconfined Compression Tests on Mixtures}

Due to their chemical composition, steel slags may show self-cementitious properties when properly cured. In order to assess the strength gain characteristics of steel slag, a few unconfined compression tests were performed on pure fresh EAF(L) slag and aged BOF slag samples. Results of the unconfined compression tests on compacted BOF and EAF(L) slag samples did not show significant strength gain with curing time. Therefore, use of activators to initiate cementation reactions was explored. In this study, Class-C fly ash was chosen as an activator, and the gain in strength over time of the compacted Class-C fly ash and steel slag mixtures was evaluated. Unconfined compression (UC) tests were performed on the following mixtures of $\mathrm{EAF}(\mathrm{L})$ and BOF slag:

EAF (L) slag and Class-C fly ash mixtures:

- Batch-2 Fresh EAF(L) slag + $5 \%$ Class-C fly ash (by weight)

- Batch-2 Fresh EAF(L) slag + $10 \%$ Class-C fly ash (by weight)

- Batch-2 Fresh EAF(L) slag $+20 \%$ Class-C fly ash (by weight)

BOF slag and Class-C fly ash mixtures:

- Batch-3 Aged BOF slag + $5 \%$ Class-C fly ash (by weight)

- Batch-3 Aged BOF slag + $10 \%$ Class-C fly ash (by weight)

Steel slag mixtures were tested as per ASTM D1502-04 (The Standard Test Methods for Unconfined Compressive Strength of Compacted Soil-Lime Mixtures). The dry mixtures were prepared with addition of $5 \%, 10 \%$ and $20 \%$ Class-C fly ash (by weight). The mixtures were thoroughly mixed, and water was then added to the samples until the optimum moisture content was attained. Samples were compacted in a split mold of $10 \mathrm{~cm}$ (4inch) in diameter and $20 \mathrm{~cm}$ (8inch) in height in five layers with 26 blows/layer using a standard Proctor rammer. The number of blows required to reach the Standard Proctor energy was calibrated for the volume of the UC mold. Prior to compaction, the inner surface of the split mold was lightly greased with Vaseline to 
facilitate easy removal of the compacted samples after curing. Prior to removal of the mold, each sample with the mold was wrapped with a transparent stretch and cured for 1 day in the moist room facility $\left(80 \%\right.$ humidity at $\left.20^{\circ} \mathrm{C}\right)$. Figure 4.30 (a), (b), (c), (d), (e) and (f) show photographs of the spilt mold used in the UC tests, dry steel slag and ClassC fly ash mixture, preparation of the sample with water spraying, compaction in the split mold, mass measurement and curing in the moist room facility, respectively. After 1 day of curing in the moist room, the samples were carefully removed from the split mold. The samples were then wrapped with a stretch and placed back in the moist room facility and maintained there for the targeted curing time periods. For all the mixtures of fly ash and steel slag, unconfined compression tests were performed on samples cured for 1, 2, 4, 7, 14 and 30 days. Figure 4.31 shows the removal of the mold, labeling of the sample with its preparation time and date and wrapping with a stretcher, curing of the samples in the moist room, and UC test in the compression test machine.

The samples were tested using an automated pneumatic compression machine (manufactured by Satec Systems, Inc) with a capacity of 54 tons (120000 lbs). The compression machine was equipped with an LVDT with a displacement measurement range of $5 \mathrm{~cm}$ (2 inch) [See Figure 4.31 (d)]. As per ASTM 5102-04, unconfined compression tests are typically performed at a deformation rate of $0.5 \%-2 \% / \mathrm{min}$. Slower rates are usually adopted when testing brittle specimens, while faster rates are typically applied to non-brittle specimens. Due to the brittle behavior of the compacted steel slag and Class-C fly ash mixtures, unconfined compression tests were performed with a strain rate of $\sim 0.75 \% / \mathrm{min}$. 

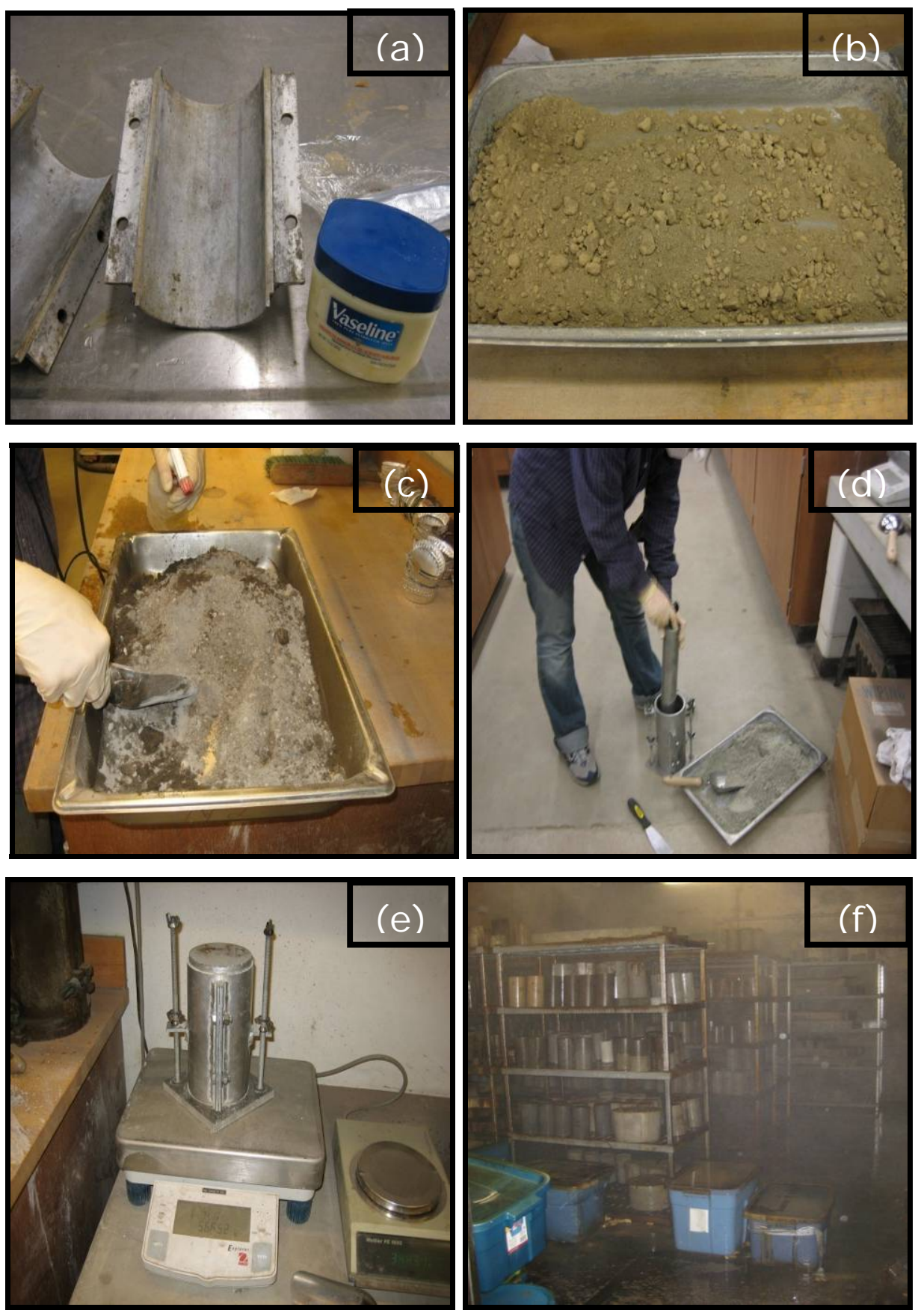

Figure 4.30 UC sample preparation steps prior to curing: (a) greasing the split mold, (b) preparing the dry steel slag and fly ash mixture, (c) spraying water to achieve the optimum moisture content of the sample, (d) compacting in layers in a mold $10 \mathrm{~cm}$ (4inch) in diameter and $20 \mathrm{~cm}$ (8inch ) in height, (e) measuring the mass of the compacted sample, and (f) placing the mold with the compacted sample in the moist room to allow curing for 1 day 

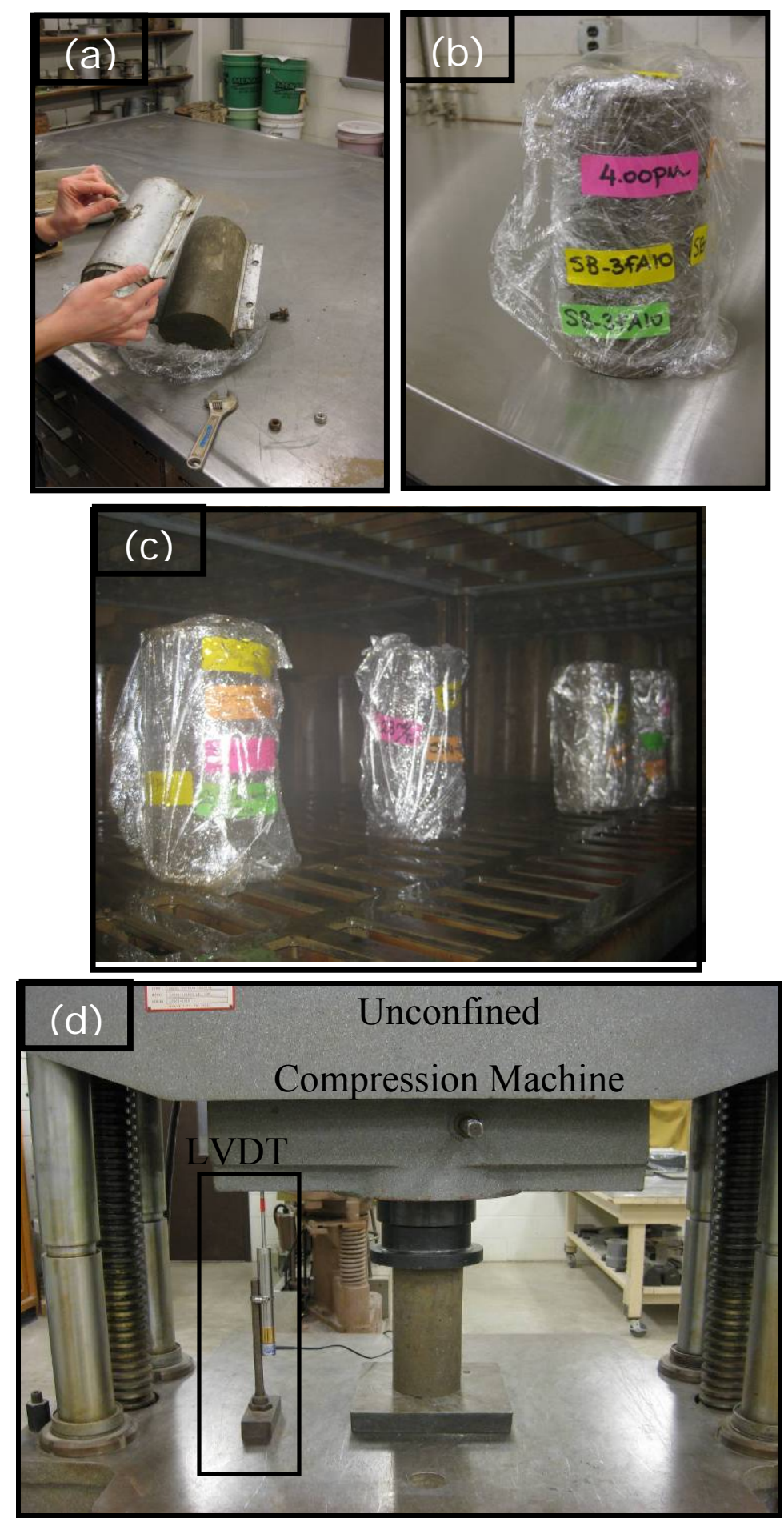

Figure 4.31 UC sample preparation and testing after the samples were cured: (a) removing the sample from the mold, (b) labeling the samples with time and date, (c) curing of samples in the moist room for the designated curing times, and (d) testing the sample in a compression test machine 


\subsubsection{Swelling Tests on Mixtures}

In order to explore methods that could be used to mitigate the swelling of steel slag, longterm CBR swelling tests were also performed on mixtures of steel slag and other recyclable materials. The effects of addition of Class-C fly ash and ground rubber on the swelling properties of steel slag were also evaluated in this research. Long-term swelling tests were performed on the following steel slag mixtures:

Mixtures of EAF (L) slag and Class-C fly ash:

- Batch-2 Fresh EAF(L) slag + 5 \% (by weight) Class-C fly ash

- Batch-2 Fresh EAF(L) slag + $10 \%$ (by weight) Class-C fly ash

- Batch-2 Fresh EAF(L) slag + $20 \%$ (by weight) Class-C fly ash

Mixtures of BOF slag and Class-C fly ash and mixtures of BOF slag and ground rubber:

- Batch-1 Fresh BOF slag $+10 \%$ (by weight) Class-C fly ash

- Batch-1 Fresh BOF slag $+10 \%$ (by weight) Class-C fly ash

- Batch-3 Aged BOF slag $+10 \%$ (by weight) ground rubber

- Batch-3 Aged BOF slag + 10\% (by weight) ground rubber

Mixtures of steel slag were prepared at their optimum moisture content and compacted in 15-cm-diameter (6 inch) CBR molds; samples were compacted with an energy equivalent to the Standard Proctor energy. The long-term swelling tests on the mixtures were set-up in accordance with ASTM D1883, following the procedure previously described for the swelling tests on pure steel slag samples (see Section 4.6). The expansion of the steel slag mixtures was monitored for a period of about 8 months.

\subsection{Summary}

This chapter describes the testing materials, testing equipment, and the experimental procedures followed in this research. The experimental program in this research was designed to determine the geotechnical properties of two different types of steel slag: BOF slag and $\mathrm{EAF}(\mathrm{L})$ slag. First, tests were performed to determine the index, mineralogical, morphological and mechanical properties of BOF and $\mathrm{EAF}(\mathrm{L})$ slag samples. Corrosivity, $\mathrm{pH}$, and leaching tests were then performed on steel slag samples to 
evaluate the environmental impact of using BOF and $\mathrm{EAF}(\mathrm{L})$ slags in geotechnical applications. Long-term swelling tests were performed on BOF and $\mathrm{EAF}(\mathrm{L})$ slag samples to determine their swelling potential. Steel slag samples were mixed with various percentages of Class-C fly ash and the strength gain characteristics of the compacted mixtures were evaluated based on the results of unconfined compression tests. Several methods that could potentially be used to mitigate the swelling of steel slag were also explored in this research. Long-term swelling tests were performed on mixtures of Class$\mathrm{C}$ fly and BOF and EAF(L) slags. The effect of addition of ground rubber to BOF slag on the long-term swelling behavior of BOF slag was also investigated. 


\section{CHAPTER 5. ENGINEERING PROPERTIES OF BOF SLAGS}

\subsection{Introduction}

This Chapter presents the results of the tests performed to obtain the engineering properties of BOF slag samples. In order to assess the variations in the grain-size distributions of the steel slag produced at the source plant, four different batches of BOF slag samples from the source plant were tested. The effect of aging on the engineering properties of BOF slag was also evaluated in this research by testing both fresh and oneyear-aged BOF slag samples. Fresh and aged BOF slag samples were named based on their time of arrival to the Purdue University research laboratory. For example, Batch-1 Fresh BOF slag refers to the fresh BOF slag samples that were received first, and B-3 Aged BOF slag refers to the aged samples that were received last. The four batches of fresh and aged BOF slag samples tested in this research were :

- Batch-1 Fresh BOF slag (B-1 Fresh BOF slag; received on 11/06)

- Batch-2 Fresh BOF slag (B-2 Fresh BOF slag; received on 10/07)

- Batch-2 Aged BOF slag (B-2 Aged BOF slag; received on 10/07)

- Batch-3 Aged BOF slag (B-3 Aged BOF slag; received on 12/07)

The results of the tests performed on of BOF slag samples are presented in the following main sections of this Chapter:

- Chemical composition

- Index properties

- Mineralogical and morphological properties

- Geotechnical properties

- Long-term swelling response

- Heavy metal leaching and corrosivity potential 


\subsection{Chemical Composition of BOF slag}

The oxide composition of BOF slag samples was determined using X-ray fluorescence (XRF) analysis by the slag processing company (Multiserv) handling and distributing the BOF slag from the source plant (Indiana Harbor West Steel Plant Indiana). Table 5.1 presents the oxide composition of BOF slag. The $\mathrm{FeO}$ content of the tested BOF slag is slightly higher than that of most of the BOF slags reported in the literature (see Table 3.2). Nonetheless, the percentages of most of the oxides present in the BOF slag samples tested in this study are within the ranges reported by other researchers (Poh et al. 2006; Tossavanien et al. 2007).

Table 5.1 Chemical composition of Batch-1 Fresh BOF slag

\begin{tabular}{cccc}
\hline Oxides & $\%$ & Oxides & $\%$ \\
\hline \hline $\mathrm{CaO}$ & 39.40 & $\mathrm{TiO}_{2}$ & 0.40 \\
$\mathrm{FeO}$ & 30.23 & $\mathrm{Na}_{2} \mathrm{O}$ & 0.25 \\
$\mathrm{SiO}_{2}$ & 11.97 & $\mathrm{Cr}_{2} \mathrm{O}_{3}$ & 0.20 \\
$\mathrm{MgO}$ & 9.69 & $\mathrm{~K}_{2} \mathrm{O}$ & 0.05 \\
$\mathrm{MnO}$ & 2.74 & $\mathrm{Cl}$ & 0.01 \\
$\mathrm{Al}_{2} \mathrm{O}_{3}$ & 2.16 & $\mathrm{SO}_{3}$ & 0.12 \\
$\mathrm{P}_{2} \mathrm{O}_{5}$ & 1.00 & L.O.I. & 1.80 \\
\hline
\end{tabular}

${ }^{\mathrm{a}}$ L.O.I $=$ Loss of ignition

\subsection{Index Properties of BOF slag}

Grain-size analyses and specific gravity, coarse aggregate absorption and Atterberg limits tests were performed on various batches of fresh and aged BOF slag samples. All BOF slag samples were characterized by both the Unified Soil Classification System (USCS) and the American Association of State Highway and Transportation Officials (AASHTO) soil classification system based on the index test results. The results of the index tests on both fresh and aged BOF slag samples are presented next. 


\subsubsection{Grain-size Analyses}

The gradations of the BOF slag samples were determined by sieve and hydrometer analyses. Several sieve analyses were performed on fresh and aged BOF slag samples obtained from different batches (see Figure 5.1). As BOF slag cools down in the pits, it breaks down into a wide range of particle sizes. Because steel slag is a by-product of the steel industry, its production is not controlled in the steel plants and, hence, slight variations were observed in the gradation of the BOF slags generated at different times at the source plant. In addition, aging of BOF slag during stockpiling in open-air facilities can cause agglomeration and break down of particles, which might also cause variations in the gradation of aged BOF slag.

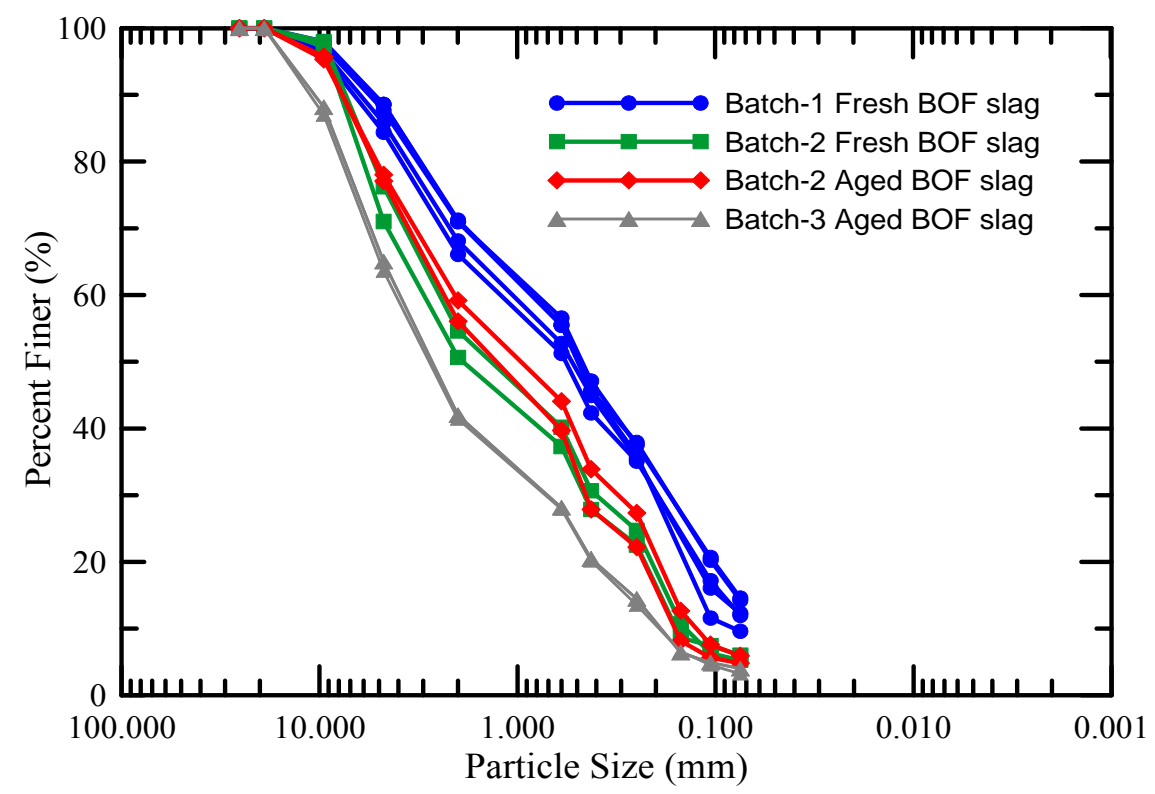

Figure 5.1 Sieve analyses of BOF slag samples

BOF slag consists mainly of sand-size particles with smaller percentages of silt-size and gravel-size particles. All the representative fresh and aged BOF slag samples were classified as poorly-graded sand (particle sizes ranging from $0.075 \mathrm{~mm}$ to $4.75 \mathrm{~mm}$ ) with silt and gravel (silt particle sizes range from $0.01 \mathrm{~mm}$ to $0.075 \mathrm{~mm}$, while gravel particle sizes range from $4.75 \mathrm{~mm}$ to $16 \mathrm{~mm}$ ). The percentages of gravel-size, silt-size and sand- 
size particles in the tested BOF slag samples were in the ranges of $14-35 \%, 4-12 \%$ and $61-74 \%$ (by weight), respectively. Batch-1 Fresh BOF slag sample contained more than $10 \%$ fines and, hence, hydrometer analysis was performed for the BOF slag particles passing through the No. 40 sieve to obtain the particle-size distribution for particles smaller than $0.425 \mathrm{~mm}$. Figure 5.2 shows the grain-size distribution curve obtained from sieve and hydrometer analysis performed for Batch-1 Fresh BOF slag, which contained fines in the silt-size range.

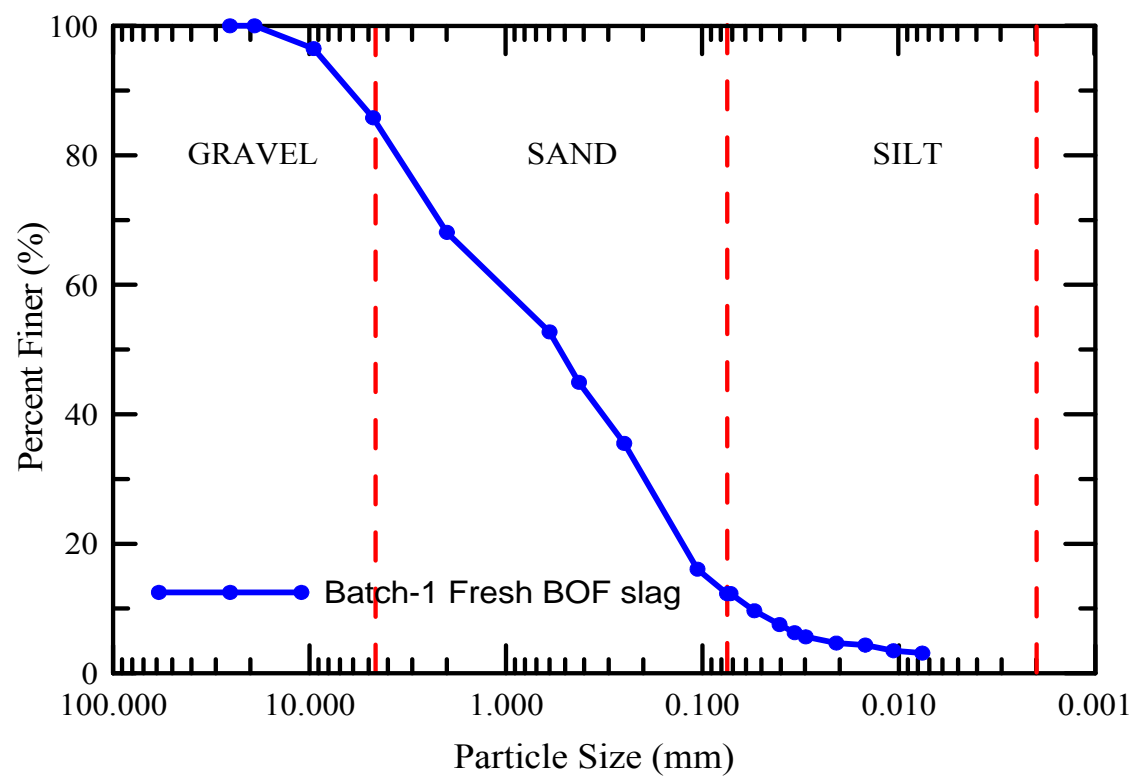

Figure 5.2 Grain-size distribution of Batch-1 Fresh BOF slag

Figure 5.3 shows the grain-size distribution curves for all the BOF slag samples considered in this research. Attempts were made to perform Atterberg limits tests on BOF slag particles passing the No.40 sieve in accordance with ASTM D4318. During the performance of the liquid limit tests, at low to moderate moisture contents, the BOF slag fines did not slide on the cup of the Casagrande device to close the groove. Further addition of water to BOF slag made it impossible to form a groove. Moist BOF slag particles crumbled quickly when rolled, making it impossible to form the 3-mm-diameter threads. Therefore, BOF slag fines are nonplastic. Table 5.2 provides the parameters derived from the representative grain-size distribution curves and the classification of the 
BOF slag samples according to the USCS and AASHTO classification systems (ASTM D2487-06 and AASHTO M145).

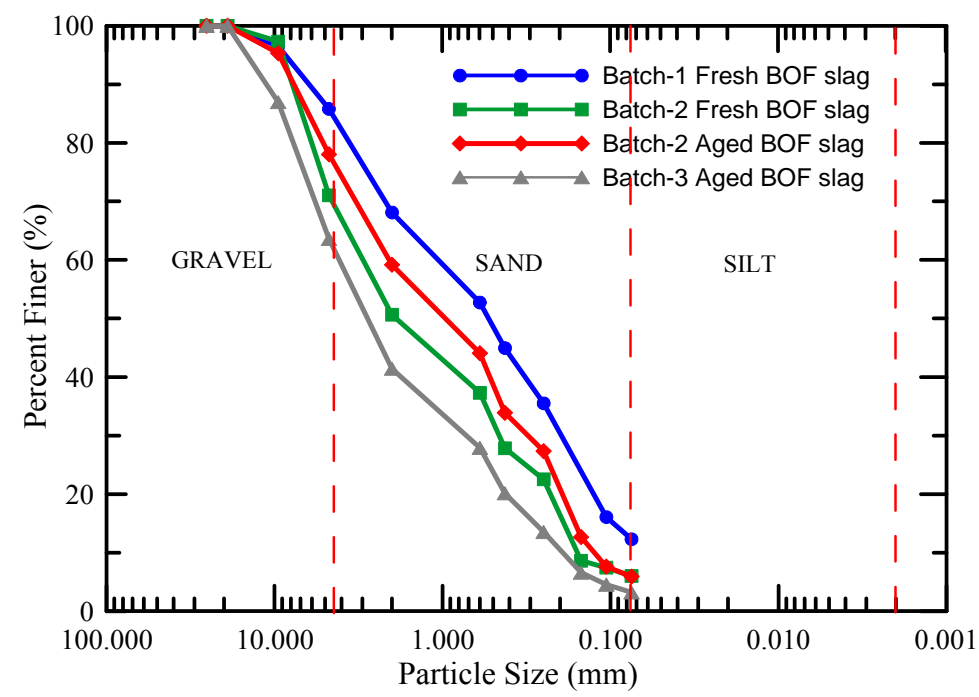

Figure 5.3 Representative grain-size distribution curves for BOF slag samples

Table 5.2 Summary of grain-size distribution analyses and classification of BOF slag samples

\begin{tabular}{|c|c|c|c|c|c|c|c|c|c|}
\hline \multirow{2}{*}{ Sample ID } & \multirow{2}{*}{$\begin{array}{c}\% \\
\text { Gravel }\end{array}$} & \multirow{2}{*}{$\begin{array}{c}\% \\
\text { Sand }\end{array}$} & \multirow{2}{*}{$\begin{array}{c}\% \\
\text { Silt }\end{array}$} & \multirow{2}{*}{$\begin{array}{c}\% \\
\text { passing } \\
\text { No.10 }\end{array}$} & \multirow{2}{*}{$\begin{array}{c}\% \\
\text { passing } \\
\text { No.40 }\end{array}$} & \multirow{2}{*}{$\begin{array}{c}D_{50} \\
(\mathrm{~mm})\end{array}$} & \multirow{2}{*}{$\mathrm{C}_{\mathrm{u}}$} & \multicolumn{2}{|c|}{ Classification system } \\
\hline & & & & & & & & USCS & AASHTO \\
\hline $\begin{array}{l}\text { B-1 Fresh } \\
\text { BOF slag }\end{array}$ & 14 & 74 & 12 & 68 & 45 & 0.55 & 210.6 & $\begin{array}{c}\text { SP-SM with } \\
\text { gravel }^{\text {a }}\end{array}$ & $A-1-b$ \\
\hline $\begin{array}{l}\text { B-2 Fresh } \\
\text { BOF slag }\end{array}$ & 24 & 71 & 5 & 55 & 31 & 1.5 & $16 \quad 0.4$ & $\begin{array}{c}\text { SP-SM with } \\
\text { gravel }^{\text {a }}\end{array}$ & A-1-b \\
\hline $\begin{array}{l}\text { B-2 Aged } \\
\text { BOF slag }\end{array}$ & 22 & 72 & 6 & 59 & 34 & 1.0 & 150.3 & $\begin{array}{c}\text { SP-SM with } \\
\text { gravel }^{\text {a }}\end{array}$ & A-1-b \\
\hline $\begin{array}{l}\text { B-3 Aged } \\
\text { BOF slag }\end{array}$ & 35 & 61 & 4 & 42 & 20 & 2.8 & 220.7 & $\begin{array}{c}\text { SP-SM with } \\
\text { gravel }^{\text {a }}\end{array}$ & A-1-b \\
\hline
\end{tabular}

${ }^{a}$ Poorly-graded sand with silt and gravel 


\subsubsection{Specific Gravity}

The specific gravity of fine (sand and silt size) and coarse (gravel size) BOF slag particles were determined using different methods, as explained in Chapter 4. The average specific gravity of each BOF slag samples was determined by calculating the weighted average of the specific gravity values obtained for these two-size fractions. The results of the specific gravity tests on BOF slag samples are discussed next.

\section{Specific Gravity and Absorption of the Coarse Fraction of BOF Slag Samples}

The specific gravity and water absorption of BOF slag particles retained by the No.4 sieve (particles larger than $4.75 \mathrm{~mm}$ ) were determined by the coarse aggregate tests in accordance with ASTM C127. Table 5.3 provides the specific gravity and absorption values of the coarse aggregate for all of the BOF slag samples tested.

Table 5.3 Specific gravity and absorption values for the coarse fraction of BOF slag

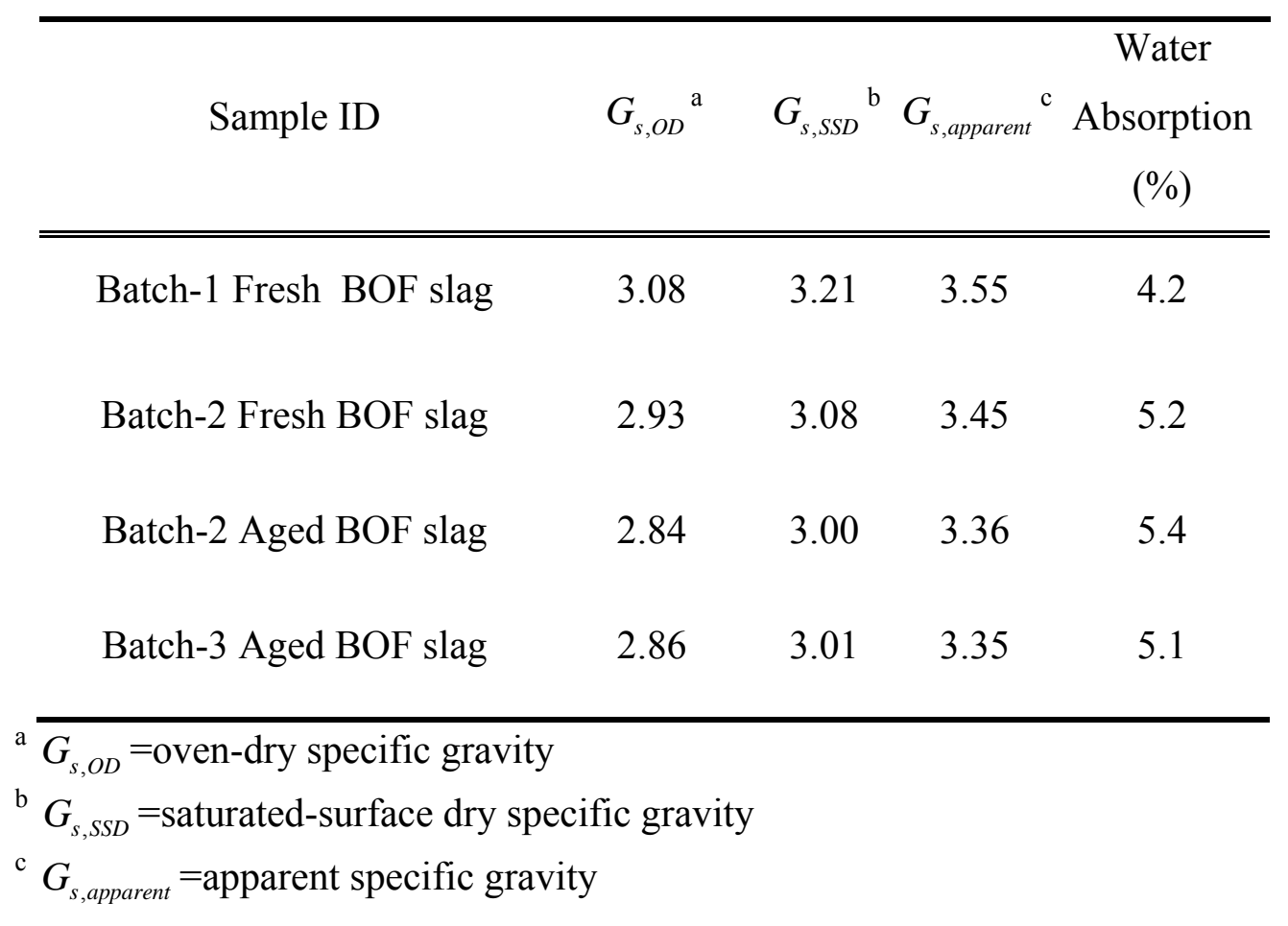


The specific gravities - $G_{s, O D}, G_{s, S S D}$, and $G_{s, a p p a r e n t}$ - are equal to the ratios of the oven-dry density, the saturated-surface dry density, and the apparent density of the coarse aggregates to the density of distilled water, respectively. As explained in Chapter 4, the apparent specific gravity is of importance in geotechnical applications. Therefore, the apparent specific gravity values were considered to be representative of the coarse fraction of the BOF slag samples. The apparent specific gravity of the coarse fraction of BOF slag samples were in the 3.35-3.55 range. The water absorption of the BOF slag samples were in the $4-5 \%$ range.

\section{Specific Gravity of the Fine Fraction of the BOF Slag Samples}

The specific gravity of the particles passing the No.4 sieve (particles smaller than 4.75 $\mathrm{mm}$ ) was determined using the water pycnometer, following ASTM D854. Table 5.4 provides the specific gravity test results for the silt- and sand-size particles of all BOF slag samples.

Table 5.4 Specific gravity of the fine fraction of BOF slag (particles smaller than $4.75 \mathrm{~mm})$

\begin{tabular}{cc}
\hline Sample ID & $G_{s, \text { fines }}$ \\
\hline \hline Batch-1 Fresh BOF slag & 3.25 \\
Batch-2 Fresh BOF slag & 3.30 \\
Batch-2 Aged BOF slag & 3.31 \\
Batch-3 Aged BOF slag & 3.33 \\
\hline
\end{tabular}

\section{Average Specific Gravity of BOF Slag Samples}

The average specific gravity values of the BOF slag samples was determined by calculating the weighted average of the specific gravity values determined for the fine (sand- and silt- size particles) and coarse (gravel-size particles) fractions of each batch. The average specific gravity for all representative BOF slag samples are compiled in 
Table 5.5. The specific gravity values of fresh and aged BOF slag samples from different batches were in the range of 3.29-3.34. These results show that the chemical composition of the BOF slag generated at the source steel plant is fairly consistent. The specific gravity of natural inorganic soils is typically in the 2.6-2.9 range. BOF slag has a higher iron oxide $\left(\mathrm{FeO} / \mathrm{Fe}_{2} \mathrm{O}_{3}\right)$ content (see Table 5.1) than natural soils and, therefore, its specific gravity is also higher.

Table 5.5 Average specific gravity of BOF slag samples

\begin{tabular}{cc}
\hline Sample ID & $G_{s, \text { average }}$ \\
\hline \hline Batch-1 Fresh BOF slag & 3.29 \\
Batch-2 Fresh BOF slag & 3.34 \\
Batch-2 Aged BOF slag & 3.32 \\
Batch-3 Aged BOF slag & 3.34 \\
\hline
\end{tabular}

\subsection{Mineralogical and Morphological Properties of BOF slag}

The mineralogical phases of fresh and aged BOF slag samples were identified using Xray diffraction analysis (XRD). The morphological characteristics of fresh and aged BOF slag samples were determined using optical microscopy and Scanning Electron Microscopy (SEM) examinations. The results of these analyses are presented next.

\subsubsection{Particle Mineralogy}

X-ray diffraction analysis was performed on Batch-1 Fresh and Batch-3 Aged BOF slag samples to determine their mineralogical phases. Both fresh and aged BOF slag samples showed almost identical XRD patterns (with slight changes in a few peak intensities; see Figure 5.4). The XRD patterns of BOF slag samples are very complex, with several overlapping peaks resulting from the many minerals present in these samples. BOF slag is cooled slowly in slag pits and, hence, there is enough time for formation of welldefined crystals. Several other researchers have reported similar XRD patterns for BOF 
slag (Reddy et al. 2006; Nicolae et al. 2007; Tossavanien et al. 2007). The X-ray diffraction patterns of BOF slag samples were analyzed by comparing the peaks present in the XRD patterns with those provided in The Joint Committee for Powder Diffraction Standards, Hanawalt System for identification of inorganic compounds (JCPDS). The software program Jade was also used to help identify the minerals present in the samples. Figure 5.5 and Figure 5.6 show the analyses of the XRD patterns of fresh and aged BOF slags (using the Jade software), respectively.

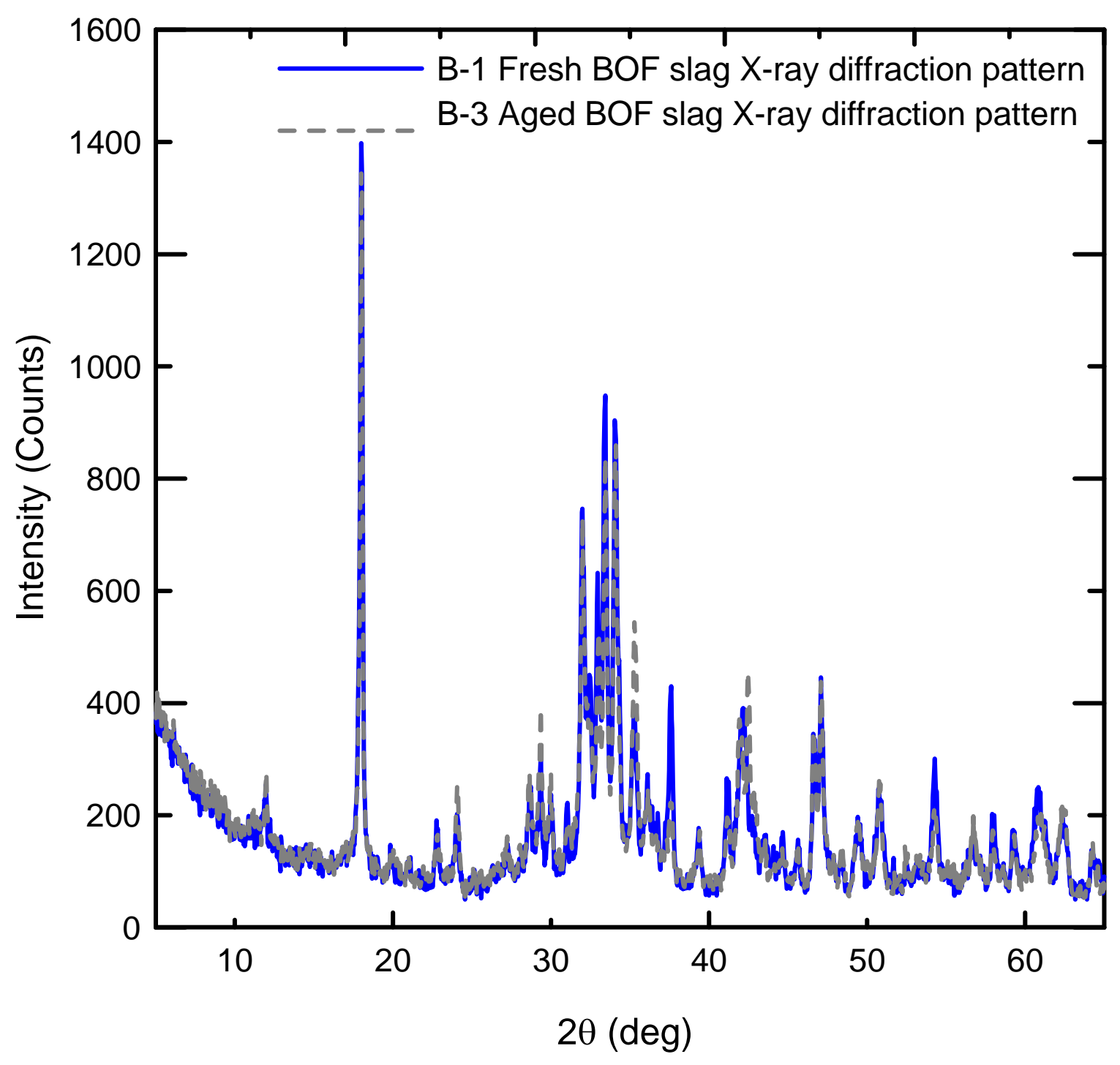

Figure 5.4 X-ray diffraction patterns for fresh and aged BOF slag samples 


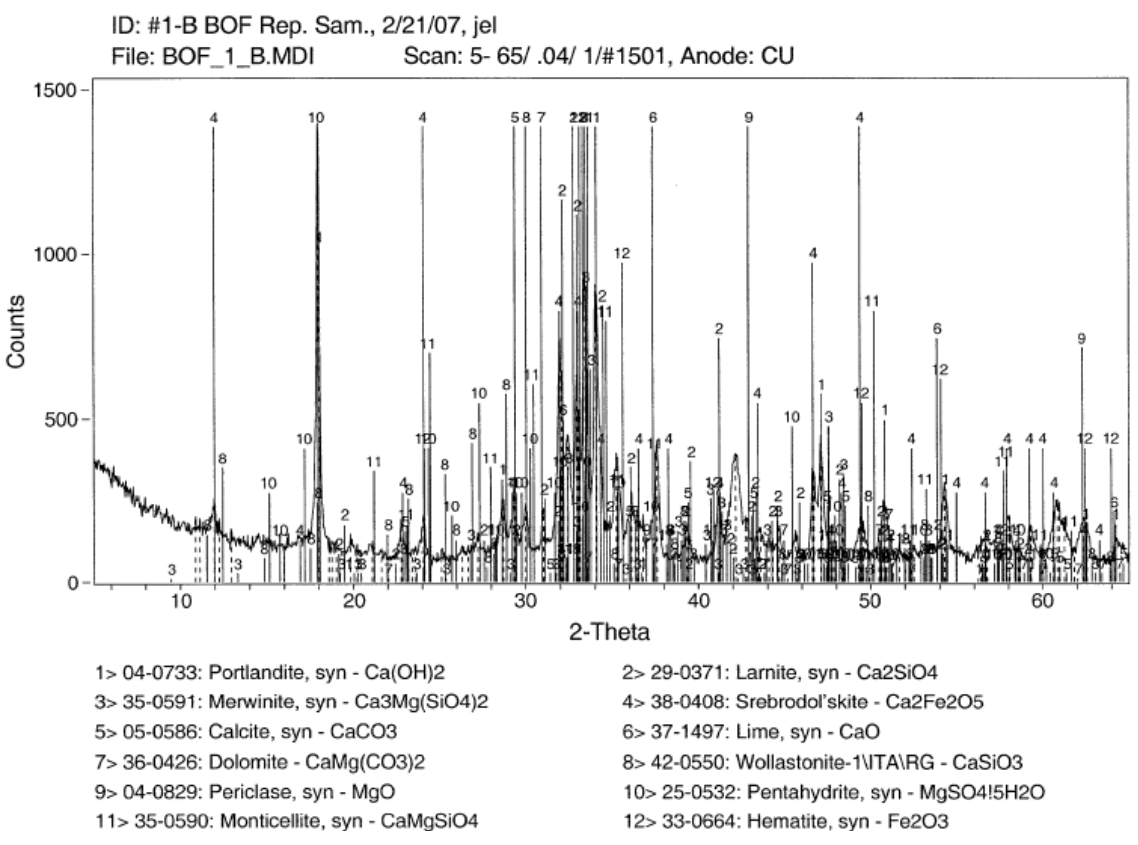

Figure 5.5 XRD analysis of Batch-1 Fresh BOF slag sample

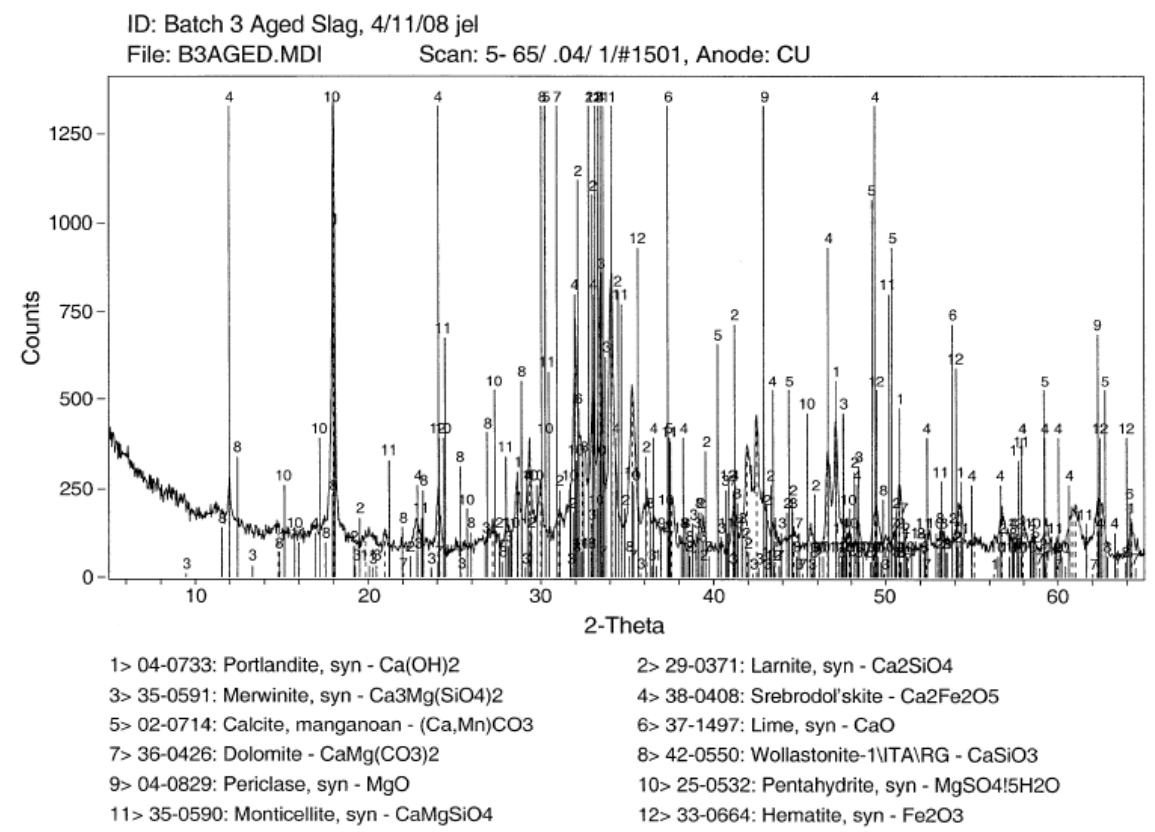

Figure 5.6 XRD analysis of Batch-3 Aged BOF slag sample 
Table 5.6 summarizes all of the mineral phases that were identified in the fresh and aged BOF slag samples. The mineral phases identified in the BOF slag samples were determined as major or minor depending on the intensity of the peaks, which gives an indication of the quantity of the mineral present in the sample. It is important to note that the very complex mineralogical composition of BOF slag, with many overlapping peaks and different solid solutions of oxides ( $\mathrm{FeO}$ and $\mathrm{MgO})$, makes the identification of the phases very difficult. Therefore, some of the overlapping mineral phases that could not be determined with certainty were identified as probable in Table 5.6. The major mineral phases present in fresh and aged BOF slag are portlandite $\left(\mathrm{Ca}(\mathrm{OH})_{2}\right)$, merwinite $\left(\mathrm{Ca}_{3} \mathrm{Mg}\right.$ $\left.\left(\mathrm{SiO}_{4}\right)\right)$ and srebrodol'skite $\left(\mathrm{Ca}_{2} \mathrm{Fe}_{2} \mathrm{O}_{5}\right)$. The presence of these minerals is expected since BOF slag contains $39 \%$ of lime $(\mathrm{CaO})$, which in the presence of moisture converts to $\mathrm{Ca}(\mathrm{OH})_{2}$. Minor phases included lime $(\mathrm{CaO})$, larnite $\left(\mathrm{Ca}_{2} \mathrm{SiO}_{4}\right)$, manganonan calcite $((\mathrm{Ca}$, $\left.\mathrm{Mn}) \mathrm{CO}_{3}\right)$ and dolomite $\left(\mathrm{CaMg}\left(\mathrm{CO}_{3}\right)_{2}\right)$.

Table 5.6 Mineralogical phases identified in fresh and aged BOF slags based on XRD analyses

\begin{tabular}{cccl}
\hline Mineral Type & Formula & Fresh BOF slag Aged BOF slag \\
\hline \hline Portlandite & $\mathrm{Ca}(\mathrm{OH})_{2}$ & major & major \\
Srebrodol'skite & $\mathrm{Ca}_{2} \mathrm{Fe}_{2} \mathrm{O}_{5}$ & major & major \\
Merwinite & $\mathrm{Ca}_{3} \mathrm{Mg}_{\left(\mathrm{SiO}_{4}\right)_{2}}$ & major & major \\
Larnite & $\mathrm{Ca}_{2} \mathrm{SiO}_{4}$ & minor & minor \\
Calcite (manganonan) & $\left(\mathrm{Ca},{\mathrm{Mn}) \mathrm{CO}_{3}}^{\mathrm{CaO}}\right.$ & minor & minor \\
Lime & $\mathrm{CaO}$ & minor & minor \\
Dolomite & $\mathrm{CaMg}\left(\mathrm{CO}_{3}\right)_{2}$ & minor & minor \\
Wollastonite & $\mathrm{CaSiO}_{3}$ & probable & probable \\
Periclase & $\mathrm{MgO}$ & probable & probable \\
Pentahydrite & $\mathrm{MgSO}_{4} \cdot 5 \mathrm{H}_{2} \mathrm{O}$ & probable & probable \\
Monticellite & $\mathrm{CaMgSiO}_{4}$ & probable & probable \\
Hematite & $\mathrm{Fe}_{2} \mathrm{O}_{3}$ & probable & probable \\
Magnesite & $\mathrm{MgCO}_{3}$ & probable & probable \\
\hline
\end{tabular}




\subsubsection{Particle Morphology}

The main objective of the SEM and optical microscopy studies was to understand the morphology (shape, angularity, sphericity, surface texture, etc.) of BOF slag particles. The morphology of the gravel-size BOF slag particles was examined using a light microscope. SEM studies were performed on sand- and silt-size BOF slag particles. The results of these studies are discussed next.

\section{Morphological Characteristics of Fresh BOF Slag Particles}

The shapes of the gravel-size fresh BOF slag particles were visible to the naked eye. The surface texture of gravel-size particles was examined using a light microscope. Figure 5.7 shows the gravel-size particles of fresh BOF slag.

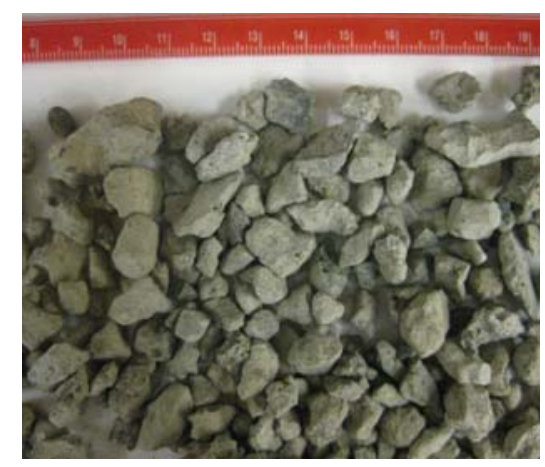

Figure 5.7 Gravel-size fresh BOF slag particles

Gravel-size particles of fresh BOF slag had shapes varying from subrounded to subangular. Distinct asperities and edges were visible in subangular, bulky particles. Most of the gravel-size particles had a high sphericity and a solid structure. A heterogeneous porous structure was also observed on the surface of a few particles. In general, a rough surface texture was observed on fresh BOF slag particles under light microscopy.

Sand- and silt-size fresh BOF slag particles were examined under SEM. Figure 5.8 (a) and (b) are SEM micrographs showing the shape and surface texture of Batch-1 
Fresh BOF slag particles, respectively. Figure 5.9 (a) and (b) are SEM micrographs showing the shape and surface texture (magnified to 200X) of sand- and silt-size Batch-2 Fresh BOF slag particles, respectively.

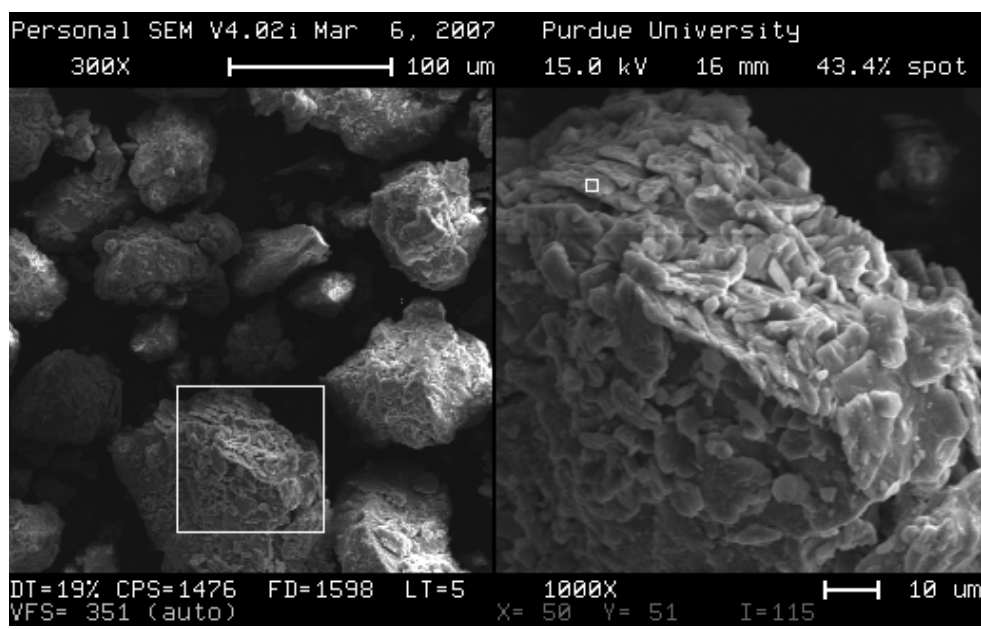

(a)

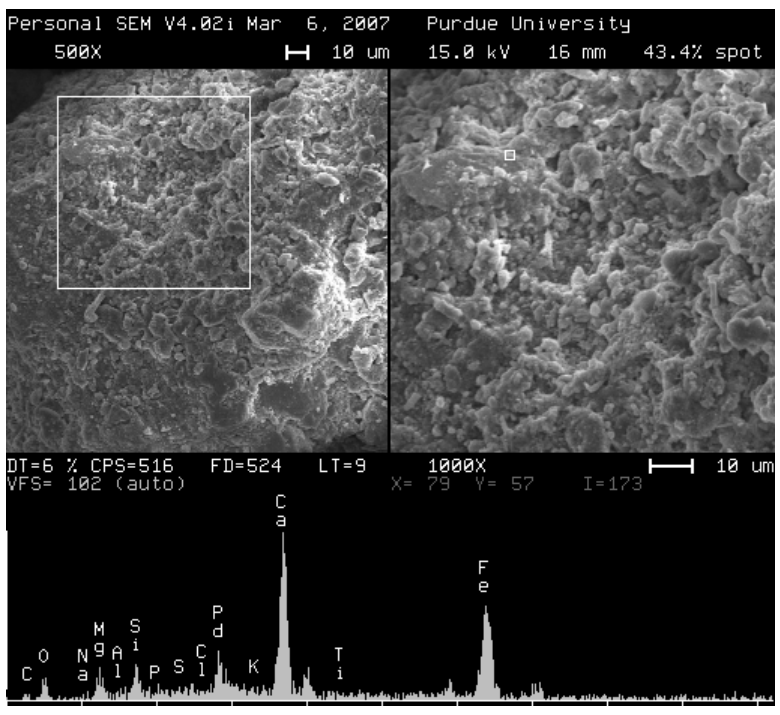

(b)

Figure 5.8 SEM micrographs of Batch-1 Fresh BOF slag sample: (a) particle shape, and (b) surface texture and elemental analysis 


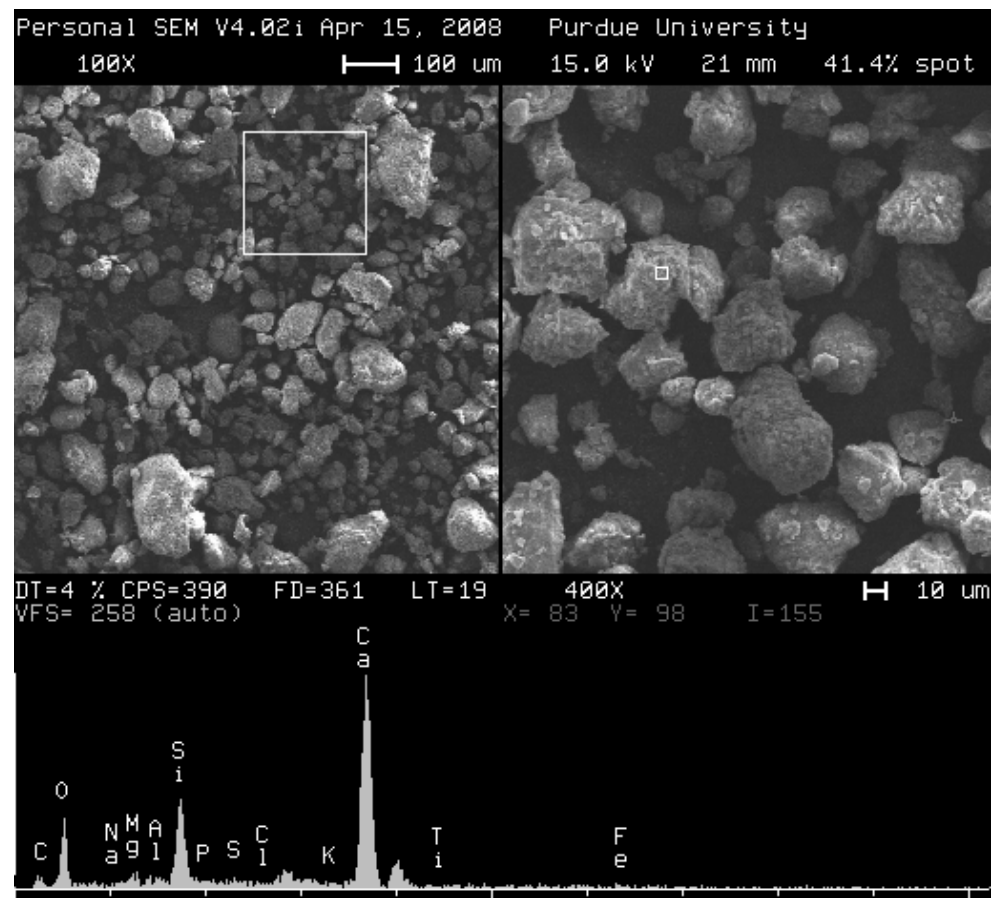

(a)

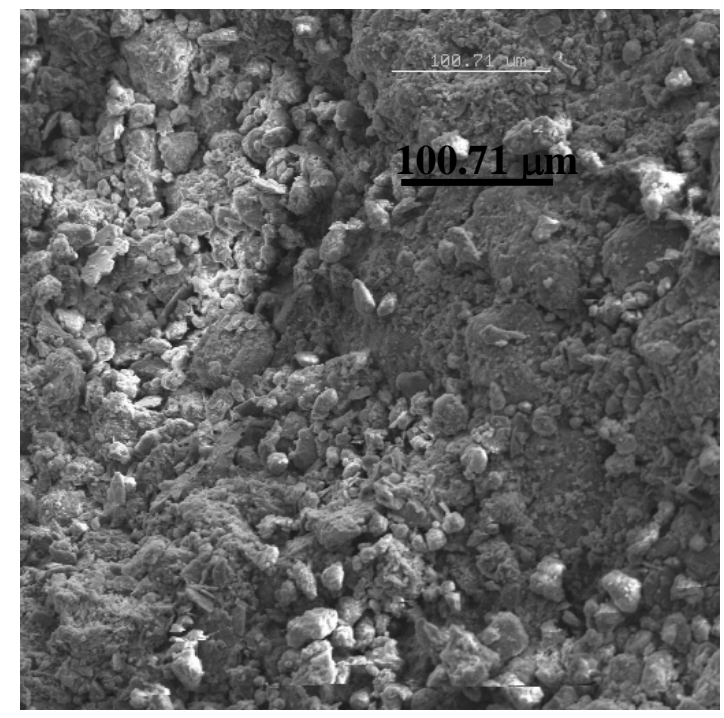

(b)

Figure 5.9 SEM micrographs of Batch-2 Fresh BOF slag sample: (a) particle shape and elemental analysis of sand- and silt-size particles, and (b) surface texture (magnification: 200X) 
SEM studies showed that sand- and silt-size fresh BOF slag particles have subrounded to angular shapes. Distinct asperities and edges were visible in angular bulky particles. Most of the sand- and silt-size particles examined under SEM had rough surface textures.

\section{Morphological Characteristics of Aged BOF Slag Particles}

In general, the morphological characteristics of gravel-size aged BOF slag particles are almost identical to those of fresh BOF slag particles, except for the presence of some agglomerated particles (see Figure 5.10). Even though the majority of the gravel-size fraction of aged BOF slag samples had solid structures, some gravel-size particles were generated from agglomeration of smaller-size BOF slag particles. Figure 5.11 shows one such agglomerated aged BOF slag particle. These agglomerated pieces showed very irregular shapes and very rough surface textures. Unlike the bulky BOF slag particles with a solid structure, these agglomerated pieces could be easily broken into smaller sizes.

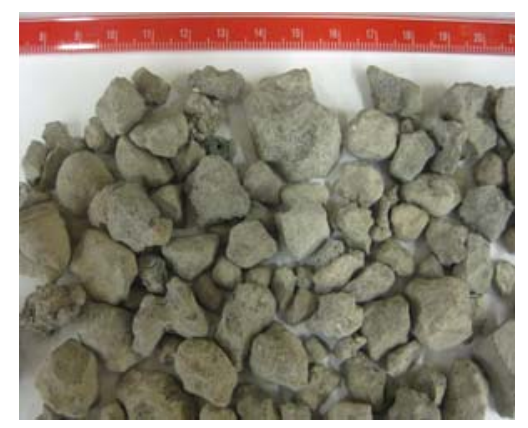

Figure 5.10 Gravel-size aged BOF slag particles

The morphological characteristics of sand- and silt-size aged BOF slag particles were also examined under SEM. Figure 5.12 (a) and (b) are SEM micrographs showing the particle shape and surface texture of aged BOF slag particles, respectively. The effects of aging could be seen as thin cloudy textures on the outer surfaces of the BOF slag particles. During aging of steel slag in open-air stockpiles, some hydrated components (such as $\mathrm{Ca}(\mathrm{OH})_{2}$ ) of BOF slag can react with $\mathrm{CO}_{2}$ from the air. The presence of this 
cloudy texture on the outer surfaces of the aged BOF slag particles was attributed to carbonation.

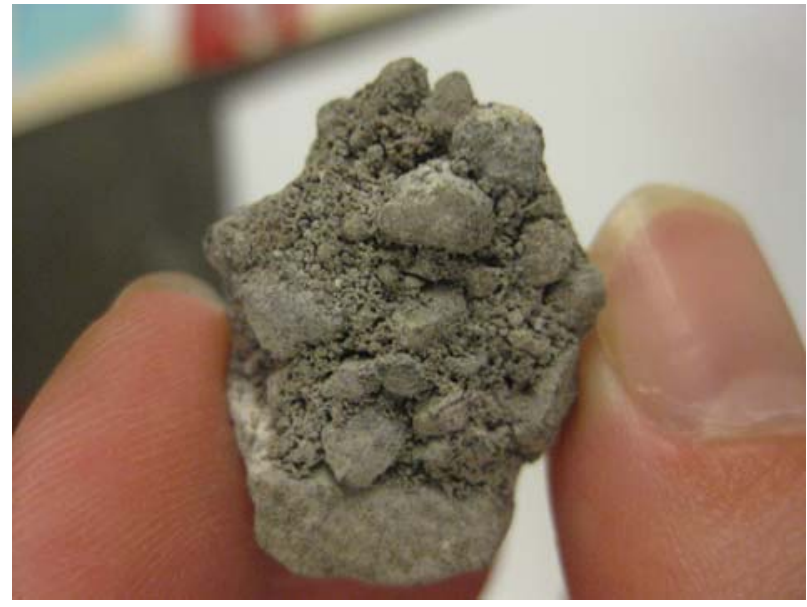

Figure 5.11 An agglomerated aged BOF slag particle

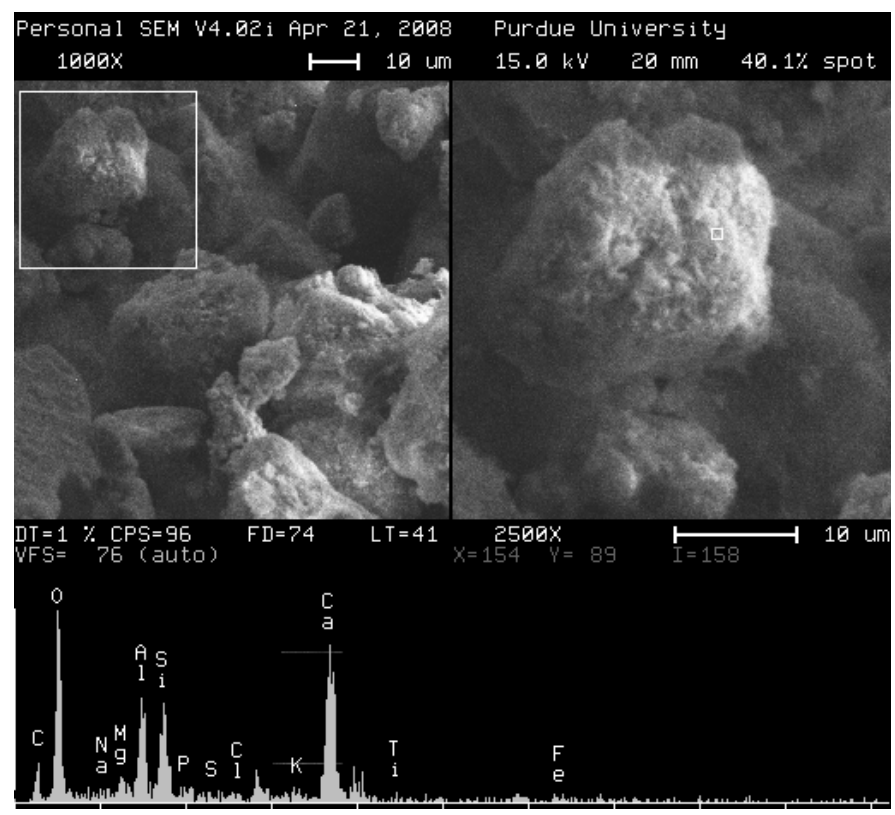

(a) 


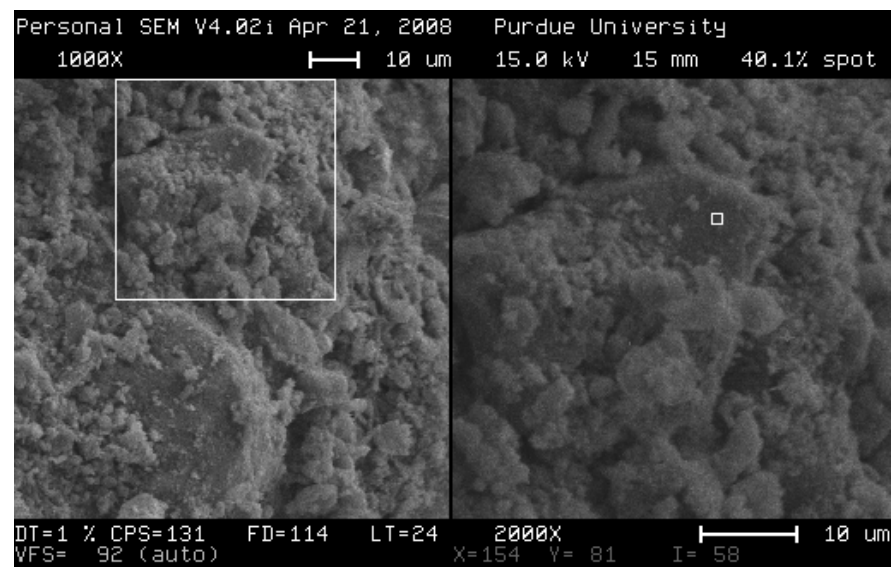

(b)

Figure 5.12 SEM micrographs of aged BOF slag particles: (a) particle shape and elemental analysis, and (b) surface texture

\subsection{Geotechnical Properties of BOF slag}

Compaction, maximum and minimum density, large-scale direct shear and triaxial tests results for BOF slag samples are provided next.

\subsubsection{Compaction Tests}

Fresh and aged BOF slag samples from different batches were tested using the standard Proctor compaction procedures. Figure 5.13 shows the moisture-density relationships (compacted dry unit weight versus moisture content curves) of the BOF slag samples. Zero-air-void curves that show the maximum possible dry unit weights are also shown in the figure (see Figure 5.13). 


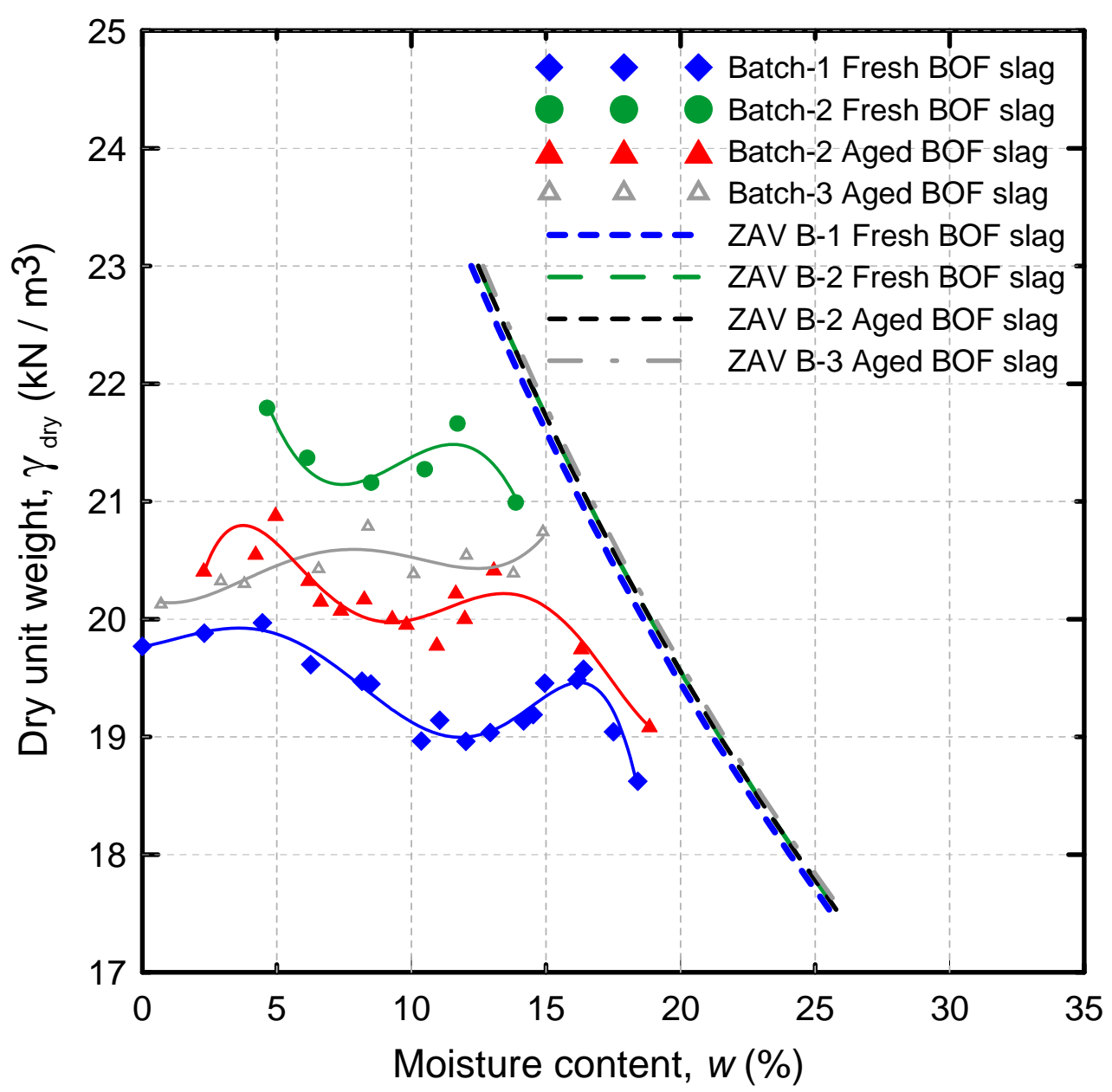

Figure 5.13 Compaction curves of BOF slag samples

Batch-1 Fresh, Batch-2 Fresh and Batch-2 Aged BOF slag samples showed irregular compaction curves with two peaks. The compaction curves obtained for these samples are similar to those of coarse-grained soils. The double-peak in the compaction curves can be explained as follows. The maximum dry unit weight $\gamma_{d, \max }$ is typically observed at a dry state. Surface tension forces develop between the particles when the soil is partially saturated, and during compaction, these surface tension forces hinder the sliding and movement of the particles into a denser state. Addition of more water breaks the surface tension forces, and thus the compacted dry unit weight values start to increase again (Foster 1962). The compaction curves of Batch-1 Fresh, Batch-2 Fresh and Batch-2 
Aged BOF slag samples reflect the effect of the surface tension forces at partially saturated states with $\gamma_{d, \max }$ values observed close to dry and fully saturated states.

Similar irregularly shaped compaction curves were observed in the literature for BOF slags. The compaction curves presented by Raposo (2005) for BOF slag had irregular shapes with $\gamma_{d \text {,max }}$ values of approximately $23-24 \mathrm{kN} / \mathrm{m}^{3}$ at moisture contents of $4 \%$ and $12 \%$.

The different values of $\gamma_{d \text {,max }}$ obtained for the BOF slag samples are a result of the differences in their gradations. As can be seen in Figure 5.3 and Table 5.2, $\gamma_{d \text {,max }}$ values increased with increases in the mean particle sizes $\left(D_{50}\right)$ of the Batch-1 Fresh, Batch-2 Aged and Batch-2 Fresh BOF slag samples. Batch-3 Aged BOF slag, on the other hand, did not follow this trend and exhibited a compaction curve without a distinct peak. This is because Batch-3 Aged BOF slag sample contained a significantly higher percentage of gravel-size particles $(\sim 35 \%)$ than the other BOF slag samples.

Particle degradation studies were performed on fresh and aged BOF slag samples by determining the gradation of slag samples before and after compaction. Figure 5.14 shows the grain-size distribution curves of the fresh and aged BOF slag samples after compaction together with the original grain-size distribution curves. The gradation of the fresh and aged BOF slag samples before and after compaction were almost identical, indicating minimal crushing of the particles during compaction. This shows that the BOF slag irregular compaction curves were not caused by particle degradation (due to compaction). Since BOF slag samples have irregular compaction curves, it is difficult to determine the optimum moisture content $\left(w_{o p t}\right)$ for field compaction. $w_{o p t}$ and $\gamma_{d, \max }$ values obtained from the Proctor compaction test results are compiled in Table 5.7. 


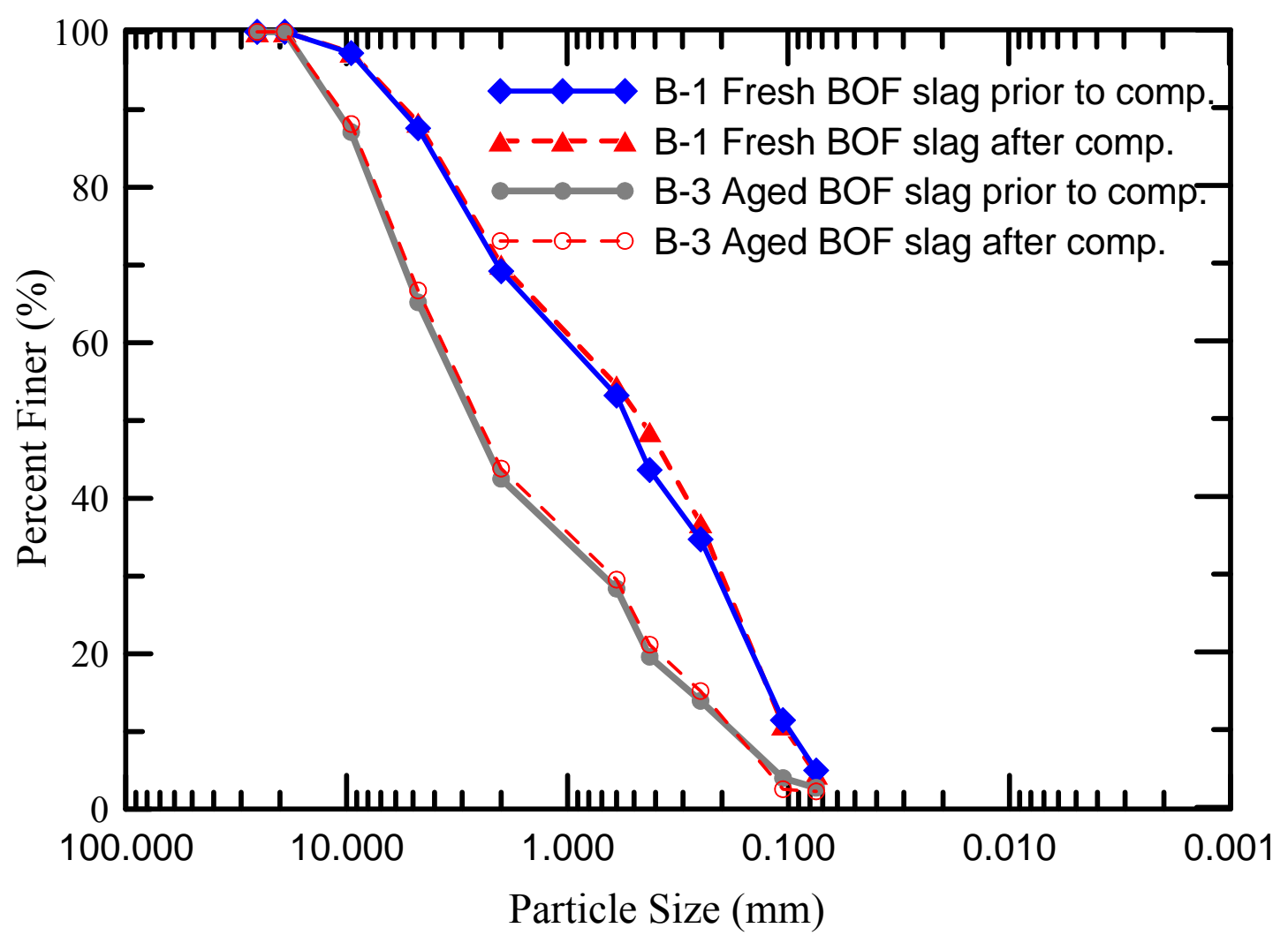

Figure 5.14 Grain-size distribution curves prior and after compaction for fresh and aged BOF slags

The optimum moisture content and the maximum dry unit weight for the BOF slag samples were in the ranges of $4-8 \%$ and $19.5-21.8 \mathrm{kN} / \mathrm{m}^{3}$, respectively. This optimum moisture content range corresponds to relative compaction values of $95-100 \%$ for all BOF slag samples. The $\gamma_{d \text {,max }}$ values of BOF slags are slightly higher than those of traditional compacted soils (typically in the $17-20 \mathrm{kN} / \mathrm{m}^{3}$ range). 
Table $5.7 \gamma_{d, \max }$ and $w_{\text {opt }}$ of BOF slag samples

\begin{tabular}{cccc}
\hline Sample ID & $w_{o p t}(\%)$ & $\gamma_{d, \max }\left(\mathrm{kN} / \mathrm{m}^{3}\right)$ & $\gamma_{d, \max }(\mathrm{pcf})$ \\
\hline \hline Batch-1 Fresh BOF slag & 4 & 19.45 & 124 \\
Batch-2 Fresh BOF slag & 5 & 21.79 & 139 \\
Batch-2 Aged BOF slag & 5 & 20.90 & 133 \\
Batch-3 Aged BOF slag & 8 & 20.79 & 132 \\
\hline
\end{tabular}

\subsubsection{Maximum and Minimum Dry Density Tests}

The maximum and minimum dry density tests were performed on BOF slag samples according to ASTM D4253 and ASTM D4254, respectively. The maximum and minimum void ratio for each BOF slag sample was calculated using the average specific gravity $\left(G_{s}\right)$ values obtained for each sample, as reported in Table 5.5. Table 5.8 presents the maximum and minimum dry unit weights and the corresponding void ratios of the BOF slag samples. The maximum dry unit weights of BOF slag obtained from the vibratory compaction method was similar (in the $\pm 5 \%$ range) to those obtained from the standard Proctor compaction test procedure (ASTM D698) (see Table 5.7). The vibratory compaction method tends to lead to slightly higher dry unit weights for coarse-grained soils than those obtained with the standard Proctor compaction method. This trend was not observed for all BOF slag samples. The slightly lower maximum dry unit weight values obtained with the vibratory compaction method were attributed to the effects of segregation and loss of fines that inevitably occurs during vibratory compaction of materials that contain a wide range of particle sizes. 
Table 5.8 Maximum and minimum dry unit weight test results

\begin{tabular}{cccccc}
\hline Sample ID & $\begin{array}{c}\gamma_{d, \min } \\
\left(\mathrm{kN} / \mathrm{m}^{3}\right)\end{array}$ & $\begin{array}{c}\gamma_{d, \min } \\
(\mathrm{pcf})\end{array}$ & $\begin{array}{c}\gamma_{d, \max } \\
\left(\mathrm{kN} / \mathrm{m}^{3}\right)\end{array}$ & $\begin{array}{c}\gamma_{d, \max } \\
(\mathrm{pcf})\end{array}$ & $e_{\min } e_{\max }$ \\
\hline \hline Batch-1 Fresh BOF slag & 16.74 & 107 & 20.45 & 130 & 0.580 .93 \\
Batch-2 Fresh BOF slag & 17.60 & 112 & 21.09 & 133 & 0.570 .85 \\
Batch-2 Aged BOF slag & 16.51 & 105 & 20.42 & 130 & 0.590 .97 \\
Batch-3 Aged BOF slag & 17.65 & 112 & 21.64 & 138 & 0.510 .84 \\
\hline
\end{tabular}

\subsubsection{Large-Scale Direct Shear Tests}

Large-scale direct shear (LDS) tests were performed on BOF slag samples to determine its shear strength parameters. The Mohr-Coulomb criterion has been traditionally used to represent the shear strength of soils:

$S=c+\sigma \tan \phi$

Eq. 5.3

where $\mathrm{S}=$ shear strength; $\mathrm{c}=$ cohesive intercept; $\phi=$ angle of internal friction; and $\sigma=$ effective normal stress acting on the shear plane. The shear strength corresponding to the peak states of the fresh and aged BOF slag samples were used to obtain the $c-\phi$ fitting parameters appearing in Eq. 5.3. The critical-state friction angles for both the fresh and aged BOF slag samples were also determined from the large-scale direct shear test results.

Table 5.9 shows the LDS testing matrix for the BOF slag samples considered in this study. Samples of Batch-1 Fresh BOF slag were also tested at two different moisture contents (corresponding to $R$ values of 95 and 100\%). Figure 5.15 (a) and (b) show the horizontal displacement versus the horizontal shear stress curves for samples of Batch-1 Fresh BOF slag prepared at $R=95 \%$ and $R=100 \%$, respectively. The horizontal displacement versus shear stress curves for dense Batch-1 Fresh BOF slag show a distinct peak, which is indicative of dilative behavior. Dilation is observed in dense frictional materials tested at low confining stresses. The peak states were observed at horizontal 
displacements of approximately $15-20 \mathrm{~mm}$. Critical state was attained at approximately $40 \mathrm{~mm}$ of horizontal displacement. Figure 5.16 (a) and (b) show the shear strength envelopes corresponding to critical and peak states for Batch-1 Fresh BOF slag samples prepared at $R=95 \%$ and $R=100 \%$. From the critical-state shear strength envelope, a critical-state friction angle of $45.5^{\circ}$ was calculated for Batch-1 Fresh BOF slag. $c-\phi$ fitting parameters equal to $73 \mathrm{kPa}$ and $52.3^{\circ}$ were obtained for Batch-1 Fresh BOF slag compacted at $R=100 \%$; these values were equal to $29 \mathrm{kPa}$ and $52.3^{\circ}$ when $\mathrm{R}=95 \%$. The highest shear strength (corresponding to critical and peak states) values were measured for $R=100 \%$.

Figure 5.17 (a) and (b) shows the horizontal displacement versus horizontal shear stress curves for Batch-2 Fresh and Batch-2 Aged BOF slag samples compacted at $R=95 \%$, respectively. Similar to Batch-1 Fresh BOF slag samples, the horizontal displacement vs. horizontal shear stress curves of Batch-2 Fresh BOF and Batch-2 Aged BOF slag samples showed that these samples are dilative. Peak states were observed at displacements of approximately 10-20 $\mathrm{mm}$. Critical state was reached at horizontal displacements of approximately 30-40 mm. Figure 5.18 (a) and (b) provide the shear strength envelopes corresponding to the critical and peak states for Batch-2 Fresh and Batch-2 Aged BOF slag samples prepared at $R=95 \%$. The critical-state friction angles for Batch-2 Fresh and Batch-2 Aged BOF slags samples were equal to $48.1^{\circ}$ and $45.3^{\circ}$, respectively. $c-\phi$ fitting parameters equal to $48 \mathrm{kPa}$ and $49.8^{\circ}$ were obtained for Batch-2 Fresh BOF slag compacted at $R=95 \%$; these values were equal to $41 \mathrm{kPa}$ and $52.8^{\circ}$ or Batch-2 Fresh BOF slag compacted at $R=95 \%$. Table 5.10 provides a summary of all shear strength parameters obtained from the large-scale direct shear tests performed on BOF slag samples. 
Table 5.9 Test matrix for direct shear testing of BOF slag samples

\begin{tabular}{|c|c|c|c|}
\hline $\begin{array}{c}\text { Material } \\
\text { Description }\end{array}$ & $\begin{array}{l}\text { Moisture content } \\
\text { (w) }\end{array}$ & $\begin{array}{c}\text { Relative } \\
\text { Compaction } \\
(R)\end{array}$ & $\begin{array}{c}\text { Confining } \\
\text { Stress } \\
(\mathrm{kPa}) \\
\end{array}$ \\
\hline \multirow{4}{*}{$\begin{array}{c}\text { Batch-1 Fresh } \\
\text { BOF slag }\end{array}$} & \multirow{4}{*}{$4 \%$} & \multirow{4}{*}{$100 \%$} & $\begin{array}{l}50 \\
\end{array}$ \\
\hline & & & 100 \\
\hline & & & 200 \\
\hline & & & 300 \\
\hline \multirow{4}{*}{$\begin{array}{l}\text { Batch-1 Fresh } \\
\text { BOF slag }\end{array}$} & \multirow{4}{*}{$7-8 \%$} & \multirow{4}{*}{$95 \%$} & 50 \\
\hline & & & 100 \\
\hline & & & 200 \\
\hline & & & 300 \\
\hline \multirow{4}{*}{$\begin{array}{c}\text { Batch-2 Fresh } \\
\text { BOF slag }\end{array}$} & \multirow{4}{*}{$7-8 \%$} & \multirow{4}{*}{$95 \%$} & 50 \\
\hline & & & 100 \\
\hline & & & 200 \\
\hline & & & 300 \\
\hline \multirow{4}{*}{$\begin{array}{c}\text { Batch-2 Aged } \\
\text { BOF slag }\end{array}$} & \multirow{4}{*}{$7-8 \%$} & \multirow{4}{*}{$96 \%$} & 50 \\
\hline & & & 100 \\
\hline & & & 200 \\
\hline & & & 250 \\
\hline
\end{tabular}

a $R=\frac{\gamma_{d}}{\gamma_{d, \max }}$, where $\gamma_{d}=$ compacted dry unit weight of the sample,

$\gamma_{d, \max }=$ maximum compacted dry unit weight obtained from the standard Proctor compaction tests 


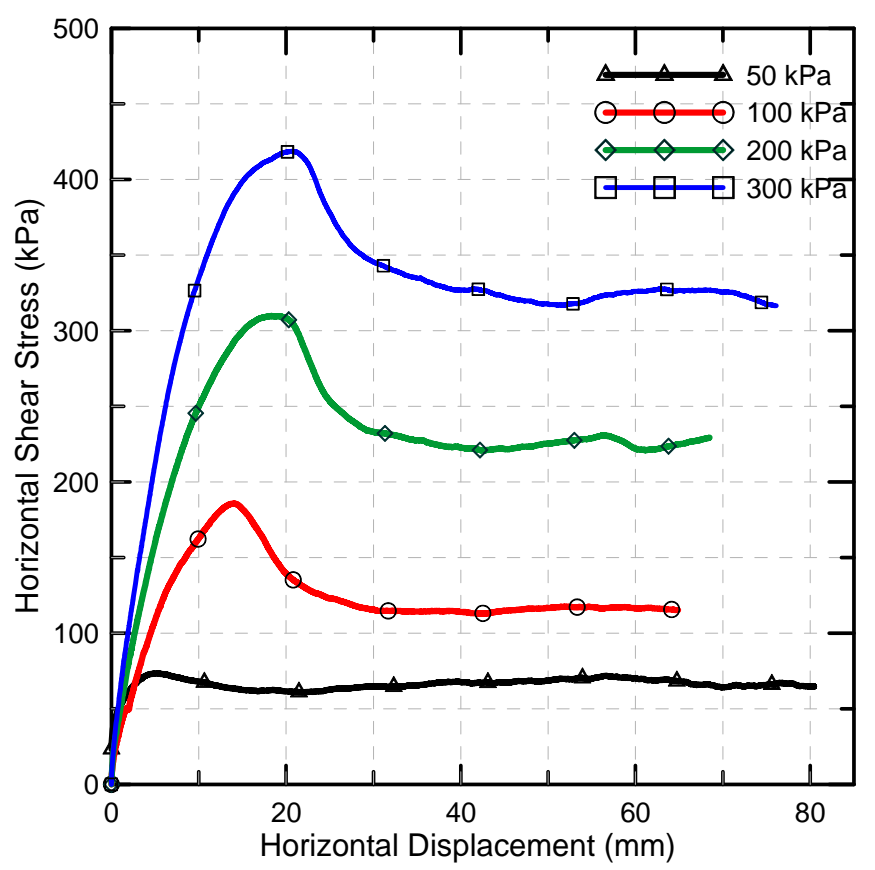

(a)

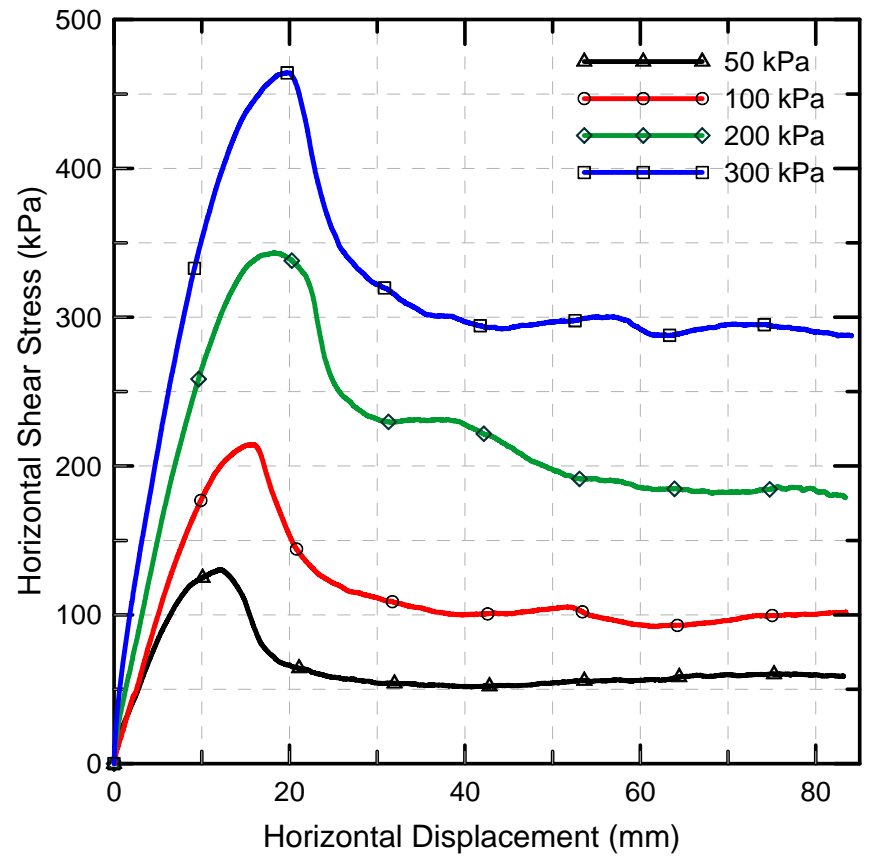

(b)

Figure 5.15 Horizontal shear stress versus horizontal displacement for Batch-1 Fresh BOF slag samples prepared at a) $R=95 \%$ and b) $R=100 \%$ 


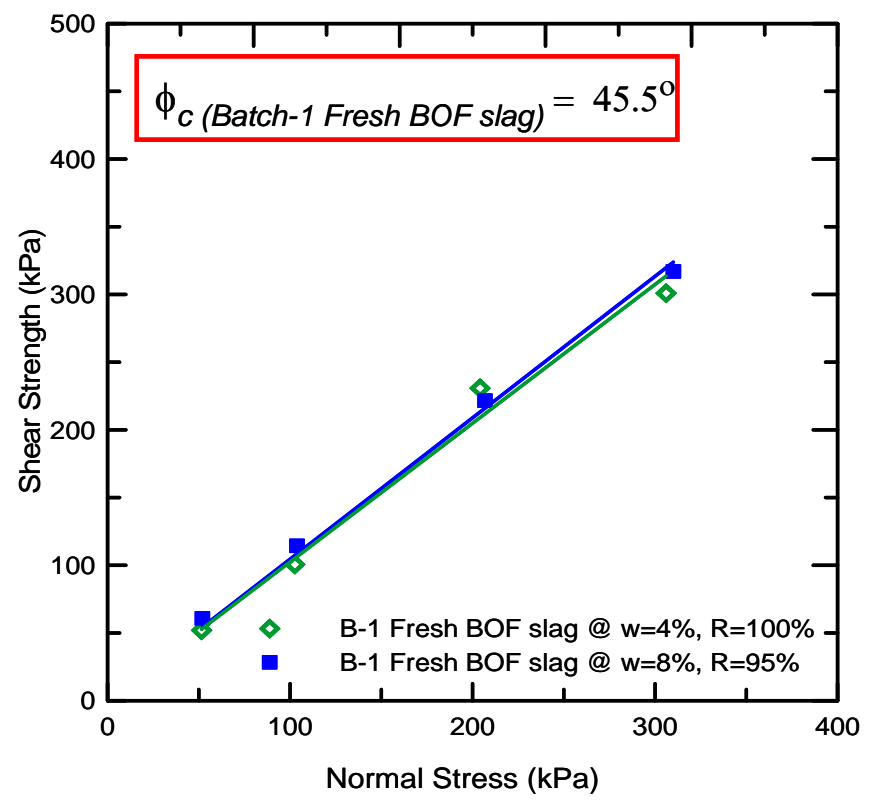

(a)

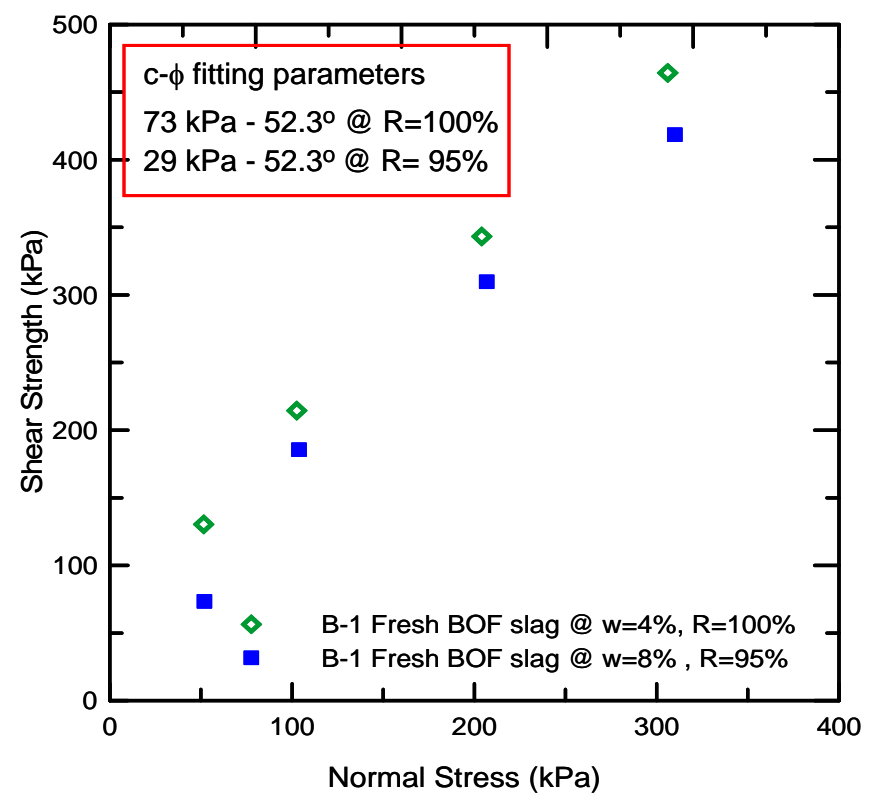

(b)

Figure 5.16 Shear strength parameters for Batch-1 Fresh BOF slag samples prepared at $R=95 \%$ and $R=100 \%$ : (a) critical-state and (b) peak-state 


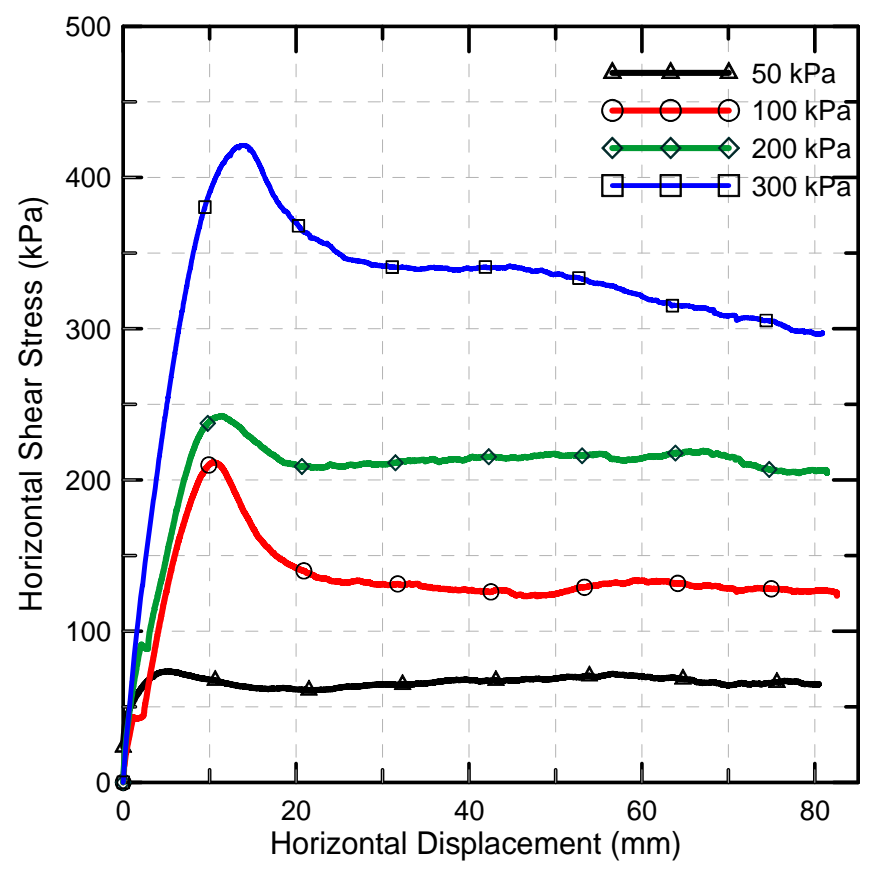

(a)

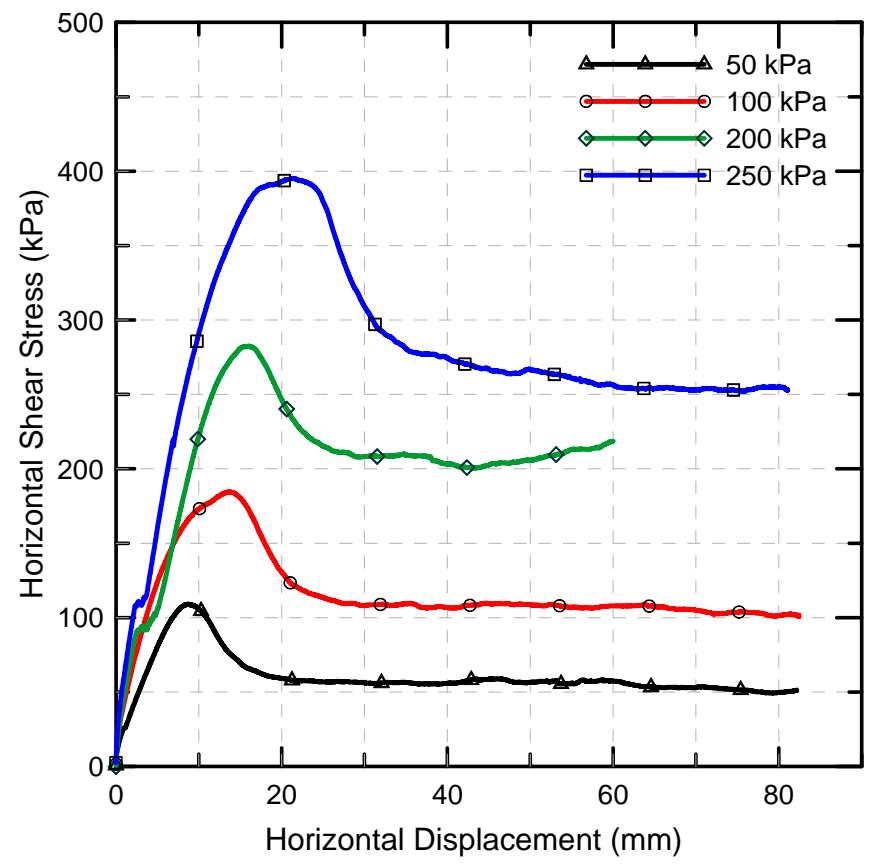

(b)

Figure 5.17 Horizontal shear stress versus horizontal displacement graphs for: (a) Batch2 Fresh BOF slag prepared at $R=95 \%$ (b) Batch- 2 Aged BOF slag prepared at $R=95 \%$ 


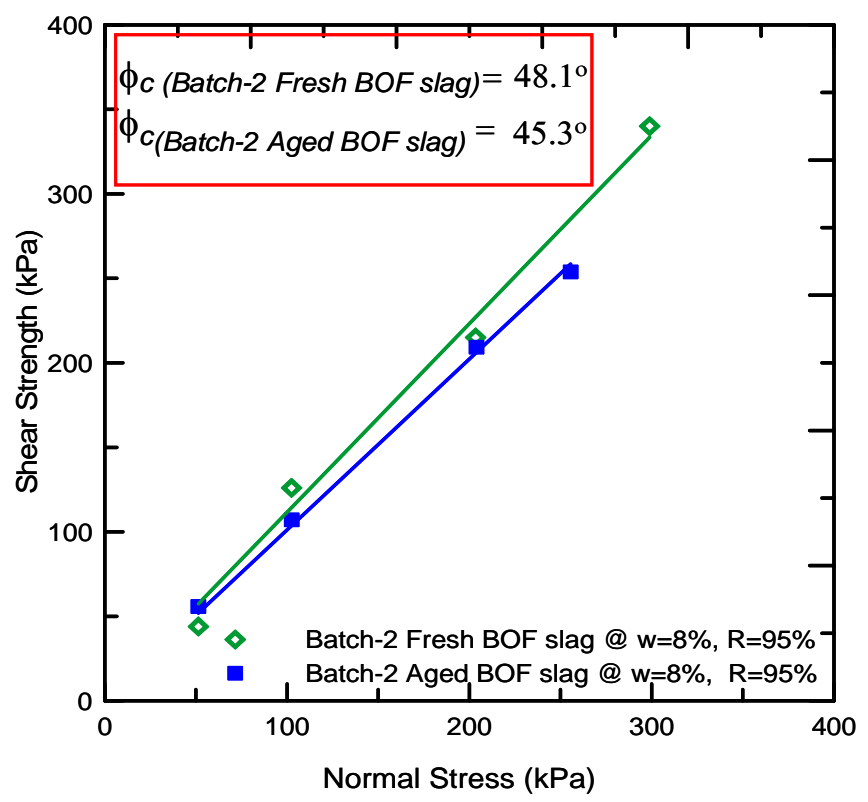

(a)

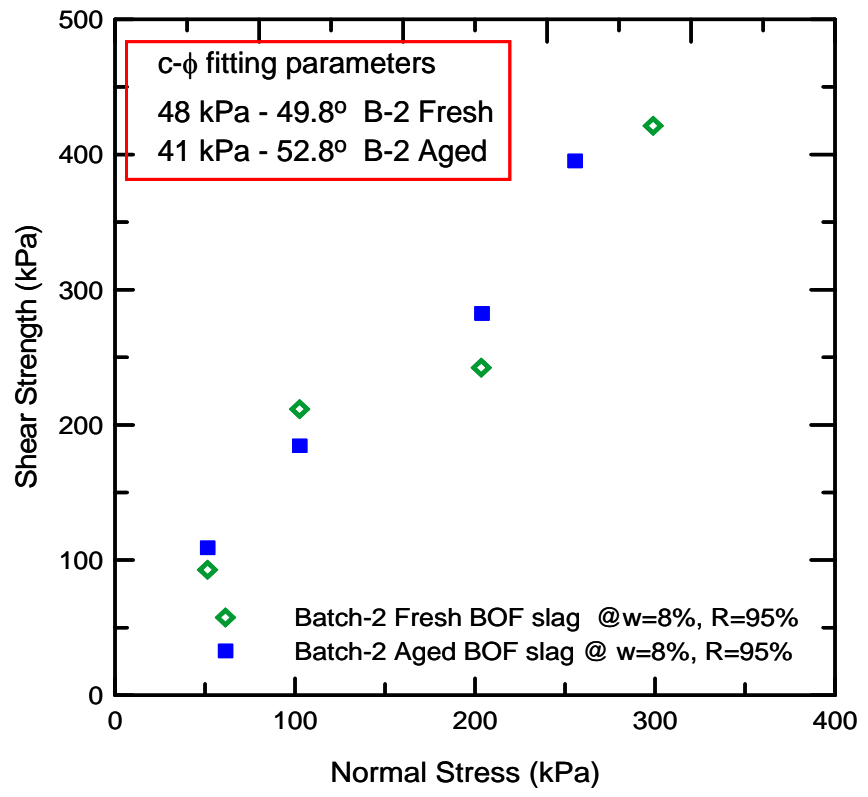

(b)

Figure 5.18 Shear strength parameters for Batch-2 Fresh BOF slag at $R=95 \%$ and Batch-2 Aged BOF slag at $R=96 \%$ : (a) critical-state, and (b) peak state 
Table 5.10 Summary of shear strength parameters obtained from large-scale direct shear tests for BOF slag

\begin{tabular}{|c|c|c|c|}
\hline Sample ID & $R$ & $\phi_{c}$ & $c-\phi$ fitting parameters ${ }^{a}$ \\
\hline Batch-1 Fresh BOF slag & $95 \%$ & \multirow{2}{*}{$45.5^{\circ}$} & $29 \mathrm{kPa}-52.3^{\circ}$ \\
\hline Batch-1 Fresh BOF slag & $100 \%$ & & $73 \mathrm{kPa}-52.3^{\circ}$ \\
\hline Batch-2 Fresh BOF slag & $95 \%$ & $48.1^{\circ}$ & $48 \mathrm{kPa}-49.8^{\circ}$ \\
\hline Batch-2 Aged BOF slag & $96 \%$ & $45.3^{\circ}$ & $41 \mathrm{kPa}-52.8^{\circ}$ \\
\hline
\end{tabular}

BOF slag exhibits much higher shear strength than natural soils typically used in the construction of geotechnical structures. The sources of the high shear strength observed for BOF slag are: i) particle angularity and surface texture, ii) presence of gravel-size particles and iii) presence of a wide range of particle sizes. These factors contribute to high inter-particle friction and particle interlocking.

\subsubsection{Triaxial Tests}

Isotropically consolidated drained (CID) triaxial tests were performed on Batch-3 Aged BOF slag samples. Only the BOF slag particles passing the $9.5 \mathrm{~mm}\left(3 / 8^{\prime \prime}\right)$ sieve were used in sample preparation for triaxial testing. All the samples were compacted at a moisture content of $6 \%$ to a relative compaction of $90 \%$ using the moist tamping technique. Tests were performed at three effective confining stresses of 50, 110 and $200 \mathrm{kPa}$. Figure 5.19 (a) and (b) show the axial strain versus deviatoric stress curves and the axial strain versus volumetric strain curves obtained from the CID triaxial tests, respectively. For confining stresses of 50 and $110 \mathrm{kPa}$, the axial strain versus volumetric strain curves show that the samples contracted initially and then dilated. The sample subjected to $200 \mathrm{kPa}$ of confining pressure contracted throughout the test. The results of the CID triaxial tests are compiled in Table 5.11 . 


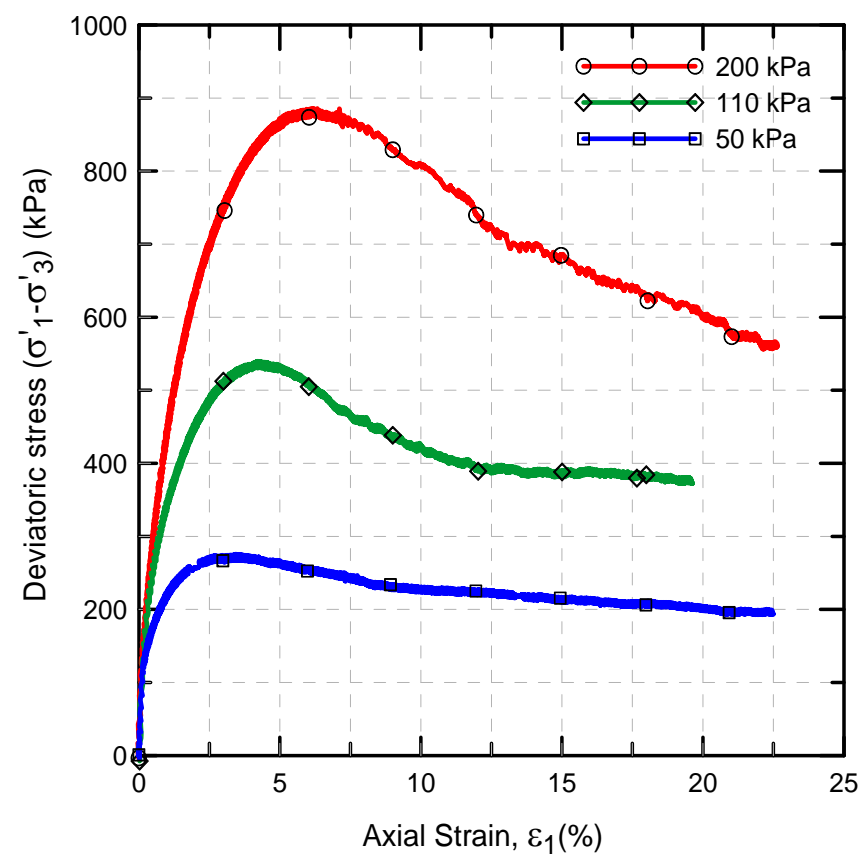

(a)

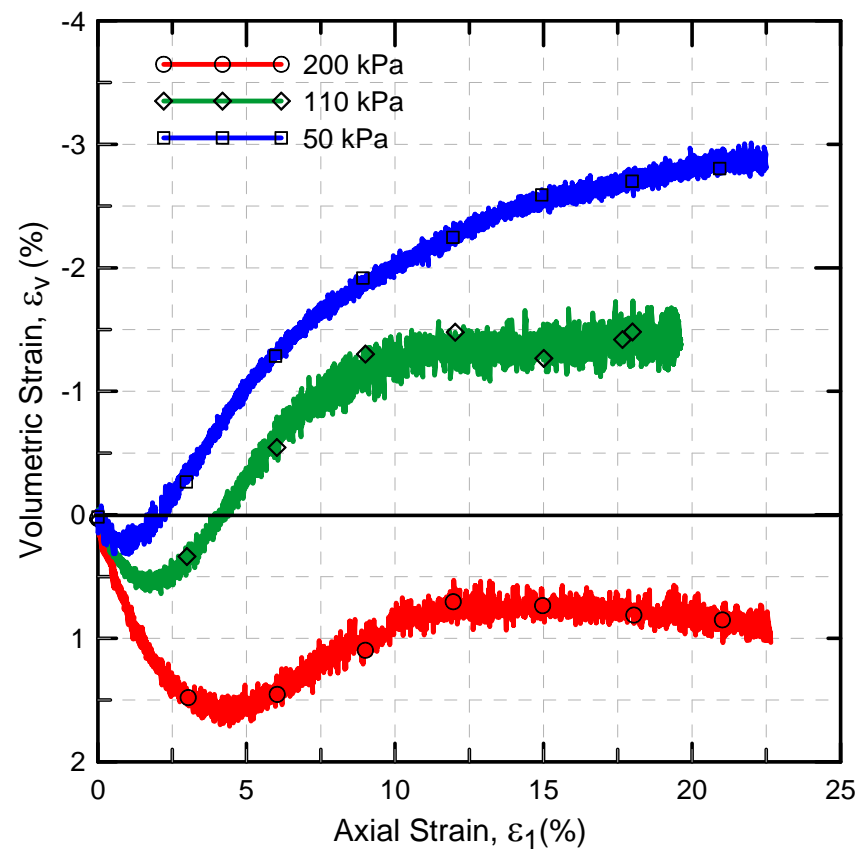

(b)

Figure 5.19 CID triaxial testing on Batch-3 Aged BOF slag (particles smaller than $9.5 \mathrm{~mm}$ ) prepared at $90 \%$ relative compaction: (a) axial strain vs. deviatoric stress, and (b) axial strain vs. volumetric strain 
Table 5.11 Results of CID triaxial tests for Batch-3 Aged BOF slag samples (particles smaller than $9.5 \mathrm{~mm}$ ) prepared at $\mathrm{R}=90 \%$

\begin{tabular}{cc}
\hline Effective Confining Stress & Peak Friction Angle \\
$\sigma_{3}^{\prime}(\mathrm{kPa})$ & $\phi_{p}$ \\
\hline \hline 50 & $47.3^{\circ}$ \\
110 & $45.2^{\circ}$ \\
200 & $43.5^{\circ}$ \\
\hline
\end{tabular}

Results of the CID triaxial tests show that the peak friction angles for Batch-3 Aged BOF slag decreased with increasing confining stress. This is due to the fact that the tendency of the particles to dilate is suppressed with the increase in effective confining stress. Lower peak friction angles were obtained from the CID triaxial tests performed on Batch-3 Aged BOF slag samples than those obtained for Batch-1 Fresh, Batch-2 Fresh and Batch-2 Aged BOF slag samples with the large-scale direct shear tests performed at similar confining stresses. There are several reasons for this result. Firstly, typically direct shear tests tend to provide higher friction angles than triaxial tests. In addition, in order to minimize the boundary effects and the difficulties encountered in sample preparation, the gravel-size particles (larger than $9.5 \mathrm{~mm}$ ) were removed from Batch-3 Aged BOF slag during triaxial sample preparation; these gravel-size particles contributed to the shear strength of the BOF slag samples tested in the LDS testing machine. Nonetheless, the triaxial test results presented in this section provide a conservative estimate of the shear strength parameters for Batch-3 Aged BOF slag (with the minus 9.5 $\mathrm{mm}$ gradation only).

\subsection{Long-term Swelling Response of BOF slag}

BOF slag samples (fresh and aged for one year) were compacted at a moisture content of $6-8 \%$ to a relative compaction of $97-100 \%$ in CBR molds. A surcharge weight equivalent to approximately $2.5 \mathrm{kPa}$ was placed on the top of the compacted samples. The BOF slag 
samples were then soaked in water and their one-dimensional swelling was monitored for a period of approximately 16 months at room temperature. Figure 5.20 shows the volumetric strain versus time curves for Batch-1 Fresh, Batch-2 Fresh, Batch-2 Aged and Batch-3 Aged BOF slag samples.

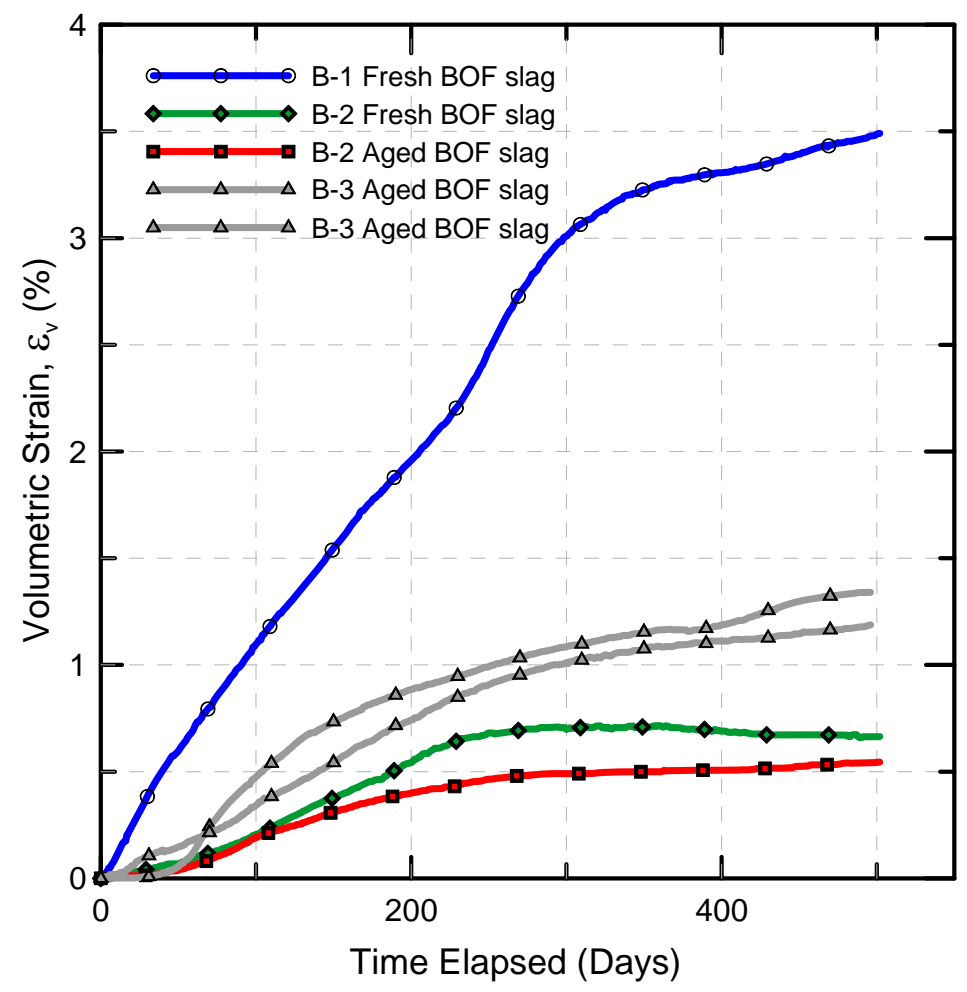

Figure 5.20 Time vs. volumetric strain curves for BOF slag samples

All fresh and aged BOF slag samples tested showed expansive behavior (see Figure 5.20). The swelling rate of the Batch-1 Fresh BOF slag sample was higher than those of all the other samples. The swelling rates for Batch-1 Fresh BOF slag were approximately $9.69 \times 10^{-3} /$ day, $1.08 \times 10^{-2} /$ day, $3.22 \times 10^{-3} /$ day and $1.73 \times 10^{-3} /$ day for the corresponding test durations of 0-7 months, 7-10 months, 10-13 months and 13-17 months. The Batch-1 Fresh BOF slag sample reached the maximum volumetric strain of approximately $3.5 \%$ after 17 months of monitoring. One the possible reasons for the higher swelling rate observed for the Batch-1 Fresh BOF slag sample is the fact that it has the finest gradation of all the BOF slag samples. The finer the gradation, the higher the surface area available 
for the particles to react with water is. Slag samples from Batch-2 Fresh and Batch-2 Aged BOF slag had similar gradations and exhibited comparable swelling rates. The swelling of Batch-2 Fresh and Batch-2 Aged BOF slag samples almost stabilized at volumetric strains of approximately $0.6 \%$ and $0.5 \%$ after 16 months of monitoring. Two long-term swelling tests were performed on identical Batch-3 Aged BOF slag samples. Both of the Batch-3 Aged BOF slag samples exhibited similar swelling rates and reached volumetric strains in the $1.2-1.3 \%$ range after 17 months. The volumetric strains obtained from the long-term swelling tests for BOF slag samples are compiled in Table 5.12.

Even after about 17 months of monitoring, the swelling of Batch-1 Fresh and Batch-3 Aged BOF slags samples did not stabilize. This is most likely due to the presence of free $\mathrm{MgO}$ which hydrates at a very slow rate. Hydration of free $\mathrm{MgO}$ may take years to complete and, hence, longer periods of aging may be required for BOF slags that contain free $\mathrm{MgO}$. The swelling test results show that aging of BOF slag is effective in reducing both the rate and the total amount of swelling, but aging alone is not sufficient to suppress the swelling of BOF slag samples to acceptable levels. 
Table 5.12 Results of long-term swelling tests performed on BOF slag samples (fresh and aged for one year)

\begin{tabular}{|c|c|c|c|c|c|}
\hline \multirow[b]{2}{*}{$\begin{array}{l}\text { Elapsed } \\
\text { Time } \\
\text { (Months) }\end{array}$} & \multicolumn{5}{|c|}{ Swelling (\%) } \\
\hline & \multicolumn{4}{|c|}{$\begin{array}{l}\text { B-1 Fresh B-2 Fresh B-2 Aged B-3 Aged } \\
\text { BOF slag BOF slag BOF slag }{ }^{\mathrm{a}} \text { BOF slag }\end{array}$} & $\begin{array}{l}\text { B-3 Aged } \\
\text { BOF slag }^{\mathrm{a}}\end{array}$ \\
\hline 1 & 0.383 & 0.045 & 0.016 & 0.009 & 0.103 \\
\hline 2 & 0.703 & 0.094 & 0.061 & 0.127 & 0.183 \\
\hline 3 & 0.996 & 0.170 & 0.150 & 0.410 & 0.289 \\
\hline 4 & 1.276 & 0.277 & 0.237 & 0.595 & 0.420 \\
\hline 5 & 1.547 & 0.376 & 0.312 & 0.734 & 0.543 \\
\hline 6 & 1.802 & 0.463 & 0.369 & 0.832 & 0.673 \\
\hline 7 & 2.036 & 0.585 & 0.412 & 0.909 & 0.787 \\
\hline 8 & 2.332 & 0.663 & 0.453 & 0.970 & 0.877 \\
\hline 9 & 2.742 & 0.695 & 0.481 & 1.034 & 0.954 \\
\hline 10 & 3.008 & 0.698 & 0.490 & 1.085 & 1.010 \\
\hline 11 & 3.164 & 0.702 & 0.498 & 1.128 & 1.048 \\
\hline 12 & 3.252 & 0.716 & 0.500 & 1.164 & 1.087 \\
\hline 13 & 3.297 & 0.698 & 0.507 & 1.172 & 1.101 \\
\hline 14 & 3.333 & 0.676 & 0.509 & 1.226 & 1.122 \\
\hline 15 & 3.393 & 0.672 & 0.525 & 1.297 & 1.146 \\
\hline 16 & 3.451 & 0.669 & 0.541 & 1.331 & 1.171 \\
\hline$\sim 17$ & 3.491 & 0.665 & 0.544 & 1.340 & 1.188 \\
\hline
\end{tabular}

a aged for one year

\subsection{Corrosivity and Leaching Potential of BOF slag}

The corrosion potential of BOF slag samples was evaluated based on the electrical resistivity and $\mathrm{pH}$ test results. Leaching of heavy metals from BOF slag samples was evaluated through TCLP tests. The results of these tests are discussed next. 


\subsubsection{Corrosivity Tests}

The corrosivity of a buried metal object embedded in a soil depends on a number of parameters that include soil resistivity, moisture content, and concentration of dissolved salts in the pore fluids. The corrosion potential of a given soil can only be assessed when all the parameters involved are properly considered. The electrical resistivity and $\mathrm{pH}$ measurements are commonly used as indicators of soil corrosivity. Table 5.13 provides soil corrosivity classification based on the resistivity and $\mathrm{pH}$ values (API 1997; Christopher et al. 1989). These two corrosivity parameters - electrical resistivity and $\mathrm{pH}$ were determined for BOF slag samples in order to evaluate their corrosion potential.

Table 5.13 Soil corrosivity classification

\begin{tabular}{cc|cc}
\hline \multicolumn{3}{c}{ Reference } & \\
\cline { 1 - 2 } $\begin{array}{c}\text { API(1997) } \\
\text { Resistivity }\end{array}$ & Christopher et al. (1989) & Classification \\
\hline \hline$>10,000$ & $\begin{array}{c}\text { Resistivity } \\
(\text { ohm-cm) }\end{array}$ & \\
\hline $2,000-10,000$ & $>10,000$ & Little Corrosive \\
\hline $1,000-2,000$ & $5,000-10,000$ & $\begin{array}{c}\text { Mildly } \\
\text { Corrosive }\end{array}$ \\
\hline $500-1,000$ & $5-6.5$ & $700-2,000$ & Moderately \\
& & $2,000-5,000$ & Corrosive \\
\hline$<500$ & $<5$ & $<700$ & Cerrosive \\
\hline
\end{tabular}

\section{Electrical Resistivity}

Electrical resistivity tests were performed on compacted BOF slag samples. Batch-2 Fresh, Batch-2 Aged and Batch-3 Aged BOF slag samples were compacted in the soil box at a moisture content of about 6-7\%, while Batch-1 Fresh BOF slag samples were compacted at two different moisture contents $(8 \%$ and $14 \%)$ to determine the effect of 
moisture content on the electrical resistivity measurements. Two electrical resistivity measurements were taken: one immediately after compaction and another after soaking the samples for about $4 \mathrm{hrs}$. Table 5.14 provides the electrical resistivity measurements for BOF slag samples.

Table 5.14 Electrical resistivity test results for BOF slag samples

\begin{tabular}{ccc}
\hline Sample ID & Moisture Content & Electrical resistivity (ohm-cm) \\
\hline \hline \multirow{2}{*}{ Batch-1 Fresh BOF slag } & $\sim 8 \%$ & 3720 \\
& Soaked condition & 1150 \\
\hline \multirow{2}{*}{ Batch-2 Fresh BOF slag } & $6-7 \%$ & 442 \\
\hline \multirow{2}{*}{ Batch-2 Aged BOF slag } & Soaked condition & 8150 \\
\cline { 2 - 3 } Batch- 3 Aged BOF slag & Soaked condition & 540 \\
\hline & Soaked condition & 4357 \\
\hline
\end{tabular}

The electrical resistivity measurements for the BOF slag samples decreased as the moisture content of the slag samples increased. The soaked samples exhibited much lower resistivities than those of the compacted BOF slag samples. Based on the soil corrosivity classification parameters provided in Table 5.13, the compacted BOF slag samples were classified as little corrosive to moderately corrosive, while the soaked BOF slag samples were categorized as corrosive to very corrosive.

$\underline{p H}$

In order to supplement the electrical resistivity measurements in evaluating the corrosivity potential of BOF slag, the $\mathrm{pH}$ of soaked BOF slag samples was also measured 
following the electrical resistivity measurements. Table 5.15 provides the $\mathrm{pH}$ measurements for all the BOF slag samples tested.

Table $5.15 \mathrm{pH}$ test results for soaked BOF slag samples

\begin{tabular}{cc}
\hline Sample ID & $\mathrm{pH}$ \\
\hline \hline Batch-1 Fresh BOF slag & 10.9 \\
Batch-2 Fresh BOF slag & 12.3 \\
Batch-2 Aged BOF slag & 12.0 \\
Batch- 3 Aged BOF slag & 12.3 \\
\hline
\end{tabular}

The study presented by Scully (1990) suggests that the rate of corrosion is low in neutral environments, whereas both very acidic and alkaline environments tend to expedite the corrosion process. The $\mathrm{pH}$ test results show that BOF slag is strongly alkaline. Considering the corrosivity parameters (electrical resistivity and $\mathrm{pH}$ ), BOF slag samples were considered potentially corrosive.

\subsubsection{Leaching Tests}

TCLP analysis was performed on Batch-1 Fresh BOF slag samples by Severn Trent Laboratories, Inc. located in Valparaiso, IN.

provides the results of the TCLP analysis for Batch-1 Fresh BOF slag.

The Environmental Protection Agency (EPA) classifies BOF slag as a solid waste. In the state of Indiana, use of BOF slag is regulated by the solid waste land disposal regulations of the Indiana Administrative Code. Solid wastes can be classified based on the concentrations of various metals in their leachates. The Indiana solid wastes are classified according to the results of TCLP (acidic leachate) or EP (neutral leachate) analyses. Table 5.17 presents the waste types and the parameter levels defined by the 
Indiana Administrative Code 329 IAC-2-9-3 based on the TCLP test results. According to the Indiana Administrative Code, four waste types are specified in order of decreasing leachate parameter concentrations. Solid waste classified as Type I has the highest leachate concentration levels for all the constituents, up to near hazardous levels. On the other hand, solid waste classified as Type IV has the lowest concentrations for all the constituents shown in Table 5.17. Typically, Type IV meets the National Primary and Secondary Drinking Water Regulations for most of the parameter concentrations. According to the Indiana restricted waste criteria, the TCLP BOF slag leachate concentration levels for almost all the heavy metal concentrations satisfy the criterion for classification of BOF slag as a Type III waste. Since the chemical composition of steel slag may vary from one batch to another, slag samples should be collected and subjected to TCLP tests often for proper waste type classification.

Table 5.16 TCLP (acidic leachate-mg/L) analysis of BOF slag

\begin{tabular}{cc}
\hline \multicolumn{2}{c}{ Concentrations (in mg/L) } \\
\hline Constituents & BOF slag \\
\hline \hline Arsenic & $<0.2$ \\
Barium & 0.1 \\
Cadmium & $<0.05$ \\
Chromium & $<0.10$ \\
Lead & $<0.5$ \\
Mercury & $<0.001$ \\
Selenium & $<0.2$ \\
Silver & $<0.1$ \\
\hline
\end{tabular}


Table 5.17 Indiana restricted waste criteria based on TCLP test results

\begin{tabular}{lcccc}
\hline \multicolumn{5}{c}{ Concentrations (in mg/L) } \\
\hline Constituent & Type IV & Type III & Type II & Type I \\
\hline \hline Arsenic & $\leq 0.05$ & $\leq 0.5$ & $\leq 1.25$ & $\leq 5.0$ \\
Barium & $\leq 1.0$ & $\leq 10.0$ & $\leq 25$ & $<100.0$ \\
Cadmium & $\leq 0.01$ & $\leq 0.1$ & $\leq 0.25$ & $<1.0$ \\
Chromium & $\leq 0.05$ & $\leq 0.5$ & $\leq 1.25$ & $<5.0$ \\
Lead & $\leq 0.05$ & $\leq 0.5$ & $\leq 1.3$ & $<5.0$ \\
Mercury & $\leq 0.002$ & $\leq 0.02$ & $\leq 0.05$ & $<0.2$ \\
Selenium & $\leq 0.08$ & $\leq 0.1$ & $\leq 0.25$ & $<1.0$ \\
Silver & $\leq 0.05$ & $\leq 0.5$ & $\leq 1.25$ & $<5.0$ \\
\hline
\end{tabular}

\subsection{Summary}

Samples of fresh and aged basic-oxygen-furnace (BOF) slag were characterized through a series of laboratory tests (specific gravity, grain-size analysis, X-ray diffraction, compaction, maximum and minimum density, large-scale direct shear, consolidated drained triaxial and long-term swelling tests). The effects of gradation on the engineering properties of both fresh and aged BOF slag samples were investigated. The corrosion potential of BOF slag samples was evaluated based on the electrical resistivity and $\mathrm{pH}$ test results. The results of TCLP tests were used to classify BOF slag according to the Indiana Administrative Code classification for solid waste. . The results of the experiments performed on BOF slag samples can be summarized as follows:

1) BOF slag samples were classified as SP-SM with gravel (poorly-graded sand with silt and gravel) and A-1-b according to the USCS and AASHTO soil classification systems, respectively. The gradation of BOF slag samples varied from one batch to another.

2) The $\mathrm{CaO}, \mathrm{FeO}, \mathrm{SiO}_{2}$, and $\mathrm{MgO}$ contents of $\mathrm{BOF}$ slag samples were equal to $39,30,12$ and $10 \%$, respectively. 
3) The specific gravity $G_{s}$ of fresh and aged BOF slag samples was in the 3.293.34 range. The $G_{s}$ of BOF slag is higher than that of natural soils because it has a higher $\mathrm{FeO}$ content.

4) The XRD patterns of both fresh and aged BOF slag samples were extremely complex with many overlapping peaks indicating a very crystalline structure. This crystalline structure resulted from the slow cooling conditions used during processing of BOF slag. The XRD patterns for fresh and aged BOF slag samples did not exhibit significant differences. Portlandite, srebrodol'skite, and merwinite were the main mineral phases identified for both fresh and aged BOF slag samples.

5) Gravel-size fresh BOF slag particles had shapes varying from subrounded to subangular. Most of the gravel-size particles had a high sphericity and a solid structure. Gravel-size aged BOF slag particles contained some agglomerates that were not observed in fresh BOF slag samples. Sand- and silt-size fresh BOF slag particles had subrounded to angular shapes. Distinct asperities and edges were visible in angular bulky particles. Sand- and silt-size BOF slag particles exhibited rough surface textures.

6) The compaction curves for BOF slags samples were irregular in shape. The optimum moisture content and maximum dry unit weight of fresh and aged BOF slag samples were in the ranges of $4-8 \%$ and $19.5-21.8 \mathrm{kN} / \mathrm{m}^{3}$, respectively.

7) The shear strength parameters of BOF slag ( $\phi_{c}$ and $c-\phi$ fitting parameters) samples were determined based on the results of large-scale direct shear and triaxial tests. Based on the large-scale direct shear tests results, the criticalstate friction angle of Batch-1 Fresh, Batch-2 Fresh and Batch-2 Aged BOF slag samples were equal to $45.5^{\circ}, 48.1^{\circ}$, and $45.3^{\circ}$, respectively. Based on the isotropically consolidated drained triaxial test (CIDTX) results, the peak friction angles of aged BOF slag samples (only particles smaller than $9.5 \mathrm{~mm}$ were used in sample preparation) prepared at about $90 \%$ relative compaction 
were equal to $47.3^{\circ}, 45.2^{\circ}$ and $43.5^{\circ}$ at effective confining stresses of 50,110 and $200 \mathrm{kPa}$, respectively.

8) Both fresh and aged BOF slag samples exhibited very high $\left(\geq 43^{\circ}\right)$ criticalstate and peak friction angles. The main sources of the high shear strength of BOF slag were the presence of a wide range of particle sizes (with gravel sizes) in their gradation and the angularity and rough surface textures of the particles.

9) Long-term swelling test results showed that both fresh and aged BOF slag samples show expansive properties in presence of water. In general, swell strains measured for aged BOF slag samples were higher than those of fresh BOF slag samples. Nonetheless, results indicated that aging BOF slag does not ensure volumetric stability.

10) Batch-1 Fresh BOF slag sample had a higher swelling rate compared to that of other batches of BOF slag samples. The rate of swelling for Batch-1 Fresh BOF slag was approximately 9.69x10-3/day, 1.08x10-2/day, 3.22x10-3/day and $1.73 \times 10-3$ for the initial 7 months, 7 to 10 months, 10-13 months and 1317 months of the test duration, respectively.

11) Batch-1 Fresh BOF slag sample reached the maximum volumetric strain of approximately $3.5 \%$ at the end of 17 -months of monitoring period. This was attributed to its fine gradation compared to other BOF slag samples.

12) The volume change of aged BOF slag samples stabilized at expansive volumetric strains of the order of 0.5 to $1.3 \%$ after 17 months of monitoring. On the other hand, no stabilization of the volumetric strains was observed for fresh BOF slag samples after 17 months of monitoring (the maximum expansive volumetric strains values were in the 0.66 to $3.5 \%$ range).

13) BOF slag was classified as solid waste Type III according to the Indiana restricted waste criterion based on the TCLP leachate concentration levels. Electrical resistivity and $\mathrm{pH}$ test results indicated that BOF slag samples were potentially corrosive. 


\title{
CHAPTER 6. ENGINEERING PROPERTIES OF EAF(L) SLAG
}

\begin{abstract}
6.1. Introduction
This Chapter presents the results of the tests performed to obtain the engineering properties of $\operatorname{EAF}(\mathrm{L})$ slag. Because there are variations in the $\operatorname{EAF}(\mathrm{L})$ slag generation, processing and chemical composition, two different batches of fresh $\mathrm{EAF}(\mathrm{L})$ slag samples from the source steel plant were tested. Based on their time of arrival to the Purdue University research laboratory, these two batches of fresh $\operatorname{EAF}(\mathrm{L})$ slag samples were designated as follows:

- Batch-1 Fresh EAF(L) slag (B-1 Fresh EAF(L) slag; received on 11/06)

- Batch-2 Fresh EAF(L) slag (B-2 Fresh EAF(L) slag; received on 12/07)

The main objective of the laboratory experiments was to determine the engineering properties of fresh $\operatorname{EAF}(\mathrm{L})$ slag for its use in geotechnical engineering applications. The test results are presented in the following main sections of this Chapter:
\end{abstract}

- Chemical composition

- Index properties

- Mineralogical and morphological properties

- Geotechnical Properties

- Long-term swelling response

- Heavy metal leaching and corrosivity potential 


\subsection{Chemical Composition of EAF(L) slag}

The oxide composition of EAF(L) slag was determined using X-ray fluorescence (XRF) analysis by the slag processing company (Edward C. Levy Co.) handling and distributing the EAF(L) slag from the source plant (Whitesville Mill, Nucor Steel). Table 6.2 shows the oxide composition of Batch-1 Fresh EAF(L) slag.

Table 6.1 Chemical composition of Batch-1 Fresh EAF(L) slag

\begin{tabular}{cc}
\hline Oxides & $\begin{array}{c}\% \\
\text { (by weight) }\end{array}$ \\
\hline $\mathrm{CaO}$ & 47.52 \\
$\mathrm{Al}_{2} \mathrm{O}_{3}$ & 22.59 \\
$\mathrm{FeO}$ & 7.61 \\
$\mathrm{MgO}$ & 7.35 \\
$\mathrm{SiO}_{2}$ & 4.64 \\
$\mathrm{SO}_{3}$ & 2.28 \\
$\mathrm{MnO}$ & 1.00 \\
$\mathrm{Cr}_{2} \mathrm{O}_{3}$ & 0.37 \\
$\mathrm{TiO}_{2}$ & 0.33 \\
$\mathrm{P}_{2} \mathrm{O}_{5}$ & 0.09 \\
$\mathrm{Na}_{2} \mathrm{O}$ & 0.06 \\
$\mathrm{~K}_{2} \mathrm{O}$ & 0.02 \\
$\mathrm{Zn}^{2}$ & 0.01 \\
$\mathrm{~L} . \mathrm{O}^{\mathrm{a}}$ & 6.20 \\
\hline
\end{tabular}

${ }^{\mathrm{a}}$ L.O.I=Loss of ignition

Table 6.2 shows that the major chemical components of $\mathrm{EAF}(\mathrm{L})$ slag are $\mathrm{CaO}, \mathrm{Al}_{2} \mathrm{O}_{3}$, $\mathrm{FeO}$ and $\mathrm{MgO}$. The percentages of the chemical constituents of ladle slag vary 
substantially depending on the grade of steel produced. Shi (2004) reported that the $\mathrm{CaO}$, $\mathrm{SiO}_{2}, \mathrm{Al}_{2} \mathrm{O}_{3}, \mathrm{MgO}$ and $\mathrm{FeO}$ contents in ladle slag are in the ranges of $30-60 \%, 2-35 \%$, 5$35 \%, 0.1-15 \%$, respectively. The $\mathrm{SiO}_{2}$ content of the $\mathrm{EAF}(\mathrm{L})$ slag used in this study was slightly lower than the lower limit of the range reported by Shi (2004). Nevertheless, the percentages of the other chemical constituents of the $\mathrm{EAF}(\mathrm{L})$ slag were within the ranges reported in the literature. The slag processing company (Edward C. Levy Co.) performs frequent tests in accordance with ASTM C25-06 (Standard Test Method for Chemical Analysis of Limestone, Quicklime and Hydrated Lime) to determine the free lime content of $\mathrm{EAF}(\mathrm{L})$ slag. The free lime $(\mathrm{CaO})$ content of the $\mathrm{EAF}(\mathrm{L})$ slag from the source plant varies between 4.9 and 15.3\% (personal communication with John Yzenas from Levy Co. 2008).

\subsection{Index Properties of EAF(L) slag}

Grain-size analyses and specific gravity, coarse aggregate absorption and Atterberg limits tests were performed on fresh $\mathrm{EAF}(\mathrm{L})$ slag samples. EAF(L) slag samples were classified according to both the Unified Soil Classification System (USCS) and the American Association of State Highway and Transportation Officials (AASHTO) soil classification system based on the index test results. The results of the index tests performed on fresh EAF(L) slag samples are presented next.

\subsubsection{Grain-size Analyses}

As EAF(L) slag cools down in the pits, it breaks down into particles with a wide range of sizes. After the cooling process is completed, $\operatorname{EAF}(\mathrm{L})$ slag is screened through sieves and grouped into two or three different size ranges. The EAF(L) slag samples received for testing consist of particles smaller than $9.5 \mathrm{~mm}$ (the finest gradation produced by the steel plant). Sieve analyses were performed on several samples from Batch-1 Fresh and Batch2 Fresh EAF(L) slag (see Figure 6.1). Both Batch-1 and Batch-2 Fresh EAF(L) consisted of sand (particle sizes ranging from $0.075 \mathrm{~mm}$ to $4.75 \mathrm{~mm}$ ) with silt and gravel (silt-size particles range from $0.008 \mathrm{~mm}$ to $0.075 \mathrm{~mm}$, while gravel-size particles range from 
4.75mm to $9.5 \mathrm{~mm})$. The grain-size distribution curves for Batch-1 Fresh and Batch-2 Fresh EAF(L) slag were very similar, with gravel-size, sand-size, and silt-size particles in the ranges of $8-10 \%, 79-80 \%$ and $11-13 \%$ (by weight), respectively.

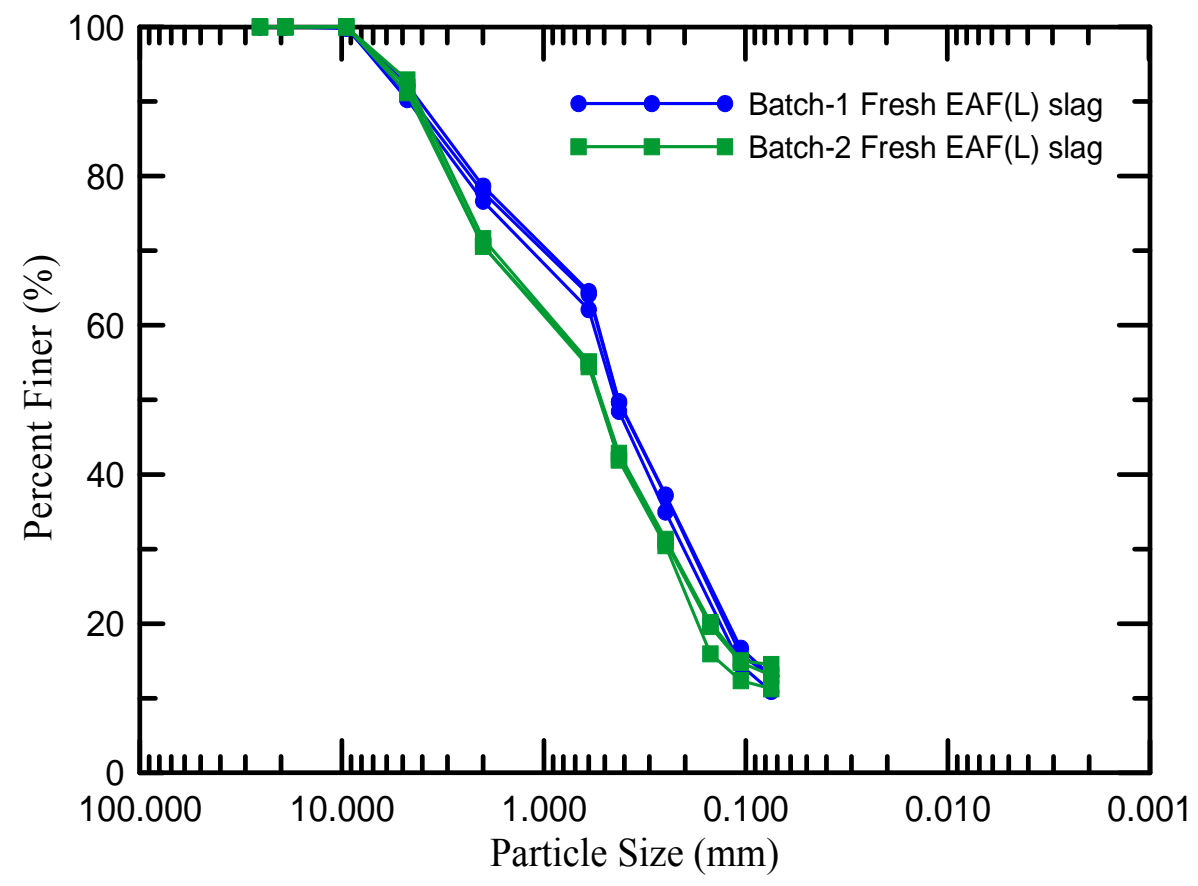

Figure 6.1 Sieve analyses of EAF(L) slag samples

In order to determine the gradation of the finer fraction (particles size less than 75 micron), hydrometer analysis was performed for Batch-1 Fresh EAF(L) slag particles passing the No. 40 sieve. Figure 6.2 shows the grain-size distribution curve obtained from the sieve and hydrometer analysis performed for Batch-1 Fresh EAF(L) slag. The fine fraction of $\operatorname{EAF}(\mathrm{L})$ slag samples were found to be in the silt-size range (with sizes ranging from $0.008 \mathrm{~mm}$ to $0.075 \mathrm{~mm}$ ). 


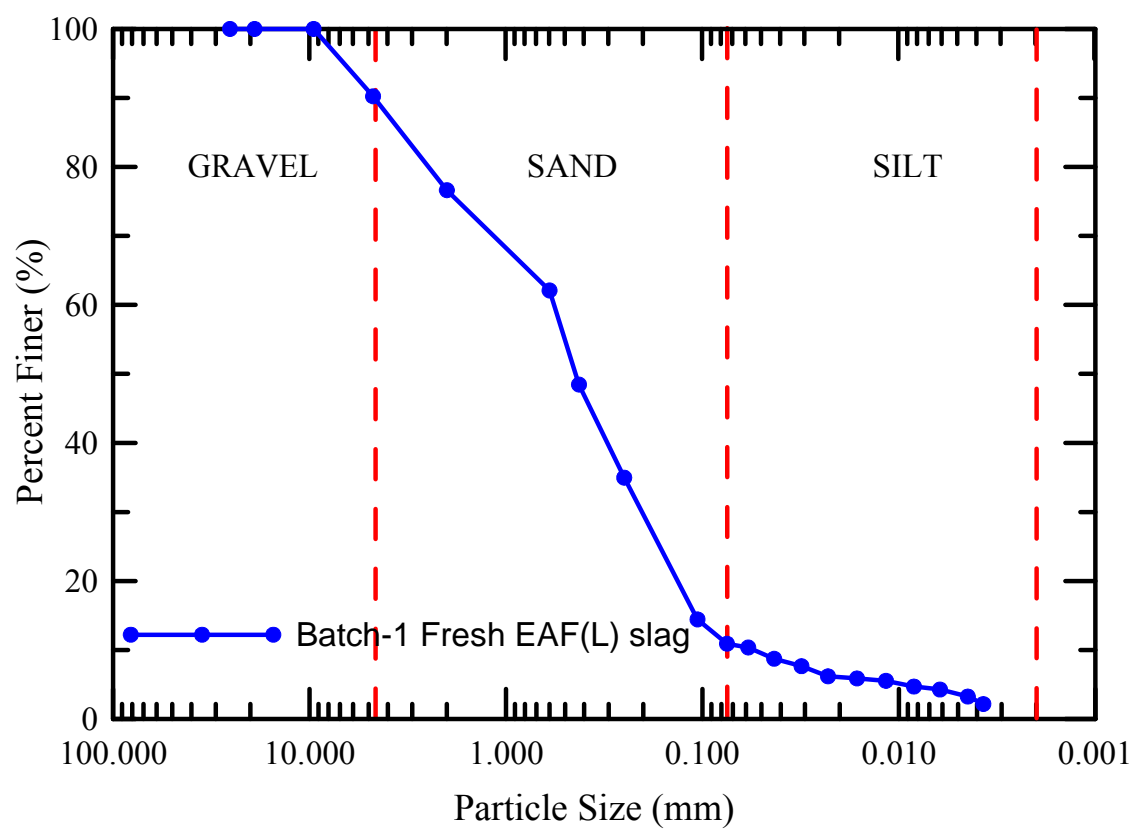

Figure 6.2 Grain-size distribution curve for Batch-1 Fresh EAF(L) slag

Figure 6.3 shows representative grain-size distribution curves for Batch-1 Fresh and Batch-2 Fresh EAF(L) slag samples. In order to classify EAF(L) slag samples based on the USCS soil classification systems, attempts were made to perform Atterberg limits tests on $\operatorname{EAF}(\mathrm{L})$ slag particles passing the No.40 sieve in accordance with ASTM D4318. During liquid limit tests, it was observed that EAF(L) slag particles at low to moderate moisture contents did not slide along the surface of the Casagrande cup to close the groove. On the other hand, the groove could not be formed with further addition of water to $\mathrm{EAF}(\mathrm{L})$ slag. Moist $\mathrm{EAF}(\mathrm{L})$ slag particles crumbled quickly, making it extremely difficult to form 3-mm-diameter threads for plastic limit determination. Therefore, EAF(L) slag fines were considered nonplastic. Based on the grain-size analyses and Atterberg limits test results, EAF(L) slag samples were classified as SP-SM with gravel (well-graded sand with silt and gravel) and A-1-b based on the USCS and AASHTO classification systems, respectively. Table 6.2 summarizes the parameters derived from the representative grain-size distribution curves and the classification of the $\mathrm{EAF}(\mathrm{L})$ slag samples according to ASTMD 2487-06 and AASHTO M145, respectively. 


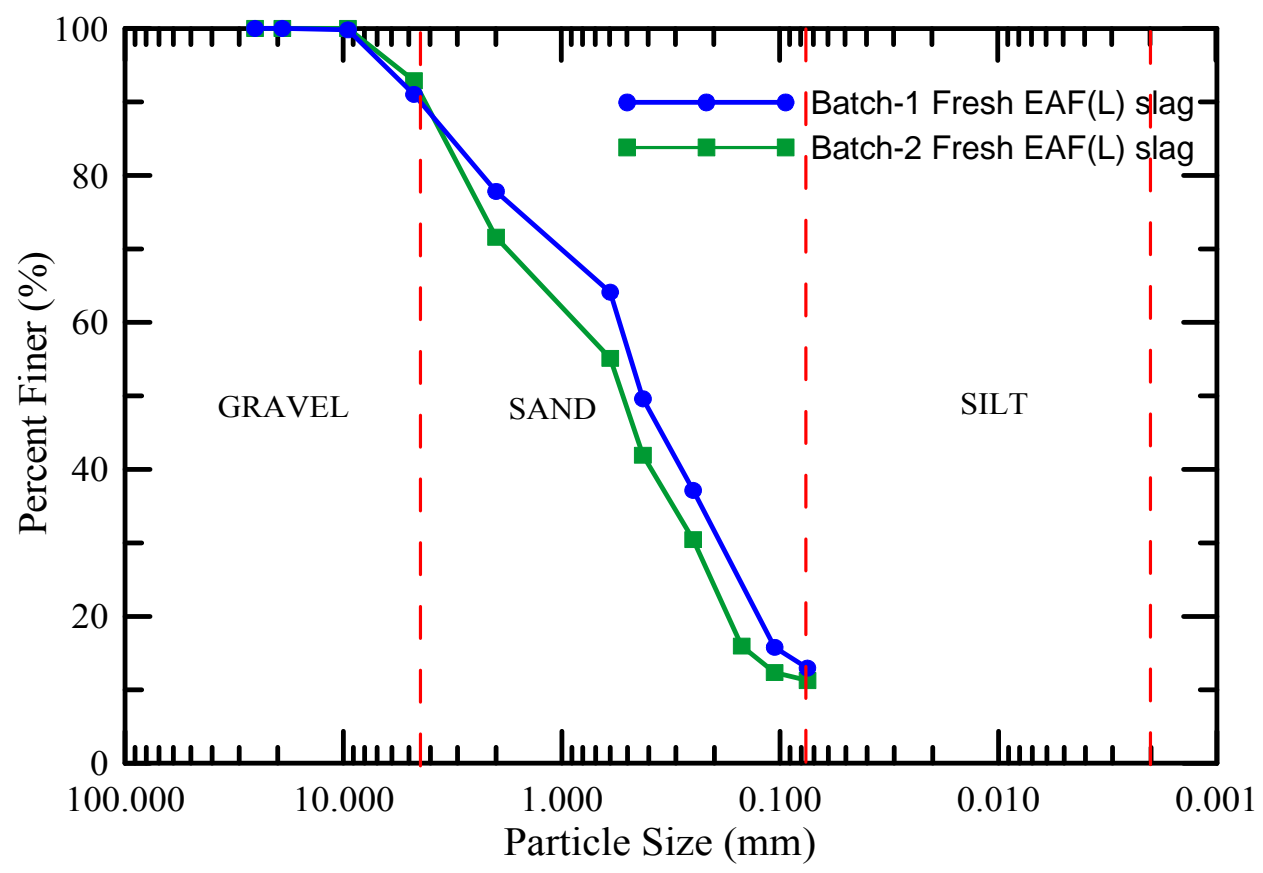

Figure 6.3 Representative grain-size distribution curves for EAF(L) slag samples

Table 6.2 Summary of grain-size distribution analyses and classification of EAF(L) slag samples

\begin{tabular}{|c|c|c|c|c|c|c|c|c|c|}
\hline \multirow{2}{*}{ Sample ID } & \multirow{2}{*}{$\begin{array}{c}\% \\
\text { Gravel }\end{array}$} & \multirow{2}{*}{\multicolumn{2}{|c|}{$\begin{array}{c}\% \quad \% \\
\text { Sand Silt }\end{array}$}} & \multirow{2}{*}{$\begin{array}{c}\% \\
\text { passing } \\
\text { No.10 }\end{array}$} & \multirow{2}{*}{$\begin{array}{c}\% \\
\text { passing } \\
\text { No.40 }\end{array}$} & \multirow{2}{*}{$\begin{array}{c}D_{50} \\
(\mathrm{~mm})\end{array}$} & \multirow{2}{*}{$\mathrm{C}_{\mathrm{u}} \quad \mathrm{C}_{\mathrm{c}}$} & \multicolumn{2}{|c|}{ Classification system } \\
\hline & & & & & & & & USCS & AASHTO \\
\hline $\begin{array}{l}\text { B-1 Fresh } \\
\text { EAF(L) slag }\end{array}$ & 10 & 79 & 11 & 77 & 48 & 0.45 & 101.3 & SW-SM with gravel ${ }^{a}$ & $A-1-b$ \\
\hline $\begin{array}{l}\text { B-2 Fresh } \\
\text { EAF slag }\end{array}$ & 8 & 79 & 13 & 71 & 42 & 0.55 & 151.3 & SW-SM with gravel ${ }^{\mathrm{a}}$ & $A-1-b$ \\
\hline
\end{tabular}

\footnotetext{
${ }^{\mathrm{a}}$ Poorly-graded sand with silt and gravel
} 


\subsubsection{Specific Gravity}

The specific gravity of fine (sand and silt size) and coarse (gravel size) EAF(L) slag particles were determined using different methods, as explained in Chapter 4. The average specific gravity of representative $\mathrm{EAF}(\mathrm{L})$ slag samples was determined by calculating the weighted average of the specific gravity values obtained for these two-size fractions. The results of the specific gravity tests performed on $\mathrm{EAF}(\mathrm{L})$ slag samples are presented next.

\section{Specific Gravity and Absorption of the Coarse Fraction of EAF(L) Slag Samples}

The specific gravity and water absorption of EAF(L) slag particles retained by the No.4 sieve (particles larger than $4.75 \mathrm{~mm}$ ) were determined by the coarse aggregate tests in accordance with ASTM C127. Table 6.3 shows the specific gravity and absorption values of the coarse aggregate for Batch-1 Fresh and Batch-2 Fresh EAF(L) slag samples.

Table 6.3 Specific gravity and absorption values for the coarse fraction of EAF(L) slag

\begin{tabular}{lcccc}
\hline Sample ID & $G_{s, O D}{ }^{\mathrm{a}}$ & $G_{s, S S D}{ }^{\mathrm{b}}$ & $G_{s, \text { apparent }}{ }^{\mathrm{c}}$ & $\begin{array}{c}\text { Water } \\
\text { Absorption } \\
(\%)\end{array}$ \\
\hline \hline Batch-1 Fresh EAF(L) slag & 2.34 & 2.55 & 2.96 & 9.1 \\
Batch-2 Fresh EAF(L) slag & 2.97 & 3.04 & 3.18 & 3.0 \\
${ }^{\mathrm{a}} G_{s, O D}=$ oven-dry specific gravity \\
${ }^{\mathrm{b}} G_{s, S S D}=$ saturated-surface dry specific gravity \\
${ }^{\mathrm{c}} G_{s, \text { apparent }}=$ apparent specific gravity
\end{tabular}

The specific gravities $-G_{s, O D}, G_{s, S S D}$, and $G_{s, a p p a r e n t}$ - are equal to the ratios of the oven-dry density, saturated-surface dry density and apparent density of the coarse aggregates to the density of distilled water, respectively. The apparent specific gravity is of importance in geotechnical applications (refer to Chapter 4) and, hence, the apparent specific gravity 
values were considered to be representative of the coarse fraction of EAF(L) slag samples. The water absorption values of the coarse fraction of Batch-1 Fresh and Batch2 Fresh EAF(L) slag were 9\% and 3\%, respectively. This is due to the fact that the Batch1 Fresh EAF(L) slag particles had a more porous structure than those of Batch-2. The $G_{\text {s,apparent }}$ of the gravel-size particles of Batch-1 Fresh and Batch-2 Fresh EAF(L) slag samples were equal to 2.96 and 3.18 , respectively.

\section{Specific Gravity of the Fine Fraction of the EAF(L) Slag Samples}

The specific gravity of the particles passing the No.4 sieve (particles smaller than $4.75 \mathrm{~mm}$ ) was determined using the water pycnometer in accordance with ASTM D854. Table 6.4 presents the specific gravity test results for the silt- and sand-size particles of Batch-1 and Batch-2 Fresh EAF(L) slag samples.

Table 6.4 Specific gravity of the fine fraction of EAF(L) slag (particles smaller than $4.75 \mathrm{~mm})$

\begin{tabular}{cc}
\hline Sample ID & $G_{s, \text { fines }}$ \\
\hline \hline Batch-1 Fresh EAF(L) slag & 2.71 \\
Batch-2 Fresh EAF(L) slag & 3.03 \\
\hline
\end{tabular}

\section{Average Specific Gravity of EAF(L) Slag Samples}

The average specific gravity of $\mathrm{EAF}(\mathrm{L})$ slag samples was determined by calculating the weighted average of the specific gravity values determined for the fine (sand- and siltsize particles) and coarse (gravel-size particles) fractions of Batch-1 Fresh and Batch-2 Fresh EAF(L) slag (see Table 6.5). The average specific gravity of Batch-1 Fresh and Batch-2 Fresh EAF(L) slag samples was equal to 2.73 and 3.04, respectively. The 
difference in the specific gravity values between Batch-1 Fresh and Batch-2 Fresh EAF(L) slag samples is mainly due to the variations in the chemical composition of the EAF(L) slag batches.

Table 6.5 Average specific gravity of EAF(L) slag samples

\begin{tabular}{cc}
\hline Sample ID & $G_{s, \text { average }}$ \\
\hline \hline Batch-1 Fresh EAF(L) slag & 2.73 \\
Batch-2 Fresh EAF(L) slag & 3.04 \\
\hline
\end{tabular}

\subsection{Mineralogical and Morphological Properties of EAF(L) slag}

The mineralogical phases present in Batch-1 Fresh and Batch-2 Fresh EAF(L) slag samples were identified using XRD analysis. The morphological characteristics of fresh EAF(L) slag samples were determined using optical microscopy and Scanning Electron Microscopy (SEM) examinations. The results of these analyses are presented next.

\subsubsection{Particle Mineralogy}

X-ray diffraction analysis was performed on Batch-1 Fresh and Batch-2 Fresh EAF(L) slag samples to determine their mineralogical phases. Figure 6.4 shows the XRD patterns of Batch-1 Fresh EAF(L) slag and Batch-2 Fresh EAF(L) slag samples. The EAF(L) slag used in this research is cooled very slowly in the pits under ambient atmospheric conditions. These slow cooling conditions allow the formation of various crystalline phases. This is reflected in the very complex XRD patterns shown in Figure 6.4 which indicate the presence of . of many different crystalline phases,. Mineral phases with distinct peaks of high intensities as well as some overlapping peaks of low intensities 
were detected. Several other researchers have reported similar XRD patterns for EAF(L) slag (Manso et al. 2005; Nicolae et al. 2007; Tossavanien et al. 2007).

The XRD patterns of Batch-1 Fresh and Batch-2 Fresh EAF(L) slag samples were analyzed by comparing the peaks present in the XRD patterns with those provided in the Joint Committee for Powder Diffraction Standards, Hanawalt System (JCPDS). In order to identify the minerals present in the samples, the software program Jade was also used. Identification of mineral phases is very difficult when a material has a very complex mineralogical composition with overlapping peaks. The XRD patterns of Batch-1 Fresh and Batch-2 Fresh EAF(L) slag samples were similar. However, some differences were observed in the XRD patterns of Batch-1 Fresh and Batch-2 Fresh EAF(L) slag samples that indicate the presence of not only different crystalline phases but also changes in the quantities of the major mineral phases. Even slight variations in the chemical composition of the molten slag can lead to significant changes in particle mineralogy. Figure 6.5 and Figure 6.6 show the results of the XRD analyses (using the Jade software) performed for Batch-1 Fresh and Batch-2 Fresh EAF(L) slag samples, respectively.

The mineral phases identified in the $\operatorname{EAF}(\mathrm{L})$ slag samples were determined as major or minor depending on the intensity of the peaks (peak intensity is related to the quantity of the mineral present in the sample). Some of the overlapping mineral phases that could not be determined with certainty were identified as probable. The three major mineral phases present in Batch-1 Fresh EAF(L) slag were portlandite $\left(\mathrm{Ca}\left(\mathrm{OH}_{2}\right)\right)$, mayenite $\left(\mathrm{Ca}_{12} \mathrm{Al}_{14} \mathrm{O}_{33}\right)$ and malenterite $\left(\mathrm{FeSO}_{4} \cdot 7 \mathrm{H}_{2} \mathrm{O}\right)$. The highest peak in the $\mathrm{XRD}$ pattern of Batch-1 Fresh EAF(L) slag was observed for portlandite (this is due to its high $\mathrm{CaO}$ content; see Table 6.1 ). Other minor phases identified were brassite $\left(\mathrm{MgHAsO}_{4} \cdot 4 \mathrm{H}_{2} \mathrm{O}\right)$, pentahydrite $\left(\mathrm{MgSO}_{4} \cdot 5 \mathrm{H}_{2} \mathrm{O}\right)$, lime $(\mathrm{CaO})$ and larnite $\left(\mathrm{Ca}_{2} \mathrm{SiO}_{4}\right)$. The major mineral phases present in Batch-2 Fresh EAF(L) slag were portlandite $\left(\mathrm{CaOH}_{2}\right)$, periclase $(\mathrm{MgO})$, and mayenite $\left(\mathrm{Ca}_{12} \mathrm{Al}_{14} \mathrm{O}_{33}\right)$. Other minor mineral phases present in Batch-2 Fresh EAF(L) slag were magnesite $\left((\mathrm{Mg}, \mathrm{Fe}) \mathrm{CO}_{3}\right)$, malenterite $\left(\mathrm{FeSO}_{4} \cdot 7 \mathrm{H}_{2} \mathrm{O}\right)$, larnite $\left(\mathrm{Ca}_{2} \mathrm{SiO}_{4}\right)$ and ferroan wollastonite $\left.((\mathrm{Ca}, \mathrm{Fe})) \mathrm{SiO}_{3}\right)$. A larger number of $\mathrm{Mg}$ bearing phases were observed for Batch-2 Fresh EAF(L) slag than for Batch-1 Fresh 
EAF(L) slag. Table 6.6 presents all the mineral phases identified in Batch-1 Fresh and Batch-2 fresh $\mathrm{EAF}(\mathrm{L})$ slag samples.

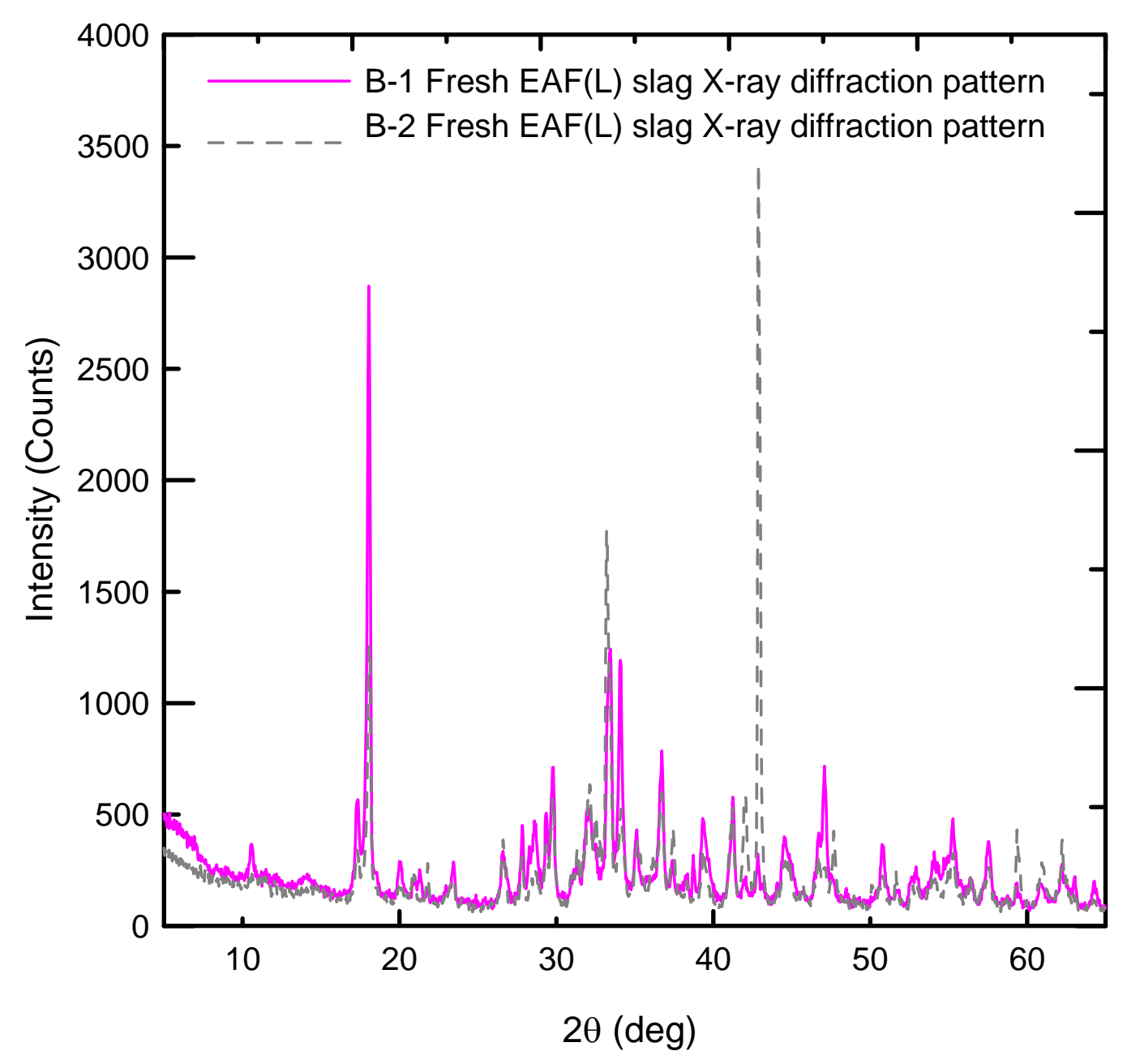

Figure 6.4 X-ray diffraction patterns for Batch-1 Fresh and Batch-2 Fresh EAF(L) slag samples 


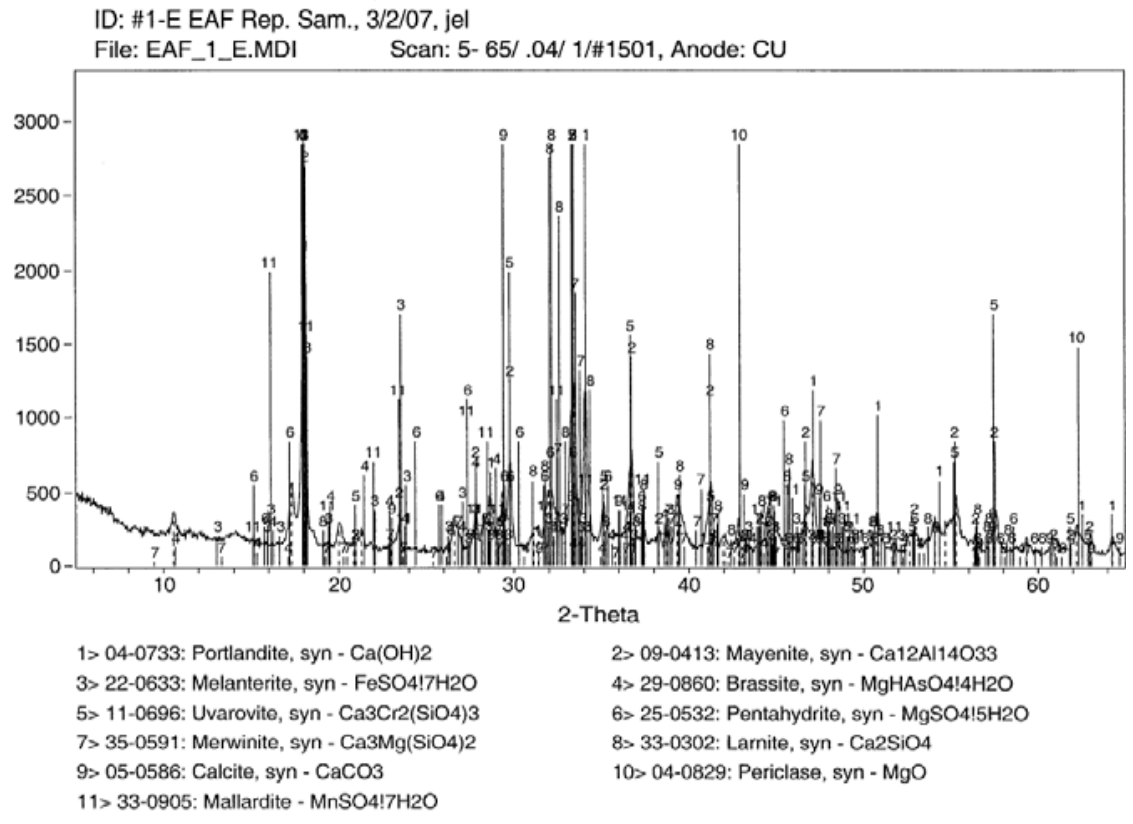

Figure 6.5 XRD analysis of Batch-1 Fresh EAF(L) slag sample

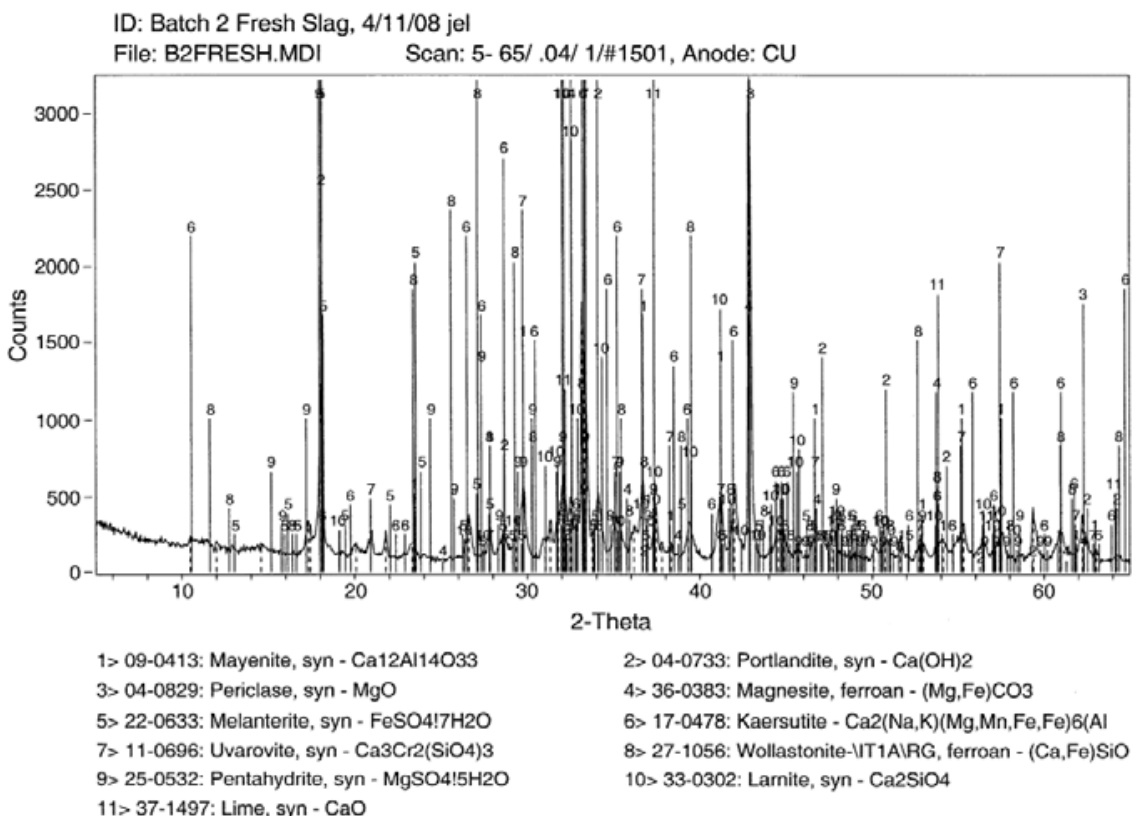

Figure 6.6 XRD analysis of Batch-2 Fresh EAF(L) slag sample 
Table 6.6 Mineralogical phases identified in Batch-1 Fresh and Batch-2 Fresh EAF(L) slags samples based on XRD analyses

\begin{tabular}{|c|c|c|c|}
\hline Mineral Type & Formula & $\begin{array}{c}\text { Batch-1 Fresh } \\
\text { EAF(L)slag } \\
\end{array}$ & $\begin{array}{c}\text { Batch-2 Fresh } \\
\text { EAF(L)slag } \\
\end{array}$ \\
\hline Portlandite & $\mathrm{Ca}(\mathrm{OH})_{2}$ & major & major \\
\hline Mayenite & $\mathrm{Ca}_{12} \mathrm{Al}_{14} \mathrm{O}_{33}$ & major & major \\
\hline Melanterite & $\mathrm{FeSO}_{4} .7 \mathrm{H}_{2} \mathrm{O}$ & major & minor \\
\hline Brassite & $\mathrm{MgHAsO}_{4} \cdot 4 \mathrm{H}_{2} \mathrm{O}$ & minor & - \\
\hline Uvavorite & $\mathrm{Ca}_{3} \mathrm{Cr}_{2}(\mathrm{SiO} 4)_{3}$ & minor & minor \\
\hline Pentahydrite & $\mathrm{MgSO}_{4} .5 \mathrm{H}_{2} \mathrm{O}$ & minor & minor \\
\hline Larnite & $\mathrm{Ca}_{2} \mathrm{SiO}_{4}$ & minor & minor \\
\hline Lime & $\mathrm{CaO}$ & minor & minor \\
\hline Wollastonite $^{\mathrm{f}}$ & $(\mathrm{Ca}, \mathrm{Fe}) \mathrm{SiO}_{3}$ & minor & minor \\
\hline Calcite & $\mathrm{CO}_{3}$ & probable & probable \\
\hline Merwinite & $\mathrm{Ca}_{3} \mathrm{Mg}\left(\mathrm{SiO}_{4}\right)_{2}$ & probable & - \\
\hline Periclase & $\mathrm{MgO}$ & minor & major \\
\hline Mallardite & $\mathrm{MnSO}_{4} .7 \mathrm{H}_{2} \mathrm{O}$ & probable & - \\
\hline Magnesite $^{\mathrm{f}}$ & $(\mathrm{Mg}, \mathrm{Fe}) \mathrm{CO}_{3}$ & - & major \\
\hline Kaersutite & $\mathrm{NaCa}_{2} \mathrm{Mg}_{4} \mathrm{Ti}\left(\mathrm{Si}_{6} \mathrm{Al}_{2} \mathrm{O}_{23}\right)(\mathrm{OH})_{2}$ & - & probable \\
\hline
\end{tabular}

ferroan; - not detected

\subsubsection{Particle Morphology}

The main objective of the SEM and optical microscopy studies was to characterize the morphology (shape, angularity, sphericity, and surface texture) of EAF(L) slag particles. The morphology of the gravel-size EAF(L) slag particles was examined under a light microscope. Sand- and silt-size EAF(L) slag particles were examined using Scanning Electron Microscopy (SEM). The morphological characteristics of Batch-1 Fresh and Batch-2 Fresh EAF(L) slag particles are discussed next. 


\section{Morphological Characteristics of Gravel-Size EAF(L) Slag Particles}

Figure 6.7 shows the gravel-size particles present in Batch-1 Fresh EAF(L) and Batch-2 Fresh $\mathrm{EAF}(\mathrm{L})$ slag samples, respectively.

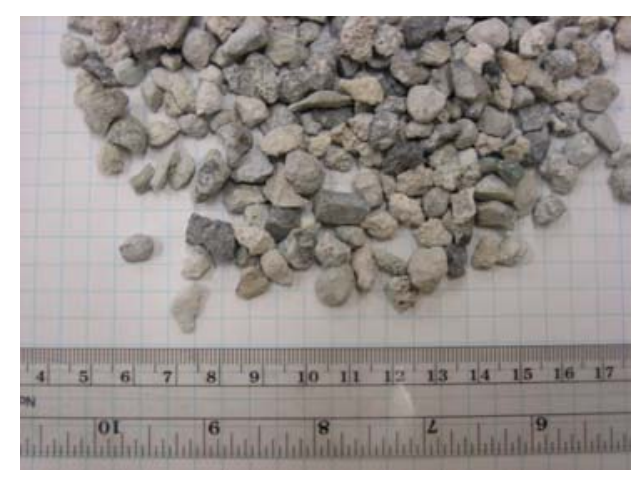

(a)

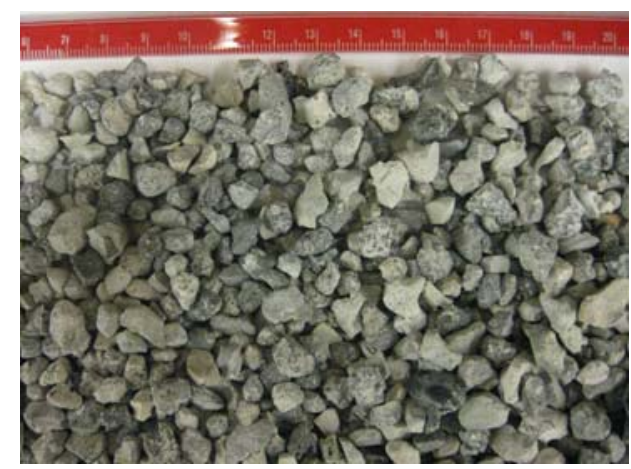

Figure 6.7 Gravel-size EAF(L) slag particles present in (a) Batch-1 Fresh EAF(L) slag sample and (b) Batch-2 Fresh EAF(L) slag sample

The gravel-size particles of fresh $\mathrm{EAF}(\mathrm{L})$ slag had shapes varying from subrounded to subangular. Both bulky and platy gravel-size particles were observed. Distinct asperities and edges were also visible in subangular bulky particles. Most of the platy particles had irregular shapes with very low sphericity and sharp edges. Figure 6.8 (a) and (b) show platy gravel-size slag particles with sharp edges present in Batch-1 Fresh and Batch-2 Fresh $\mathrm{EAF}(\mathrm{L})$ slag samples, respectively. 


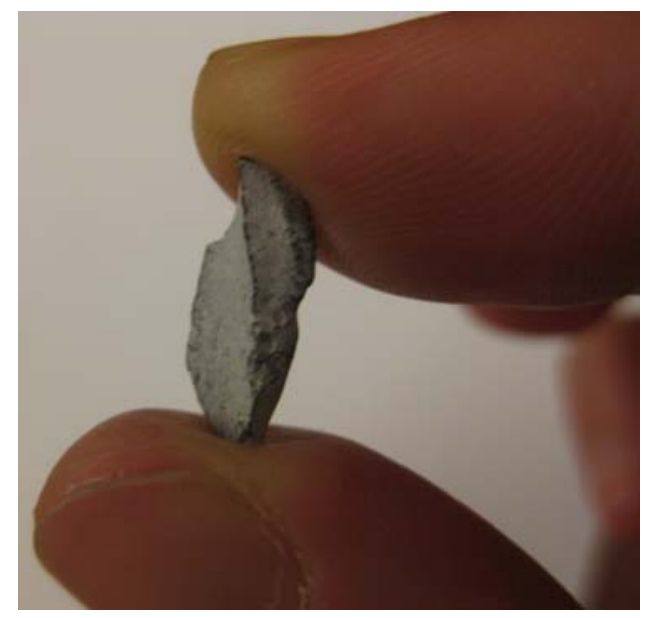

(a)

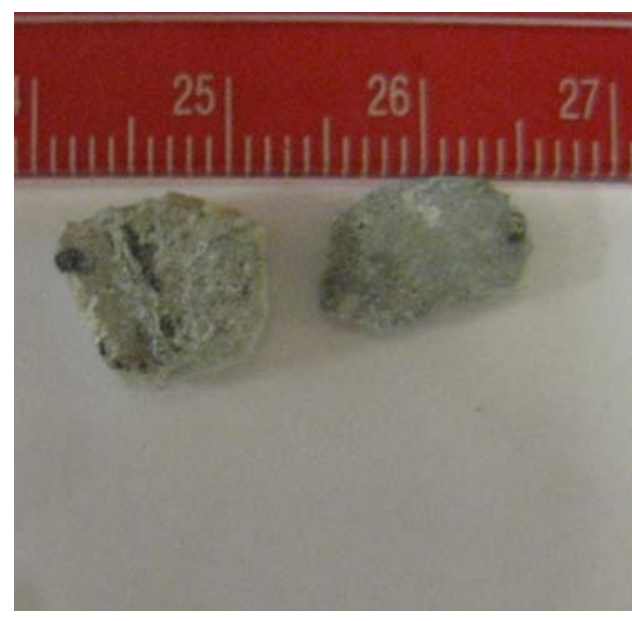

(b)

Figure 6.8 Platy gravel-size particles present in (a) Batch-1 Fresh EAF(L) slag sample, and (b) Batch-2 Fresh EAF(L) slag sample

The main difference observed in the morphology of the gravel-size particles of the two different $\operatorname{EAF}(\mathrm{L})$ slag samples was the presence of particles with popcorn-like porous structure in Batch-1 Fresh EAF(L) slag (see Figure 6.9). The gravel-size particles of Batch-2 Fresh EAF(L) slag did not have a porous structure visible to the naked eye. This morphological difference between gravel-size particles from these two $\mathrm{EAF}(\mathrm{L})$ slag samples might be due to differences in the slag chemical composition and cooling rate .(a fast cooling rate leads to entrapment of water or air in the slag particles). The presence of porous gravel-size particles in Batch-1 Fresh EAF(L) slag also explains its higher water absorption and lower specific gravity values (see Table 6.3 ).

A rough surface texture was observed on gravel-size particles from both Batch-1 Fresh and Batch-2 Fresh EAF(L) slag samples examined under light microscopy. Some platy-shaped particles had smooth surfaces. 


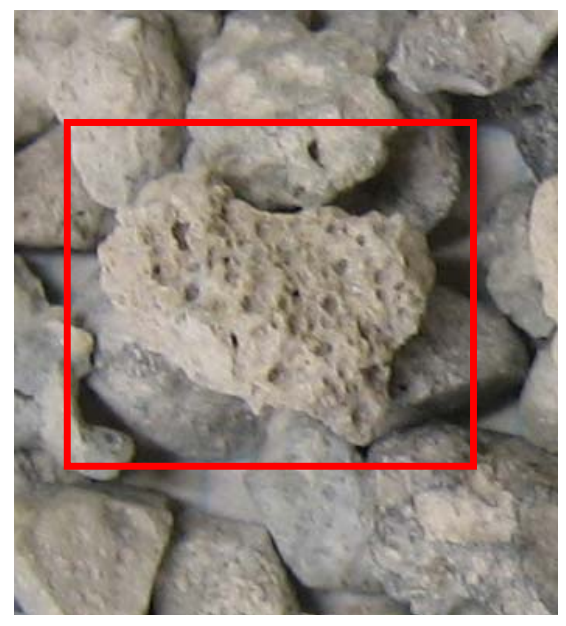

Figure 6.9 Porous structure evident in gravel-size particles of Batch-1 Fresh EAF(L) slag sample

\section{Morphological Characteristics of Sand-and Silt-Size EAF(L) Slag Particles}

Sand- and silt-size EAF(L) slag particles were examined in the Scanning Electron Microscope (SEM). Figure 6.10 (a) and (b) show the sand- and silt-size particles from Batch-1 Fresh EAF(L) slag. Figure 6.11 (a), (b), and (c) are SEM micrographs of the surface texture of the sand-size particles from Batch-1 Fresh EAF(L) slag. Figure 6.12 (a) and (b) show the sand- and silt-size particles from Batch-2 Fresh EAF(L) slag.. Figure 6.13 (a), (b) and (c) are SEM micrographs of the surface texture of the sand-size particles from Batch-2 Fresh EAF(L) slag. 


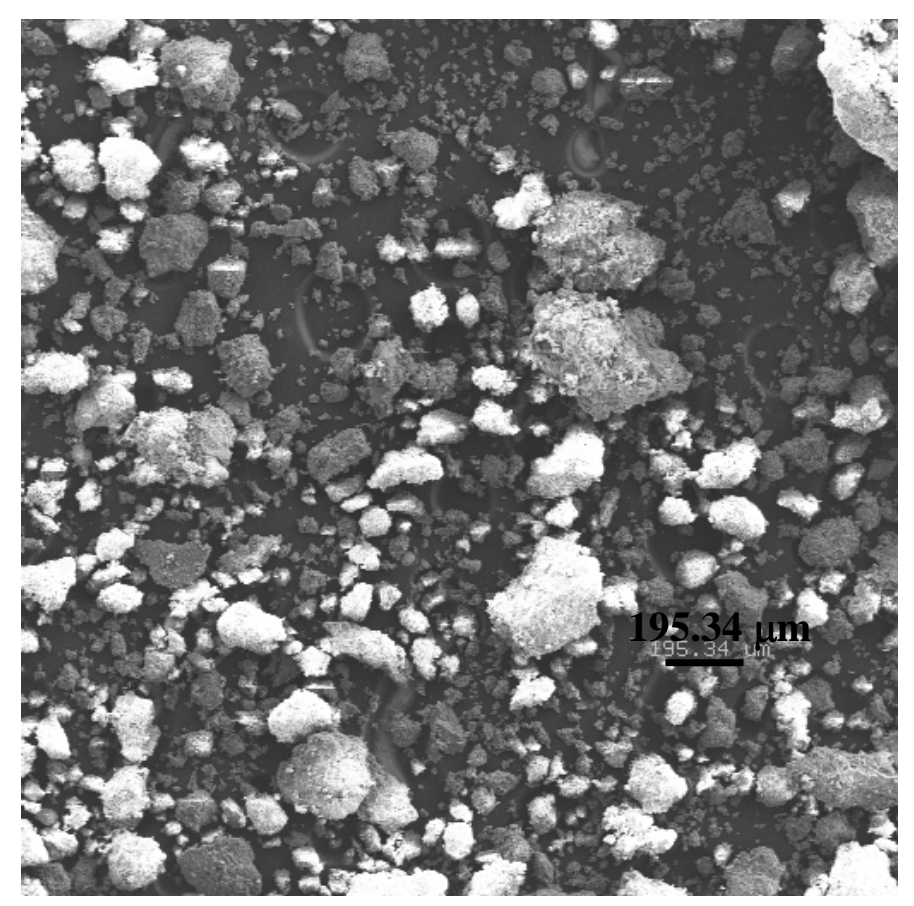

(a)

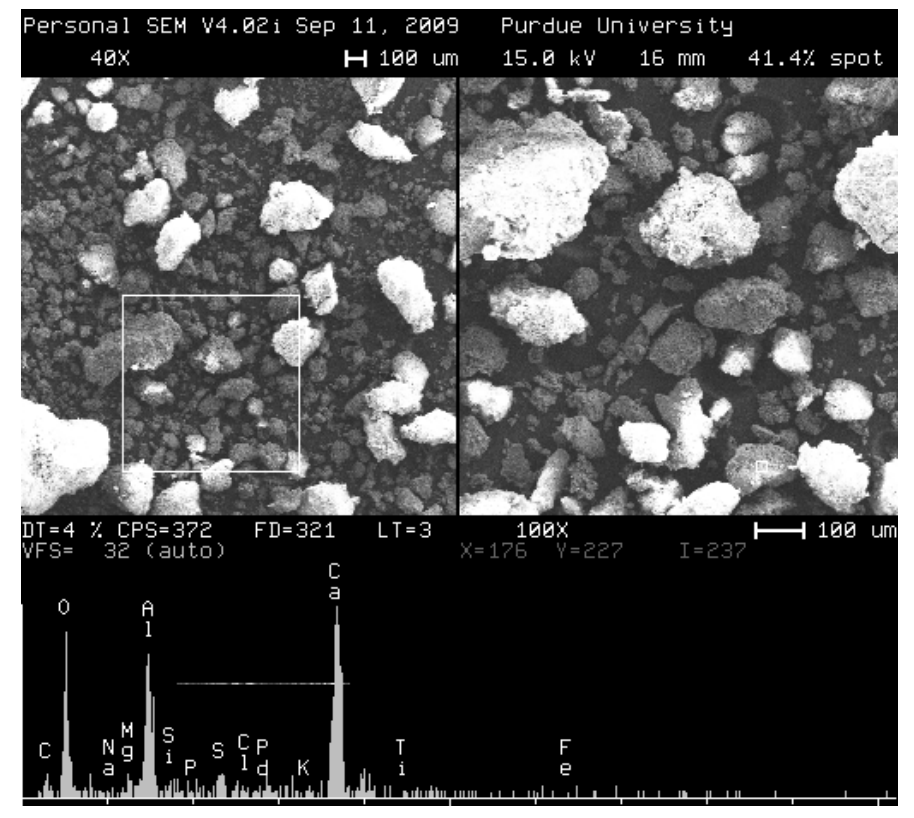

(b)

Figure 6.10 SEM micrographs of Batch-1 Fresh EAF(L) slag (a) sand- and silt-size particle shapes (magnification $=50 \mathrm{X}$ ) and (b) particles with their elemental analysis 


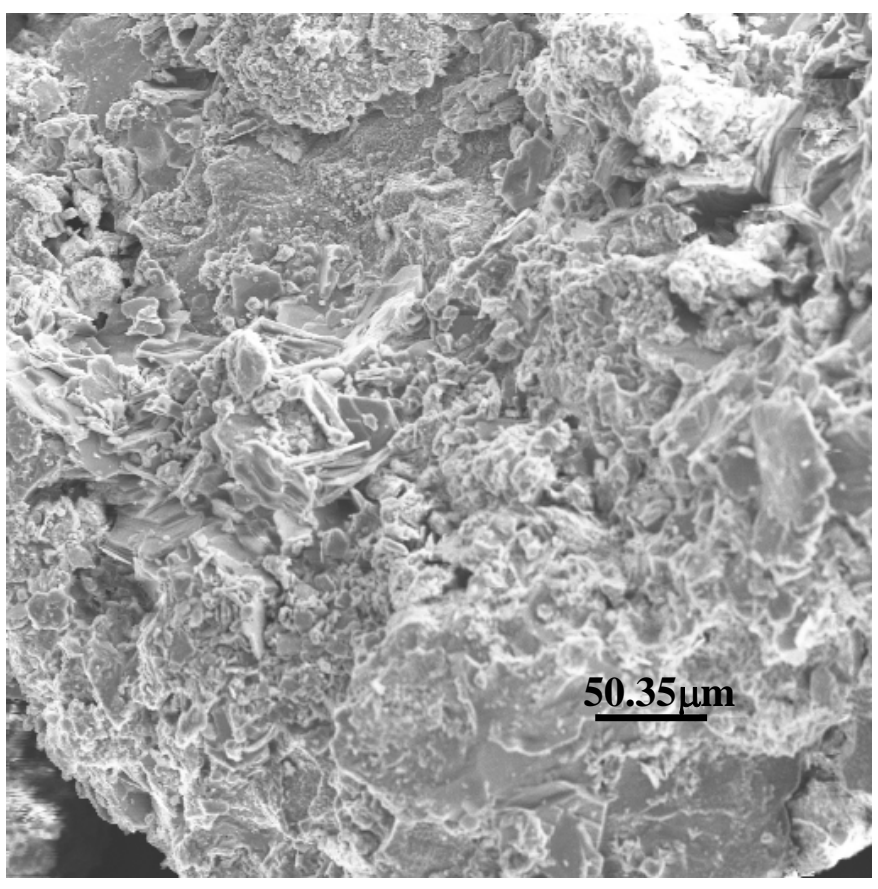

(a)

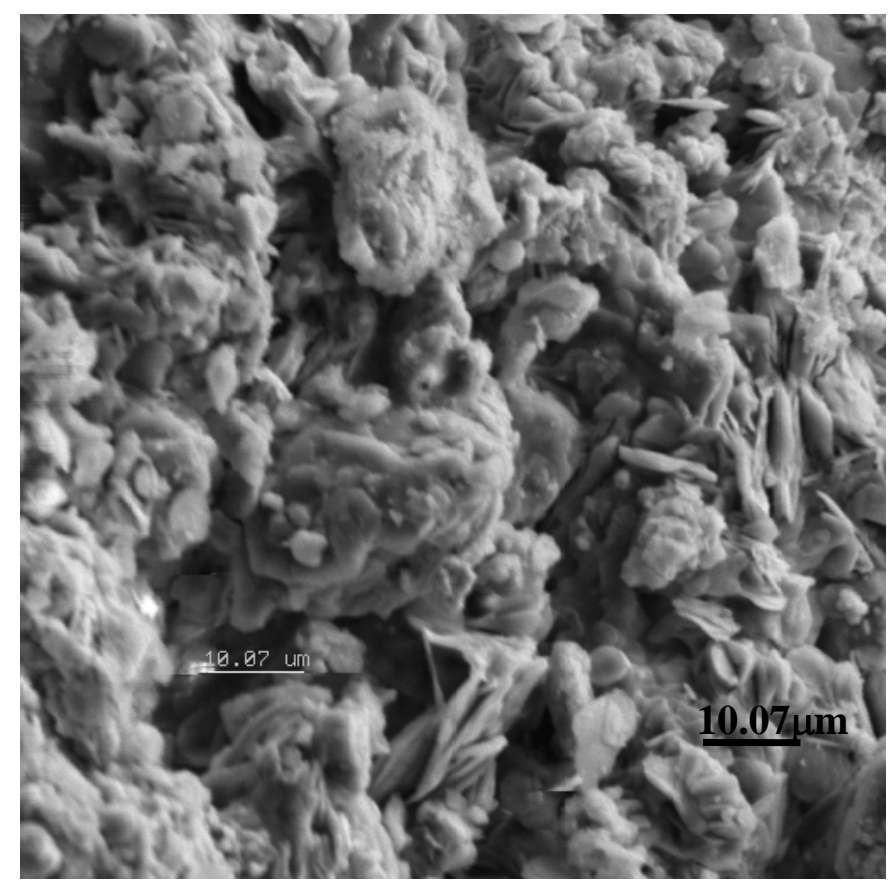

(b) 


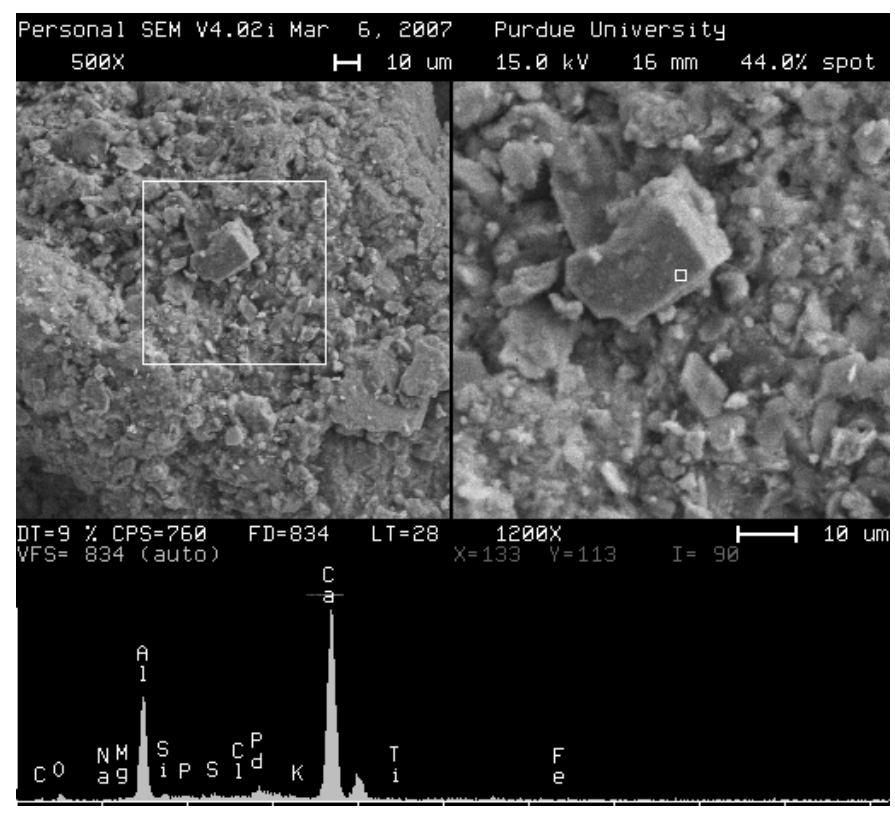

(c)

Figure 6.11 SEM micrographs of Batch-1 Fresh EAF(L) slag: (a) surface texture of a sand-size particle (magnification=250X), (b) surface texture of a sand-size particle (magnification=1200X) and (c) crystalline structure and elemental analysis

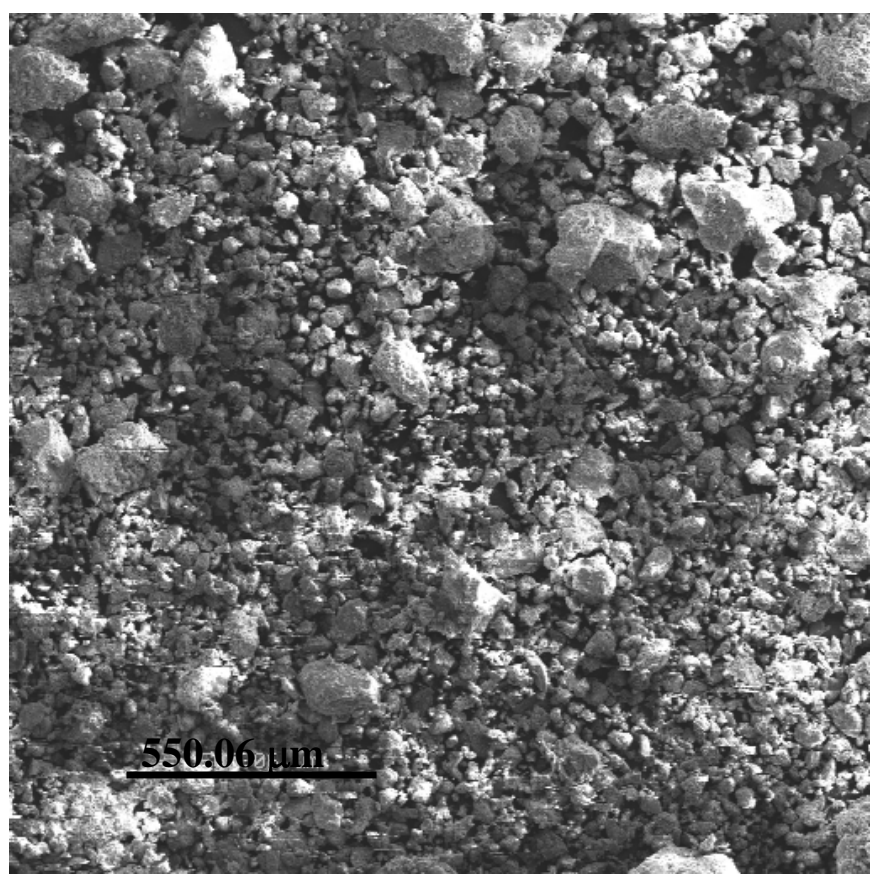

(a) 


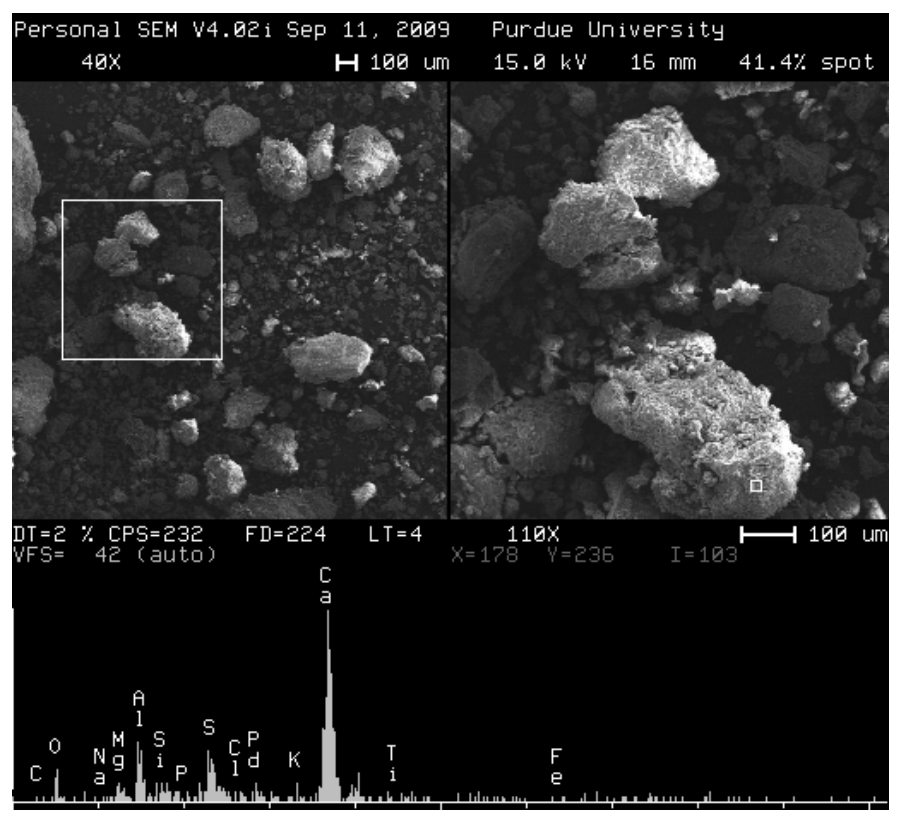

(b)

Figure 6.12 SEM micrographs of Batch-2 Fresh EAF(L) slag: (a) sand- and silt-size particle shapes (magnification $=50 \mathrm{X}$ ) and (b) particles with their elemental analysis

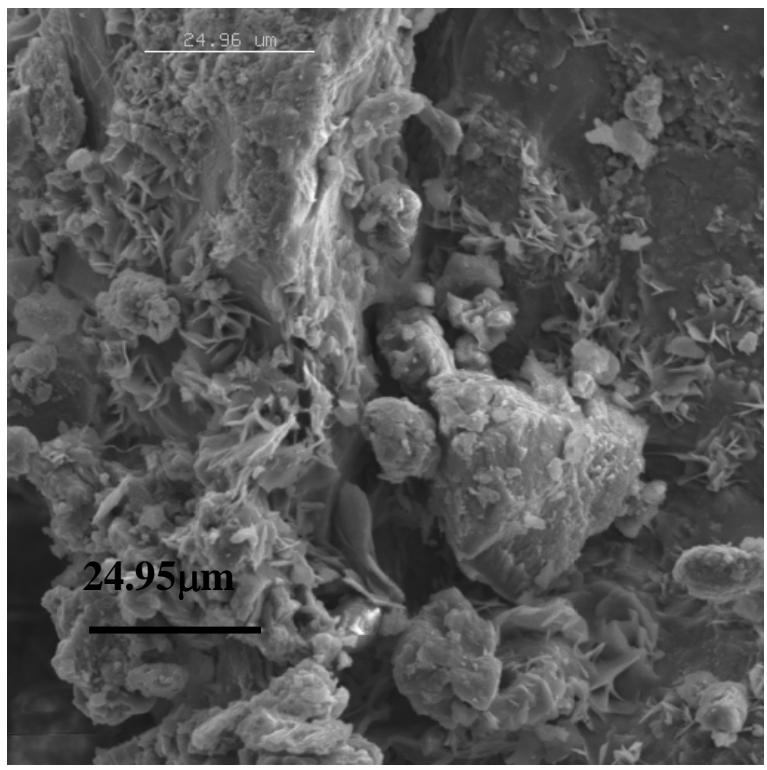

(a) 


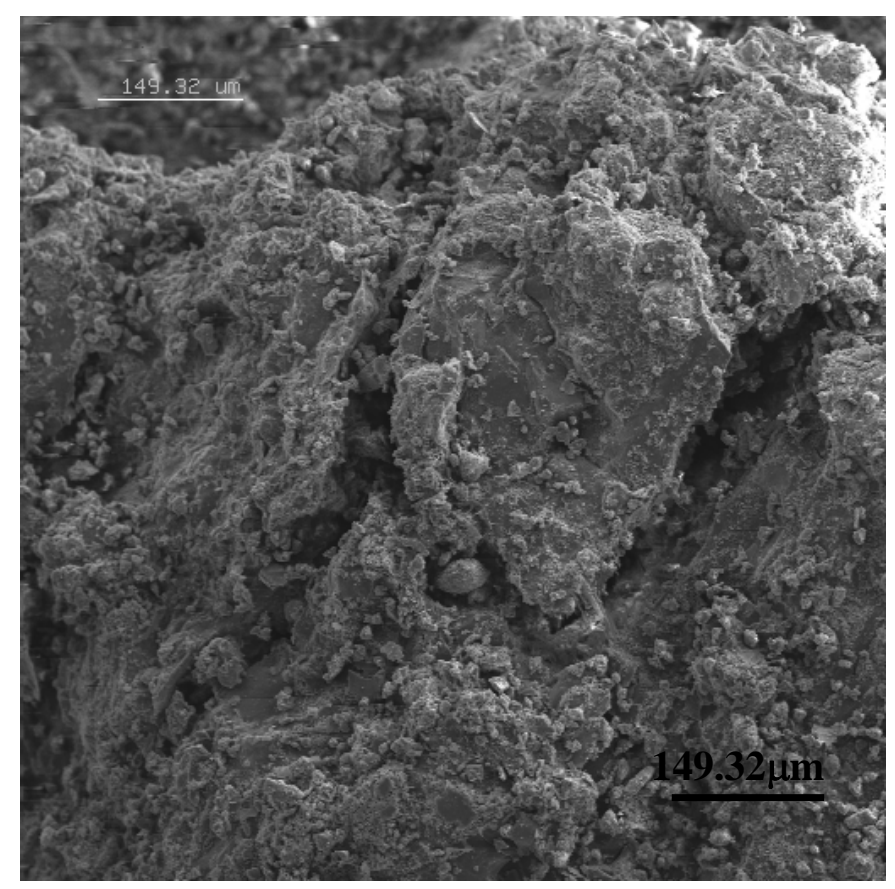

(b)

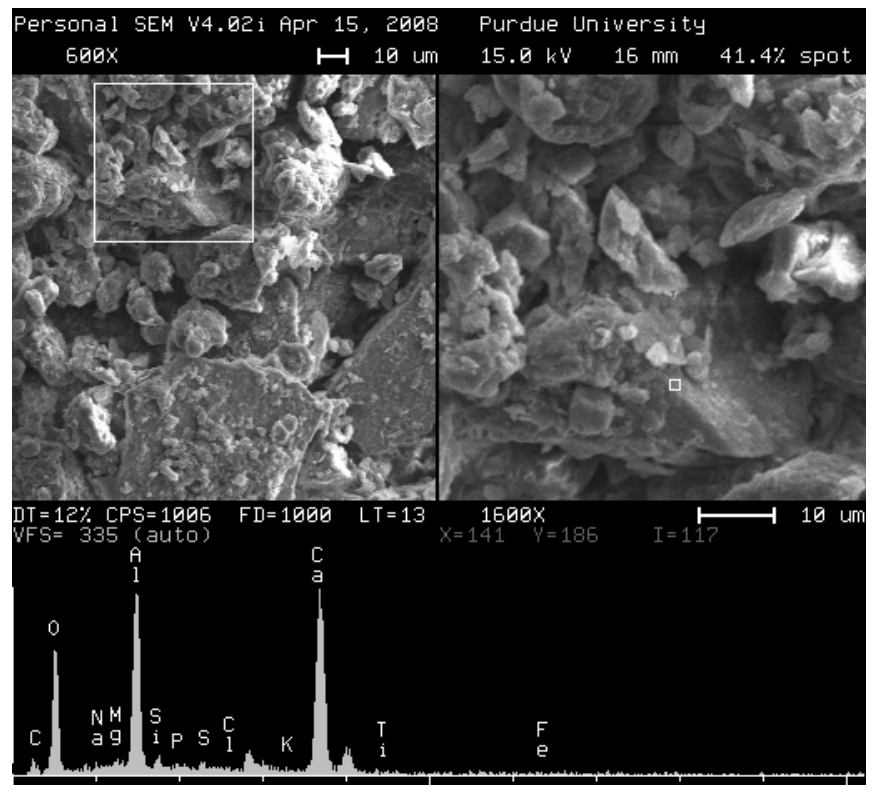

(c)

Figure 6.13 SEM micrographs of Batch-2 Fresh EAF(L) slag: (a) surface texture of a sand-size particle (magnification=800X), (b) very rough surface texture of a sand-size particle (magnification=120X), (c) crystalline structure and elemental analysis 
Sand- and silt-size particles from Batch-1 Fresh and Batch-2 Fresh EAF(L) slag samples had similar morphological features. The sand- and silt-size fresh EAF(L) slag particles from both batches had subrounded to subangular shapes (see Figure 6.10 and Figure 6.12). Some very irregularly shaped platy particles were also observed in both samples.

Most of the sand-size particles examined under SEM had extremely rough surface textures. Platy crystalline structures were observed for both Batch-1 Fresh and Batch-2 Fresh EAF(L) slag (see Figure 6.11 and Figure 6.13). Some of the SEM micrographs of sand-size Batch-1 Fresh EAF(L) slag particles indicated the presence of a porous structure (see Figure 6.11 (b)). A porous structure was not observed for Batch-2 Fresh EAF(L) slag particles.

\subsection{Geotechnical Properties of EAF(L) slag}

The results of compaction, maximum and minimum density, and large-scale direct shear test performed on $\mathrm{EAF}(\mathrm{L})$ slag samples are presented next.

\subsubsection{Compaction Tests}

Batch-1 Fresh and Batch-2 Fresh EAF(L) slag samples were tested using the standard Proctor compaction procedure. Figure 6.14 shows the moisture-density relationship (compacted dry unit weight versus moisture content curves) of the EAF(L) slag samples

with the zero-air-void curves that show the maximum possible dry unit weights of EAF(L) slag samples (see Figure 6.14).

Batch-1 Fresh EAF(L) slag sample exhibited a compaction curve with a single peak at a moisture content of approximately $14 \%$. The maximum dry unit weight $\left(\gamma_{d, \max }\right)$ was measured as $16.8 \mathrm{kN} / \mathrm{m}^{3}$. Batch-2 Fresh EAF(L) slag sample had an irregular compaction curve similar to the 1 and $1 / 2$ peaks curves commonly observed in coarsegrained soils. The maximum dry unit weight was approximately $20.0 \mathrm{kN} / \mathrm{m}^{3}$ at the optimum moisture content of $11 \%$. 


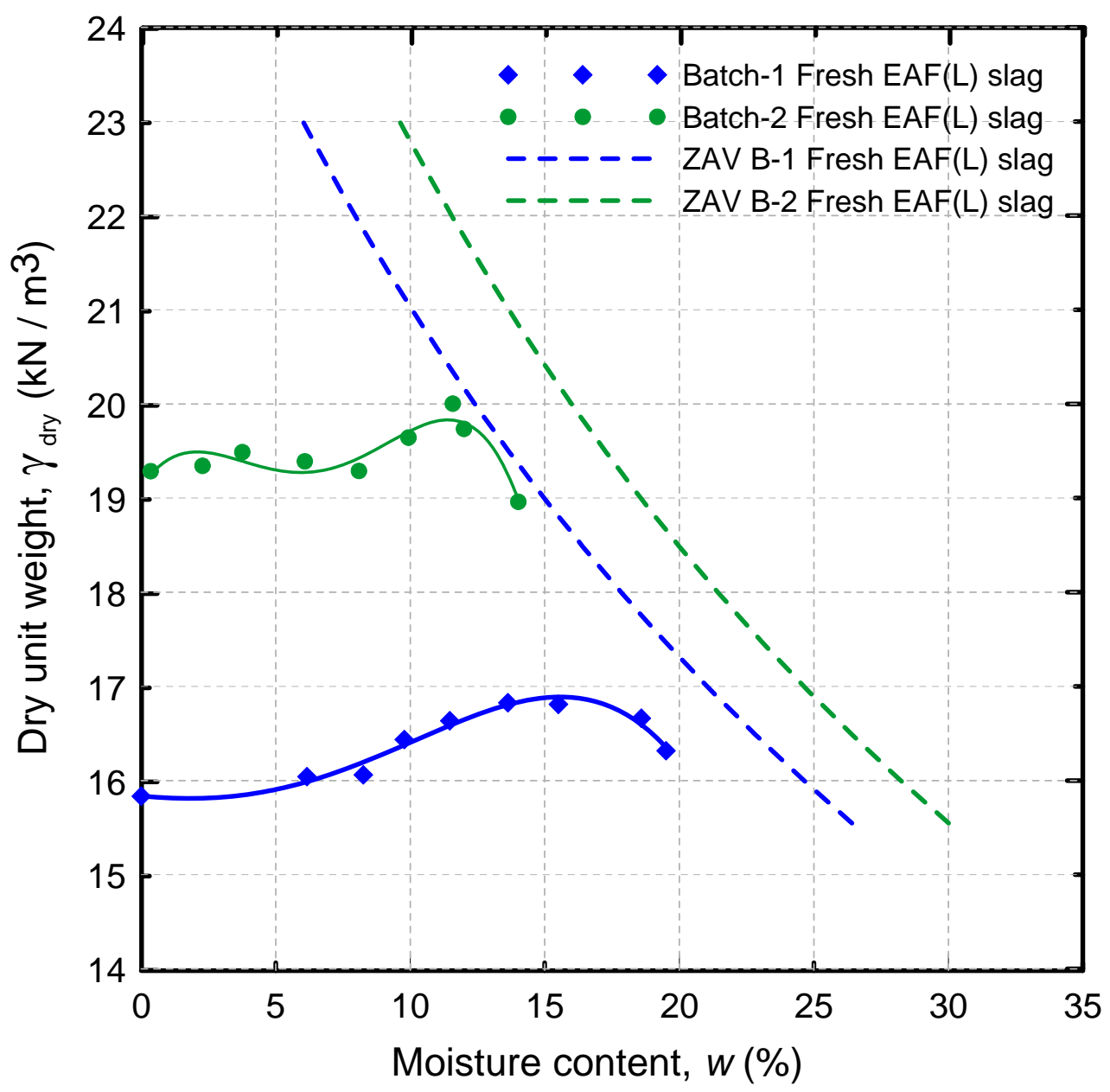

Figure 6.14 Compaction curves of fresh EAF(L) slag samples

The difference between the compacted dry unit weights of Batch-1 Fresh and Batch-2 Fresh $\mathrm{EAF}(\mathrm{L})$ slag samples was mainly related to different specific gravity values of the two samples. Batch-1 Fresh and Batch-2 Fresh (EAF) slag samples had specific gravities of 2.7 and 3.0, respectively. The heavier Batch-2 Fresh EAF(L) slag particles resulted in a higher maximum unit weight value compared to Batch-1 Fresh EAF(L) slag. The well defined single peak observed in the moisture content vs. dry unit weight curve of Batch-1 Fresh $\mathrm{EAF}(\mathrm{L})$ slag might be due to the presence of particles with very rough surface textures and porous structures that might have prevented the formation of surface tension forces. 
Compaction studies on EAF and ladle slags are scarce in the literature. Rohde et al. (2003) presented standard Proctor compaction tests results performed on EAF slag. EAF slag considered in their study contained approximately $85 \%$ gravel-size particles and the compaction curve of EAF slag had two sharp peaks at moisture content values of about $3 \%$ and $5 \%$. The maximum dry unit weight of EAF slag was approximately 23 $\mathrm{kN} / \mathrm{m}^{3}$. The irregular shape of the compaction curve was attributed to the EAF slag particle shape, grain-size distribution and mineralogy. Gradation of the EAF(L) slag was slightly modified by crushing the particles and decreasing the gravel-size particles to 68 $\%$. For this finer gradation of the EAF slag sample, $\gamma_{d, \max }$ was approximately $26 \mathrm{kN} / \mathrm{m}^{3}$ at the optimum moisture content of about 6\%. Andreas et al. (2005) presented the standard Proctor compaction test results on ladle slag-EAF slag mixture which contained 35\% EAF slag (by weight). The dry unit weight-moisture content relationship for this mixture had a single peak with the maximum dry unit weight of $22 \mathrm{kN} / \mathrm{m}^{3}$ at approximately $13 \%$ moisture content.

Particle degradation studies were performed on Batch-1 Fresh EAF(L) slag sample by determining the gradation of $\mathrm{EAF}(\mathrm{L})$ slag sample before and after compaction. Figure 6.15 shows the grain-size distribution curves of Batch-1 Fresh EAF(L) slag before and after compaction. It was observed that Batch-1 Fresh EAF(L) slag sample exhibited almost identical gradations prior to and after compaction indicating minimal crushing of particles during compaction. $w_{o p t}$ and $\gamma_{d, \max }$ values obtained from the Proctor compaction test results for Batch-1 Fresh and Batch-2 Fresh EAF(L) samples are compiled in Table 6.7. $\gamma_{d, \max }$ of $\operatorname{EAF(L)~slags~are~comparable~to~the~reported~range~}$

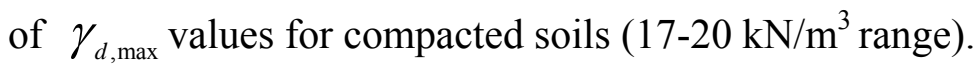




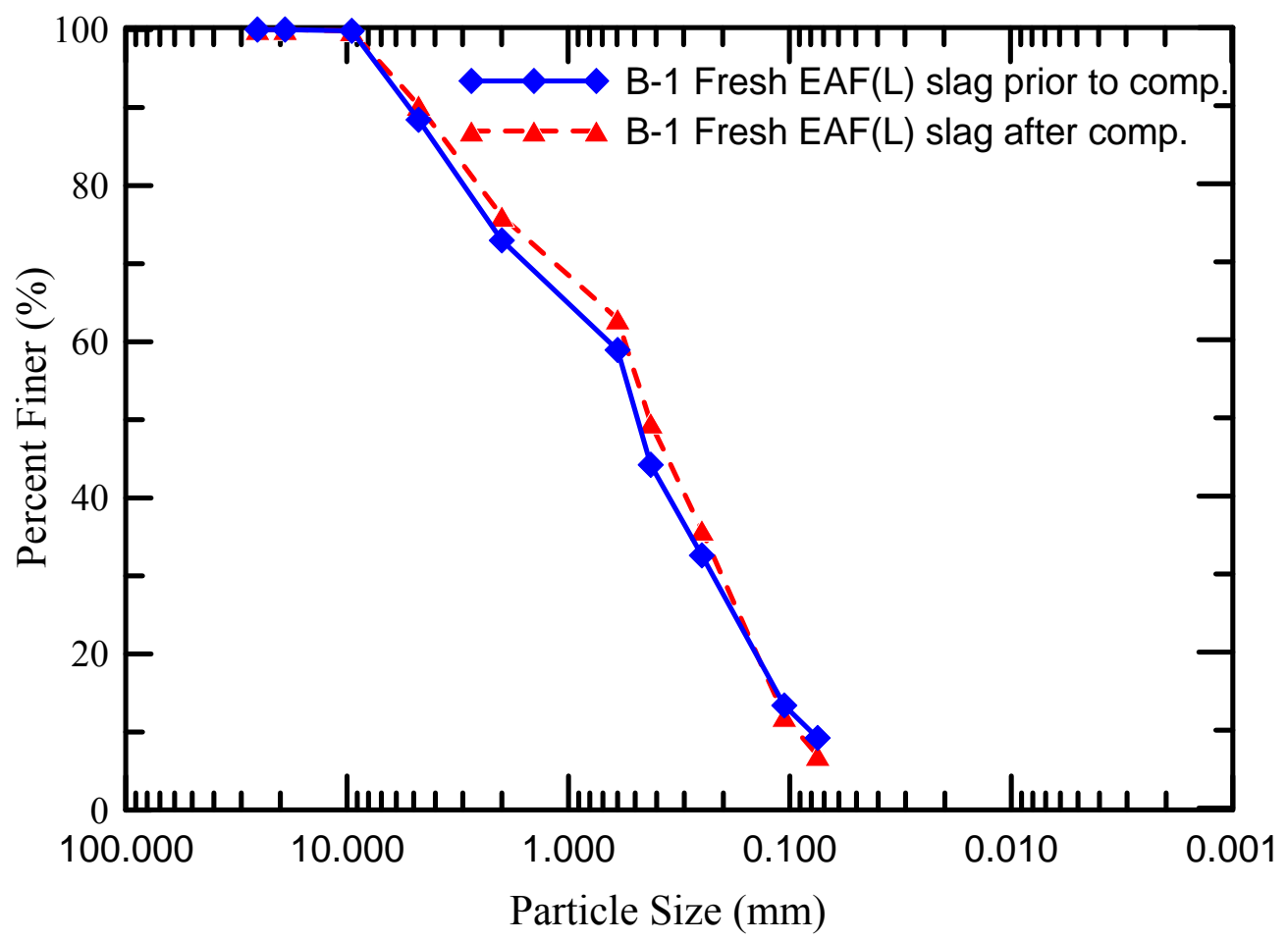

Figure 6.15 Grain-size distribution curves prior and after compaction of fresh $\operatorname{EAF}(\mathrm{L})$ slags

Table $6.7 \gamma_{d, \text { max }}$ and $w_{\text {opt }}$ of $\operatorname{EAF}(\mathrm{L})$ slag samples

\begin{tabular}{cccc}
\hline Sample ID & $w_{\text {opt }}(\%)$ & $\gamma_{d, \max }\left(\mathrm{kN} / \mathrm{m}^{3}\right)$ & $\gamma_{d, \max }(\mathrm{pcf})$ \\
\hline \hline Batch-1 Fresh EAF(L) slag & 13 & 16.84 & 107 \\
Batch-2 Fresh EAF(L) slag & 11 & 20.02 & 124 \\
\hline
\end{tabular}

6.5.2. Maximum and Minimum Dry Density Tests

The maximum and minimum dry density tests were performed on $\operatorname{EAF}(\mathrm{L})$ slag samples in accordance with ASTM D4253 and ASTM D4254, respectively. The maximum and minimum void ratio for each $\operatorname{EAF}(\mathrm{L})$ slags sample was also calculated using the average $G_{s}$ values of each sample, as reported in Table 6.5. Table 6.8 presents the maximum and 
minimum dry unit weight with the maximum and minimum void ratio values of the EAF(L) slag samples. The maximum dry unit weight obtained from the vibration method was marginally higher $(+3 \%)$ than the one obtained with the standard Proctor test for Batch-1 Fresh EAF(L) slag. On the other hand for Batch-2 Fresh EAF(L) slag sample, the maximum dry unit weight obtained with the vibratory compaction method was identical to the one obtained with the standard Proctor compaction test (refer to Table 6.7 and Table 6.8).

Table 6.8 Maximum and minimum dry unit weight test results

\begin{tabular}{ccccccc}
\hline Sample ID & $\begin{array}{c}\gamma_{d, \min } \\
\left(\mathrm{kN} / \mathrm{m}^{3}\right)\end{array}$ & $\begin{array}{c}\gamma_{d, \min } \\
(\mathrm{pcf})\end{array}$ & $\begin{array}{c}\gamma_{d, \max } \\
\left(\mathrm{kN} / \mathrm{m}^{3}\right)\end{array}$ & $\begin{array}{c}\gamma_{d, \max } \\
(\mathrm{pcf})\end{array}$ & $e_{\min }$ & $e_{\max }$ \\
\hline \hline Batch-1 Fresh & 82 & 12.91 & 17.23 & 110 & 0.60 & 1.08 \\
EAF(L) slag & & & & & & \\
Batch-2 Fresh & 102 & 16.12 & 20.08 & 127 & 0.48 & 0.84 \\
EAF(L) slag & & & & & & \\
\hline
\end{tabular}

\subsubsection{Large-Scale Direct Shear Tests}

Large-scale direct shear (LDS) tests were performed on EAF(L) slag samples to determine its shear strength parameters. Mohr-Coulomb criterion has been traditionally used to represent the shear strength of soils:

$S=c+\sigma \tan \phi$

where $\mathrm{S}=$ shear strength; $\mathrm{c}=$ cohesion intercept; $\phi=$ angle of internal friction; and $\sigma=$ effective normal stress acting on the shear plane. The shear strength corresponding to the peak states of the $\operatorname{EAF}(\mathrm{L})$ slag samples were used to obtain the $c-\phi$ fitting parameters appearing in Eq. 6.3. The critical-state friction angles of fresh EAF(L) slag samples were also determined from large-scale direct shear test results. Table 6.9 shows the LDS testing matrix for EAF(L) slag samples considered in this study. 
Table 6.9 Test matrix for direct shear testing of EAF(L) slag samples

\begin{tabular}{|c|c|c|c|}
\hline $\begin{array}{c}\text { Material } \\
\text { Description }\end{array}$ & $\begin{array}{l}\text { Moisture content } \\
\text { (w) }\end{array}$ & $\begin{array}{c}\text { Relative } \\
\text { Compaction } \\
(R)^{\mathrm{a}}\end{array}$ & $\begin{array}{c}\text { Confining } \\
\text { Stress } \\
(\mathrm{kPa}) \\
\end{array}$ \\
\hline \multirow{4}{*}{$\begin{array}{l}\text { Batch-1 Fresh } \\
\text { EAF(L) slag }\end{array}$} & \multirow{4}{*}{$10-11 \%$} & \multirow{4}{*}{$100 \%$} & 50 \\
\hline & & & 100 \\
\hline & & & 200 \\
\hline & & & 300 \\
\hline \multirow{4}{*}{$\begin{array}{l}\text { Batch-2 Fresh } \\
\text { EAF(L) slag }\end{array}$} & \multirow{4}{*}{$13-14 \%$} & \multirow{4}{*}{$95 \%$} & 50 \\
\hline & & & 100 \\
\hline & & & 200 \\
\hline & & & 300 \\
\hline \multirow{4}{*}{$\begin{array}{l}\text { Batch-2 Fresh } \\
\text { EAF(L) slag }\end{array}$} & \multirow{4}{*}{$10-11 \%$} & \multirow{4}{*}{$100 \%$} & 50 \\
\hline & & & 100 \\
\hline & & & 200 \\
\hline & & & 300 \\
\hline
\end{tabular}

${ }^{\text {a }} R=\frac{\gamma_{d}}{\gamma_{d, \max }}$, where $\gamma_{d}=$ compacted unit weight of the sample,

$\gamma_{d, \max }=$ maximum compacted dry unit weight obtained from the standard Proctor compaction tests

Samples of Batch-1 Fresh EAF(L) slag were tested at two different moisture contents (corresponding to $R$ values of 95 and 100\%). Figure 6.16 (a) and (b) show the horizontal displacement versus horizontal shear stress curves for samples of Batch-1 Fresh $\mathrm{EAF}(\mathrm{L})$ prepared at $R=95 \%$ and $R=100 \%$, respectively. The horizontal displacement versus shear strength graphs for Batch-1 Fresh $\operatorname{EAF}(\mathrm{L})$ slag exhibited a distinct peak indicating the dilative behavior of the samples during shearing. Dilation is observed in dense frictional materials tested at low confining stresses. The sharp peak seen in the horizontal displacement versus horizontal shear stress curve of $\operatorname{EAF}(\mathrm{L})$ slag sample is similar to that observed in lightly cemented sands. The slight cementation 
between the $\mathrm{EAF}(\mathrm{L})$ slag particles might have led to this sharp peak in the horizontal shear stress versus horizontal displacement curve of Batch-1 Fresh EAF(L) slag sample. The peak states were observed at observed approximately $10 \mathrm{~mm}$ of horizontal displacement of the lower shear box. The critical state was attained at approximately 40 $\mathrm{mm}$ of horizontal displacement of the lower box for the samples tested. Figure 6.17 (a) and (b) show the shear strength envelopes corresponding to critical and peak states for Batch-1 Fresh EAF(L) slag samples compacted to relative compaction values of $95 \%$ and $100 \%$, respectively. From the critical-state shear-strength envelope, a critical-state friction angle of $40.4^{\circ}$ was calculated for Batch-1 Fresh EAF(L) slag. $c-\phi$ fitting parameters equal to $67 \mathrm{kPa}$ and $45.2^{\circ}$ were obtained for Batch-1 Fresh EAF(L) slag samples prepared at $R=100 \%$; these values were equal to $26 \mathrm{kPa}$ and $44.5^{\circ}$ when $R=95 \%$. Highest shear strength values (both the critical and peak states) were measured for $R=100 \%$. Figure 6.18 shows the horizontal displacement versus horizontal shear stress curve for Batch-2 Fresh EAF(L) slag samples prepared at $R=100 \%$. Similar to Batch-1 Fresh EAF(L) slag samples, the horizontal displacement vs. horizontal shear stress curves of Batch- 2 Fresh EAF(L) slag samples also showed dilative behavior. Peak states were observed in the horizontal displacement range of 0-15 $\mathrm{mm}$. Critical state was attained at horizontal displacements of approximately 30-40 mm. Figure 6.19 (a) and (b) show the shear strength envelopes corresponding to the critical and peak states for Batch-2 Fresh EAF(L) slag samples prepared at $R=95 \%$, respectively. The critical-state friction angle was equal to $40.8^{\circ}$ for Batch-2 Fresh EAF(L) slag. $c-\phi$ fitting parameters equal to 93 $\mathrm{kPa}$ and $43.6^{\circ}$ were obtained for Batch-2 Fresh EAF(L) slag samples prepared at $R=100 \%$. Table 6.10 presents a summary of the shear strength parameters obtained from the large-scale direct shear tests performed on $\mathrm{EAF}(\mathrm{L})$ slag samples. 


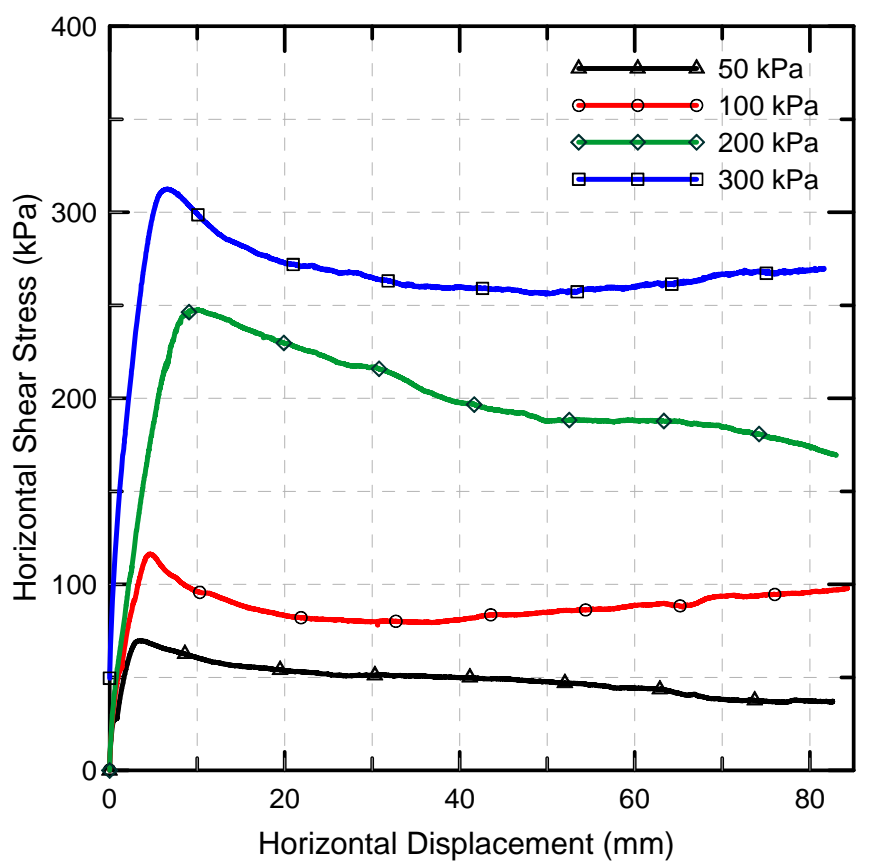

(a)

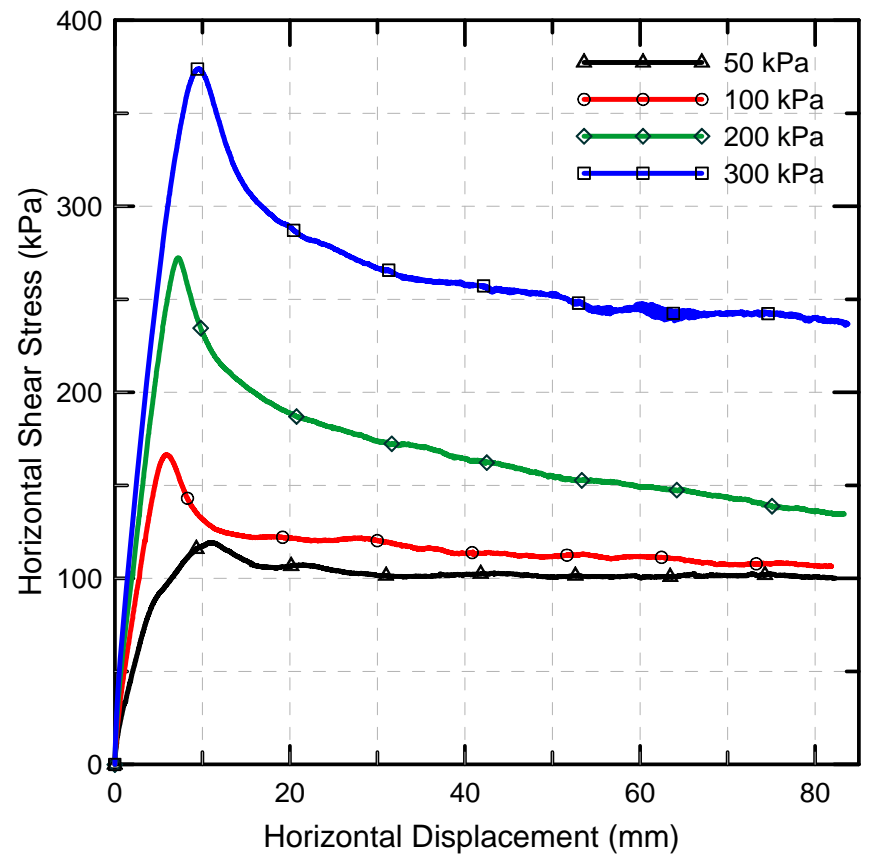

(b)

Figure 6.16 Horizontal displacement versus horizontal shear stress for Batch-1 Fresh EAF(L) slag samples prepared at a) $R=95 \%$, and b) $R=100 \%$ 


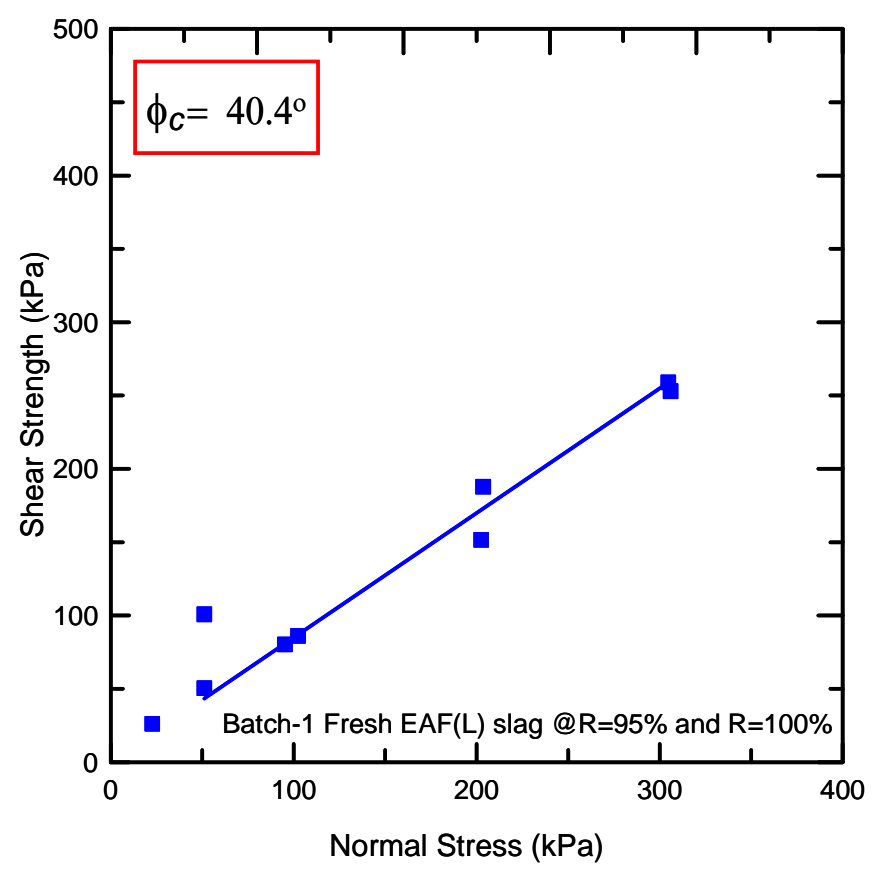

(a)

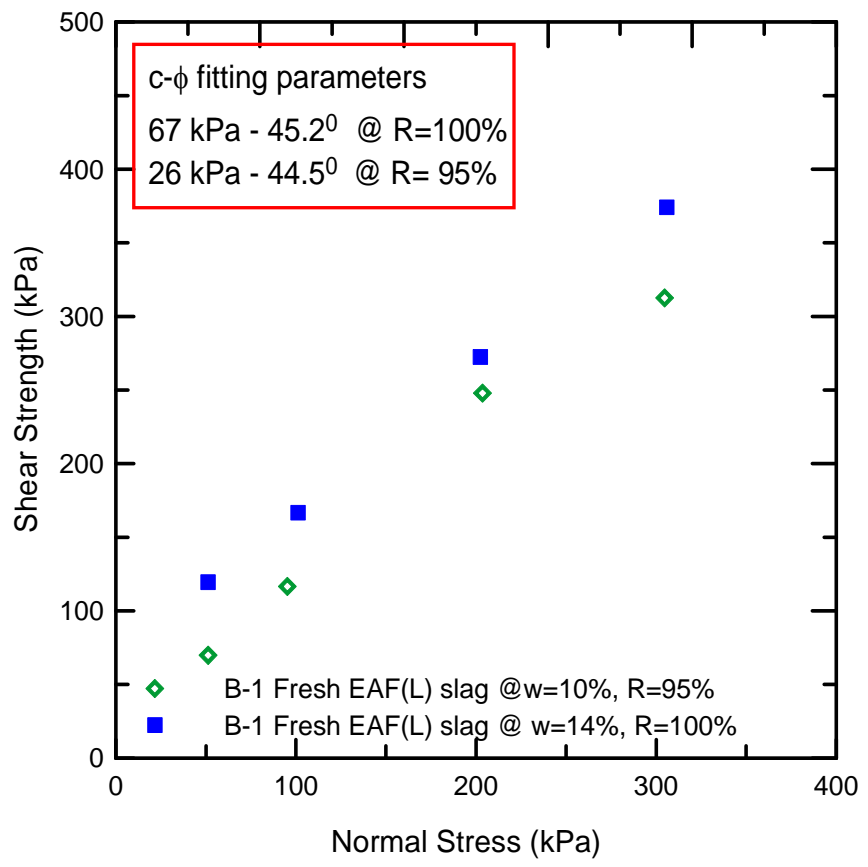

(b)

Figure 6.17 Shear strength parameters for Batch-1 Fresh EAF(L) slag samples prepared at $R=95 \%$ and $R=100 \%$ : (a) critical-state, and (b) peak-state 


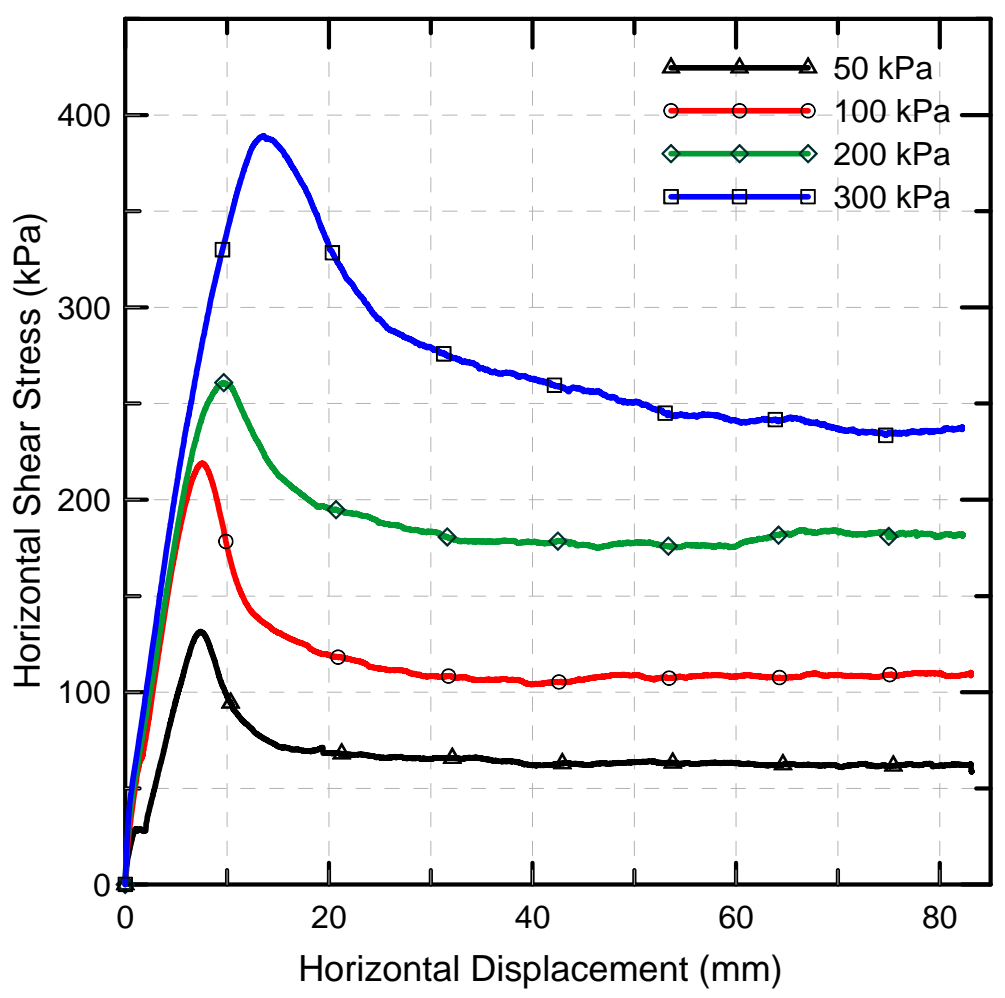

Figure 6.18 Horizontal displacement versus horizontal shear stress for Batch-2 Fresh EAF(L) slag sample prepared at $R=100 \%$ 


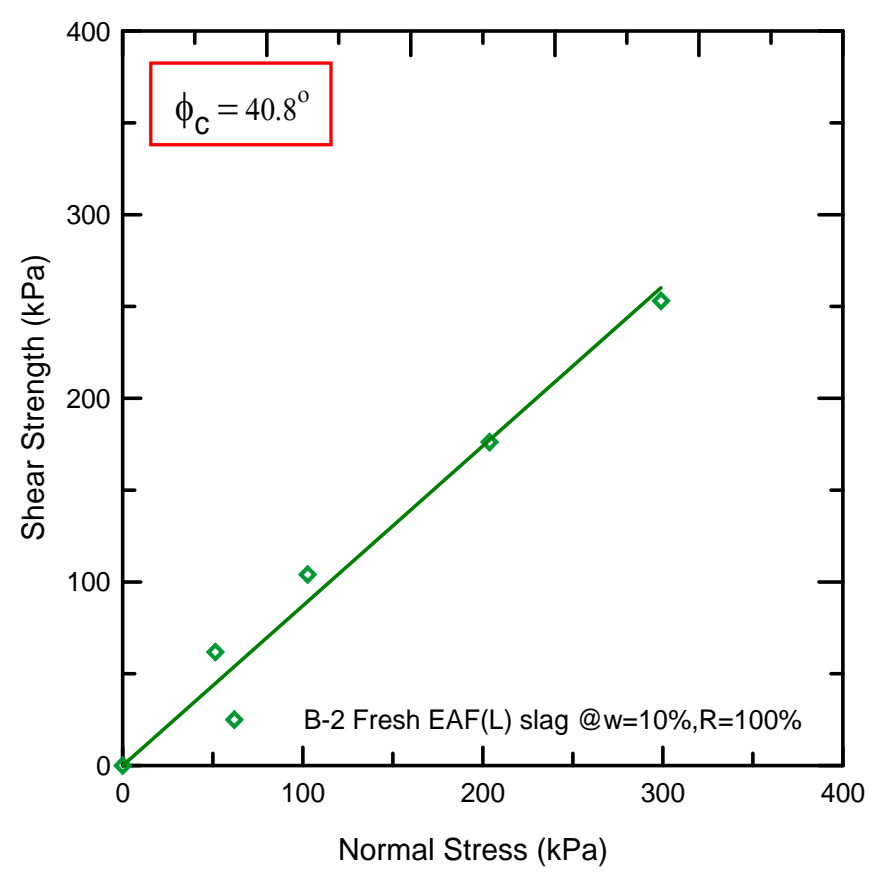

(a)

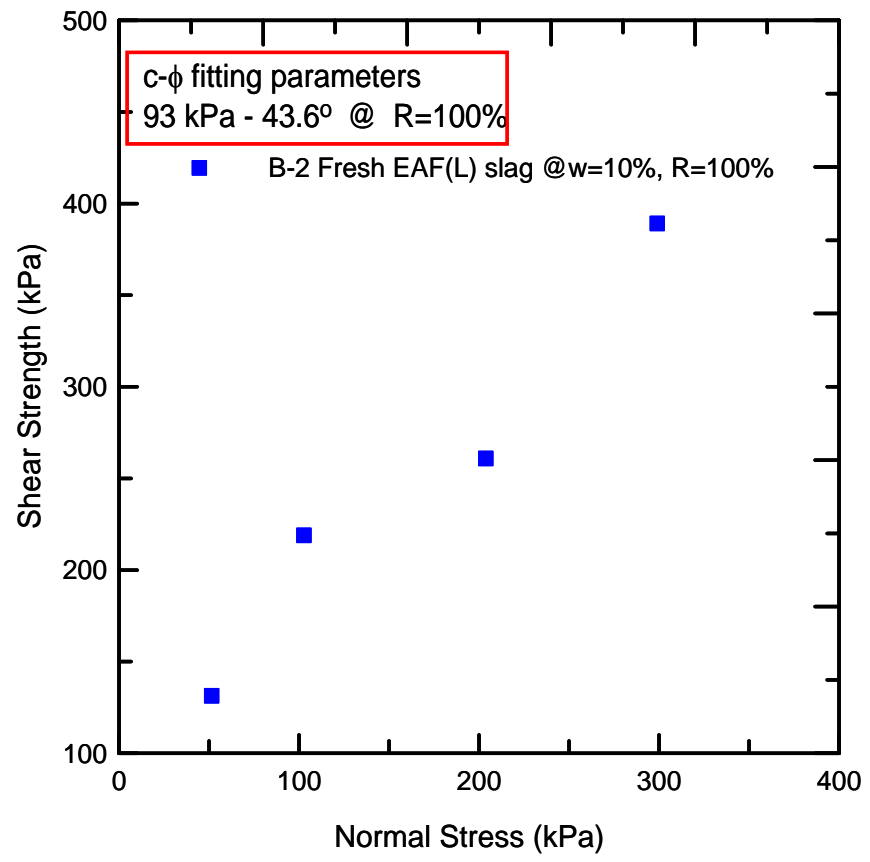

(b)

Figure 6.19 Shear strength parameters for Batch-2 Fresh EAF(L) slag prepared at $R=100 \%$ : (a) critical state, and (b) peak state 
Table 6.10 Summary of shear strength parameters obtained from large-scale direct shear tests for $\mathrm{EAF}(\mathrm{L})$ slag

\begin{tabular}{cccc}
\hline Sample ID & $R$ & $\phi_{c}$ & $c-\phi$ fitting parameters $^{a}$ \\
\hline \hline Batch-1 Fresh EAF(L) slag & $95 \%$ & & $26 \mathrm{kPa}-44.5^{\circ}$ \\
Batch-1 Fresh EAF(L) slag & $100 \%$ & & $67 \mathrm{kPa}-45.2^{\circ}$ \\
Batch-2 Fresh EAF(L) slag & $100 \%$ & $40.8^{\circ}$ & $93 \mathrm{kPa}-43.6^{\circ}$ \\
\hline
\end{tabular}

$R=$ Relative compaction; $\phi_{c}=$ critical-state friction angle

${ }^{a}$ fitting parameters correspond to the peak shear strength envelopes

EAF(L) slag exhibits slightly higher friction angles compared to that of the naturally available soils. The high friction angles of $\operatorname{EAF}(\mathrm{L})$ slag can be attributed to $\mathrm{EAF}(\mathrm{L})$ slag particle morphology and grain-size distribution. In addition to the presence of subangular particles with rough surface textures, well-graded grain-size distribution of EAF(L) slag, which contains a wide range of particle sizes (silt- to gravel-size particles) resulted in slightly high friction angles compared to natural sands.

\subsection{Long-term Swelling Response of EAF(L) slag}

The $\mathrm{EAF}(\mathrm{L})$ slag samples were compacted at a moisture content of approximately $10 \%$ to a relative compaction of $100 \%$ in CBR molds. A surcharge weight equivalent to a pressure of approximately $2.5 \mathrm{kPa}$ was placed on the top of the compacted samples. After soaking the samples in water, the one-dimensional swelling of the EAF(L) slag samples was monitored for about 17 months at room temperature. The tests were performed on both Batch-2 Fresh EAF(L) slag and Batch-2 Aged EAF(L) slag samples (the Batch-2 Aged EAF(L) slag was aged for a period of one month only and thus could also be considered fresh). Figure 6.20 shows the results of the long-term swelling test performed on the fresh and aged EAF(L) slag samples. 


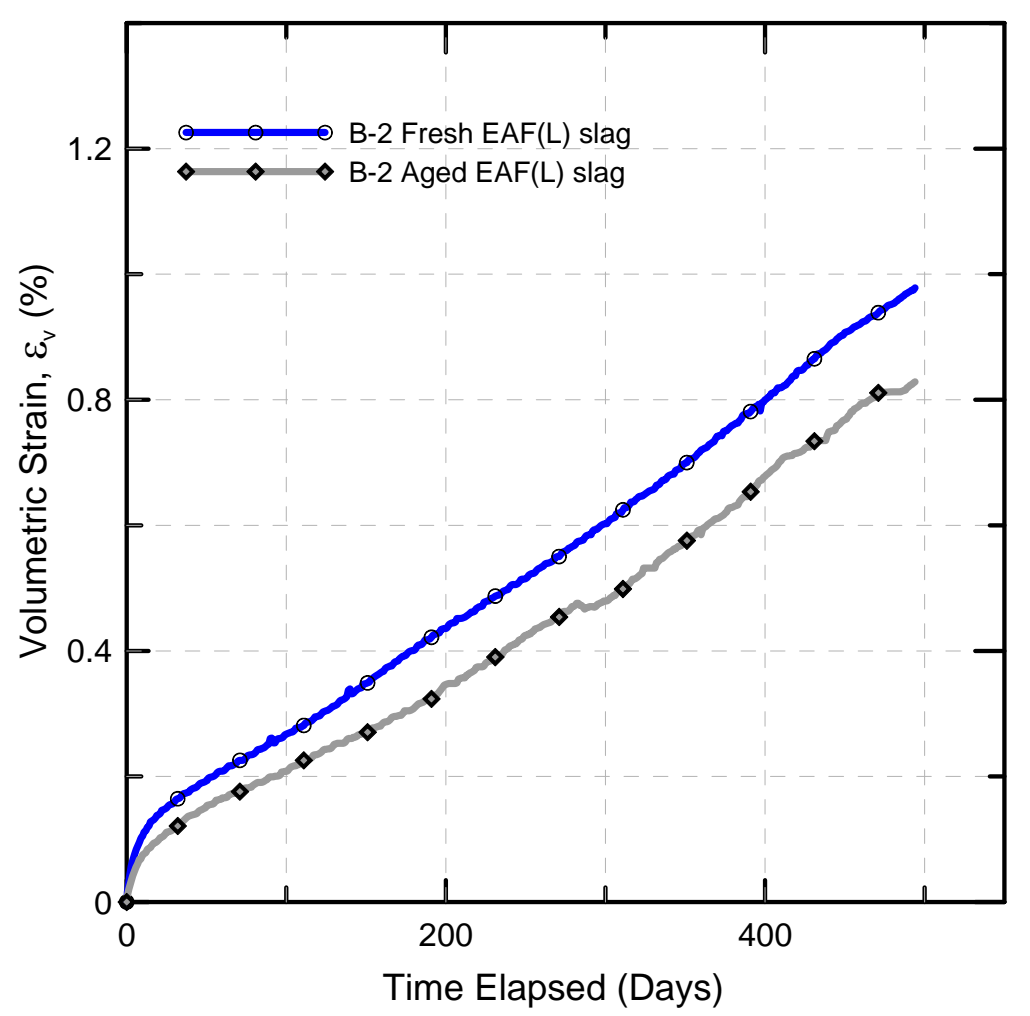

Figure 6.20 Time vs. volumetric strain curves for $\mathrm{EAF}(\mathrm{L})$ slag samples

Both the Batch-2 fresh and aged EAF(L) slag samples increased in volume during the entire testing period. The time versus volumetric strain curves for the fresh and aged $\mathrm{EAF}(\mathrm{L})$ slag samples were similar. In the first 10 days of the monitoring period, the swelling rate of the aged $\mathrm{EAF}(\mathrm{L})$ slag sample was slightly lower (approximately $0.008 \%$ /day) than that of the fresh $\operatorname{EAF(L)~slag~sample~}(0.01 \%$ /day). After the initial 10 days, the swelling rates for the fresh and aged $\operatorname{EAF}(\mathrm{L})$ slag samples were equal to $1.804 \mathrm{x} 10^{-}$ $3 /$ day and $1.556 \times 10^{-3} /$ day. The aging of the $\operatorname{EAF}(\mathrm{L})$ slag sample for one month reduced slightly its swelling rate. The swelling strains of the $\operatorname{EAF}(\mathrm{L})$ slag samples calculated at the end of each month of the monitoring period are provided in Table 6.11. 
Table 6.11 Results of long-term swelling tests performed on EAF(L) slag samples (fresh and aged for one month)

\begin{tabular}{|c|c|c|}
\hline \multirow{4}{*}{$\begin{array}{c}\text { Elapsed } \\
\text { Time } \\
\text { (Months) }\end{array}$} & \multicolumn{2}{|c|}{ Swelling (\%) } \\
\hline & Batch-2 & Batch-2 \\
\hline & Fresh EAF(L) & Aged EAF(L) \\
\hline & slag & slag $^{\mathrm{a}}$ \\
\hline 1 & 0.160 & 0.118 \\
\hline 2 & 0.208 & 0.166 \\
\hline 3 & 0.261 & 0.199 \\
\hline 4 & 0.296 & 0.236 \\
\hline 5 & 0.348 & 0.269 \\
\hline 6 & 0.401 & 0.308 \\
\hline 7 & 0.452 & 0.357 \\
\hline 8 & 0.502 & 0.408 \\
\hline 9 & 0.550 & 0.453 \\
\hline 10 & 0.603 & 0.479 \\
\hline 11 & 0.657 & 0.532 \\
\hline 12 & 0.720 & 0.585 \\
\hline 13 & 0.779 & 0.650 \\
\hline 14 & 0.845 & 0.715 \\
\hline 15 & 0.907 & 0.768 \\
\hline 16 & 0.953 & 0.813 \\
\hline 16.5 & 0.978 & 0.829 \\
\hline
\end{tabular}

aged for one month

The results also indicate that an aging period of one-month aging is not sufficient to suppress the swelling of $\operatorname{EAF}(\mathrm{L})$ slag. The rate of swelling remained the same throughout the monitoring period. In addition, the swelling of EAF(L) slag samples did not stabilize after 17 months of exposure to water. At the end of 17 months, the 
volumetric strains of Batch-1 Fresh and Batch-2 Aged EAF(L) slag samples were about $0.98 \%$ and $0.83 \%$, respectively.

\subsection{Corrosivity and Leaching Potential of EAF(L) slag}

The corrosion potential of EAF(L) slag was evaluated based on the electrical resistivity and $\mathrm{pH}$ test results. Leaching of heavy metals from EAF(L) slag was also evaluated through TCLP tests. The results of these tests are presented next.

\subsubsection{Corrosivity Tests}

The corrosivity of a buried metal object embedded in a soil depends on a number of parameters that include soils resistivity, moisture content, and concentration of dissolved salts in the pore fluids. The corrosion potential of a given soil can only be assessed when all the parameters involved are properly considered. The electrical resistivity and $\mathrm{pH}$ measurements are commonly used as indicators of soil corrosivity. Table 6.12 presents provides soil corrosivity classification based on the resistivity and $\mathrm{pH}$ values (API 1997; Christopher et al. 1989). These two corrosivity parameters - electrical resistivity and $\mathrm{pH}$ were determined for $\mathrm{EAF}(\mathrm{L})$ slag samples in order to evaluate their corrosion potential. 
Table 6.12 Soil corrosivity classification

\begin{tabular}{cc|cc}
\hline \multicolumn{3}{c}{ Reference } & \\
\cline { 1 - 3 } $\begin{array}{c}\text { API(1997) } \\
\text { Resistivity }\end{array}$ & $\mathrm{pH}$ & $\begin{array}{c}\text { Resistivity } \\
(\text { ohm-cm) }\end{array}$ & \\
\hline \hline$>10,000$ & $>10,000$ & Little Corrosive \\
\hline $2,000-10,000$ & $5,000-10,000$ & $\begin{array}{c}\text { Mildly } \\
\text { Corrosive }\end{array}$ \\
\cline { 1 - 2 } $1,000-2,000$ & $2,000-5,000$ & $\begin{array}{c}\text { Moderately } \\
\text { Corrosive }\end{array}$ \\
\hline $500-1,000$ & $5-6.5$ & $700-2,000$ & Corrosive \\
\hline$<500$ & $<5$ & $<700$ & Very Corrosive \\
\hline
\end{tabular}

\section{Electrical Resistivity}

Electrical resistivity measurements were made on compacted samples of Batch-1 Fresh and Batch-2 Fresh EAF(L) slag. The compacted samples were then soaked in water. Two electrical resistivity measurements were taken: one immediately after compaction and another after soaking the samples for about 4 hrs. Table 6.13 provides the electrical resistivity measurements for $\mathrm{EAF}(\mathrm{L})$ slag samples.

Table 6.13 Electrical resistivity test results for $\operatorname{EAF}(\mathrm{L})$ slag samples

\begin{tabular}{ccc}
\hline Sample ID & Moisture content & Electrical resistivity (Ohm-cm) \\
\hline \hline \multirow{2}{*}{ Batch-1 Fresh EAF(L) slag } & $\sim 14 \%$ & 963 \\
& Soaked condition & 538 \\
Batch-2 Fresh EAF(L) slag & $\sim 10 \%$ & 3053 \\
& Soaked condition & 556 \\
\hline
\end{tabular}


The soaked EAF(L) slag samples exhibited much lower resistivities than those of the compacted EAF(L) slag samples. Based on the soil corrosivity classification parameters provided in Table 6.12, as-compacted EAF(L) slag samples can be categorized as mildly corrosive to corrosive, while the $\mathrm{EAF}(\mathrm{L})$ slag samples in the soaked condition as corrosive.

$\underline{p H}$

In order to supplement the electrical resistivity measurements in evaluating the corrosivity potential of EAF(L) slag, the $\mathrm{pH}$ of soaked EAF(L) slag samples was also taken on soaked EAF(L) slag samples following the measurement of its electrical resistivity. Table 6.14 provides the $\mathrm{pH}$ measurements for all the $\mathrm{EAF}(\mathrm{L})$ slag samples tested.

Table $6.14 \mathrm{pH}$ measurements on soaked EAF(L) slag samples

\begin{tabular}{cc}
\hline Sample ID & $\mathrm{pH}$ \\
\hline \hline Batch-1 Fresh EAF(L) slag & 11.4 \\
Batch-2 Fresh EAF(L) slag & 12.1 \\
\hline
\end{tabular}

The study presented by Scully (1990) indicates that the rate of corrosion is low in neutral environments, whereas both very acidic and alkaline environments tend to increase the rate of corrosion. The $\mathrm{pH}$ test results show that $\mathrm{EAF}(\mathrm{L})$ slag samples are very alkaline. Based on the electrical resistivity and $\mathrm{pH}$ measurements on them, EAF(L) slag samples were considered as potentially corrosive. 


\subsubsection{Leaching Test}

TCLP analysis was performed on Batch-1 Fresh EAF(L) slag samples by Severn Trent Laboratories, Inc. located in Valparaiso, IN. Table 6.15 provides the results of the TCLP analysis conducted on Batch-1 Fresh EAF(L) slag.

Table 6.15 TCLP (acidic leachate-mg/L) analysis of EAF(L) slag

\begin{tabular}{cc}
\hline & Concentrations (in mg/L) \\
\hline Constituent & EAF(L) slag \\
\hline \hline Arsenic & $<0.2$ \\
Barium & 0.58 \\
Cadmium & $<0.05$ \\
Chromium & $<0.10$ \\
Lead & $<0.5$ \\
Mercury & $<0.001$ \\
Selenium & $<0.2$ \\
Silver & $<0.1$ \\
\hline
\end{tabular}

The Environmental Protection Agency (EPA) classifies EAF(L) slag as a solid waste. In the state of Indiana, use of EAF(L) slag is regulated by the solid waste land disposal regulations of the Indiana Administrative Code. Solid wastes can be classified based on the concentrations of various metals in their leachates. The Indiana solid wastes are classified according to the results of TCLP (acidic leachate) or EP (neutral leachate) analyses. Table 6.16 presents the waste types and the parameter levels defined by the Indiana Administrative Code 329 IAC-2-9-3 based on the TCLP test results. According to the Indiana Administrative Code, four waste types are specified in order of decreasing leachate parameter concentrations. Solid waste classified as Type I has the highest leachate concentration levels for all the constituents, up to near hazardous levels. On the other hand, solid waste classified as Type IV has the lowest concentrations for all the 
constituents shown in Table 6.16. Typically, Type IV meets the National Primary and Secondary Drinking Water Regulations for most of the parameter concentrations. According to the Indiana restricted waste criteria, the TCLP EAF(L) slag leachate concentration levels for almost all of the heavy metal concentrations satisfy the criterion for classification of EAF(L) slag as a Type III waste. Since the chemical composition of steel slag may vary from one batch to another, slag samples should be collected and subjected to TCLP tests often for proper waste type classification.

Table 6.16 Indiana restricted waste criteria based on TCLP tests

\begin{tabular}{lcccc}
\hline \multicolumn{4}{c}{ Concentrations (in mg/L) } \\
\hline Constituents & Type IV & Type III & Type II & Type I \\
\hline \hline Arsenic & $\leq 0.05$ & $\leq 0.5$ & $\leq 1.25$ & $\leq 5.0$ \\
Barium & $\leq 1.0$ & $\leq 10.0$ & $\leq 25$ & $<100.0$ \\
Cadmium & $\leq 0.01$ & $\leq 0.1$ & $\leq 0.25$ & $<1.0$ \\
Chromium & $\leq 0.05$ & $\leq 0.5$ & $\leq 1.25$ & $<5.0$ \\
Lead & $\leq 0.05$ & $\leq 0.5$ & $\leq 1.3$ & $<5.0$ \\
Mercury & $\leq 0.002$ & $\leq 0.02$ & $\leq 0.05$ & $<0.2$ \\
Selenium & $\leq 0.08$ & $\leq 0.1$ & $\leq 0.25$ & $<1.0$ \\
Silver & $\leq 0.05$ & $\leq 0.5$ & $\leq 1.25$ & $<5.0$ \\
\hline
\end{tabular}

\subsection{Summary}

Fresh $\mathrm{EAF}(\mathrm{L})$ slag samples were characterized through a series of laboratory tests (specific gravity, grain-size analysis, X-ray diffraction, compaction, maximum and minimum density, large-scale direct shear and long-term swelling tests). The corrosion potential of $\mathrm{EAF}(\mathrm{L})$ slag samples was evaluated based on the electrical resistivity and $\mathrm{pH}$ test results. The results of TCLP tests were used to classify EAF(L) slag according to Indiana Administrative Code classification for solid waste. The results of the experiments performed on $\mathrm{EAF}(\mathrm{L})$ slag samples can be summarized as follows: 
1) $\mathrm{EAF}(\mathrm{L})$ slag samples were classified as SW-SM with gravel (well-graded sand with silt and gravel) and A-1-b according to the USCS and AASHTO soil classification systems.

2) The $\mathrm{CaO}, \mathrm{Al}_{2} \mathrm{O}_{3}, \mathrm{FeO}, \mathrm{MgO}$ and $\mathrm{SiO}_{2}$, contents of $\mathrm{EAF}(\mathrm{L})$ slag were approximately 48, 23, 8, 7 and 5\%, respectively.

3) The specific gravity $G_{s}$ of Batch-1 Fresh EAF(L) slag and Batch-2 Fresh EAF(L) slag samples were 2.73 and 3.04, respectively. The difference in the specific gravity values were attributed to the variations in the chemical composition of EAF(L) slag generated at the source steel plant.

4) The XRD patterns of fresh $\mathrm{EAF}(\mathrm{L})$ slag samples were extremely complex with very high intensity peaks due to the presence of various minerals. The complex XRD patterns and high intensity peaks of EAF(L) slags were attributed to the very slow cooling conditions applied during processing of EAF(L) slag. The main mineral phases of Batch-1 Fresh were portlandite, mayenite, and malenterite. Portlandite, mayenite, periclase and magnesite were determined as the major mineral phases in Batch-2 Fresh EAF(L) slag.

5) Gravel-size particles of fresh $\mathrm{EAF}(\mathrm{L})$ slag had subrounded to subangular shapes. Both bulky and platy gravel-size particles were observed. Most of the platy particles had irregular shapes with very low sphericity and sharp edges. Batch-1 Fresh EAF(L) slag samples also contained gravel-size particles with popcorn like porous structure.

6) Sand- and silt-size particles from both Batch-1 Fresh and Batch-2 Fresh EAF(L) slag samples exhibited subrounded to subangular shapes. Distinct asperities and edges were visible in angular bulky particles. Both batches of EAF(L) slag contained irregularly shaped platy particles. SEM micrographs showed that the majority of the sand-size particles had extremely rough surface textures with distinct crystal structures.

7) The optimum moisture content and maximum dry unit weight of Batch-1 Fresh EAF(L) slag sample were $13 \%$ and $16.8 \mathrm{kN} / \mathrm{m}^{3}$, respectively. The same parameters for Batch-2 Fresh EAF(L) slag samples were equal to $11 \%$ and 
$20.0 \mathrm{kN} / \mathrm{m}^{3}$, respectively. Difference in the dry unit weight values of Batch-1 Fresh and Batch-2 Fresh EAF(L) slag samples was attributed to the different specific gravities of these samples.

8) The shear strength parameters of $\operatorname{EAF}(\mathrm{L})$ slag samples were determined based on the results of large-scale direct shear test. Critical-state friction angle of Batch-1 Fresh and Batch-2 Fresh EAF(L) slag samples were determined as $40.4^{\circ}$, and $40.8^{\circ}$ respectively. $c-\phi$ fitting parameters for Batch-1 Fresh EAF(L) slag sample was determined at peak states as $26 \mathrm{kPa}$ and $44.5^{\circ}$ for $95 \%$ relative compaction and $67 \mathrm{kPa}$ and $45.2^{\circ}$ for $100 \%$ relative compaction, respectively. $c-\phi$ fitting parameters were determined as $93 \mathrm{kPa}-43.6^{\mathrm{o}}$ for Batch-2 Fresh EAF(L) slag samples prepared at 100\% relative compaction.

9) In the initial 10 days of the long-term swelling tests, one-month aged EAF(L) slag exhibited a slightly lower swelling rate (approximately $0.008 \%$ /day) than that of fresh $\operatorname{EAF}(\mathrm{L})$ slag $(0.01 \%$ /day). After the initial 10 days, the swelling rates were approximately $1.804 \times 10^{-3} /$ day and $1.556 \times 10^{-3} /$ day for fresh and one-month aged $\mathrm{EAF}(\mathrm{L})$ slag samples, respectively.

10) The rate of swelling remained almost constant throughout the monitoring period and hence, swelling of EAF(L) slag samples did not stabilize after 17months of exposure to water. At the end of 17 months, the volumetric strains of Batch-1 Fresh and Batch-2 Aged EAF(L) slag samples reached 0.98\% and $0.83 \%$, respectively. The long-term swelling test indicated that an aging period of one-month aging is not sufficient to suppress swelling of EAF(L) slag.

11) $\operatorname{EAF(L)~slag~was~classified~as~solid~waste~Type~III~according~to~Indiana~}$ restricted waste criterion based on the TCLP leachate concentration levels. Electrical resistivity and $\mathrm{pH}$ test results indicated that EAF(L) slag samples were potentially corrosive. 


\section{CHAPTER 7. ENGINEERING PROPERTIES OF STEEL SLAG MIXTURES}

\subsection{Introduction}

This Chapter presents the results of the experiments performed on various mixtures of BOF and EAF(L) slag. The effectiveness of several steel slag mixtures in reducing the long-term swelling potential of BOF and $\mathrm{EAF}(\mathrm{L})$ slag was assessed in this research. The effect of 5 and $20 \%$ Class-C fly ash addition to EAF(L) slag on the compaction characteristics of EAF(L) slag was investigated. Mixtures of steel slag were prepared by adding 5 and 10\% Class-C fly ash (by weight) to BOF slag and 5, 10 and 20\% Class-C fly ash by weight to $\mathrm{EAF}(\mathrm{L})$ slag. Unconfined compression tests were performed on compacted Class-C fly ash and steel slag mixtures to evaluate the strength gain with time as a result of the cementitious reactions. Long-term swelling tests were performed on both mixtures of BOF and 10\% Class-C fly ash and EAF(L) slag and 5, 10 and 20\% Class-C fly ash (by weight). The effect of adding $10 \%$ ground rubber (by weight) to BOF slag on the long-term swelling behavior of the mixture was also investigated.

The results of the tests performed on steel slag mixtures are presented in the following order in this Chapter:

- Compaction characteristics of EAF(L) slag and Class-C fly ash mixtures

- Strength gain behavior of EAF(L) slag and Class-C fly ash mixtures

- Strength gain behavior of BOF slag and Class-C fly ash mixtures

- Long-term swelling of various mixtures of steel slag [BOF and $\mathrm{EAF}(\mathrm{L})]$ slag 


\subsection{Compaction Characteristics of EAF(L) slag and Class-C Fly Ash Mixtures}

Standard proctor compaction tests were performed on mixtures of Batch-2 Fresh EAF(L) slag and Class-C fly ash. Figure 7.1 shows the compaction curves for EAF(L) slag and for mixtures of EAF(L) slag and 5 and 20\% Class-C fly ash (by weight). Addition of 20\% Class-C fly ash (by weight) to $\mathrm{EAF}(\mathrm{L})$ slag resulted in an increase in maximum dry unit weight and also a slight decrease in the optimum moisture content of EAF(L) slag. During compaction, the silt-size Class-C fly ash particles can effectively fill the voids present within the EAF(L) slag matrix. Therefore, a slightly higher dry unit weight was measured for EAF(L) slag and 20\% Class-C fly ash mixture compared to that of EAF(L) slag. Figure 7.1 provides the maximum dry unit weight and the optimum moisture content of EAF(L) slag and mixtures of EAF(L) slag and 5, and 20\% Class-C fly ash (by weight).

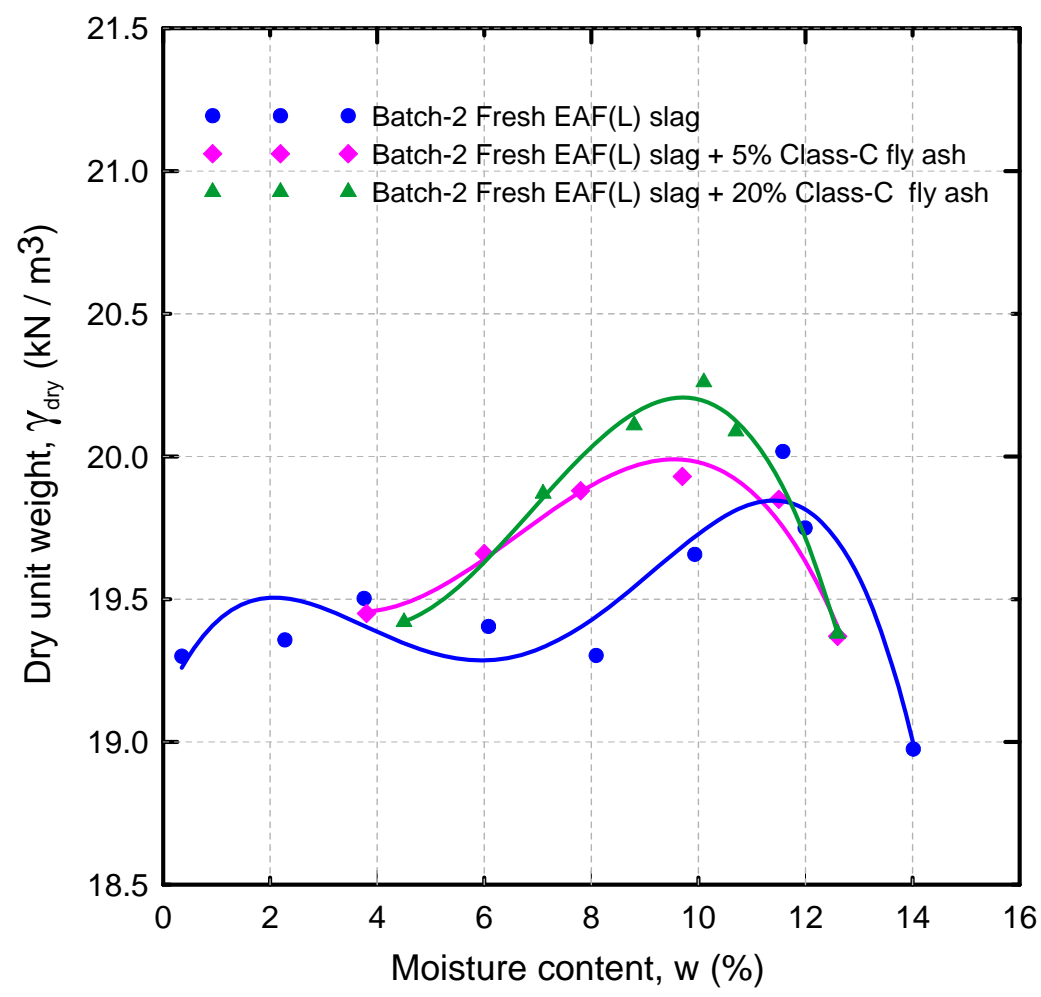

Figure 7.1 Compaction curves for EAF(L) slag and Class-C fly ash mixtures 
Table 7.1 $\gamma_{d, \max }$ and $w_{\text {opt }}$ of EAF(L) slag and Class-C fly ash mixtures

\begin{tabular}{cccc}
\hline Sample ID & $w_{\text {opt }}(\%)$ & $\begin{array}{c}\gamma_{d, \max } \\
\left(\mathrm{kN} / \mathrm{m}^{3}\right)\end{array}$ & $\begin{array}{c}\gamma_{d, \max } \\
(\mathrm{pcf})\end{array}$ \\
\hline \hline Batch-2 Fresh EAF(L) slag & 11 & 20.02 & 124 \\
Batch-2 Fresh EAF(L) slag +5\% fly ash & 10 & 19.92 & 127 \\
Batch-2 Fresh EAF(L) slag +20 \% fly ash & 11 & 20.09 & 128 \\
\hline
\end{tabular}

\subsection{Strength Gain Behavior of EAF(L) Slag and Class-C Fly Ash Mixtures}

Attempts were made to perform unconfined compression tests on Batch-1 Fresh EAF(L) to determine its strength gain characteristics. Only a few intact samples could be recovered from the unconfined compression molds after numerous trials. Figure 7.2 shows the axial strain vs. axial stress curves obtained from these unconfined compression tests performed on Batch-1 Fresh EAF(L) slag samples cured for 1, 2, 3 and 7 days. As evident from the plots, compacted EAF(L) slag samples did not show significant strength gain with curing time. Similarly, Batch-2 Fresh EAF(L) slag samples did not show self cementing properties, and hence intact samples of Batch-2 Fresh EAF(L) slag could not be recovered from the unconfined compression molds.

In order to enhance the unconfined compressive strength of EAF (L) slag samples, varying amounts of Class-C fly ash was added to EAF(L) slag samples. The mixtures were then compacted and cured for 1, 2, 4, 7, 14 and 30 days after sample preparation. Unconfined compression tests were performed on the following $\operatorname{EAF}(\mathrm{L})$ slag and Class-C fly ash mixtures:

- Batch-2 Fresh EAF(L) slag $+5 \%$ Class-C fly ash (by weight)

- Batch-2 Fresh EAF(L) slag $+10 \%$ Class-C fly ash (by weight)

- Batch-2 Fresh EAF(L) slag + $20 \%$ Class-C fly ash (by weight)

Figure 7.3, Figure 7.4 and Figure 7.5 show the axial strain vs. axial stress curves obtained from the unconfined compression tests performed on compacted $\mathrm{EAF}(\mathrm{L})$ slag and Class-C fly ash mixtures with 5, 10 and 20\% Class-C fly ash (by weight), respectively. 


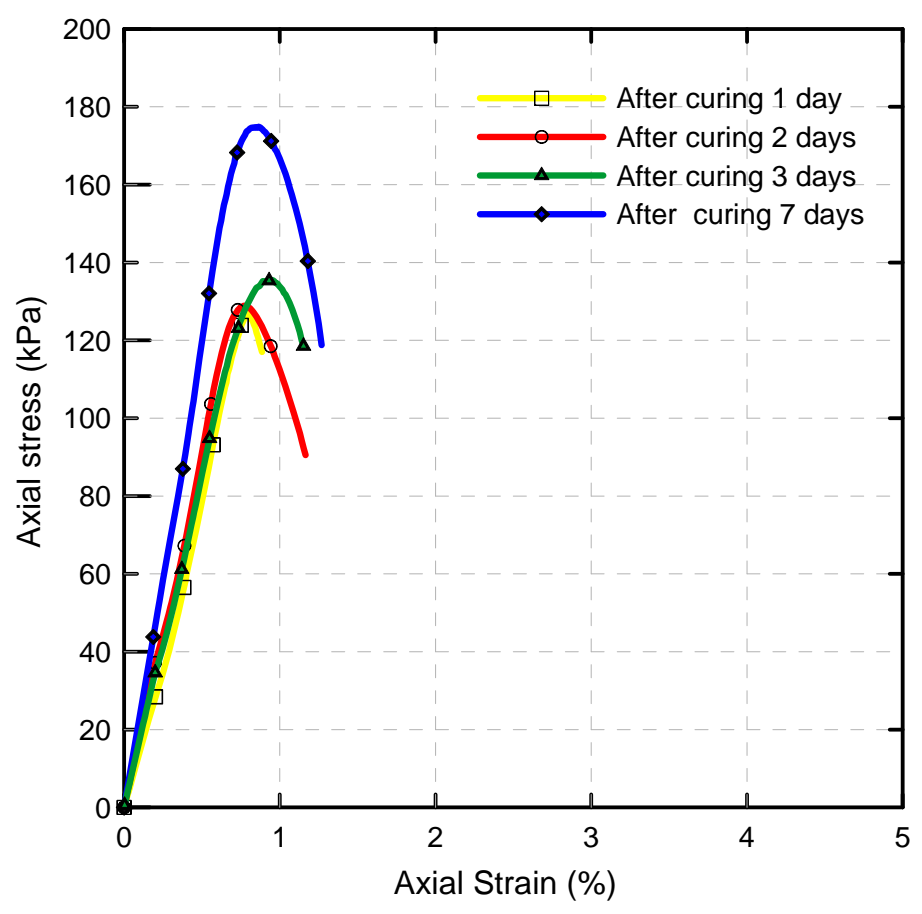

Figure 7.2 Unconfined compression test results on compacted EAF(L) slag samples after 1 day, 2 days, 3 days and 7 days of curing times

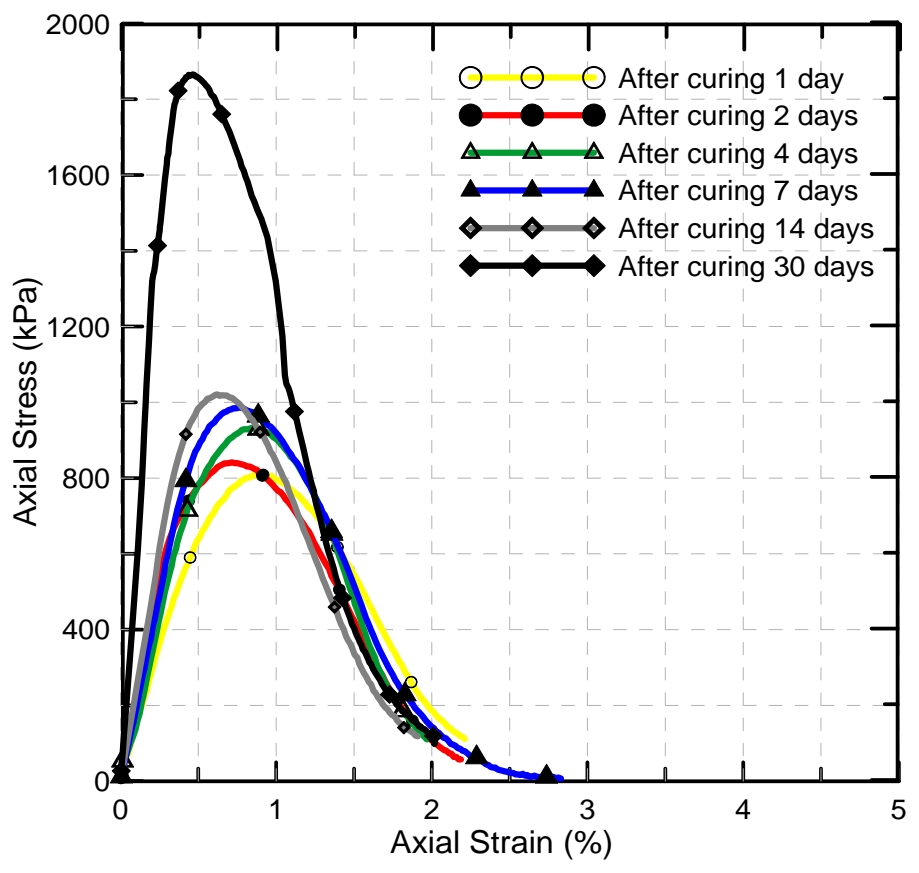

Figure 7.3 Unconfined compression test results on compacted EAF(L) slag and Class-C fly ash mixtures with 5\% Class-C fly ash (by weight) for various curing times 


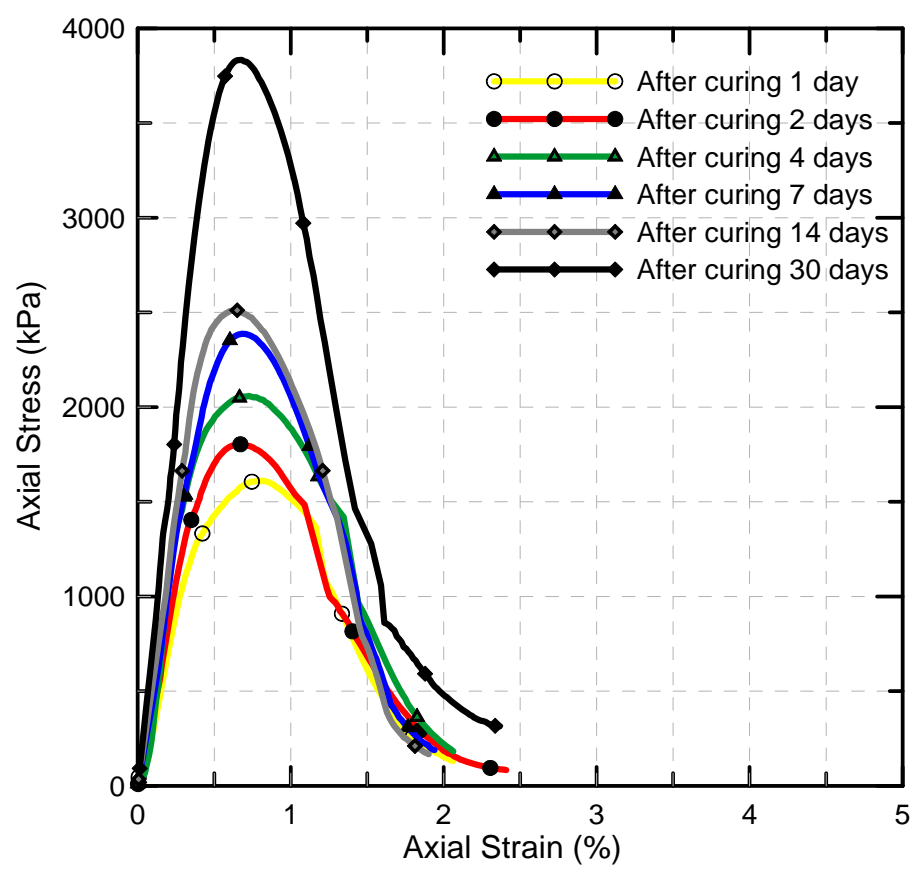

Figure 7.4 Unconfined compression test results on compacted EAF(L) slag and Class-C fly ash mixtures with $10 \%$ Class-C fly ash (by weight) for various curing times

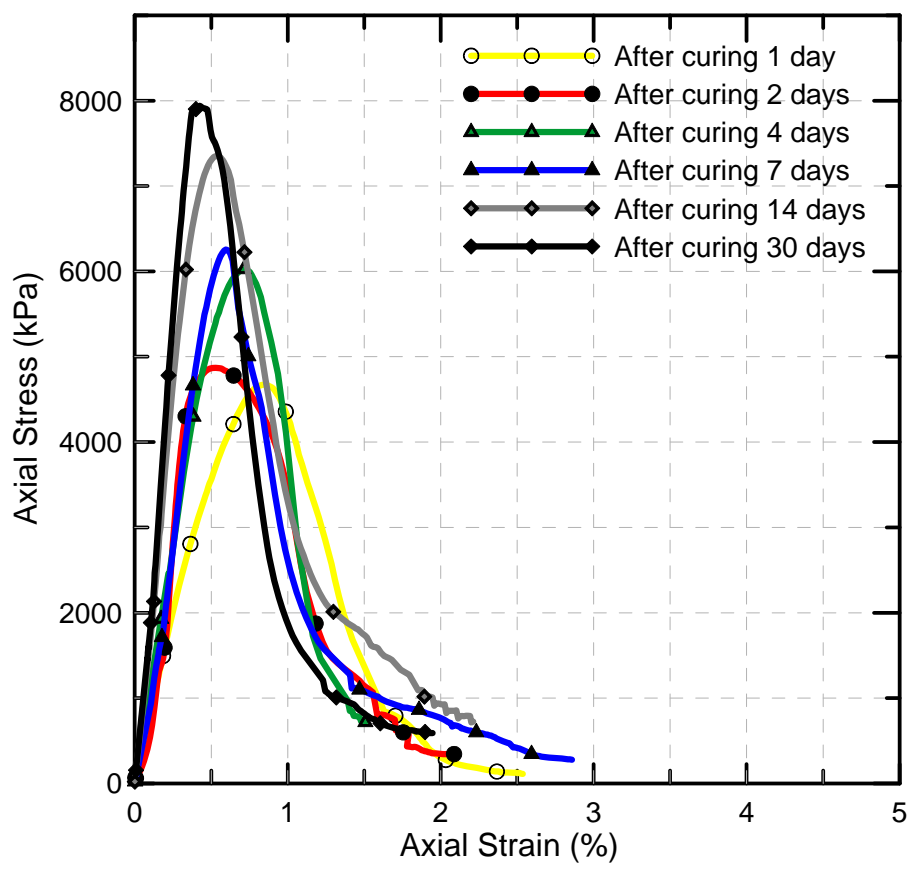

Figure 7.5 Unconfined compression test results on compacted EAF(L) slag and Class-C fly ash mixtures with $20 \%$ Class-C fly ash (by weight) for various curing times 
Unconfined compression test results show that the unconfined compression strength of EAF(L) slag and Class-C fly ash mixtures increases with curing time which indicates the occurrence of cementitious reactions. In order to observe the strength gain trend of EAF(L) slag and Class-C fly ash mixtures, curing period vs. unconfined compression strength of the samples were plotted. Figure 7.6 and Figure 7.7 show the curing time vs. unconfined compressive strength plots of only EAF(L) slag and mixtures of EAF(L) slag and 5,10, and 20\% Class-C fly ash, in SI and in FPS units, respectively. The unconfined compressive strength of EAF(L) slag samples and Class-C fly ash mixtures was much higher than that of $\mathrm{EAF}(\mathrm{L})$ slag samples for the same curing periods. The unconfined compressive strength of the EAF(L) slag and Class-C fly ash mixtures increased with increasing Class-C fly ash content and hence, EAF(L) slag and 20\% Class-C fly ash mixtures had the maximum unconfined compression strength values out of all EAF(L) slag mixtures tested in this study. The very high unconfined compressive strength values of EAF(L) slag and Class-C fly ash mixtures showed that Class-C fly ash facilitates the cementitious reactions.

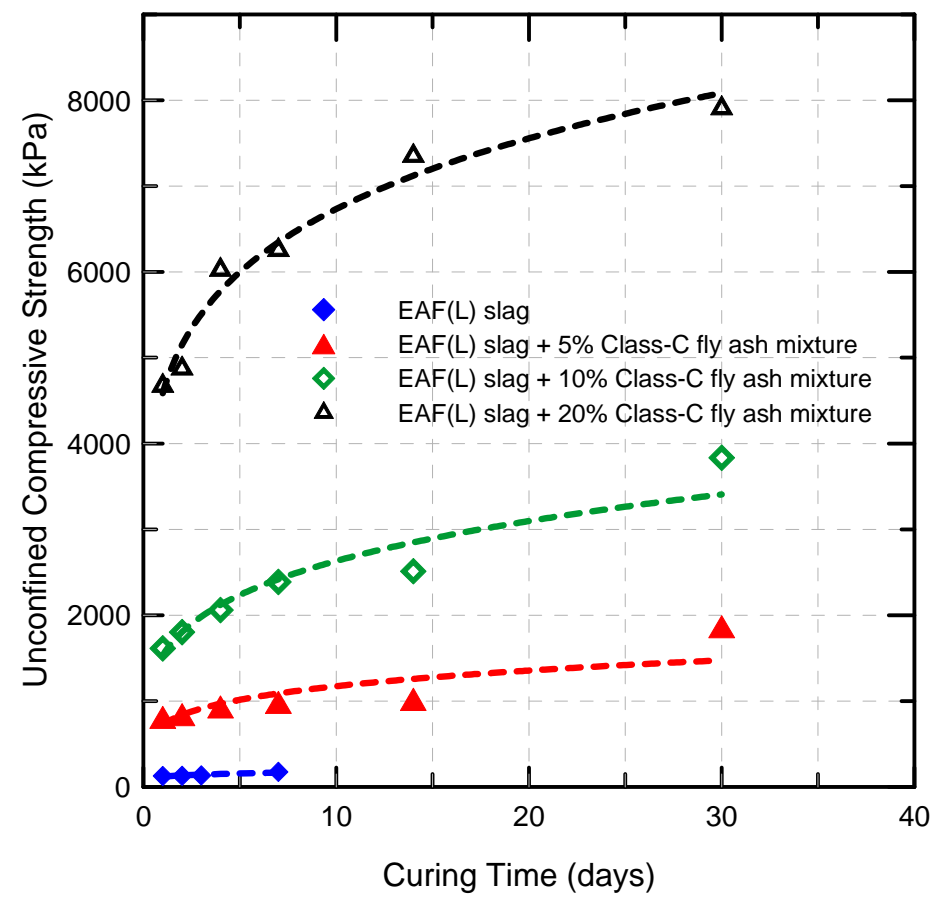

Figure 7.6 Curing time vs. unconfined compressive strength (in $\mathrm{kPa}$ ) of EAF(L) slag and EAF(L) slag and Class-C fly ash mixtures 


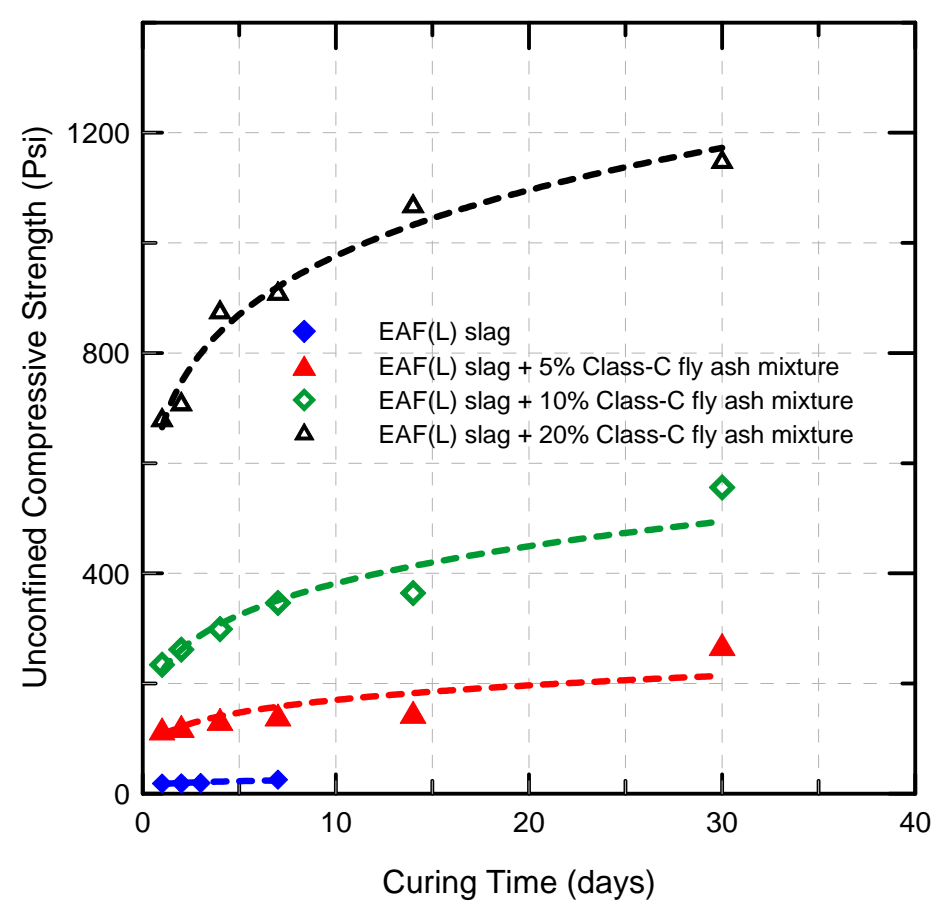

Figure 7.7 Curing time vs. unconfined compressive strength (in psi) of compacted $\mathrm{EAF}(\mathrm{L})$ slag and $\mathrm{EAF}(\mathrm{L})$ slag and Class-C fly ash mixtures

In order to represent the strength gain of $\operatorname{EAF}(\mathrm{L})$ slag and Class-C fly ash mixtures with curing time mathematically, power functions were fitted to the data points. Table 7.2 provides the empirical equations (regression functions) which relates the unconfined compressive strength of EAF(L) slag and Class-C fly ash mixtures with curing time. Table 7.3 and Table 7.4 provide the unconfined compression strength values for $\mathrm{EAF}(\mathrm{L})$ slag and Class-C fly ash mixtures tested at various curing time periods in SI and FPS units, respectively. 
Table 7.2 Regression functions that represent the time vs. unconfined compressive strength gain behavior of EAF(L) slag and Class-C fly ash mixtures

\begin{tabular}{cccc}
\hline Mixtures & $(\mathrm{kPa})$ & $(\mathrm{psi})$ & $\mathrm{R}^{2}$ \\
\hline \hline EAF(L) slag + 5\% Class-C Fly ash & $q_{u}=725.75 t^{0.2086}$ & $q_{u}=105.26 t^{0.2086}$ & 0.7354 \\
EAF(L) slag + 10\% Class-C Fly ash & $q_{u}=1532.2 t^{0.235}$ & $q_{u}=222.2 t^{0.235}$ & 0.9281 \\
EAF(L) slag + 20\% Class-C Fly ash & $q_{u}=4587.2 t^{0.1666}$ & $q_{u}=665.32 t^{0.1666}$ & 0.9695 \\
\hline
\end{tabular}

$q_{u}=$ unconfined compressive strength; $t=$ time (in days)

Table 7.3 Summary of unconfined compressive strength of EAF(L) slag and Class-C fly ash mixtures (in $\mathrm{kPa})$

\begin{tabular}{cccccccc}
\hline \multicolumn{3}{l}{ Unconfined Compression Strength of EAF(L) Slag and Class-C fly ash Mixtures } & (kPa) \\
\hline \hline Curing time: & 1 day & 2 day & 4 day & 7 day & 14 day & 30 day \\
\hline Fresh EAF(L) slag + 5\% Class-C Fly ash & 810 & 842 & 932 & 986 & 1021 & 1866 \\
Fresh EAF(L) slag + 10\% Class-C Fly ash & 1614 & 1804 & 2059 & 2387 & 2512 & 3833 \\
Fresh EAF(L) slag + 20\% Class-C Fly ash & 4672 & 4871 & 6024 & 6255 & 7351 & 7905 \\
\hline
\end{tabular}

Table 7.4 Summary of unconfined compressive strength of EAF(L) slag and Class-C fly ash mixtures (in psi)

\begin{tabular}{cccccccc}
\hline \multicolumn{6}{l}{ Unconfined Compression Strength of EAF(L) Slag and Class-C Fly ash Mixtures (psi) } \\
\hline \hline Curing time: & 1 day & 2 day & 4 day & 7 day & 14 day & 30 day \\
\hline Fresh EAF(L) slag + 5\% Class-C Fly ash & 117 & 122 & 135 & 143 & 148 & 271 \\
Fresh EAF(L) slag + 10\% Class-C Fly ash & 234 & 262 & 299 & 346 & 364 & 556 \\
Fresh EAF(L) slag + 20\% Class-C Fly ash & 678 & 707 & 874 & 907 & 1066 & 1147 \\
\hline
\end{tabular}

\subsection{Strength Gain Behavior of BOF Slag and Class-C Fly Ash Mixtures}

Attempts were made to perform unconfined compression tests on Batch-1 Fresh and Batch-3 Aged BOF slag samples. Compacted BOF slag samples did not show selfcementing properties and hence, intact samples could not be recovered from the 
unconfined compression molds. In order to assess the strength gain characteristics of BOF slag samples due to addition of Class-C fly ash, BOF slag samples were mixed with varying amounts of Class-C fly ash. The following mixtures were compacted and cured for the same set of curing periods $(1,2,4,7,14$ and 30 days after sample preparation) before UC testing:

- Batch-3 Aged BOF slag + $5 \%$ Class-C fly ash (by weight)

- Batch-3 Aged BOF slag + $10 \%$ Class-C fly ash (by weight)

Figure 7.8 and Figure 7.9 show the axial strain vs. axial stress curves obtained during UC testing of compacted BOF slag mixtures and 5 and $10 \%$ Class-C fly ash contents (by weight), respectively. Figure 7.10 and Figure 7.11 show the curing time vs. unconfined compressive strength of BOF slag and Class-C fly ash mixtures with 5 and $10 \%$ Class-C fly ash (by weight), in SI and in FPS units, respectively. Strength of BOF slag and Class-C fly ash mixtures increased with increasing Class-C fly ash content and hence, unconfined compression strengths of BOF slag mixtures with $10 \%$ Class-C fly ash (by weight) were higher than that of BOF slag mixtures with 5\% Class-C fly ash after the same curing times. Unconfined compressive strength of the BOF slag and 5 and 20\% Class-C fly ash mixtures increases with curing time, as the cementitious reactions becomes prevalent with curing. In order to represent the strength gain behavior of BOF slag and Class-C fly ash mixtures with curing time mathematically, power functions were fitted to the data points. Table 7.5 provides the empirical equations (regression functions) that can be used to predict the unconfined compressive strength of BOF slag and Class-C fly ash mixtures with curing time. Table 7.6 and Table 7.7 summarizes the unconfined compression strength of BOF slag and Class-C fly ash mixtures tested at various curing time periods in SI and FPS units, respectively. 


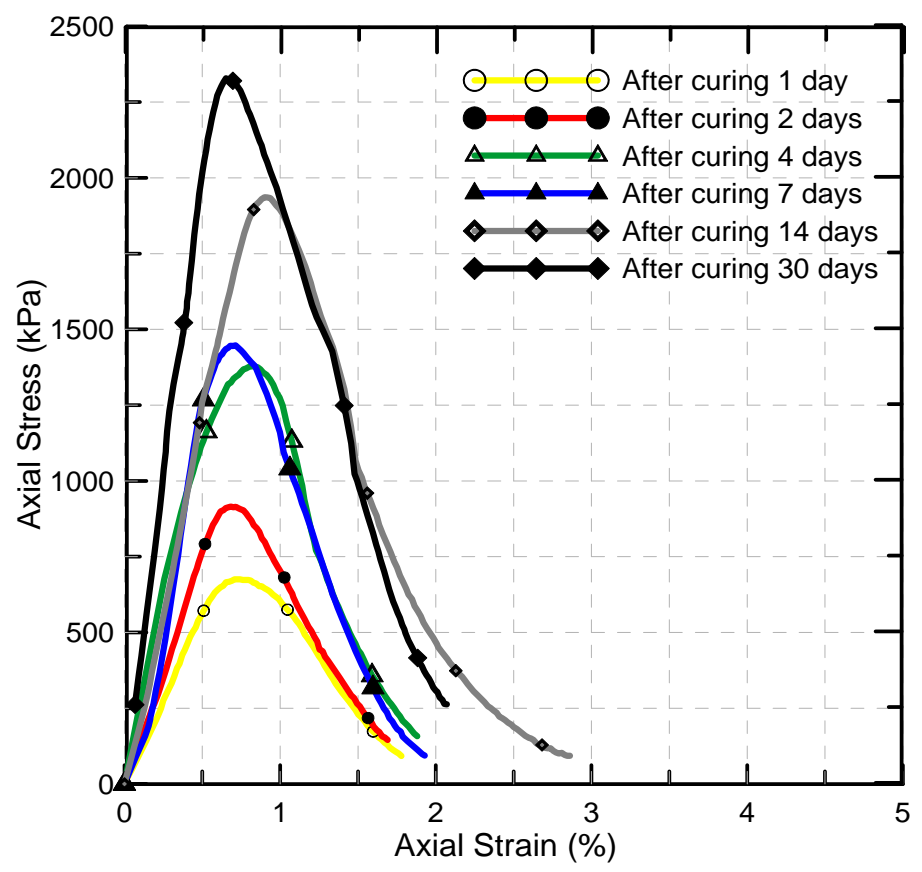

Figure 7.8 Unconfined compression test results on compacted BOF slag and Class-C fly ash mixtures with 5\% Class-C fly ash (by weight) for various curing times

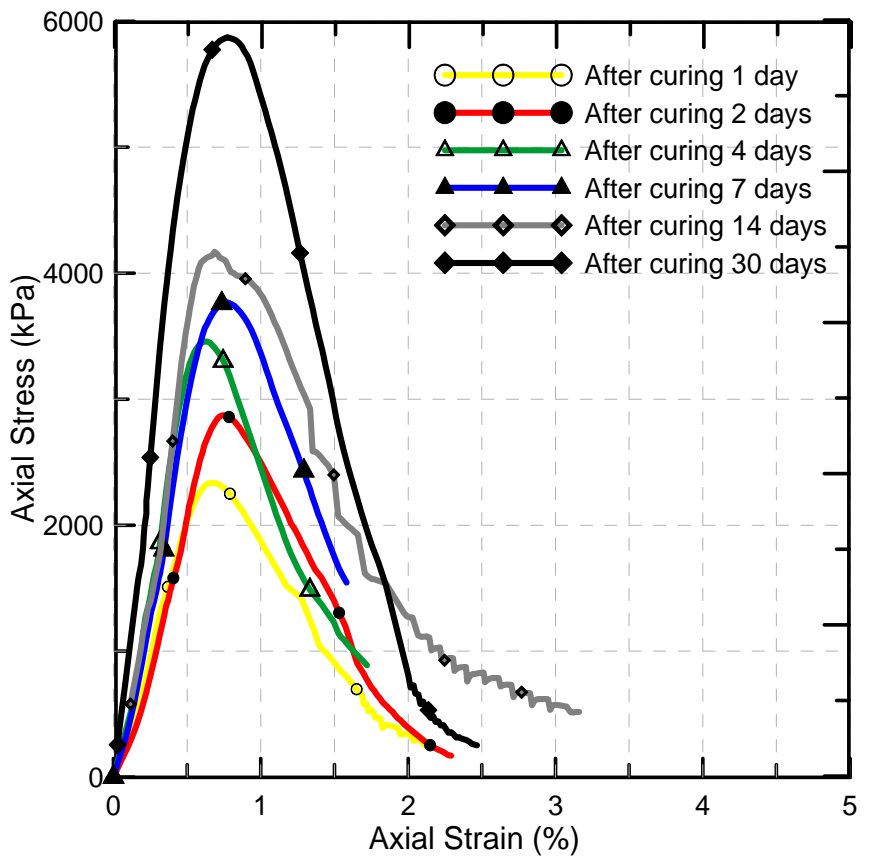

Figure 7.9 Unconfined compression test results on compacted BOF slag and Class-C fly ash mixtures with $10 \%$ Class-C fly ash (by weight) for various curing times 


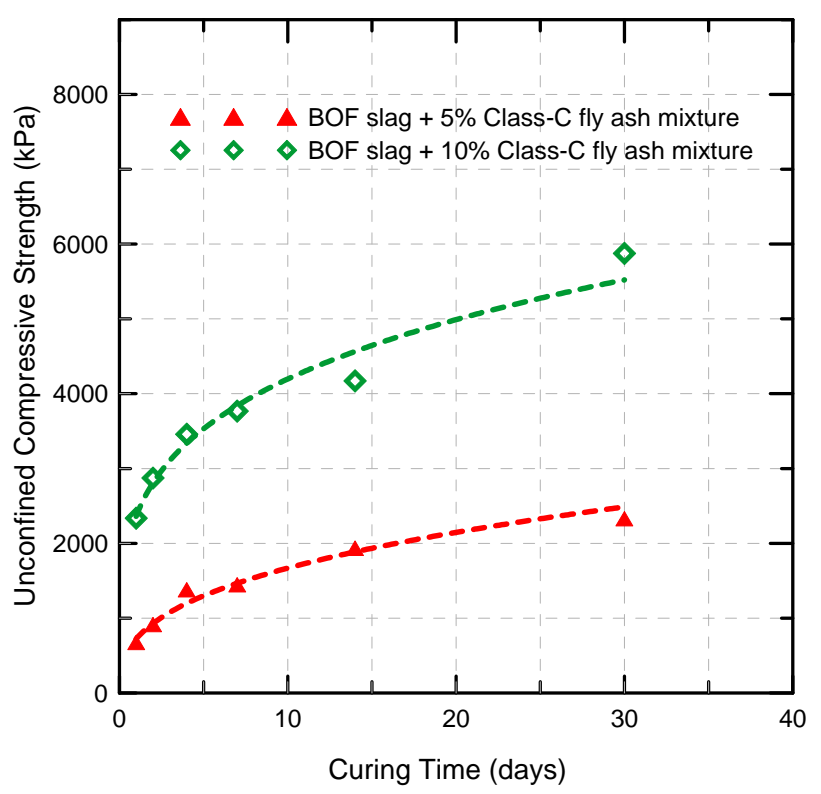

Figure 7.10 Curing time vs. unconfined compressive strength (in $\mathrm{kPa}$ ) of compacted BOF slag and Class-C fly ash mixtures

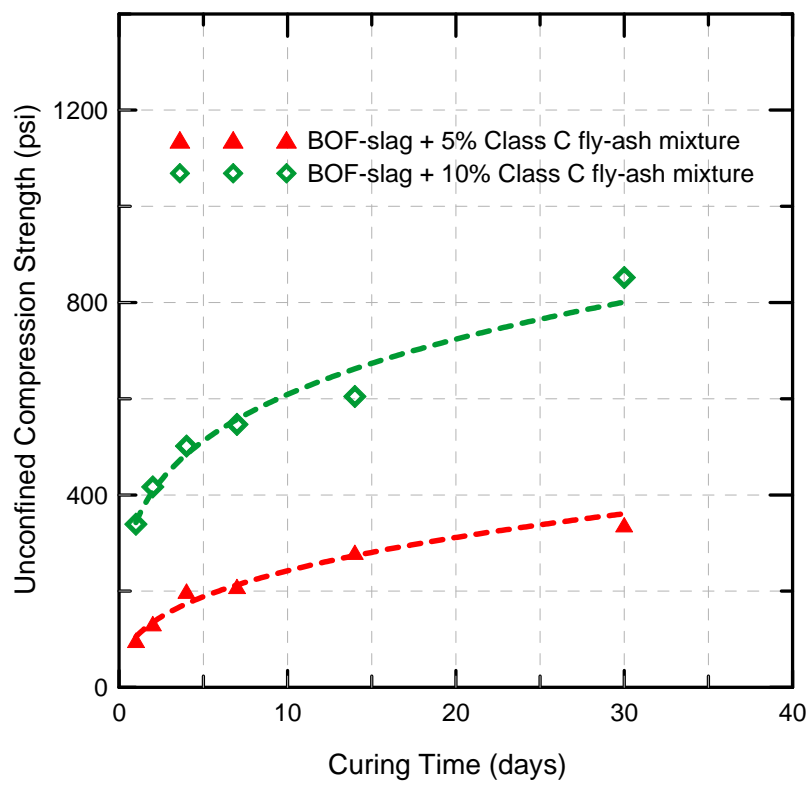

Figure 7.11 Curing time vs. unconfined compressive strength (in psi) of compacted BOF slag and Class-C fly ash mixtures 
Table 7.5 Regression functions that that represent the time vs. unconfined compressive strength gain behavior of BOF slag and Class-C fly ash mixtures

\begin{tabular}{cccc}
\hline Mixtures & $(\mathrm{kPa})$ & $(\mathrm{psi})$ & $\mathrm{R}^{2}$ \\
\hline \hline BOF slag + 5\% Class-C Fly ash & $q_{u}=724.08 t^{0.3628}$ & $q_{u}=104.99 t 0.3631$ & 0.9714 \\
BOF slag + 10\% Class-C Fly ash & $q_{u}=2362.2 t^{0.2496}$ & $q_{u}=342.61 t 0.2496$ & 0.9717 \\
\hline
\end{tabular}

$q_{u}=$ unconfined compressive strength; $t=$ time (in days)

Table 7.6 Summary of the unconfined compressive strength (in $\mathrm{kPa}$ ) of BOF slag and Class-C fly ash mixtures

\begin{tabular}{cccccccc}
\hline Unconfined Compressive Strength of BOF Slag and Class-C Fly ash Mixtures & $(\mathrm{kPa})$ \\
\hline \hline Curing time: & 1 day & 2 day & 4 day & 7 day & 14 day & 30 day \\
\hline Aged BOF slag + 5\% Class-C Fly ash & 675 & 915 & 1379 & 1447 & 1936 & 2328 \\
Aged BOF slag + 10\% Class-C Fly ash & 2337 & 2873 & 3458 & 3768 & 4170 & 5874 \\
\hline
\end{tabular}

Table 7.7 Summary of the unconfined compressive strength (in psi) of compacted BOF slag and Class-C fly ash mixtures

\begin{tabular}{cccccccc}
\hline Unconfined Compressive Strength of BOF Slag and Class-C Fly ash Mixtures (psi) \\
\hline \hline Curing time: & 1 day & 2 day & 4 day & 7 day & 14 day & 30 day \\
\hline Aged BOF slag + 5\% Class-C Fly ash & 98 & 133 & 200 & 210 & 281 & 338 \\
Aged BOF slag + 10\% Class-C Fly ash & 339 & 417 & 502 & 547 & 605 & 852 \\
\hline
\end{tabular}

\subsection{Long-term Swelling Response of EAF (L) Slag and Class-C Fly Ash Mixtures}

The long-term swelling tests were performed on the EAF(L) slag and Class-C fly ash mixtures with 5, 10 and 20\% Class-C (by weight). Fresh EAF(L) slag and Class-C fly as samples were compacted at approximately $10 \%$ moisture content to $100 \%$ relative compaction in CBR molds. A surcharge weight equivalent to approximately $2.5 \mathrm{kPa}$ were placed on the top of the compacted samples and samples were soaked in water. Onedimensional swelling of the $\mathrm{EAF}(\mathrm{L})$ slag mixtures were monitored for a period of about 
16 months at room temperature. Figure 7.12 shows the time vs. volumetric strain curves obtained from the long-term swelling tests performed on $\operatorname{EAF}(\mathrm{L})$ slag and Class-C fly ash mixtures. This figure clearly indicates that the swelling of EAF(L) slag and Class-C fly ash mixtures decreased with increasing Class-C fly ash content. A maximum swelling strain of $0.09 \%$ was recorded for the mixture with 5\% Class-C fly ash (by weight). The swelling strains of EAF(L) slag reduced by approximately $90 \%$ for $5 \%$ Class-C fly ash addition. With further increase in the fly ash content (by weight)- mixtures with 10 and $20 \%$ Class-C fly ash contents- swelling of the EAF(L) slag and Class-C fly ash mixtures reduced to negligible levels. Figure 7.13 shows the comparison of long-term swelling test results on $\operatorname{EAF}(\mathrm{L})$ slag and mixtures of $\mathrm{EAF}(\mathrm{L})$ slag with 5,10 and 20\% Class-C fly ash content (by weight). This figure clearly shows that the addition of Class-C fly ash was effective in suppressing swelling of $\operatorname{EAF}(\mathrm{L})$ slag samples. Swell strains obtained from the long-term swelling tests performed on $\operatorname{EAF}(\mathrm{L})$ slag and mixtures of $\mathrm{EAF}(\mathrm{L})$ slag and 5, 10 and 20\% Class-C fly ash are compiled in Table 7.8.

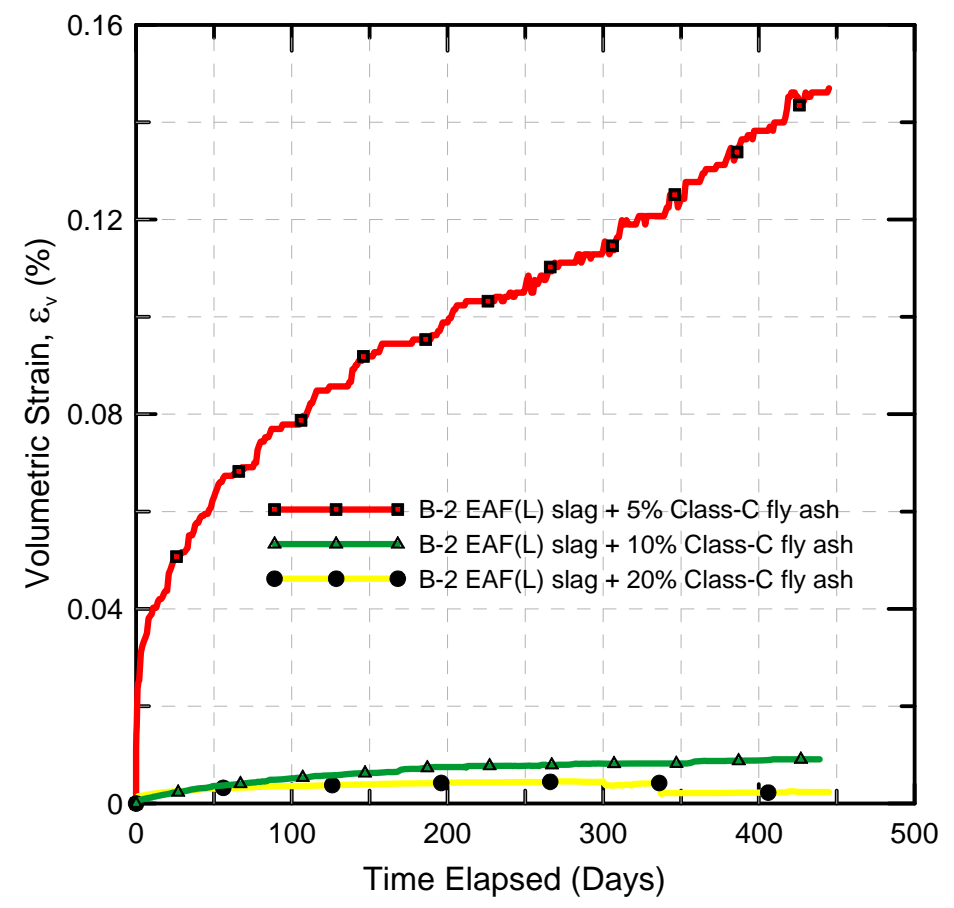

Figure 7.12 Time vs. volumetric strain curve for mixtures of EAF(L) slag and 5, 10 and $20 \%$ Class-C fly ash (by weight) 


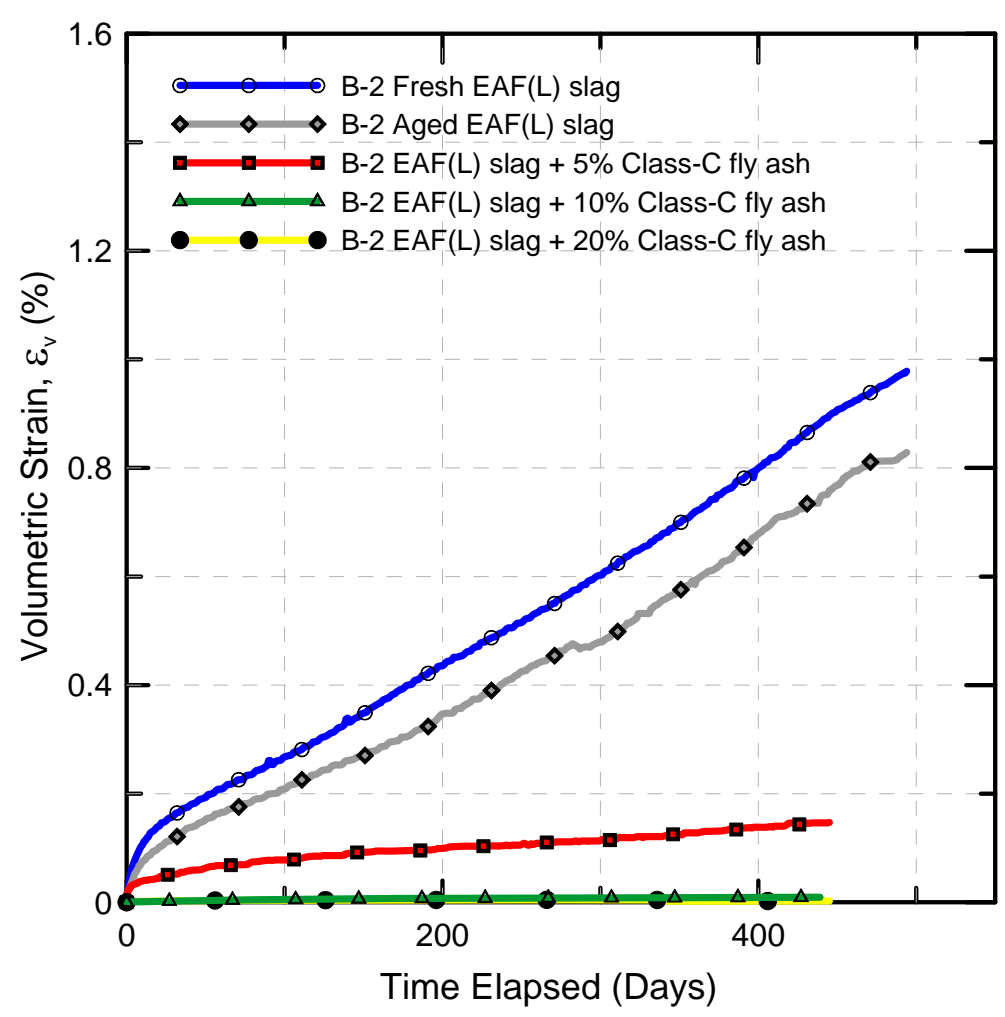

Figure 7.13 Time vs. volumetric strain for EAF(L) slag and mixtures of EAF(L) slag and 5, 10 and 20\% Class-C fly ash (by weight) 
Table 7.8 Volumetric strains obtained from the long-term swelling tests for fresh EAF(L) slag and mixtures of fresh EAF(L) slag and 5,10 and 20\% Class-C fly ash (by weight)

\begin{tabular}{|c|c|c|c|c|}
\hline \multirow[b]{2}{*}{$\begin{array}{c}\text { Elapsed } \\
\text { Time } \\
\text { (Months) }\end{array}$} & \multicolumn{4}{|c|}{ Swell Strain (\%) } \\
\hline & $\begin{array}{l}\text { Batch-2 Fresh } \\
\text { EAF(L) slag }\end{array}$ & $\begin{array}{c}\text { Batch-2 Fresh } \\
\text { EAF(L) slag + } \\
5 \% \text { Class-C fly } \\
\text { ash }\end{array}$ & $\begin{array}{l}\text { Batch-2 Fresh } \\
\text { EAF(L) slag + } \\
10 \% \text { Class-C } \\
\text { fly ash }\end{array}$ & $\begin{array}{c}\text { Batch-2 Fresh } \\
\text { EAF(L) slag } \\
+20 \% \text { Class-C } \\
\text { fly ash }\end{array}$ \\
\hline 1 & 0.160 & (0.052 & $2.45 \mathrm{E}-03$ & $2.62 \mathrm{E}-03$ \\
\hline 2 & 0.208 & 0.067 & $3.82 \mathrm{E}-03$ & $3.23 \mathrm{E}-03$ \\
\hline 3 & 0.261 & 0.077 & 4.94E-03 & $3.46 \mathrm{E}-03$ \\
\hline 4 & 0.296 & 0.085 & $5.75 \mathrm{E}-03$ & $3.67 \mathrm{E}-03$ \\
\hline 5 & 0.348 & 0.092 & $6.26 \mathrm{E}-03$ & $3.96 \mathrm{E}-03$ \\
\hline 6 & 0.401 & 0.095 & $7.13 \mathrm{E}-03$ & $4.16 \mathrm{E}-03$ \\
\hline 7 & 0.452 & 0.102 & $7.46 \mathrm{E}-03$ & 4.33E-03 \\
\hline 8 & 0.502 & 0.105 & $7.76 \mathrm{E}-03$ & 4.37E-03 \\
\hline 9 & 0.550 & 0.110 & 7.94E-03 & $4.55 \mathrm{E}-03$ \\
\hline 10 & 0.603 & 0.114 & $8.18 \mathrm{E}-03$ & $4.55 \mathrm{E}-03$ \\
\hline 11 & 0.657 & 0.121 & $8.20 \mathrm{E}-03$ & 4.13E-03 \\
\hline 12 & 0.720 & 0.128 & $8.66 \mathrm{E}-03$ & $2.14 \mathrm{E}-03$ \\
\hline 13 & 0.779 & 0.136 & $8.81 \mathrm{E}-03$ & $2.23 \mathrm{E}-03$ \\
\hline 14 & 0.845 & 0.145 & $9.08 \mathrm{E}-03$ & $2.49 \mathrm{E}-03$ \\
\hline 15 & 0.907 & 0.147 & $9.08 \mathrm{E}-03$ & $2.38 \mathrm{E}-03$ \\
\hline 16 & 0.953 & - & - & - \\
\hline 16.5 & 0.978 & - & - & - \\
\hline
\end{tabular}

- data not available

7.6. Long-term Swelling Response of BOF Slag Mixtures

The effects of addition of Class-C fly ash and ground rubber to BOF slag on the swelling properties of BOF slag samples were evaluated. The long-term swelling tests were 
performed on mixtures of BOF slag and 10\% Class-C fly ash (by weight). The mixtures were compacted at approximately $6-8 \%$ moisture content to $96-100 \%$ relative compaction in CBR molds. A surcharge weight equivalent to approximately $2.5 \mathrm{kPa}$ were placed on the top of the compacted samples of BOF slag mixtures and next, these samples were soaked in water. One-dimensional swelling of BOF slag mixtures were monitored for a period of about 9 months at room temperature.

The long-term swelling test results on BOF slag samples showed that Batch-1 Fresh BOF slag and Batch-3 Aged BOF slag samples had higher volumetric strains compared to that of Batch-2 Fresh and Batch-2 Aged BOF slag samples. Therefore, several mixtures of Batch-1 Fresh and Batch-3 Aged BOF slag were considered for longterm swelling tests. Long-term swelling tests were performed on the following BOF slag mixtures:

- Batch-1 Fresh BOF slag $+10 \%$ Class-C fly ash (by weight)

- Batch-1 Fresh BOF slag $+10 \%$ Class-C fly ash (by weight)

- Batch-3 Aged BOF slag $+10 \%$ ground rubber (by weight)

- Batch-3 Aged BOF slag $+10 \%$ ground rubber (by weight)

Figure 7.14 shows time vs. volumetric strain curves obtained from the long-term swelling tests on BOF slag mixtures. Figure 7.15 shows long-term swelling test results on Batch-1 Fresh and Batch-3 together with the results on BOF slag mixtures for comparison.

The tests results on BOF slag mixtures showed that the addition of $10 \%$ ground rubber reduced the swelling of Batch-1 Fresh BOF slag and Batch-3 Aged BOF slag samples by approximately $30 \%$ and $70 \%$, respectively. On the other hand, addition of $10 \%$ Class-C fly ash suppressed the swelling of both Batch-1 Fresh BOF slag and Batch3 Aged BOF slag to negligible levels. The long-term swelling test results on BOF slag samples indicated that Class-C fly ash addition is more effective in stabilizing swelling potential of BOF slag than addition of ground rubber to BOF slag samples. 


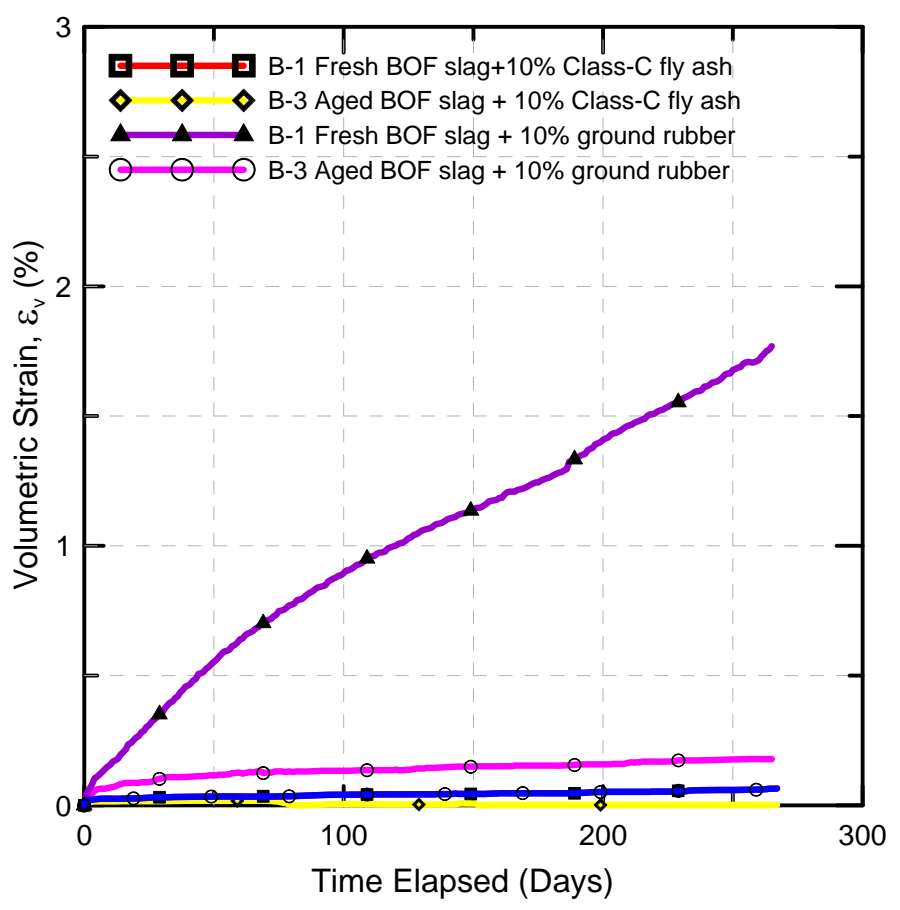

Figure 7.14 Time vs. volumetric strain curves for mixtures of fresh and aged BOF slag prepared with 10\% Class-C fly ash and 10\% ground rubber addition(by weight)

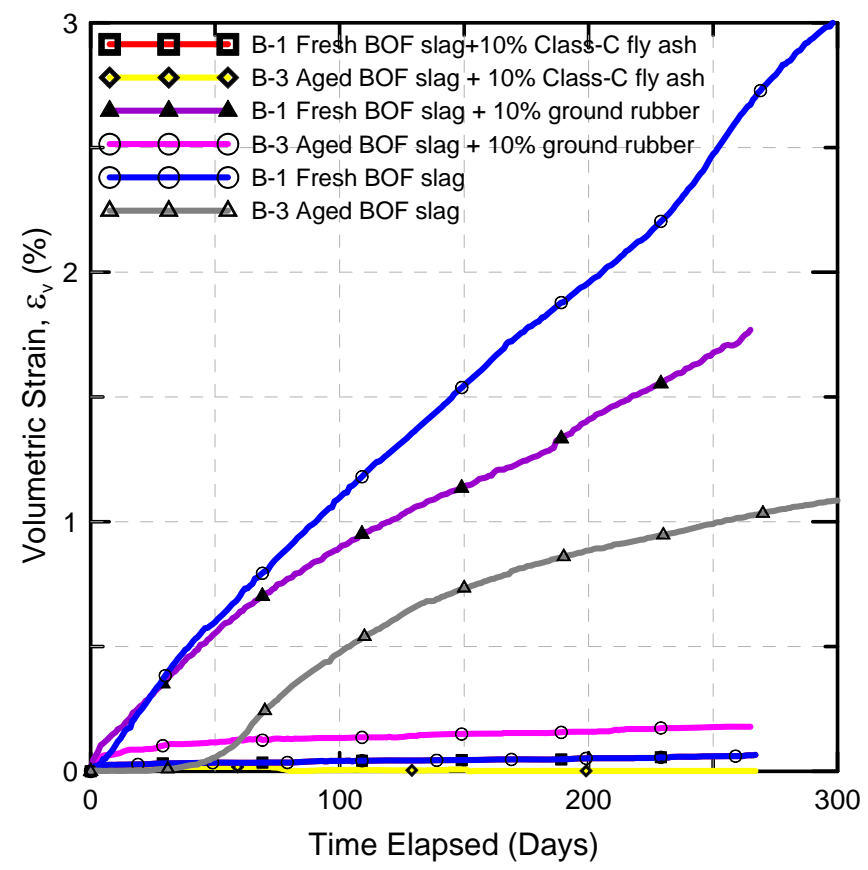

Figure 7.15 Time vs. volumetric strain curve for BOF slag and mixtures of BOF slag 
Table 7.9 Swell-strains obtained from the long-term swelling tests for BOF slag and mixtures of BOF slag and 5,10 and 20\% Class-C fly ash and ground rubber (by weight)

\begin{tabular}{|c|c|c|c|c|c|c|}
\hline \multicolumn{7}{|c|}{ Swell Strain (\%) } \\
\hline \multirow[b]{2}{*}{$\begin{array}{c}\text { Elapsed } \\
\text { Time } \\
\text { (Months) }\end{array}$} & \multirow[b]{2}{*}{$\begin{array}{c}\text { B-1 } \\
\text { Fresh } \\
\text { BOF } \\
\text { slag }\end{array}$} & \multirow[b]{2}{*}{$\begin{array}{c}\text { B-3 } \\
\text { Aged } \\
\text { BOF } \\
\text { slag }\end{array}$} & \multicolumn{2}{|c|}{$\begin{array}{c}\text { BOF slag and Class-C } \\
\text { fly ash mixtures }\end{array}$} & \multicolumn{2}{|c|}{$\begin{array}{l}\text { BOF slag and ground } \\
\text { rubber mixtures }\end{array}$} \\
\hline & & & $\begin{array}{c}\text { B-1 Fresh } \\
\text { BOF slag }+ \\
10 \% \\
\text { Class-C } \\
\text { Fly ash }\end{array}$ & $\begin{array}{c}\text { B-3 Aged } \\
\text { BOF slag }+ \\
10 \% \\
\text { Class-C } \\
\text { Fly ash }\end{array}$ & $\begin{array}{c}\text { B-1 Fresh } \\
\text { BOF slag+ } \\
\text { 10\% Ground } \\
\text { rubber }\end{array}$ & $\begin{array}{c}\text { B-1 Fresh } \\
\text { BOF slag+ } \\
10 \% \\
\text { Ground } \\
\text { rubber }\end{array}$ \\
\hline 1 & 0.383 & 0.009 & 0.031 & 0.017 & 0.356 & 0.104 \\
\hline 2 & 0.703 & 0.127 & 0.034 & 0.017 & 0.640 & 0.127 \\
\hline 3 & 0.996 & 0.410 & 0.039 & 0.003 & 0.840 & 0.133 \\
\hline 4 & 1.276 & 0.595 & 0.043 & 0.003 & 1.000 & 0.138 \\
\hline 5 & 1.547 & 0.734 & 0.045 & 0.007 & 1.140 & 0.151 \\
\hline 6 & 1.802 & 0.832 & 0.047 & 0.002 & 1.267 & 0.153 \\
\hline 7 & 2.036 & 0.909 & 0.052 & 0.002 & 1.464 & 0.164 \\
\hline 8 & 2.332 & 0.970 & 0.059 & 0.002 & 1.616 & 0.173 \\
\hline 9 & 2.742 & 1.034 & $0.064^{\mathrm{a}}$ & $0.002^{\mathrm{a}}$ & $1.769^{\mathrm{a}}$ & $0.178^{\mathrm{a}}$ \\
\hline 10 & 3.008 & 1.085 & - & - & - & - \\
\hline 11 & 3.164 & 1.128 & - & - & - & - \\
\hline 12 & 3.252 & 1.164 & - & - & - & - \\
\hline 13 & 3.297 & 1.172 & - & - & - & - \\
\hline 14 & 3.333 & 1.226 & - & - & - & - \\
\hline 15 & 3.393 & 1.297 & - & - & - & - \\
\hline 16 & 3.451 & 1.331 & - & - & - & - \\
\hline$\sim 17$ & 3.491 & 1.340 & - & - & - & - \\
\hline
\end{tabular}

${ }^{a}$ the swell-strains corresponds to after 265 days (approximately 9 months) after immersion for BOF slag mixtures

- data not available 


\subsection{Summary}

This Chapter presents the results of the compaction, unconfined compression and longterm swelling tests performed on various steel slag $[\mathrm{BOF}$ and $\mathrm{EAF}(\mathrm{L})$ slag] mixtures. The results of these laboratory tests are summarized as follows:

1) Proctor compaction tests on $\mathrm{EAF}(\mathrm{L})$ slag showed that the addition of $20 \%$ Class$\mathrm{C}$ fly ash resulted in a slight increase in maximum dry unit weight and also a decrease in the optimum moisture content of $\operatorname{EAF}(\mathrm{L})$ slags. This was attributed to the fact that fine fly ash particles fill the voids in the $\operatorname{EAF}(\mathrm{L})$ slag matrix during compaction.

2) The maximum dry unit weight of compacted $\operatorname{EAF}(\mathrm{L})$ slag and Class-C fly ash mixtures with 5 and $20 \%$ Class-C fly ash content (by weight) at $10 \%$ moisture content were $19.9 \mathrm{kN} / \mathrm{m}^{3}$ and $20.1 \mathrm{kN} / \mathrm{m}^{3}$, respectively.

3) Fresh $\operatorname{EAF}(\mathrm{L})$ slag and Class-C fly ash mixtures showed excellent strength gain with time. Two-day unconfined compression strength of compacted EAF(L) slag and Class-C-fly ash mixtures with 5, 10 and 20\% Class-C fly ash content (by weight) were 842, 1804 and $4871 \mathrm{kPa}$, respectively.

4) Aged BOF slag and Class-C fly ash mixtures also showed excellent strength gain with time. Two-day unconfined compression strength of compacted BOF slag and Class-C-fly ash mixtures with 10 and 20\% Class-C fly ash content (by weight) were 915 and $2873 \mathrm{kPa}$, respectively.

5) Results of long-term swelling tests performed on BOF slag and Class-C fly ash mixtures showed that the addition of $10 \%$ Class-C fly ash suppresses the swelling of both fresh and aged BOF slag samples to negligible levels.

6) Results of long-term swelling test performed on $\operatorname{EAF}(\mathrm{L})$ slag and Class-C fly ash mixtures showed that the addition of $5-10 \%$ Class-C fly ash suppresses the swelling of fresh $\mathrm{EAF}(\mathrm{L})$ slag almost completely.

7) The long-term swelling test results on BOF slag samples indicated that $10 \%$ Class-C fly ash addition is more effective in stabilizing swelling potential of BOF slag than addition of $10 \%$ ground rubber (by weight). 


\section{CHAPTER 8. SUMMARY AND CONCLUSIONS}

\subsection{Summary}

The main goal of this study was to evaluate the suitability of using steel slag in place of conventional geo-materials. The mineralogical, morphological, index and mechanical properties of representative samples of fresh and aged basic-oxygen-furnace (BOF) slag and of fresh electric-arc-furnace-ladle $(\mathrm{EAF}(\mathrm{L}))$ slag from two different steelmaking plants were evaluated through a series of laboratory tests (specific gravity, grain-size analysis, X-ray diffraction, compaction, maximum and minimum density, large-scale direct shear, consolidated drained triaxial and swelling tests). The effects of gradation on the engineering properties of both fresh and aged steel slag samples were also investigated.

Various mixtures of steel slag (BOF and EAF(L)) and Class-C fly ash were also investigated. The mixtures were prepared by adding 5 and $10 \%$ Class-C fly ash (by weight) to aged BOF slag and 5, 10 and 20\% Class-C fly ash (by weight) to fresh EAF(L) slag. Unconfined compression tests were performed after various curing times to evaluate the strength gain characteristics of the mixtures. Long-term swelling tests were performed for compacted mixtures of both fresh and aged BOF slag and 10\% Class-C fly ash (by weight) and for compacted mixtures of fresh EAF(L) slag and 5, 10 and 20\% Class-C fly ash (by weight). The effect of adding 10\% ground rubber (by weight) to fresh and aged BOF slag on the long-term swelling behavior of the mixtures was also investigated.

\subsection{Conclusions}

Based on the findings of the present study, the following conclusions are drawn: 
1) The gradation of different BOF slag samples varied from one batch to another. In general, BOF slag had a well-graded grain-size distribution with particle sizes ranging from silt to gravel size.

2) The $\mathrm{CaO}, \mathrm{FeO}, \mathrm{SiO}_{2}$, and $\mathrm{MgO}$ contents of $\mathrm{BOF}$ slag were equal to $39 \%, 30 \%$, $12 \%$ and $10 \%$, respectively. The specific gravity of fresh and aged BOF slag samples from different batches was in the 3.29-3.34 range.

3) XRD patterns of BOF slag samples showed extremely crystalline and complex structures which result from the slow cooling conditions used during processing of this slag. Similar XRD patterns were observed for fresh and aged BOF slag samples. The main mineral phases present in fresh and aged BOF slag were portlandite, srebrodol'skite, and merwinite.

4) The shapes of gravel-size particles present in fresh BOF slag varied from subrounded to subangular. Most of the gravel-size particles had a high sphericity and a solid structure. Agglomerates were observed in the gravel-size range of aged BOF slag particles (these were not observed in fresh BOF slag samples). Sand- and silt-size fresh BOF slag particles had subrounded to angular shapes. Distinct asperities and edges were visible in angular bulky sand particles. Sandand silt-size particles exhibited rough surface textures.

5) The compaction curves for BOF slags were irregular in shape. The optimum moisture content and maximum dry unit weight of BOF slag samples were in the ranges of $4-8 \%$ and $19.5-21.8 \mathrm{kN} / \mathrm{m}^{3}$, respectively.

6) The shear strength parameters for BOF slag (critical-state friction angle and c- $\phi$ fitting parameters) were determined based on large-scale direct shear and triaxial test results. Based on the large-scale direct shear tests results, the critical-state friction angle of Batch-1 Fresh, Batch-2 Fresh and Batch-2 Aged BOF slag samples were equal to $45.5^{\circ}, 48.1^{\circ}$, and $45.3^{\circ}$, respectively. Isotropically consolidated drained (CID) triaxial tests were performed on the Batch-3 Aged BOF slag with minus $9.5 \mathrm{~mm}$ gradation (particles smaller than 9.5mm). For samples prepared at $90 \%$ relative compaction, Batch-3 Aged BOF slag exhibited 
peak friction angles of $47.3^{\circ}, 45.2^{\circ}$ and $43.5^{\circ}$ for effective confining stresses of 50 , 110 and $200 \mathrm{kPa}$, respectively. Both fresh and aged samples of BOF slag exhibited very high $\left(\geq 43^{\circ}\right)$ critical-state and peak friction angles.

7) Leaching of heavy metals from BOF slag was investigated through Toxicity Characteristic Leaching Procedure (TCLP) analysis. Based on the leachate concentration levels of BOF slag samples obtained from the TCLP analysis, BOF slag is classified as Type III solid waste according to the Indiana restricted waste criterion. Electrical resistivity and $\mathrm{pH}$ test results indicated that BOF slag samples are potentially corrosive. Additional studies are required to evaluate the long-term environmental impact of using BOF slag in geotechnical applications.

8) $\mathrm{EAF}(\mathrm{L})$ slag has a well-graded grain-size distribution with particle sizes ranging mainly from silt to gravel size.

9) The $\mathrm{CaO}, \mathrm{Al}_{2} \mathrm{O}_{3}, \mathrm{FeO}, \mathrm{MgO}$ and $\mathrm{SiO}_{2}$ contents of $\mathrm{EAF}(\mathrm{L})$ slag were equal to $48 \%, 23 \%, 8 \%, 7 \%$ and $4 \%$, respectively. The specific gravity of Batch-1 Fresh EAF(L) slag and Batch-2 Fresh EAF(L) slag samples were determined as 2.73 and 3.04, respectively. The difference in the specific gravity values were attributed to the variations in the chemical composition of EAF(L) slag generated at the source steel plant.

10) XRD patterns of EAF(L) slag samples showed extremely crystalline and complex structures with very high intensities peaks. The complex XRD patterns and high intensity peaks of EAF(L) slags were attributed to the very slow cooling of slag . The main mineral phases present in Batch-1 Fresh EAF(L) slag were portlandite, mayenite, and malenterite. Portlandite, mayenite, periclase and magnesite were identified as the major phases in Batch-2 Fresh EAF(L) slag.

11) Gravel-size particles of fresh $E A F(L)$ slag had shapes varying from subrounded to subangular. Both bulky and platy gravel-size particles were observed. Most of the platy particles had irregular shapes with very low sphericity and sharp edges. The main morphological difference observed between the gravel-size particles of two different $\mathrm{EAF}(\mathrm{L})$ slag samples was the presence of particles with popcorn like 
porous structure in Batch-1 Fresh EAF(L) slag sample. This was not observed in Batch-2 Fresh EAF(L) slag. Sand- and silt-size fresh particles from both Batch-1 Fresh and Batch-2 Fresh EAF(L) slag samples exhibited subrounded to subangular shapes. Distinct asperities and edges were visible in subangular bulky particles. Some very irregularly shaped platy particles were also observed in both samples. Most of the sand-size particles examined under SEM from both Batch-1 Fresh EAF(L) slag and Batch-2 Fresh EAF(L) slag samples showed extremely rough surface textures.

12) The optimum moisture content and maximum dry unit weight of Batch-1 Fresh EAF(L) slag sample were $13 \%$ and $16.8 \mathrm{kN} / \mathrm{m}^{3}$, respectively. The optimum moisture content and maximum dry unit weight of Batch-2 Fresh EAF(L) slag samples were $11 \%$ and $20.0 \mathrm{kN} / \mathrm{m}^{3}$, respectively.

13) The shear strength parameters of $\operatorname{EAF}(\mathrm{L})$ slag (critical-state friction angle and $c-\phi$ fitting parameters) were determined based on the large-scale direct shear test results. Critical-state friction angle of Batch-1 Fresh, and Batch-2 Fresh EAF(L) slag samples were determined as $40.4^{\circ}$, and $40.8^{\circ}$, respectively. $c-\phi$ fitting parameters of Batch-1 Fresh EAF(L) slag samples prepared at 95\% and $100 \%$ relative compaction were determined as $26 \mathrm{kPa}-44.5^{\circ}$ and $67 \mathrm{kPa}-45.2^{\circ}$ respectively. For Batch-2 Fresh EAF(L) slag sample prepared at 100\% relative compaction $c-\phi$ fitting parameter was determined as $93 \mathrm{kPa}-43.6^{\circ}$.

14) Leaching of heavy metals from $\operatorname{EAF(L)~slag~was~investigated~through~Toxicity~}$ Characteristic Leaching Procedure (TCLP) analysis. Based on the leachate concentration levels obtained from the TCLP analysis for EAF(L) slag samples, EAF(L) slag is classified as Type III solid waste according to the Indiana restricted waste criterion. Electrical resistivity and $\mathrm{pH}$ test results indicated that EAF(L) slag samples are potentially corrosive.

15) Proctor compaction tests on EAF(L) slag and Class-C fly ash mixtures showed that the addition of $20 \%$ Class-C fly ash (by weight ) to EAF(L) slag resulted in a slight increase in the maximum dry unit weight and the optimum moisture content 
of EAF(L) slags. This was attributed to the fact that fine fly ash particles fill the voids in the $\mathrm{EAF}(\mathrm{L})$ slag matrix. The maximum dry unit weight of compacted EAF(L) slag and Class-C fly ash mixtures with 5 and 20\% Class-C fly ash content (by weight) at $10 \%$ moisture content were recorded as $19.9 \mathrm{kN} / \mathrm{m}^{3}$ and 20.1 $\mathrm{kN} / \mathrm{m}^{3}$, respectively.

16) Both fresh and aged BOF slag samples (with minus $16 \mathrm{~mm}$ gradation) increased in volume in the presence of water. Aging of BOF slag for one year was effective in reducing the expansion rate and the maximum expansion values. However, aging alone was not sufficient to guarantee volumetric stability.

17) The volume change of aged BOF slag samples stabilized at expansive volumetric strains of the order of 0.5 to $1.3 \%$ after 17 months of monitoring. On the other hand, no stabilization of the volumetric strains was observed for fresh BOF slag samples after 17 months of monitoring (the maximum expansive volumetric strains values were in the 0.66 to $3.5 \%$ range).

18) The volume change of fresh BOF slag samples with the fine gradation did not stabilize and reached volumetric strains of $3.5 \%$ after 16 months of monitoring. This result indicated that finer gradation and hence, the larger surface area facilitates the hydration reactions. Therefore use of fine gradations of BOF slag in embankment construction can be detrimental.

19) Fresh and one-month aged $\mathrm{EAF}(\mathrm{L})$ slag samples (with $9.5 \mathrm{~mm}$ gradation) increased in volume in presence of water.

20) In the initial 10 days of the monitoring period, one-month aged $E A F(L)$ slag exhibited a slightly lower swelling rate (approximately $0.008 \% /$ day) than that of fresh $\mathrm{EAF}(\mathrm{L})$ slag $(0.01 \%$ /day). After the initial 10 days, the swelling rates were approximately $1.804 \times 10^{-3} /$ day and $1.556 \times 10^{-3} /$ day for fresh and one-month aged EAF(L) slag samples, respectively.

21) Volumetric strains for fresh and one-month aged EAF(L) slag samples did not stabilize after 16 months of monitoring. The maximum expansive volumetric 
strain values for fresh and one-month aged $\operatorname{EAF}(\mathrm{L})$ slag were 0.98 and $0.83 \%$, respectively.

22) Fresh $\mathrm{EAF}(\mathrm{L})$ slag and Class-C fly ash mixtures showed excellent strength gain with time. The two-day unconfined compressive strength of compacted EAF(L) slag and Class-C fly ash mixtures with 5, 10 and 20\% Class-C fly ash content (by weight) were 842,1804 and $4871 \mathrm{kPa}$, respectively.

23) Aged BOF slag and Class-C fly ash mixtures showed excellent strength gain with time. The two-day unconfined compressive strength of compacted BOF slag and Class-C fly ash mixtures with 10 and $20 \%$ Class-C fly ash content by weight were 915 and $2873 \mathrm{kPa}$, respectively.

24) Results of long-term swelling tests on BOF slag and Class-C fly ash mixtures showed that the addition of $10 \%$ Class-C fly ash suppresses the swelling of both fresh and aged BOF slag samples to negligible levels.

25) Results of long-term swelling test on EAF(L) slag and Class-C fly ash mixtures showed that the addition of $10 \%$ Class-C fly ash suppresses the swelling of EAF(L) slag almost completely.

\subsection{Recommendations and Future Work}

Based on the work performed in this research study, the following ideas and recommendations are suggested for future research:

1) In order to couple the rate of swelling obtained from the long-term swelling tests presented in this research with the maximum expansion values obtained from the accelerated swelling tests, accelerated swelling tests could be performed on BOF and $\mathrm{EAF}(\mathrm{L})$ slag samples.

2) Based on the experimental results, we suggest the use of mixtures of aged BOF slag and 10\% Class-C fly ash and of EAF(L) slag and 5-10\% Class-C fly ash in subgrade stabilization projects. Mixtures of EAF(L) slag and Class-C fly ash and mixtures of BOF slag and Class-C fly ash could be effective in soil stabilization. 
3) Use of mixtures of aged BOF slag and soil or BOF slag and Class-C fly ash could be explored also in the context of embankment construction projects.

4) Experiments similar to the ones presented in this research can be performed on mixtures of BOF slag and soil and mixtures of EAF slag and soil with different percentages of EAF and BOF slag content to evaluate the properties of the soilslag mixtures.

5) Implementation projects can help facilitate the use of steel slag in routine projects by INDOT engineers. Fully monitored demonstration projects (equipped with settlement plates, pressure cells, vertical and horizontal inclinometers) are needed to evaluate the field performance of embankments and subgrades constructed with mixtures of steel slag (BOF and $\mathrm{EAF}(\mathrm{L})$ slag) and soil or steel slag (BOF and EAF(L) slag) and Class-C fly ash.

6) The short and long-term environmental impact of using BOF and EAF(L) slag in geotechnical applications should also be carefully assessed in the context of field implementation projects. In order to account for the variations in steel slag generation, leaching characteristics of the slag samples should be checked routinely during implementation projects. 


\section{LIST OF REFERENCES}

Acar, Y.B., Seal, R.K., and Puppala, A.J.(1990). "Engineering and compaction characteristics of boiler slag." Geotechnics of Waste Fills-Theory and Practice, ASTM STP1070, American Society of Testing Materials, pp 123-141.

Ahmedzade, P., and Sengoz, B. (2009). "Evaluation of steel slag coarse aggregate in hot mix asphalt concrete." Journal of Hazardous Materials, Vol. 165, No. 1-3, pp. 300-305.

Aiban, S.A. (2006). "Utilization of steel slag aggregate for road bases." Journal of Testing and Evaluation, Vol. 34, No. 1, pp. 65-75.

Alanyali, H., Col, M., Yilmaz, M., and Karagoz, S. (2006). "Application of magnetic separation to steelmaking slags." Waste Management, Vol. 26, No.10, pp.1133-1139.

Alshibli, K.A., and Sture, S. (2000). "Shear band formation in plane strain experiments of sand." Journal of Geotechnical and Geoenvironmental Engineering, ASCE, Vol. 126, No. 6, pp. 495-503.

Altun, I.A., and Yilmaz, I. (2002). "Study on steel furnace slags with $\mathrm{MgO}$ additive in Portland cement." Cement and Concrete Research, Vol. 32, No.8, pp. 1247-1249.

American Petroleum Institute (API). (1997). "Cathodic Protection of Aboveground Petroleum Storage Tanks", API Recommended Practice 651, $2^{\text {nd }}$ Edition, Washington, D.C.

American Association of State Highway and Transportation Officials, AASHTO M145-91, "Standard specification for classification of soils and soil-aggregate mixtures for highway construction purposes." Philadelphia, PA.

American Society for Testing and Materials, ASTM C127-07, "Standard test method for density, relative density (Specific gravity), and absorption of coarse aggregate." Philadelphia, PA.

American Society for Testing and Materials, ASTM C151/C151M-09, "Standard test method for autoclave expansion of hydraulic cement." Philadelphia, PA.

American Society for Testing and Materials, ASTM C618-08a, "Standard test method for coal fly ash and raw or calcined natural pozzolan for use in concrete." Philadelphia, PA.

American Society for Testing and Materials, ASTM C702-98, "Standard practice for reducing samples of aggregate to testing size." Philadelphia, PA. 
American Society for Testing and Materials, ASTM C989, "Standard specification for Slag Cement for Use in Concrete and Mortars.” Philadelphia, PA.

American Society for Testing and Materials, ASTM D1883-07, "Standard specification for CBR(California Bearing Ratio) of laboratory-compacted soils." Philadelphia, PA.

American Society for Testing and Materials, ASTM D2487-06, "Standard practice for classification of soils for engineering purposes (Unified Soil Classification System).” Philadelphia, PA.

American Society for Testing and Materials, ASTM D2940-03, "Standard specification for graded aggregate material for bases or subbases for highways or airports." Philadelphia, PA.

American Society for Testing and Materials, ASTM D3080-04, "Standard test method for direct shear test of soils under consolidated drained conditions." Philadelphia, PA.

American Society for Testing and Materials, ASTM D422-63, "Standard test method for particle-size analysis of soils." Philadelphia, PA.

American Society for Testing and Materials, ASTM D4253-00, "Standard test methods for maximum index density and unit weight of soils using a vibrotary table." Philadelphia, PA.

American Society for Testing and Materials, ASTM D4253-00, "Standard test methods for maximum index density and unit weight of soils using a vibrotary table." Philadelphia, PA.

American Society for Testing and Materials, ASTM D4254-00, "Standard test methods for minimum index density and unit weight of soils and calculation of relative density." Philadelphia, PA.

American Society for Testing and Materials, ASTM D4318-05, "Standard test method for liquid limit, plastic limit, and plasticity index of soils." Philadelphia, PA.

American Society for Testing and Materials, ASTM D4792-00, "Standard test method for potential expansion of aggregates from hydration reactions." Philadelphia, PA.

American Society for Testing and Materials, ASTM D5102-04, "Standard test methods unconfined compressive strength of compacted soil-lime mixtures." Philadelphia, PA.

American Society for Testing and Materials, ASTM D698-00, "Standard test methods for laboratory compaction characteristics of soils using standard effort $\left(12,400 \mathrm{ft}-\mathrm{lb} / \mathrm{ft}^{3}\right.$ $(600 \mathrm{kN}-\mathrm{m} / \mathrm{m} 3))$." Philadelphia, PA.

American Society for Testing and Materials, ASTM D854-06, "Standard test methods for specific gravity of soil solids by water pycnometer." Philadelphia, PA.

American Society for Testing and Materials, ASTM G51-95, "Standard test method for measuring $\mathrm{pH}$ of soil for use in corrosion testing." Philadelphia, PA.

American Society for Testing and Materials, ASTM G57-95, "Standard test method for field measurement of soil resistivity using the Wenner four-electrode method." Philadelphia, PA. 
Anastasiou, E., and Papayianni, I. (2006). "Criteria for the use of steel slag aggregates in concrete." Measuring, Monitoring and Modeling Concrete Properties, An International Symposium dedicated to Professor Surendra P. Shah, Northwestern University, U.S.A, pp.419-426.

Andreas, L., Herrmann, I., Lidstrom-Larrsson, M., and Lagerkvist, A. (2005). "Physical properties of steel slag to be reused in a landfill cover." Proceedings of Sardinia, Tenth International Waste Management and Landfill Symposium, Environmental Sanitary Engineering Centre, Cagliari, Italy, Oct. 3-7.

Asi, I.M. (2007). "Evaluating skid resistance of different asphalt concrete mixes." Building and Environment, Vol. 42, No.1, pp. 325-329.

Bagampadde, U., Wahhab, H.I.A., and Aiban, S.A. (1999). "Optimization of steel slag aggregates for bituminous mixes in Saudi Arabia." Journal of Materials in Civil Engineering, ASCE, Vol. 11, No. 1, pp. 30-35.

Barra, M., Ramonich, E.V., and Munoz, M.A. (2001). "Stabilization of soils with steel slag and cement for application in rural and low traffic roads." Proceedings of the Beneficial Use of Recycled Materials in Transportation Application, RMCR University of Durham, Arlington, Va., Nov. 13-15, pp. 423-432.

Bayless, E.R., and Schulz, M.S. (2003). "Mineral precipitation and dissolution at two slag-disposal sites in northwestern Indiana, USA.” Environmental Geology, Vol. 45, No.2, pp. 252-261.

Bayless, E.R., Greeman, T.K., and Harvey, C.C. (1998). "Hydrology and geochemistry of a slag-affected aquifer and chemical characteristics of slag-affected ground water, Northwestern Indiana and Northeastern Illinois." U.S. Geological Survey, WaterResources Investigations Report 97-4198, Indianapolis, IN.

Bock,L.P., and Bergh, H.V., (2004). "Stainless steel slags in hydraulic bound mixtures for road construction, 2 case studies in Belgium." International RILEM Conference on the Use of Recycled Materials in Buildings and Structures, November 8-11, Barcelona, Spain.

Boyer, B.B. (1994).“Alkaline leachate and calcerous tufa originating from slag in highway embankment near Baltimore, Maryland." Transportation Research Record 1434, Transportation Research Board, National Research Council, Washington, D.C., pp. 3-7.

Brandt, D., and Warner, J.C. (2005). "Metallurgy Fundamentals." The Good heartWilcox Company, Inc., Tinley park, Illinois.

Byers, C.C., Saleh, M.F., and Pidwerbesky, B.D. (2004). "Evaluation of melter slag as a base course material." The International Journal of Pavement Engineering, Vol. 5, No. 4, pp. 193-199.

California Department of Transportation (CALTRANS). "Slag aggregate", CALTRANS Specification S28-M25 A11-16-07, 2007, California, CA. 
Cerato, A.B., and Lutenegger, A.J. (2006). "Specimen size and scale effects of direct shear box tests of sands." Geotechnical Testing Journal, Vol. 29, No. 6, pp. 507-516.

Cha, W., Kim, J., and Choi, H.(2006). "Evaluation of steel slag for organic and inorganic removals in soil aquifer treatment." Water Research, Vol. 40, No.5, pp. 1034-1042.

Chaurand, P., Rose, J., Briois, V., Olivi, L., Hazemann, J., Proux, O., Domas, J., and Bottero, J. (2007). "Environmental impacts of steel slag reused in road construction: a crystallographic and molecular (XANES) approach." Journal of Hazardous Materials, Vol. 139, No.3, pp. 537-542.

Christopher, B.R., Gill, S.A., Giroud, J.P., Juran, I., Mitchell, J.K., Schlosser, F. and Dunnicliff, J. (1989). "Reinforced soil structures: Volume-1 design and construction guidelines." Federal Highway Administration, Report No. FHWA-RD-89-043, McLean, VA.

Chu, S., and Kao, H. (1993). "Study of engineering properties of a clay modified by fly ash and slag." Fly Ash for Soil Improvement, ASCE Geotechnical Special Publication No.36, Sharp, K. D., ed., pp. 89-99.

Conjeaud, M., George, C.M., and Sorrentino, F.P. (1981). "A new steel slag for cement manufacture: mineralogy and hydraulicity." Cement and Concrete Research, Vol. 11, No.1, pp. 85-102.

Cramer, S., and Sippel, C. (2005). "Effects of ground granulated blast furnace slag in Portland cement concrete." Final Report 0.092-02-0.14a, Wisconsin Highway Research Program, Wisconsin Department of Transportation, Madison, WI.

Crawford, C.B., and Burn, K.N. (1969). "Building damage from expansive steel slag backfill." Journal of the Soil Mechanics and Foundations Division, Vol. 95, No.6, pp. 1325-1334.

Danilov, E.V. (2003). "Modern technology for recycling steelmaking slags." Metallurgist, Vol. 47, No. 5-6, pp. 232-234.

Das, B., Prakash, S., Reddy, P.S.R., and Misra, V.N. (2007). "An overview of utilization of slag and sludge from steel industries." Resources Conservation and Recycling, Vol. 50, No. 1, pp.40-57.

DePree, P.J., and Ferry, C.T. (2008). 'Mitigation of expansive electric arc furnace slag in Brownfield redevelopment." Proceedings of GeoCongress 2008: Geosustainability and Geohazard Mitigation, ASCE, New Orleans, Louisiana, 271-278.

Dippenaar, R. (2004). "Industrial uses of slag-The use and re-use of iron and steelmaking slags." $7^{\text {th }}$ International Conference on Molten Slags, Fluxes and Salts, The South African Institute of Mining and Metallurgy, Cape Town, Jan 25-28, pp. 57-69.

Drizo, A., Forget, C., Robert, P.Chapuis. (2006). "Phosphorus removal by electric arc furnace slag and serpentinite", Water Research, Vol. 40, No.8, pp. 1547-1554. 
Duncan, J.M. (2004). Notes of a lecture presented at the Kenneth L. Lee Memorial Seminar Long Beach, California April 28, 2004.

Ellis, C.I. (1980). "Soil compaction at low moisture content-filed trials in Sudan." $7^{\text {th }}$ Regional Conference for Africa on soil Mechanics and Foundation Engineering, Accra, Ghana.

Emery, J. "Steel slag utilization in asphalt mixes." National Slag Association Publications No. 186-1.

Emery, J.J. (1974). "A simple test procedure for evaluating the potential expansion of steel slag." Proc. of the 1974 Annual Conference, Roads and Transportation Association of Canada, Toronto, Ont., pp.90-103.

Emery, J.J. (1980). "Pelletized Lightweight Slag Aggregate," Proceedings of Concrete International, Concrete Society.

Evans, A.C. (2006). "Compaction control of large-sized granular solis/aggregates: the vibrating hammer method of compaction and time domain reflectometry", MS Thesis, Purdue University, West Lafayette, IN, USA.

Fallman, A-M.(2000). "Leaching of chromium and barium from steel slag in laboratory and field tests-a solubility controlled process?" Waste Management, Vol.20, No.2-3. pp.149-154.

Farrand, B., and Emery, J. (1995). "Recent improvements in quality of steel slag aggregate." Transportation Research Record 1486, Transportation Research Board, National Research Council, Washington, D.C., pp. 137-141.

Foster,C. R. (1962). "Field Problems: Compaction," in Foundation Engineering, Edited by Leonards, G. A. McGraw Hill Book Co., Inc., New York.

Geiseler, J. (1994). "Steel slag-generation, processing and utilization." Proceedings of the International Symposium on Resource Conservation and Environmental Technologies in Metallurgical Industry, Toronto, Canada, Aug 20-25, pp.87-97.

Geiseler, J. (1996). "Use of steel works slag in Europe." Waste Management, Vol. 16, No.1-3, pp. 59-63.

Ghionna, V., Pedroni, S., Tenani, P., and Veggi, S. (1996). "Geotechnical investigation on steel slags mixtures for landfills embankments construction." Proceedings of the Second International Conference on Environmental Geotechnics, Osaka, Japan, November 5-8, Balkema , Rotterdam, 709-714.

Gupta, J.D., Kneller, W.A., Tamirisa, R., and Skrzypczak-Jankun, E. (1994). "Characterization of base and subbase iron and steel slag aggregates causing deposition of calcareous tufa in drains." Transportation Research Record 1434, Transportation Research Board, National Research Council, Washington, D.C., pp. 816.

Hale, B.C., Lovell, C.W., and Wood, L.E. (1981). "Development of a laboratory compaction-degradation test for shales." Transportation Research Record 790, 
Transportation Research Board, National Research Council, Washington, D.C., pp. 45-52.

Huang, W. H., and Lovell, C.W. (1990). "Bottom ash as embankment material." Geotechnics of Waste Fills-Theory and Practice, ASTM STP1070, American Society of Testing Materials, pp. 71-85.

Huijgen, J.J.W., Witkamp, G.J., and Comans, R.N.J. (2005). "Mineral $\mathrm{CO}_{2}$ sequestration by slag carbonation." Environmental Science and Technology, Vol. 34, No. 24, pp. 9676-9672.

Indraratna, B. (1996). "Utilization of lime, slag and fly ash for improvement of a colluvial soil in New South Wales, Australia." Geotechnical and Geological Engineering, Vol.14, No.3, pp.169-191.

Jha, V.K., Kameshima, Y., Okada, K.(2004). "Hazardous ion uptake behavior of thermally activated steel-making slag.", Journal of Hazardous Materials, Vol. 114, No. 1-3, pp. 139-144.

Johnson, D.C. (2000) "Accelerated carbonation of waste calcium silicate materials." SCI lecture Paper Series, Society of Chemical Engineers, pp1-10.

Juckes, L.M. (2003). "The volume stability of modern steelmaking slags." Mineral Processing and Extractive Metallurgy, Vol.112, No.3, pp.177-197.

Kamon, M., Nontananandh, S., and Katsumi, T. (1993). "Utilization of stainless-slag by cement hardening." Soils and Foundations, Vol. 33, No. 3, pp. 118-129.

Kandhal, P.S., and Hoffman, G.L. (1997). "Evaluation of steel slag fine aggregate in hot-mix asphalt mixtures." Transportation Research Record 1583, Transportation Research Board, National Research Council, Washington, D.C., pp. 28-36.

Kim, B.(2003).'Properties of coal ash mixtures and their use in highway embankments." PhD Thesis, Purdue University, West Lafayette, IN, USA.

Kneller, A.W., Gupta, J., Borkowski, L.M., and Dollimore, D. (1994). "Determination of original free lime content of weathered iron and steel slag by thermogravimetric analysis." Transportation Research Record 1434, Transportation Research Board, National Research Council, Washington, D.C., pp. 17-22.

Kumar, S., Kumar, R., Bandopadhyay, A., Alex, T.C., Kumar, R.B., Das, S.K., and Mehrotra, S.P. (2008). "Mechanical activation of granulated blast furnace slag and its effect on the properties and structure of portland slag cement." Cement and Concrete Composites, Vol. 30, No.8, pp.679-685.

Lea, F.M. (2004). "Lea's Chemistry of Cement and Concrete, $4^{\text {th }}$ Edition, Elsevier. Butterwort-Heinemann Publishers, Oxford, UK, pp. 637-649.

Lee, A.R.(1974). "Blastfurnace and steel slag: production, properties and uses." Edward Arnold Ltd,. London. 
Lee, P.Y. (1976). "Study of irregular compaction curves." Soil Specimen Preparation for Laboratory Testing, ASTM STP 599, American Society of Testing Materials, pp. 278-288.

Lee, P.Y., and Suedkamp, R.J. (1972). "Characteristics of irregularly shaped compaction curves.” Highway Research Record 381, pp 1-9.

Lekakh, S.N., Rawlins, C.H., Robertson, D.G.C., Richards, V.L., and Peaslee, K.D. (2008). "Kinetics of aqueous leaching and carbonization of steelmaking slag." Metallurgical and Materials Transactions B, Vol. 39, No.1, pp.125-134.

Lopez, F.A., and Lopez-Delgado, A. (2002). "Enhancement of electric arc furnaced dust by recycling to electric arc furnace." Journal of Environmental Engineering, ASCE, Vol. 128, No.12, pp. 1169-1174.

Luxan. M.P, R. Sotolongo, Dorrego, F., and Herrero, E. (2000). "Characteristics of the slags produced in the fusion of scrap steel by electric arc furnace." Cement and Concrete Research, Vol. 30, No. 4, pp. 517-519.

Mahieux, P.Y., Aubert, J.E., and Escadellias, G. (2009). "Utilization of weathered basic oxygen furnace slag in the production of hydraulic road binders." Construction and Building Materials, Vol. 23, No.2, pp. 742-747.

Manso, J.M., Gonzalez, J.J., and Polanco, J.A. (2004). "Electric arc furnace slag in concrete." Journal of Materials in Civil Engineering, ASCE, Vol. 16, No. 6, pp. 639645.

Manso, J.M., Losanez, M., Polanco, J.A., and Gonzalez, J.J. (2005). "Ladle furnace slag in construction." Journal of Materials in Civil Engineering, ASCE, Vol. 17, No. 5, pp. 513-518.

Manso, J.M., Polanco, J.A., Losanez, M., and Gonzales, J.J. (2006). "Durability of concrete made with EAF slag as aggregate." Cement and Concrete Composites, Vol. 28, No.6, pp.528-534.

Maslehuddin, M, Sharif, M.A., Shameem, M., Ibrahim, M., and Barry, M.S. (2003). "Comparison of properties of steel slag and crushed limestone aggregates." Construction and Building Materials, Vol. 17, No.2, pp. 105-112.

Mathur, S., Soni, S.K., and Murty, A. (1999). "Utilization of industrial wastes in lowvolume roads." Transportation Research Record 1652, Transportation Research Board, National Research Council, Washington, D.C., pp. 246-256.

Matsuoka, H. and, Liu, S. (1998). "Simplified direct shear box test on granular materials and its application to rockfill materials." Soils and Foundations, Vol.38, No. 4, pp. 275-284.

Miklos, P. (2000). "The utilization of electric arc furnace slags in Denmark." Engineering of slags: a scientific and technological challenge: $2^{\text {nd }}$ European Slag Conference: Proceedings, 9-11 October, Dusseldorf.

Monaco, A., and Wu, W.K. (1994). "The effect of cooling conditions on the characterization of steel slag." Resource Conservation and Environmental 
technologies in Metallurgical Industries: Proceedings of the International Symposium on Resource Conservation and Environmental Technologies in Metallurgical Industry, Toronto, Canada, Aug 20-25, pp.107-116.

Monkman, S., and Shao, Y. (2006). "Assessing the carbonation behavior of cementitious metarials." Journal of Materials in Civil Engineering, ASCE, Vol.18, No.6, pp. 768-776.

Montgomery, D.G., and Wang, G. (1992). "Instant-chilled steel slag aggregate in concrete - strength related properties" Cement and Concrete Research, Vol. 21, No.6, pp.1083-1091.

Motz, H., and Geiseler, J. (2001). "Products of steel slags an opportunity to save natural resources." Waste Management, Vol. 21, No. 3, pp. 285-293.

Murphy, J.N., Meadowcroft, T.R., and Barr, P.V. (1997). "Enhancement of the cementitious properties of steelmaking slag." Canadian Metallurgical Quarterly, Vol. 36, No. 5, pp. 315-331.

Mymrin, V.A., Ponte, H.A., Ponte, M.J.J.S., and Maul, A.M. (2005). "Structure formation of slag-soil construction materials." Materials and Structures, Vol. 38, No.1, pp. 107-113.

Nicolae, M., Vilciu, I., and Zaman, F. (2007). "X-ray diffraction analysis of steel slag and blast furnace slag viewing their use for road construction." U.P.B. Sci. Bull., Vol. 69, No.2, pp. 99-108.

Noureldin, A.S., and McDaniel, R.S. (1990). "Evaluation of surface mixtures of steel slag and asphalt." Transportation Research Record 1269, Transportation Research Board, National Research Council, Washington, D.C., pp. 133-149.

NSA Bulletin MF 172-13. "Slag ands its relation to the corrosion characteristics of ferrous metals.", National Slag Association Publications, Alexandria, VA, undated.

Opdyke, S.M., Evans, J.C. (2005). "Slag-cement-bentonite slurry walls.” Journal of Geotechnical and Geoenvironmental Engineering, ASCE, Vol. 131, No. 6, pp. 673681.

Oregon Department of Transportation (ODOT). "Steel slag in hot mix asphalt concrete", CDOT Specification S28-M25 A11-16-07, 2007, California, CA.

Osinubi, K.J. (2006). "Influence of compactive efforts on lime-slag treated tropical black clay." Journal of Materials in Civil Engineering, ASCE, Vol.18, No.2, pp. 175181.

Oss, H.G. (2006). "Slag-Iron and Steel, Annual Review 2006." Mineral Industry Surveys, U.S. Geological Survey, Minerals Yearbook, Reston, VA, U.S.

Pamukcu, S., and Tuncan, A. (1993). "Laboratory characterization of cement-stabilized iron-rich slag for reuse in transportation facilities." Transportation Research Record 1424, Transportation Research Board, National Research Council, Washington, D.C., pp. 25-33. 
Patel, J.P. (2006). "Broader use of steel slag aggregate in concrete." Msc. Thesis, Cleveland University, USA.

Poh, H.Y., Ghataora, S.G., and Ghazireh, N. (2006). "Soil stabilization using basic oxygen steel slag fines" Journal of Materials in Civil Engineering, ASCE, Vol. 18, No .2, pp. 229-240.

Proctor, D.M., Fehling, K.A., Shay, E.C., Wittenborn, J.L., Avent, C., Bigham R.D., Connolly, M., Lee, B., Shepker, T.O., and Zak, M.A. (2000). "Physical and chemical properties of blast furnace, basic oxygen furnace, and electric arc furnace steel industry slag”, Environmental Science and Technology, Vol. 34, No. 8, pp. 15761582.

Qasrawi, H., Shalabi, F., and Asi, I. (2009). "Use of low CaO unprocessed steel slag in concrete as fine aggregate." Construction and Building Materials, Vol. 23, No.2, pp. 1118-1125.

Qian, G.R., Sun, D.D., Tay, J.H., and Lai, Z.Y. (2002a). "Hydrothermal reaction of autoclave stability of $\mathrm{Mg}$ bearing $\mathrm{RO}$ phase in steel slag." British Ceramic Transactions, Vol. 101, No.4, pp. 159-164.

Qian, G.R., Sun, D.D., Tay, J.H., Lai, Z., and Xu, G. (2002b). “Autoclave properties of kirschteinite-based steel slag." Cement and Concrete Research, Vol. 32, No. 9, pp. 1377-1382.

Ramachandran, V.S., Serad, P.J., and Feldman, R.F. (1964). "Mechanism of hydration of calcium oxide." Nature, Vol. 201, No. 4916, pp.288-299.

Rao, S.R. (2006). "Resource recovery and recycling from metallurgical wastes." Waste management series 7, Elsevier B.V.eds., Amsterdam, The Netherlands, pp.269-327.

Rasheeduzzafar, and Hussain, S.E. (1991). "Effect of microsilica and blast furnace slag on pore solution composition and alkali-silica reaction." Cement and Concrete Research, Vol. 13, No. 3, pp. 219-225.

Reddy, A.S., Pradhan, R.K., and Chandra, S. (2006). "Utilization of basic oxygen furnace (BOF) slag in the production of a hydraulic cement binder." International Journal of Mineral Processing, Vol. 79, No. 2, pp. 98-105.

Renfrew, S., and Perkins, D. (2004). "Utilization of steel slag in a California cement plant." $46^{\text {th }}$ Cement Industry Technical Conference, Chattanooga TN, April 25-30, pp.111-119.

Roadcap, G.S., Kelly, W.R., and Bethke, C.M.(2005). "Geochemistry of extremely alkaline (pH.>12) ground water in slag-fill aquifers." Ground Water, Vol. 43, No. 6, pp. 806-816.

Robinson, H.L. (2000). "The utilization of blastfurnace and steel making slags as aggregates for construction." Proceedings of the $11^{\text {th }}$ Extractive Industry Geology Conference 2000, 36 ${ }^{\text {th }}$ forum on the Geology of Industrial Minerals, Industrial Minerals and Extractive Industry Geology, The Geological Society of London, pp. 327-330. 
Rohde, L., Nunez, W.P., and Ceratti, J.A.P. (2003). "Electric arc furnace steel slagbase material for low-volume roads." Transportation Research Record 1819, Transportation Research Board, National Research Council, Washington, D.C., pp. 201-207.

Rojas, M.F., and M.I.S. Rojas. (2004). "The chemical assessment of the electric arc furnace slag as construction material: expansive compounds." Cement and Concrete Research, Vol. 34, No. 10, pp. 1881-1888.

Sakadevan, K., and Bavor, H.J. (1998). "Phosphate adsorption characteristics of soils, slag and zeolite to be used as subtrates in constructed wetland systems." Water Research, Vol. 32, No.2, pp.393-399.

Salgado, R. (2008). “The Engineering of Foundations”, McGraw-Hill, New York.

Schoenberger, H. (2001). "Final Draft: Best Available Techniques Reference Document on the Production of Iron and Steel." Publications of EC: European Commission, Joint Research Centre, IPTS, European IPPC Bureau.

Scully, J. C. (1990). "The Fundamentals of Corrosion." Pergamon Press, $3{ }^{\text {rd }}$ Edition, Oxford, New York, USA.

Seetharaman, S. (2005). "Fundamentals of Metallurgy". Woodhead Publishing Limited and CRC Press LLC, Boca Raton, Florida, USA.

Sezer, A., Inan G., Yilmaz, H.R., and Ramyar, K. (2006). "Utilization of a very high lime fly ash for improvement of Izmir clay" Building and Environment, Vol. 41, No. 2, pp.150-155.

Shen, D., Wu, C., and Du, J. (2009). "Laboratory investigation of basic oxygen furnace slag for substitution of aggregate in porous asphalt mixture." Construction and Building Materials, Vol. 23, No.1, pp. 453-461.

Shen, H., and Forssberg, E. (2003). "An overview of recovery of metals from slags." Waste Management, Vol. 23, No. 10, pp. 933-949.

Shen, H., Forssberg, E., and Nordtsrom, U. (2004). "Physicochemical and mineralogical properties of stainless steel slags oriented to metal recovery." Resources Conservation and Recycling, Vol.40, No.3, pp.245-271.

Shen, W., Zhou, M., Ma,W., Hu, J., and Cai, Z. (2009). "Investigation on the application of steel slag-fly ash-phosphogypsum solidified material as road base material.” Journal of Hazardous Materials, Vol. 164, No.1, pp. 99-104.

Shi, C. (2002). "Characteristics and cementitious properties of ladle slag fines from steel production." Cement and Concrete Research, Vol. 32, No. 3, pp. 459-462.

Shi, C. (2004). "Steel slag - its production, processing and cementitious properties." Journal of Materials in Civil Engineering, ASCE, Vol.16, No. 3, pp. 230- 236.

Shih, P.H., Wu, Z.Z., and Chiang, H.L. (2004). "Characteristics of bricks made from waste steel slag." Waste Management, Vol. 24, No. 10, pp. 1043-1047. 
Simoni, A., and Houlsby, G.T. (2006). "The direct shear strength and dilatancy of sandgravel mixtures." Geotechnical and Geological Engineering, Vol.24, No.3, pp. 523549.

Sobolev, K.(2005)."Mechano-chemical modification of cement with high volumes of blast furnace slag." Cement and Concrete Composites, Vol. 27, No.7-8, pp.847-853.

State of Ohio Department of Transportation (ODOT). "Open heart and basic oxygen furnace steel slag aggregate used for items 203, 304, 306, 307, 410, 411, 617, 503 or 603”, ODOT Supplemental Specification 905, April 1, 1998, Ohio, OH.

State of Ohio Department of Transportation (ODOT). "Quality control requirements for steel slag aggregate producers/processors”, ODOT Supplement Specification 1071, April 18, 2008, Ohio, OH.

Stock, A.F., Ibberson, C.M., and Taylor, I.F. (1996) "Skidding characteristics of pavement surfaces incorporating steel slag aggregates." Transportation Research Record 1545, Transportation Research Board, National Research Council, Washington, D.C., pp. 35-40.

Stolaroff, J.K., Lowry, G.V., and Keith, D.W. (2005). "Using CaO- and MgO-rich industrial waste streams for carbon sequestration." Energy Conversion and Management, Vol. 46, No.5, pp. 687-699.

Taylor, H.F.W.(1990).“Cement chemistry.” Academic Press Harcourt Brace Jovanovich Publishers, pp. 277-290.

Teir, S., Sanni, E., Fogelholm, C.J., and Zevenhoven, R. (2007).'Dissolution of steelmaking slags in acetic acid for precipitated calcium carbonate production." Energy, Vol. 32, No.4, pp. 528-539.

Topkaya, Y., Sevinc, N., and Gunaydin, A. (2004). "Slag treatment at Karademir integrated iron and steel works." International Journal of Mineral Processing, Vol. 74, No. 1-4, pp. 31-39.

Tossavainen, M., Engstrom, F., Yang, Q., Menad, N., Larsson, M.L., and Bjorkman, B.(2007). "Characteristics of steel slag under different cooling conditions." Waste Management, Vol. 27, No. 10, pp. 1335-1344.

Tsakiridis., P.E., Papadimitriou, G.D., Tsivilis, S., and Koroneos, C. (2008). "Utilization of steel slag for Portland cement clinker production." Journal of Hazardous Materials, Vol. 152, No.2, pp. 805-811.

Tufekci, M., Demirbas, A., and Genc, H.(1997). "Evaluation of steel furnace slags as cement additives." Cement and Concrete Research, Vol. 27, No.11, pp. 1713-1717.

United Stated Geological Survey (USGS). (1994-2006). "Slag-Iron and Steel, Annual Review", Mineral Industry Surveys, U.S. Geological Survey, Minerals Yearbook, Reston, VA, U.S.

Verhasselt, A., and Choquet, F. (1989). "Steel slags as unbound aggregate in road construction: problems and recommendations." International Symposium on Unbound Aggregates in Roads, London, 204-211. 
Wachsmuth, F., Geiseler, J., Fix, W., Koch, K., and Schwerdtfeger, K. (1981). "Contribution to the structure of BOF-slags and its influence on their volume stability.” Canadian Metallurgical Quarterly, Vol.20, No.3, pp. 279-284.

Wagaman, T., Lasely, B., and Stanley, W.J.(2006). "Slag: the ultimate renewable resource, part 2." Pitt and Quarry Weekly Report, $<$ http://www.pitandquarry.com/pitandquarry/Slag-the-ultimate-renewable-resourcepart-2/ArticleStandard/Article/detail/303385> (Feb.1, 2006)

Wang, G., and Emery, J. (2004). "Technology of slag utilization in construction." Proceedings of the fifth international symposium on waste processing and recycling in mineral and metallurgical industries. (eds: S.R. Rao, F.W. Harrison, J.A. Kozinski, L.M. Amaratunga, T.C. Cheng and G.G. Richards), Canadian Institute of Mining, Metallurgy and Petroleum, Hamilton, Ontario, Canada, pp. 39-48.

Wang,G.(1992)."Properties and utilization of steel slag in engineering applications." Ph.D.thesis, University of Wollongong, New South Wales, Australia.

Wild, S., Kinuthia, J.M., Jones, G.I., and Higgins, D.D. (1998). “ Effects of partial substitution of lime with ground granulated blast furnace slag (GGBS) on the strength properties of lime-stabilized sulphate-bearing clay soils." Engineering Geology, Vol.51, No.1, pp.37-53.

Wu, P., Matsushima, K., and Tatsuoka, F. (2008). "Effect of specimen size and some other factors on the strength and deformation of granular soil in direct shear tests." Geotechnical Testing Journal, Vol. 31, No. 1, pp. 45-64.

Wu, S., Xue, Y., Ye, Q., and Chen, Y. (2007). "Utilization of steel slag aggregates for stone mastic asphalt (SMA) mixtures." Building and Environment, Vol.42, No.7, pp. 2580-2585.

Xue, Y., Hou, H., and Zhu, S. (2009). "Characteristics and mechanisms of phosphate adsorption onto basic oxygen furnace slag." Journal of Hazardous Materials, Vol. 162, No.2-3, pp. 973-980.

Xue, Y., Wu, S., Hou, H., and Zha, J. (2006). "Experimental investigation of basic oxygen furnace slag used as aggregate in asphalt mixture." Journal of Hazardous Materials, Vol. 138, No. 2, pp. 261-268.

Xuequan, W., Hong, Z., Xinkai, H., and Husen, L. (1999). "Study on steel slag and fly ash composite Portland cement." Cement and Concrete Research, Vol. 29, No.7, pp. 1103-1106.

Yan, J., Baverman, C., Moreno, L., and Neretineks, I. (1998). "Evaluation of timedependent neutralizing behaviors of MSWI bottom ash and steel slag." The Science of the Total Environment, Volume 216, Issues 1-2, pp. 41-54.

Yuasa, G., Yajima, T., Ukai, A., and Ozawa, M. (1984). "Refining practice and application of the ladle furnace (LF)." Transactions of the Iron and Steel Institute of Japan, Vol. 24, No.5, pp.412-418. 
Yunxia, L., Mingkai, Z., Xiao, C., and Fang, X. (2008). "Methods for improving volume stability of steel slag as fine aggregate." Journal of Whuan University of Technology-Materials Science Edition, Vol. 23, No.5, pp. 737-742.

Zia, N., and Fox, P.J. (2000). "Engineering properties of loess-fly ash mixtures for roadbase construction." Transportation Research Record 1714, Transportation Research Board, National Research Council, Washington, D.C., pp. 49-56.

Ziemkiewicz, P. (1998). "Steel Slag:Applications for AMD Control" Proceedings of the 1998 Conference on Hazardous Waste Research, Snowbird, Utah, May 18-21, pp.4462. 